Elisangela Maria Santos Mattos

\title{
Impacto farmacoeconômico da implantação do método de dispensação de drogas em forma de kit em procedimentos cirúrgicos e anestésicos
}

Dissertação apresentada à Faculdade de Medicina da Universidade de São Paulo para obtenção do título de Mestre em Ciências

Área de concentração: Cirurgia do Aparelho Digestivo

Orientador: Prof. Dr. Joel Faintuch

SÃO PAULO

2005 


\section{FICHA CATALOGRÁFICA}

Preparada pela Biblioteca da

Faculdade de Medicina da Universidade de São Paulo

Creprodução autorizada pelo autor

Mattos, Elisangela Maria Santos

Impacto farmacoeconômico da implantação do método de dispensação de drogas em forma de kit em procedimentos cirúrgicos e anestésicos / Elisangela Maria Santos Mattos. -- São Paulo, 2005.

Dissertação(mestrado)--Faculdade de Medicina da Universidade de São Paulo.

Departamento de Gastroenterologia.

Área de concentração: Cirurgia do Aparelho Digestivo.

Orientador: Joel Faintuch.

Descritores: 1.SERVIÇO DE FARMÁCIA HOSPITALAR 2.ECONOMIA FARMACÊUTICA 3.SISTEMAS DE MEDICAÇÃO HOSPITALAR 4.CENTRO CIRÚRGICO HOSPITALAR/provisão \& distribuição 5.ANESTÉSICOS/provisão \& distribuição

USP/FM/SBD-366/05 


\section{AGRADECIMENTOS}

À Deus por sempre iluminar o meu caminho.

Ao Hospital das Clínicas da Faculdade de Medicina da Universidade de São Paulo pela oportunidade de crescimento profissional, tanto na experiência obtida durante os quatro anos em que fiz parte de seu quadro de funcionários, quanto pelo trabalho realizado que hoje apresento como minha tese de mestrado.

Ao Prof. Dr. Joaquim Gama Rodrigues, diretor e corpo docente da Disciplina de Cirurgia do Aparelho Digestivo/Coloprostologia, por aceitar- me como farmacêutica em seu departamento, me aceitando e apoiando nesta nova etapa, como um de seus pós-graduandos.

Ao Prof. Dr. Joel Faintuch, pelas orientações, incentivos e apoio não só como orientador da tese, mas também nas maiores dificuldades de ordem pessoal, que surgiram no decorrer do trabalho.

À Dra Sonia Lucena Cipriano, que me abriu as portas da Divisão de Farmácia, dando me a oportunidade de fazer parte de sua equipe de farmacêuticos, me auxiliando e transformando no profissional que sou hoje, tornando possível este sonho.

Aos meus familiares pelo afeto e apoio, que recebi durante toda minha vida, principalmente nos trajetos mais difíceis.

Aos meus pais, em especial por serem grandes exemplos de vida, profissionalismo, honestidade, garra, coragem e pelo grande amor demonstrado por seus filhos, netos, genrro e nora.

À meu marido Marcos Antonio Falopa Junior, por ser companheiro e amigo, pela paciência, carinho em todos os momentos de nossa vida.

À Maria Aparecida Fabiano, pelo apoio pessoal e profissional desde nossa apresentação. 


\section{SUMÁRIO}

Lista de Tabelas

Lista de Gráficos

Resumo

Summary

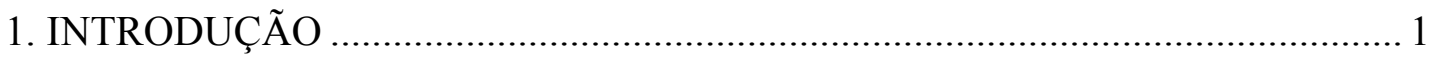

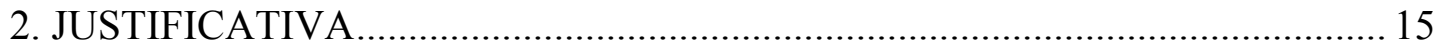

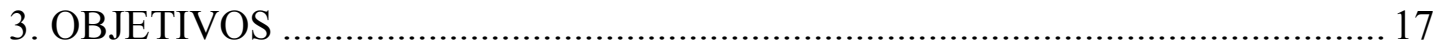

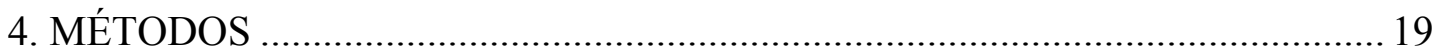

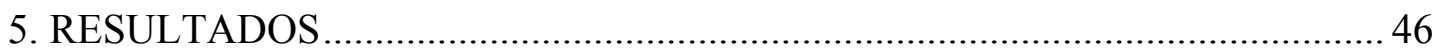

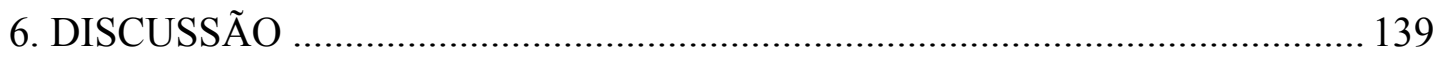

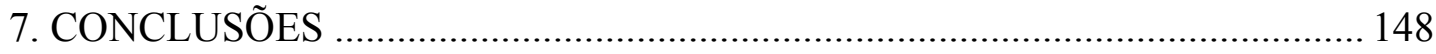

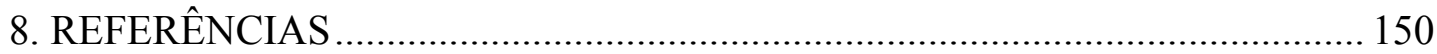




\section{LISTA DE TABELAS}

\section{Tabelas de pré kit fase pré implantação}

Tabela 1. Sala 21 - primeiro dia de consumo 48

Tabela 2. Sala 21 - segundo dia de consumo 49

Tabela 3. Sala 21 - terceiro dia de consumo.................................................... 51

Tabela 4. Sala 22 - primeiro dia de consumo..................................................... 53

Tabela 5. Sala 22 - segundo dia de consumo.................................................... 55

Tabela 6. Sala 22 - terceiro dia de consumo....................................................... 57

Tabela 7. Sala 23 - primeiro dia de consumo..................................................... 59

Tabela 8. Sala 23 - segundo dia de consumo................................................... 61

Tabela 9. Sala 23 - terceiro dia de consumo.................................................... 63

Tabela 10. Sala 24 - primeiro dia de consumo.................................................. 65

Tabela 11. Sala 24 - segundo dia de consumo.................................................. 66

Tabela 12. Sala 24 - terceiro dia de consumo.................................................. 68

Tabela 13. Sala 25 - primeiro dia de consumo................................................ 70

Tabela 14. Sala 25 - segundo dia de consumo.................................................. 72

Tabela 15. Sala 25 - terceiro dia de consumo.................................................... 74

Tabela 16. Sala 26 - primeiro dia de consumo.................................................. 76

Tabela 17. Sala 26 - segundo dia de consumo................................................ 77

Tabela 18. Sala 26 - terceiro dia de consumo.................................................... 78

Tabela 19. Sala 27 - primeiro dia de consumo................................................. 80

Tabela 20. Sala 27 - segundo dia de consumo................................................. 82

Tabela 21. Sala 27 - terceiro dia de consumo................................................... 84

Tabela 22. Sala 28 - primeiro dia de consumo................................................ 86

Tabela 23. Sala 28 - segundo dia de consumo.................................................. 88

Tabela 24. Sala 28 - terceiro dia de consumo..................................................... 90

Tabela 25. Sala 29 - primeiro dia de consumo.................................................... 92

Tabela 26. Sala 29 - segundo dia de consumo................................................... 94

Tabela 27. Sala 29 - terceiro dia de consumo..................................................... 96

Tabela 28. Sala 30 - primeiro dia de consumo.................................................. 98

Tabela 29. Sala 30 - segundo dia de consumo................................................. 100

Tabela 30. Sala 30 - terceiro dia de consumo...................................................... 102 
Tabelas de pós kit fase pós implantação

Tabela 31. Sala 21 - primeiro dia de consumo.................................................... 104

Tabela 32. Sala 21 - segundo dia de consumo................................................. 105

Tabela 33. Sala 21 - terceiro dia de consumo.................................................... 106

Tabela 34. Sala 22 - primeiro dia de consumo.................................................. 107

Tabela 35. Sala 22 - segundo dia de consumo.................................................. 108

Tabela 36. Sala 22 - terceiro dia de consumo.................................................... 109

Tabela 37. Sala 23 - primeiro dia de consumo................................................ 110

Tabela 38. Sala 23 - segundo dia de consumo................................................. 111

Tabela 39. Sala 23 - terceiro dia de consumo.................................................. 112

Tabela 40. Sala 24 - primeiro dia de consumo................................................. 113

Tabela 41. Sala 24 - segundo dia de consumo................................................... 114

Tabela 42. Sala 24 - terceiro dia de consumo.................................................... 115

Tabela 43. Sala 25 - primeiro dia de consumo.................................................. 116

Tabela 44. Sala 25 - segundo dia de consumo................................................ 117

Tabela 45. Sala 25 - terceiro dia de consumo.................................................. 118

Tabela 46. Sala 26 - primeiro dia de consumo.................................................. 119

Tabela 47. Sala 26 - segundo dia de consumo................................................. 120

Tabela 48. Sala 26 - terceiro dia de consumo.................................................... 121

Tabela 49. Sala 27 - primeiro dia de consumo................................................... 122

Tabela 50. Sala 27 - segundo dia de consumo................................................. 123

Tabela 51. Sala 27 - terceiro dia de consumo................................................... 124

Tabela 52. Sala 28 - primeiro dia de consumo................................................ 125

Tabela 53. Sala 28 - segundo dia de consumo................................................. 126

Tabela 54. Sala 28 - terceiro dia de consumo.................................................. 127

Tabela 55. Sala 29 - primeiro dia de consumo.................................................... 128

Tabela 56. Sala 29 - segundo dia de consumo................................................... 129

Tabela 57. Sala 29 - terceiro dia de consumo..................................................... 130

Tabela 58. Sala 30 - primeiro dia de consumo.................................................. 131

Tabela 59. Sala 30 - segundo dia de consumo.................................................. 132

Tabela 60. Sala 30 - terceiro dia de consumo.................................................. 133 
Tabelas comparativas entre os levantamentos pré e pós implantação do kit

Tabela 61. Comparação da quantidade de estoque inicial de medicamentos de cada sala cirúrgica antes e após a implantação do kit

Tabela 62. Comparação da quantidade extra de medicamentos necessários em cada sala cirúrgica antes e após a implantação do kit.

Tabela 63. Comparação da quantidade utilizada de medicamentos de cada sala cirúrgica antes e após a implantação do kit

Tabela 64. Comparação de consumo (em recursos financeiros) dos medicamentos antes e após a implantação do kit.

Tabela 65. Teste " $t$ " comparando os dados coletados em cada sala cirúrgica antes e após a implantação do kit. 


\section{LISTAS DE GRÁFICOS}

Gráfico 1: Apresentação dos dados coletados com referência as alterações do elenco do kit após os dois testes

Gráfico 2: Apresentação dos dados coletados com referência nas alterações necessárias nos campos da nota de débito, devido aos erros no preenchimento. 40

Gráfico 3: Alterações no estoque físico inicial das salas. 134

Gráfico 4: Medicamentos extra solicitados 135

Gráfico 5: Consumo de medicamentos por sala. 136

Gráfico 6: Consumo das salas convertido em reais 137 


\section{RESUMO}

Santos Mattos EM. Impacto farmacoeconômico da implantação do método de dispensação de drogas em forma de kit em procedimentos cirúrgicos e anestésicos. São Paulo, 2003. 153p. Tese de Mestrado (Pós-Graduação) - Faculdade de Medicina da Universidade de São Paulo - FMUSP.

Proposta: O hospital é parte integrante de um sistema coordenado de saúde, cuja função é a prestação de serviços. Os administradores hospitalares preocupam-se em obter o menor custo possível e maximizar a qualidade. Como o custo hospitalar tem uma parcela importante representada pelo consumo de materiais e medicamentos, sendo a farmácia o setor responsável pelo controle, estoque e dispensação, o profissional farmacêutico tem-se aprimorado profissionalmente e desenvolvido pesquisas e estudos, para reformular suas atividades básicas e retomar algumas funções primárias como a farmacoeconomia, a fim de adequar-se as novas exigências. É relevante neste contexto o sistema de distribuição de medicamentos, que se iniciou com a dose coletiva, cujos principais problemas era o aumento do potencial de erros de medicação, as perdas econômicas decorrentes da falta de controles, e o tempo excessivo gasto pela enfermagem para separar a medicação, em vez de dar assistência aos pacientes. Depois avançou para dose individualizada, que além de minimizar e/ou extinguir todas as desvantagens da dose coletiva, apresentava um controle mais efetivo do consumo dos medicamentos, aumentando a integração do farmacêutico com a equipe de saúde, sendo sua principal desvantagem, o aumento das necessidades de recursos humanos e infra-estrutura da Farmácia Hospitalar. E por último a dose unitária, originada da dose individualizada, que tem como principais objetivos racionalizar a terapêutica, diminuir custos sem reduzir a qualidade da dispensação; e garantir que os medicamentos prescritos cheguem ao paciente de forma segura e higiênica, assegurando a eficácia do esquema terapêutico prescrito. Após associar os conceitos descritos acima, a farmácia do Centro Cirúrgico do Instituto Central do Hospital das Clínicas da Faculdade de Medicina da USP propôs-se a identificar o elenco representativo de produtos, e utilizar estes grupos de medicamentos, na elaboração, ampliação, e experimentação do sistema de dispensação de kit. Esta nova alternativa pretende atingir como os dois principais benefícios a melhor utilização de recursos econômicos e a elevação da qualidade de assistência prestada ao paciente e equipe multiprofissional. Método: $O$ método de pesquisa utilizado foi um estudo de caso qualitativo/quantitativo, sendo o mesmo realizado no Centro Cirúrgico do Hospital das Clínicas da Faculdade de Medicina da Universidade de São Paulo, no período de 12/05/2002 a 22/07/2002. Foram escolhidas como amostra as dez salas do bloco III, onde pudemos acompanhar procedimentos de médio e grande porte de determinadas especialidades médicocirúrgicas. O estudo foi dividido em três etapas, sendo as duas primeiras experimentais, e a terceira apenas de análise e interpretação dos achados. Foi realizado o mapeamento do elenco de medicamentos disponibilizado (seja nos carrinhos de drogas, nos kits e nas solicitações extra) e o levantamento do consumo de três dias de funcionamento de cada sala cirúrgica do Bloco III, nas duas etapas experimentais. Na primeira etapa - pré kit - o levantamento foi realizado através da 
verificação do elenco e das quantidades contidas nos carros de parada e anestesia de cada uma das salas, às 06h30min da manhã antes do início das cirurgias e no final da tarde após o término da última, assim, delimitando o consumo/dia/sala. Estes levantamentos eram feitos em dias aleatórios para não induzir a equipe médica ou a enfermagem em modificar seu consumo. Na segunda etapa - pós kit - realizou-se o levantamento dentro da unidade farmacêutica através da análise dos documentos de dispensação do kit e notas de débito, onde estavam relacionadas as quantidades de medicamentos utilizadas e solicitadas pela auxiliar de enfermagem durante a cirurgia. A confirmação desta documentação era feita através da conferencia do kit e devolução de medicamentos extra. Os carros de medicamentos não estavam mais sendo utilizados, apenas os kits e os medicamentos extra, que pela rotina estabelecida deviam ser devolvidos após o término de cada cirurgia, não permanecendo nada em sala entre uma cirurgia e outra. Após o fechamento dos dois levantamentos pré e pósimplantação do kit procedeu-se às seguintes análises dos resultados: Comparação do consumo de medicamentos por sala/dia; Relação de preço de cada medicamento utilizado; Cálculo do valor total gasto por sala/dia; Comparação do valor gasto por sala/dia. Vale assinalar que: Os anestésicos inalatórios não entraram no levantamento dos medicamentos utilizados nas cirurgias, pois comportam frações diferentes para cada paciente; No primeiro dia de mapeamento (pré e pós) das salas cirúrgicas, os medicamentos vencidos encontrados foram recolhidos e considerados como consumidos. Resultados: Não houve críticas nem reclamações em relação ao novo sistema implantado. Quantitativamente, houve uma redução de aproximadamente $47 \%$ no estoque inicial, $54 \%$ nas solicitações extras e $30,4 \%$ no consumo de medicamentos, com impacto muito relevante sobre os custos. Conclusões: Foi viável e benéfica a prática de implantação dos kits, pois houve redução de aproximadamente $60 \%$ nos gastos, estimados pelo preço de medicamentos, traduzindo menores perdas e desperdícios.

Descritores: 1. SERVIÇO DE FARMÁCIA HOSPITALAR 2. ECONOMIA FARMACÊUTICA 3. SISTEMAS DE MEDICAÇÃO HOSPITALAR 4. CENTRO CIRÚRGICO HOSPITALAR/provisão \& distribuição 5. ANESTÉSICOS/provisão \& distribuição 


\section{SUMMARY}

Santos Mattos EM. The drug dispensation method implementation impact of Pharmacy-economic in kit on anesthetic and surgery procedure. São Paulo, 2003. 153p. Tese de Mestrado (Pós-Graduação) - Faculdade de Medicina da Universidade de São Paulo - FMUSP.

Purpose: The hospital a integrant of a health coordinated system, which duty is offer services. The hospital administrators' worry is get the lowest cost as possible and increasing the quality. As the hospital cost has an important installment represented by the medicine and materials consumed, and the pharmacy being the control responsible section, storage and dispensation, the pharmacist has improving professionally and developing researches and studies, in order to reformulate ones basics activities and recover some primary functions such as pharmaco economy, in order to adequate the new demands. The medicine distribution system is relevant in this context, which has started with a collective dose, which the main problems were the medicine error increased, the economic losses because of the lack of control, and the excessive expenses by the nurse ring in order to sort out the medicine, instead of patient care. Then it upgrade to the individual dose, which has not only decrease and /or extinguishes all the disadvantage of collective dose, presented a more effective control of the medicine consume, increasing the pharmacist integration along with health group, being the main disadvantage, the increase of Hospital Pharmacy infrastructure and human recourse need. And the one dose being the last one, being a derivation from the individual dose, which has as the main targets rationalize the therapy, decrease the costs without reducing the dispensation quality; and guaranty that the prescribed medicine reach the patient in a hygienic and safe fashion, guarantying the efficacy of the prescribed therapeutic scheme. After having connect the above described concepts, the Surgery Room of Instituto Central do Hospital das Clínicas da Faculdade de Medicina da USP purpose identify a representative product group, and use these medicine group, on the kit dispensation system elaboration, increase, and experiment. This new alternative intend to hit as the two main benefits which are the better use of economic resources and increasing the assistance quality giving to the patient and to the multi professional team. Method: The used research method applied was a qualitative/quantitative study case, where it was applied at the Centro Cirúrgico do Hospital das Clínicas da Faculdade de Medicina da Universidade de São Paulo, from 12/05/2002 to 22/07/2002. Were chosen as samples the ten surgey rooms of Block III, where we could follow big and medium port procedures of specific medical surgery specialties. The study was divided into three steps, where the first two experiments, and the third one was only analyses and comprehension of found. From the available medicine group mapping was taken ( which means ones in the drug trolleys, at the kits and the extra solicitations) and the inventory of three day consumptions of each surgery room at the Block III, at the two experimental steps. At the first step - pre kit - the inventory was taken through a verification of the group the quantities which were in the drug emergency trolley and anesthesia of each room, at 06:30 min a.m. before the surgeries starting and at the late afternoon after the last surgery happened, so, determining the consumption/ 
day/room. These inventories were chosen in random days way in order not to prompt the medical or the nursing group to modify their consumption. At the second step - post kit - the inventory was taken in the pharmacy unit through out of a kit dispensation documents analyses and debit note, which were listed the medicine amount used and from the nurse asked for during the surgery. This document confirmation was done through out of the kit checking and the extra medicine return. The medicine trolley were not use any more, only the kits and the extra medicine, which through the established routine should be returned after each surgery ended, and nothing was left in the surgery room between surgeries. The analyses of the results were taken right after the closing of the two research pre and post kit implementation: Medicine consume comparison by room /day; Listing the price of each medicine used; Total expenses calculated by room/day; Comparison of expenses by room/day. Is worthwhile note that: The inhale ting anesthetic are not considered on the used medicine inventory used at the surgery, because it holds different fractions for each patient; At the first surgery room mapping day (pre and post) the out of day medicine were took away and considered as used. Results: There were no criticism nor complaints related to implemented new system. Quantitatively, there was a decrease of $47 \%$ on the initial stock, $54 \%$ at the extra solicitations and $30,4 \%$ at the medicine consumption, with a very related impact on the costs. Conclusions: The implementation of the kits was totally viable (ver no dicionário eu esqueci..) because there was about $60 \%$ costs reduction, estimated by the medicine price, presenting less losses and wastings.

Descriptors: 1. HOSPITAL PHARMACY SERVICE 2. PHARMACEUTICAL ECONOMICS 3. HOSPITAL MEDICATION SYSTEMS 4. HOSPITAL SURGERY DEPARTMENT/ supply \& distribution 5. ANESTHETICS/ supply \& distribution 
1. INTRODUÇÃO 
Segundo a Organização Mundial de Saúde - (OMS) "O Hospital é parte integrante de um sistema coordenado de saúde, cuja função é dispensar à comunidade completa assistência à saúde, preventiva e curativa, incluindo serviços extensivos à família, em seu domicílio e também um centro de formação para os que trabalham no campo da saúde e para as pesquisas biosociais", como Maia Neto, 1990. ${ }^{1}$

Para o Ministério da Saúde, o hospital visa primordialmente, prevenir e diagnosticar a doença, restaurar a saúde, educar e desenvolver pesquisa, como citou Bittar, $1996^{2}$

Outros autores como Borba, $1991^{3}$ e Martins, $1999^{4}$ respectivamente definem hospital como uma instituição devidamente aparelhada de pessoal e material, em condições de diagnosticar e tratar pessoas que necessitam de assistência médica diária e cuidados permanentes de enfermagem, em regime de internação e que devem ser administrados para gerar os serviços necessários à comunidade, com o menor custo possível e maximizando a qualidade. O custo hospitalar, portanto, é um instrumento de trabalho fundamental para a otimização das operações da instituição e serve de alerta para quaisquer resultados que exijam correções, auxiliando também na determinação do preço de venda, nas decisões de investimento de instalações hospitalares, na definição dos volumes de estoques de materiais e medicamentos, estudado por Martins, $2000^{5}$.

Como os itens dos estoques de materiais e medicamentos, estão relacionados intimamente com este instrumento, devemos nos voltar para o setor que os controlam a farmácia hospitalar, que é definida por Cimino, $1973^{6}$, como unidade tecnicamente aparelhada para prover os medicamentos e produtos afins de que necessitam para o funcionamento das Clínicas e demais Serviços.

Levando-se em consideração a amplitude da Farmácia Hospitalar de hoje, podemos conceitua-la mais amplamente como sendo uma unidade de assistência 
técnica, administrativa e contábil sob a coordenação/gerência/controle do profissional farmacêutico, que visa o envolvimento de acordo com as necessidades das outras áreas.

Gomes et al, $2001^{7}$, considera a Farmácia Hospitalar um órgão de abrangência assistencial técnico-científico e administrativa, onde se desenvolvem atividades ligadas à produção, ao armazenamento, ao controle hospitalar, bem como à orientação de pacientes internos e ambulatoriais visando sempre à eficácia da terapêutica, além da redução dos custos. Volta-se, também, para o ensino e a pesquisa, propiciando um vasto campo de aprimoramento profissional.

Devido à importância deste setor faz-se necessário conhecermos seu funcionamento, suas atividades apresentadas por Zanini, $2001^{8}$ :

$\checkmark$ distribuir medicamentos por dose unitária e/ou individualizada para todas as unidades de internação;

$\checkmark$ manter/controlar estoque padrão de medicamentos e produtos farmacêuticos utilizados nas unidades de internação;

$\checkmark$ dispensar medicamentos para pacientes externos e em alta hospitalar prestando orientação farmacêutica adequada;

$\checkmark$ manter central de abastecimento farmacêutico e executar as atribuições e tarefas inerentes ao controle físico e contábil necessários à prestação de contas do hospital;

$\checkmark$ elaborar pedidos de compra de medicamentos, emitir pareceres técnicos;

$\checkmark$ inspecionar, receber, armazenar e distribuir medicamentos, produtos e insumos farmacêuticos;

$\checkmark$ controlar, de acordo com a legislação vigente, medicamentos que podem levar à dependência física e/ou psíquica ou que provoque efeitos colaterais importantes;

$\checkmark$ participar da comissão de Farmácia e Terapêutica ou similar fornecendo subsídios técnicos, para tomada de decisões quanto à inclusão de medicamentos;

$\checkmark$ participar das atividades de pesquisas clínicas, que utilizam medicamentos, providenciar sua aquisição, controlar e definir normas 
para solicitação à farmácia, bem como fornecer orientação sobre o uso racional de medicamentos;

$\checkmark$ participar de reuniões técnico-científicas desenvolvidas nos serviços assistenciais do hospital;

$\checkmark$ elaborar e prestar, quando solicitado, informações técnico-científicos sobre medicamentos e outros produtos Farmacêuticos.

Ainda segundo Zanini, $2001^{8}$, são funções prioritárias da Farmácia Hospitalar para implementação de outras diretrizes, que objetivam o uso seguro e eficaz dos medicamentos:

$\checkmark$ realização de estudos farmacoepidemológicos;

$\checkmark$ elaboração de avaliações farmacoeconômicas;

$\checkmark$ estruturação de programas de farmacovigilância;

$\checkmark$ elaboração de protocolos farmacoterápicos;

$\checkmark$ desenvolvimentos de atividades de farmácia clínica /atenção farmacêuticas;

$\checkmark$ desenvolvimento de programas de terapia nutricional;

$\checkmark$ implantação de central de misturas endovenosas;

$\checkmark$ estruturação do centro de informação de medicamento;

$\checkmark$ desenvolvimento de atividades educacionais e de pesquisa.

Dentre todas as atividades, a mais básica e ligada ao controle de estoque temos a dispensação de medicamentos, cuja importância está na forma como é realizada, a qual necessita ser racional, eficiente, econômica, segura e deve estar de acordo com o esquema terapêutico prescrito. Quanto maior a eficácia do sistema de distribuição, mais garantido será o sucesso da terapêutica e da profilaxia instauradas no hospital, sendo que as principais funções descritas por Gomes et al, $2001^{9}$ deste sistema são:

$\checkmark \quad$ reduzir erros de medicação;

$\checkmark$ racionalizar a distribuição;

$\checkmark$ aumentar o controle sobre medicamentos;

$\checkmark$ reduzir os custos com medicamentos;

$\checkmark$ aumentar a segurança para os pacientes. 
A dispensação de medicamentos se insere no contexto das estatísticas de utilização, distribuição, consumo e custos, que tem sido objeto de grande atenção tanto por parte de pesquisadores individuais como a própria Organização Mundial de Saúde, como declaram Consentino et al, $2000{ }^{10}$, Aouizerate et al, $2002{ }^{11}$.

Como atualmente os medicamentos representam uma grande parcela no orçamento dos hospitais e são de suma importância no tratamento de grande parte das doenças, fica justificada, portanto, a implementação de medidas que assegurem o uso racional destes produtos.

É importante ressaltar que a mesma é uma atividade técnico-científica de orientação ao paciente, de suma importância para a observância ao tratamento e eficaz, quando bem acompanhada pelo farmacêutico.

Exemplo disto é o que ocorre em Valencia, na Espanha, descrito por Meneu, $2002^{12}$ onde se estimula a atuação dos profissionais farmacêuticos no momento da dispensação, pois oferece um valor superior de assistência sanitária que implica nos custos, em que todos os produtos famacêuticos passam por supervisão, qualidade e controle.

A Organización Panamericana de la Salud, $1987^{13}$ lembra que uma distribuição correta e racional de medicamentos deve garantir três fatores: segurança, rapidez e controle.

Os objetivos de um sistema racional de distribuição de medicamentos São: diminuir os erros de medicação, racionalizar o serviço de enfermagem, aumentar o controle sobre os medicamentos, diminuir o custo da medicação e aumentar a segurança para o paciente, como demonstra Ribeiro, $1991^{14}$.

Na prática existem quatro tipos de sistema de distribuição de medicamentos, definidos por Garrinson, $1979^{15}$ : coletivo, individual, combinado ou misto e dose unitária.

Sistema de distribuição coletivo, estudado por Cavallini et al, $2002{ }^{16}$, é o mais primitivo e arcaico dos sistemas, entretanto ainda utilizado em muitos hospitais brasileiros, caracteriza-se, principalmente, pelo fato dos medicamentos serem distribuídos por unidade de internação e/ou serviço a partir de uma solicitação da enfermagem, implicando a formação vários estoques nas unidades assistenciais. Neste sistema os medicamentos são liberados sem que o serviço de farmácia tenha 
conhecimento de: para quem o medicamento está sendo solicitado, por que está sendo solicitado e por quanto tempo será necessário; logo, podemos verificar que não há contato com a prescrição médica que somente ocorre em caso de supostas dúvidas sobre medicamentos.

Neste sistema o farmacêutico, profissional capacitado para executar as atividades relacionadas aos medicamentos, está praticamente marginalizado do sistema e sua função é desempenhada pela equipe de enfermagem, relatou Ribeiro, $1991^{14}$.

Segundo Lima et al, $200{ }^{17}$, a falta de participação efetiva do farmacêutico na revisão e análise da prescrição médica, além de prejudicar a assistência ao paciente, faz com que a enfermagem gaste cerca de $25 \%$ do seu tempo de trabalho em procedimentos relacionados aos medicamentos como: transcrever prescrição, verificar o estoque existente na unidade, preencher solicitação, ir à farmácia, aguardar separação dos mesmos, transportá-los até a unidade, guardá-los nos seus devidos lugares, separar os que são necessários a cada horário, fazer cálculos, prepará-los e administrá-los, aumentando assim o índice de erros, desde o ato da prescrição até o momento da administração, devido à sobrecarga deste profissional da saúde.

O sistema coletivo apresenta mais desvantagens que vantagens:

Vantagens:

$\checkmark$ facilidade de acesso aos medicamentos para uso imediato;

$\checkmark$ pouco volume de requisições à farmácia;

$\checkmark$ recursos humanos e infra-estrutura da farmácia reduzidos;

$\checkmark$ ausência de investimentos iniciais.

Desvantagens:

$\checkmark$ ausência do farmacêutico na equipe de saúde;

$\checkmark$ mínima devolução de medicamentos à farmácia;

$\checkmark$ aumento do potencial de erros de medicação (doses, formas farmacêuticas,

$\checkmark$ horários de administração);

$\checkmark$ perdas econômicas decorrentes da falta de controle;

$\checkmark$ estoques espalhados pelo hospital e sem controle;

$\checkmark$ perda do medicamento por validade;

$\checkmark$ possibilidade de contaminação; 
$\checkmark$ tempo excessivo gasto pela enfermagem para separar a medicação, em vez de dar assistência aos pacientes.

Tentando minimizar estas desvantagens, surgiu o sistema de distribuição por dose individualizada, normalmente adotado nas Farmácias de ambulatório, onde a enfermagem envia a prescrição médica de cada paciente ou cópia dela à Farmácia do Hospital para que os medicamentos sejam dispensados para cobrir 24 horas de tratamento. Ao recebe-la, o farmacêutico prepara ou supervisiona a preparação das doses para cada um em particular a serem utilizados por 24 horas ou por vários dias, e encaminha para as unidades de enfermagem e demais setores requisitantes.

O sistema de distribuição individualizado já é adotado em hospitais brasileiros, existindo algumas variações de acordo com as peculiaridades de cada instituição, como: forma da prescrição médica, o modo de preparo e distribuição das doses e fluxo da rotina operacional. Este sistema pode ser direto quando utiliza a prescrição médica ou sua cópia direta ou indireto utiliza a transição da prescrição médica feita no nome do paciente, como estudado por Ribeiro, $1991^{14}$.

Segundo o Ministério da Saúde, $1994^{18}$, esse sistema já apresenta mais vantagens que o anterior, desde que o farmacêutico participe do processo.

Vantagens:

$\checkmark$ diminuição do estoque nas unidades assistenciais;

$\checkmark$ redução potencial de erros de medicação;

$\checkmark$ facilidade para devoluções à farmácia;

$\checkmark$ reduz tempo do pessoal de enfermagem gast nas atividades com medicamentos;

$\checkmark$ redução de custos com medicamentos;

$\checkmark$ controle mais efetivo sobre os medicamentos;

$\checkmark$ aumento da integração do farmacêutico com a equipe de saúde.

Desvantagens:

$\checkmark$ aumento das necessidades de recursos humanos e infra-estrutura da Farmácia Hospitalar;

$\checkmark$ exigência de investimento inicial;

$\checkmark$ incremento das atividades desenvolvidas pela farmácia; 
$\checkmark$ necessidade de plantão na Farmácia Hospitalar;

$\checkmark$ erro de distribuição e administração de medicamentos;

$\checkmark$ não permite controle total sobre as perdas econômicas (caducidade, dose não administrada, desvios e outros).

O que foi descrito até aqui evidencia que o sistema individualizado representa um avanço na conquista da garantia e segurança quanto à prescrição. Por isso, muitos farmacêuticos optam por esse sistema antes de implantar a dose unitária.

Devido a algumas dificuldades de cultura, envolvimento de todos os profissionais da saúde e até mesmo financeiro das instituições, foi detectado por Maia Neto, $1990^{1}$, que muitos hospitais adotam o sistema combinado, onde ao mesmo tempo a farmácia central e as satélites dividem as tarefas na preparação de doses. Esse esquema facilita a adequação aos horários de ministração de doses e objetiva uma redução nos recursos humanos, aproveitando da melhor forma possível o horário de trabalho dos funcionários da farmácia. Esse sistema geralmente é aplicado nos hospitais de porte extra (acima de 500 leitos), face ao consumo elevado e a necessidade de se preparar grande número de doses.

O sistema combinado também pode ser considerado como tal, quando na Farmácia Central se prepara todas “doses standart” a serem utilizadas pelas farmácias satélites. Assim sendo, têm-se centralizado a maior parte dos equipamentos necessários a preparações das doses standarts, desafogando as Farmácias Satélites, tanto no espaço físico como em termos de ocupação de pessoal, conforme descrito por Maia Neto, $1990 .^{1}$

Por último o autor nos traz o sistema de dose unitária, que se originou da dose individualizada, onde os medicamentos são dispensados unitariamente, nas doses certas, acondicionados em tiras plásticas lacradas com o nome e o leito do paciente, contendo o horário de administração. Assim, a medicação é encaminhada ao paciente certo, na dose certa, no horário certo.

Esse sistema tem como principais objetivos:

$\checkmark$ racionalizar a terapêutica, diminuindo custos sem reduzir a qualidade da dispensação;

$\checkmark$ garantir que os medicamentos prescritos cheguem ao paciente de forma segura e higiênica, garantindo a eficácia do esquema terapêutico prescrito. 


\section{Vantagens:}

$\checkmark$ redução do potencial de erros de medicação;

$\checkmark$ atuação efetiva e dinâmica do profissional farmacêutico;

$\checkmark$ devolução dos medicamentos não administrados;

$\checkmark$ redução do tempo gasto pela enfermagem para separar medicação;

$\checkmark$ redução de custos com medicamentos pelo maior controle de estoque e faturamento;

$\checkmark$ medicação dispensada em doses organizadas e higiênicas;

$\checkmark$ maior segurança para o médico, para a enfermagem e, sobretudo, para o paciente.

Desvantagens:

$\checkmark$ investimento necessário para implantação do sistema;

$\checkmark$ aumento das atividades na farmácia;

$\checkmark$ aumento no número de funcionários na Farmácia;

$\checkmark$ aquisição de materiais e equipamentos especializados.

Seguindo o alto padrão de controle de estoque que os sistemas de dose individualizada e única oferecem, foi idealizada a distribuição dos medicamentos por meio de kits, nos setores onde a dose utilizada para cada paciente dependerá de seu estado naquele exato momento e de certas características de seu fenótipo, genótipo e patologias, como no centro cirúrgico e na oncologia.

O Kit é um conceito amplamente utilizado em diversas ocasiões onde tenha que distribuir um conjunto de coisas ( que pode ser de diversas naturezas) a um grupo de pessoas. Por exemplo, a refeição distribuída num avião para seus passageiros durante o vôo, normalmente, é uma maletinha ou invólucro de plástico, que é denominado "kit refeição" pelas companhias aéreas.

Segunda a definição de Gomes et al, $2001^{9}$, o kit é um recipiente que acondiciona organizadamente um elenco de medicamentos, facilitando de maneira individualizada sua distribuição e utilização durante os procedimentos cirúrgicos.

Em vários países são desenvolvidos muitos estudos, cujo modo de dispensação é por kits, como por exemplo:

Na República Tcheca, o estudo feito por Kleisner et al, $2002{ }^{19}$, para o desenvolvimento de um método simples e reproduzível de preparação de um kit 
ciprofloxacino, através da utilização da reação de óxido-redução de um polímero, no qual se encontra os requerimentos para simplificar, depende da técnica rotulada com Tc e eficiente diagnóstico das infecções por imagem cintilográficas.

Nos estados de Maryland e Alabama, Estados Unidos da América, Holbrook et al, $2001^{20}$, realizaram os abastecimentos de vacina e placebo através do Centro de Distribuição de Drogas; as seringas necessitaram estar rotuladas e empacotadas em kits, que continham uma vacina e um placebo injetáveis; o número do kit corresponderia a seqüência atribuída de injeções. Cada participante teve um tratamento único, determinado pelo código que correspodia ao número do kit.

A implantação do kit individualizado resulta em otimizar e racionalizar o uso dos medicamentos, diminuir o tempo gasto no atendimento, monitorar o prazo de validade de medicamentos em circulação, disponibilizar elenco maior de medicamentos, eliminar a burocracia pelo decréscimo no mínimo (receitas, solicitações, memorandos, etc) necessários para retirada dos medicamentos da farmácia, sistema ideal para atender ao centro cirúrgico.

Os benefícios com a dispensação de medicamentos através de kits são apresentados abaixo por Gomes et al, $2001^{9}$ :

$\checkmark$ Para o hospital:

- Melhor utilização de seus recursos econômicos;

- Elevação da qualidade de assistência prestada ao paciente.

$\checkmark$ Para o médico:

- Maior garantia do cumprimento de sua prescrição farmacoterapêutica;

$\checkmark$ Para a enfermagem:

- Maior disponibilidade de tempo para dedicar ao paciente, por retirarlhes atividades inerentes à farmácia;

$\checkmark$ Para o paciente:

- Maior disponibilidade assistencial pela melhor utilização do arsenal farmacoterapêutico, pela garantia da disponibilidade dos medicamentos e pela segurança no uso.

$\checkmark$ Para o farmacêutico:

- Maior integração na equipe de saúde ao assumir atividades que lhe são específicas e de acordo com a sua função profissional. 
Para checar e confirmar qual é o melhor e mais adequado sistema, processo e procedimento para uma instituição é necessário um estudo que avalie o custobenefício para a mesma, portanto, escolhemos a farmacoeconomia.

Segundo Castilho, $1995^{21}$, a farmacoeconomia é definida como a descrição e análise dos custos das terapias medicamentosas para os pacientes, sistema de saúde e a sociedade. Seu objetivo é propiciar informações para tomada de decisão identificando, mensurando e comparando recursos consumidos, e conseqüentemente clínicas, econômicas e humanísticas de produtos e serviços farmacêuticos.

A farmacoeconomia é uma área da Economia da Saúde, que associa os conceitos clínicos de eficácia, segurança e qualidade dos diversos processos da assistência sanitária com as medidas de custo da economia. Assim, ela pode ser definida como a "aplicação da teoria econômica a farmacoterapia" ou "avaliação econômica do medicamento".

Ela é um instrumento que ajuda a selecionar as opções mais eficientes (com boa relação custo/efeito) e pode ajudar na distribuição dos recursos sanitários de uma forma mais justa e equilibrada. Contribui para uso racional do medicamento ao incorporar o custo aos quesitos de segurança, eficácia e qualidade das diferentes terapias medicamentosas, e a busca pela melhor relação entre custos e resultados. Embora empregando a palavra "fármaco" em sua nomenclatura, apresenta ferramentas que podem ser utilizadas igualmente na avaliação de medicamentos, programas de saúde e mesmo de sistemas administrativos, desde que observadas as devidas características de cada um.

Segundo Alan Lyles, $2003^{22}$, a avaliação tecnológica de novos produtos médicos tornou-se rotina com os resultados das crises fiscais, a lentidão econômica, os avanços da medicina, os novos produtos farmacêuticos e o aumento do custo no abastecimento dos serviços de saúde. Portanto, as análises custo-benefício (CBA) e análises custo-efetividade (CEA) dos produtos farmacêuticos são aplicados há pouco tempo; a primeira execução foi em 1970, os farmacoeconomistas não identificaram distinta marca na avaliação tecnológica até 1986, e desde 1990, os resultados de CBA e CEA, particularmente avaliados aqueles produtos farmacêuticos que têm aparecido com mais freqüência nas revisões críticas da literatura. 
Para melhor entender os objetivos sociais da farmacoeconomia, em todos os seus sentidos, basta citar os objetivos da política de medicamentos essenciais da Organização Mundial da Saúde (OMS), 1980/81, e mantidos até hoje em suas publicações.

Alguns destes objetivos que devem ser atingidos com o programa governamental de medicamentos foram amplamente discutidos por Zanini et al, $2001^{8}$, são os seguintes:

$\checkmark$ disciplinar a aquisição de produtos farmacêuticos no sistema oficial da saúde;

$\checkmark$ orientar o estabelecimento de prioridades para a produção interna de matérias-primas farmacêuticas prioritárias;

$\checkmark$ liberar o receituário médico da vinculação a marcas de fabricantes;

$\checkmark$ conferir maior rentabilidade aos recursos governamentais destinados à assistência farmacêutica;

$\checkmark$ estimular a padronização de medicamentos de comprovada eficácia;

$\checkmark$ facilitar o controle de preços dos produtos por meio da montagem de matrizes de custo.

Portanto, qualquer estudo que vise à "otimização de recursos", inclusive atividades de gestão, estudos de utilização, incentivo à produção até mesmo a política de genéricos, podem transformar-se em avaliação econômica de medicamentos, pois, sob o ponto de vista social, a farmacoeconomia tem por objetivo evitar a redução de custos que possam conduzir a níveis inaceitáveis a qualidade do tratamento.

Á avaliação da farmacoeconomia identifica, mede e compara os custos (recursos consumidos com produtos farmacêuticos e serviços) e as conseqüências (econômicas, clínicas, e humanísticas) provenientes de sua utilização. Ela é um instrumento que ajuda a selecionar as opções mais eficientes (com boa relação custo/efeito) e pode ajudar na distribuição dos recursos sanitários de forma mais justa e equilibrada.

Nessa realidade não só do Brasil, mas em paises do mundo inteiro, faz-se obrigatório o melhor aproveitamento dos meios de tratamento disponíveis. O grande desafio reside em como reduzir as despesas sem comprometer a qualidade dos tratamentos considerando as relações entre efetividade, riscos, beneficio e custo. 
Basile et al, $2000^{23}$, classifica como um dos principais elementos de estudo da farmacoeconomia a definição de custos. Para completa determinação e mensuração do custo de um tratamento devem ser considerados todos os recursos utilizados que podem ser divididos em:

$\checkmark$ Custos diretos: demandam pagamentos;

$\checkmark$ Custos indiretos: associados à perda de ganhos;

$\checkmark$ Custos intangíveis: fatores impossíveis de serem quantificados objetivamente, como: dor, bem-estar.

Tão importante quanto o custo é o resultado do tratamento, em que são incluídos, também, aqueles não desejáveis, pois podem demandar despesas adicionais de tratamentos. O ideal, ao optar por produto farmacêutico, seria que este apresentasse maior efetividade e menor custo em relação aos seus concorrentes.

Quanto à farmacoeconomia e a saúde, ainda hoje, no meio hospitalar, considera-se que o cliente é uma pessoa com alguns agravos à saúde; uma parte dos profissionais dessa área assume a postura que "a saúde não tem preço".

Gomes et al, 2001 ${ }^{9}$, defendem que além do aspecto econômico, a preocupação com a qualidade é um requisito essencial, pois o paciente tem direito a uma assistência de qualidade independente da situação financeira da instituição. A importância do serviço de saúde e indiscutível ao lado de uma série de outros serviços, fator de extrema relevância para a qualidade de vida da população, representando preocupação de todos os gestores.

Dentro desse contexto, Bevilácqua, $2001^{24}$, diz o profissional farmacêutico tem uma grande importância na sistematização da distribuição e controle de medicamento através de serviços que racionalizem seu uso em Hospitais e outros serviços, visando a melhorar a qualidade e diminuir o custo de atendimento à saúde.

O desafio consiste em alcançar a melhoria de qualidade e a redução do custo, em um contexto econômico no qual setor público assume a responsabilidade pela assistência à saúde da maior parcela da população. O que falta aos países em desenvolvimento para melhorar as condições de saúde da população não é propriamente mais dinheiro, exceto nos países mais pobres do mundo, e sim o melhor direcionamento dos recursos existentes para a saúde. 
Portanto, a farmacoeconomia tem sido bastante difundida em outros países, dando origem a muitos trabalhos:

$\mathrm{Na}$ Austrália, Robertson et al, $2003^{25}$, fizeram um estudo que aponta para a farmacoeconomia em pesquisa da prescrição médica, refletindo o aumento do uso de técnicas de avaliação econômica para decisão de compra de drogas em variedade de conjuntos, como programas subsidiados, planos de compras providenciais, programas de seguros, e para hospitais e autoridades de saúde em formulários de decisão (pedido de padronização).

$\mathrm{Na}$ França, Spath et al, $2003^{26}$, realizaram entrevistas qualitativas com farmacêuticos em hospitais e clínicas na região do Reno-Alpes da França para determinar regra de dados da economia para selecionar remédio em formulários, identificando barreiras que dificultem o uso dessa informação e estudar qual o grau de influência do estabelecimento de saúde.

Um setor importante e adequado para iniciar um estudo farmacoeconomico devido suas características é o Centro Cirúrgico (pois os pacientes permanecem apenas o tempo necessário para as intervenções cirúrgicas), localizado em área isolada no hospital, onde se tenha bom planejamento de circulação dos recursos humanos que exercerão as técnicas cirúrgicas e assépticas já conhecidas e também de aprimoramento das diferentes clínicas do hospital, como descreveu Cavallini et al, $2002{ }^{16 .}$

Como confirma Maia Neto, $1990^{1}$, o Centro Cirúrgico é uma unidade que dispensa comentários quanto à sua higienização. A desinfecção deve ser ininterrupta, portanto o farmacêutico hospitalar tem muito que fazer de comum acordo com a enfermagem e demais profissionais que ali trabalham. Sendo que, neste setor, compete ao farmacêutico o controle e vigilância dos medicamentos e correlatos consumidos ou utilizados por paciente. 
A adequação de um sistema de distribuição de medicamentos numa área restrita e com características bem definidas como o Centro Cirúrgico poderá significar uma diminuição importante nas despesas hospitalares, pois esse processo otimiza o elenco e racionaliza o uso de medicamentos, além de aumentar a praticidade do serviço, melhorar a interação entre a equipe multiprofissional e qualidade da assistência prestada ao paciente. 
3. OBJETIVOS 


\section{OBJETIVO GERAL}

Avaliar se ocorre uma redução significante do custo por sala/dia de procedimentos cirúrgicos e principalmente evitar o desperdício de medicamentos.

\section{OBJETIVOS ESPECÍFICOS}

$\checkmark$ Comparar os estoques das salas cirúrgicas antes e após a implantação de distribuição de medicamentos em kits;

$\checkmark$ Identificar o custo dos medicamentos utilizados nas salas cirúrgicas antes e após a implantação do kit;

$\checkmark$ Avaliar o impacto econômico da adequação do sistema de distribuição de medicamentos nos procedimentos cirúrgicos. 
Os procedimentos aqui utilizados foram estratificados em duas categorias: os relacionados à implantação do sistema e aqueles concernentes à análise dos resultados propriamente ditos.

A primeira etapa não foi objeto de investigação, pois já havia sido implementada quando o presente protocolo se iniciou. Contudo, ela é minuciosamente descrita, pois constitui-se em alicerce no qual se fundamentou toda a pesquisa farmacoeconômica que se seguiu.

\subsection{METODOLOGIA DA IMPLANTAÇÃO DO KIT}

Num Hospital público de grande porte, a dificuldade de se empregar a farmacoeconomia é maior, principalmente devido à diversidade de procedimentos, sendo que a instituição estudada possui 33 salas cirúrgicas, distribuídas em quatro blocos:

Bloco I - São dez salas para cirurgias de emergência, divididas entre:

$\checkmark$ Quatro salas de Pronto Socorro - cirurgia geral:

$\checkmark$ Seis salas de Centro Obstétrico, onde:

- Uma sala pré-parto para monitoramento;

- Uma sala de parto normal;

- Uma sala para reanimação de recém nascido ( $\mathrm{RN}$ );

- Três salas cirúrgicas para procedimento obstétrico.

Bloco II - Dez salas cirúrgicas onde são realizados procedimentos de pequeno e médio porte (Oftalmologista, Otorrinolaringologista e outros).

Bloco III - Dez salas cirúrgicas onde são realizados procedimentos de médio e grande porte (Cólon, Plástica, Pneumologista e outros).

Bloco IV - Três salas para cirurgias de coluna, transplantes hepáticos e neurológicos, basicamente. 
Excluindo a área de emergência, nos outros blocos cirúrgicos são realizadas aproximadamente setenta cirurgias/dia previamente agendadas e trinta cirurgias /dia de emergência dando um total de cem cirurgias/dia. Para atender toda esta demanda, foi aberto um espaço físico para a montagem de uma farmácia no Centro Cirúrgico, entre 1995 e 2000, com a mesma estrutura e procedimentos operacionais, como por exemplo, a utilização da dose combinada.

Ao ser montada, foram recolhidos os medicamentos que estavam de posse da enfermagem (anterior distribuidora e controladora desses produtos no Centro Cirúrgico) e em seguida, foram elaboradas as rotinas básicas para a realização do atendimento desse setor.

Esse atendimento baseou-se nas características do sistema de distribuição por dose coletiva, em que cada sala cirúrgica possuía dois carros de medicamentos que eram repostos por requisições da enfermagem, não tendo nenhuma verificação e/ou controle da farmácia, exceto os medicamentos controlados pela portaria 344, que devido às suas exigências eram dispensados no momento da cirurgia, em caixas de isopor, cujo elenco e quantidade já estavam pré-determinados, iniciando o sistema de distribuição por dose individualizada não ficando disponíveis na sala cirúrgica como os demais medicamentos.

Em 2001, a Farmácia do Centro Cirúrgico, da Divisão de Farmácia do Instituto Central dos Hospital das Clínicas, assumiu um papel fundamental no uso racional dos medicamentos, buscando a redução de custos sem o prejuízo da qualidade. Procurou-se um sistema de distribuição de medicamentos que atendessem as necessidades de controles específicos de alguns produtos e oferecesse um atendimento rápido e seguro ao paciente e à equipe de saúde.

Entretanto, foi necessário iniciar um grande projeto de modificação, indo desde a estrutura física até a administrativa para se adequar ao próximo grande passo, que foi o seguinte:

\footnotetext{
$\checkmark$ elaboração das rotinas e reformulação das já existentes;

$\checkmark$ mudança e adequação da área física;

$\checkmark$ implantação da Farmácia Clínica.
} 
Foi conseguido pela proximidade do profissional farmacêutico à equipe multiprofissional, entender o funcionamento do Centro Cirúrgico que se iniciou com:

$\checkmark$ reposição de soluções de grande volume nos blocos cirúrgicos;

$\checkmark$ criação de uma única nota de débito, abolindo os diversos tipos de documentos utilizados para dispensação;

$\checkmark$ troca da dose coletiva pela individualizada (kits), para o atendimento das salas cirúrgicas;

$\checkmark$ desvinculação do estoque de psicofármacos e entorpecentes das mãos da enfermagem;

$\checkmark$ implantação de kits cirúrgicos/anestésicos;

$\checkmark$ elaboração de kit de parada cárdio-respiratória.

A Farmácia do Centro Cirúrgico buscou o aprimoramento do sistema de dispensação de medicamentos e produtos correlatos às salas cirúrgicas, ao perceber que um elenco e quantidade maior de medicamentos de outras classes farmacológicas, como os anestésicos gerais eram bastante representativos tanto no aspecto de consumo quanto nos controles envolvidos na sua dispensação e utilização, optando assim em utilizar todos esses grupos de medicamentos na elaboração, ampliação e experimentação do sistema de dispensação de kit.

Assim esperava-se eliminar o risco de troca de medicamentos, gerenciar com maior eficiência eventuais faltas de produtos, evitar perdas por vencimento do prazo de validade, além de proporcionar maior segurança do estoque descentralizado das salas cirúrgicas.

Considerando o número de procedimentos cirúrgicos diários envolvendo anestesia geral em todas as salas, estabeleceu-se o número de dois kits por sala, como sendo suficientes para o atendimento diário.

Para Padronização e Implantação do kit foram necessários definir:

$\checkmark$ elenco de medicamentos;

$\checkmark$ impressos de controle/nota de débito de medicamentos e psicofármacos/ entorpecentes;

$\checkmark$ modelo do recipiente/kit para armazenamento;

$\checkmark$ aplicação de teste piloto para três modelos de recipientes e elenco definido; 
$\checkmark$ normas e rotinas operacionais;

apresentação às diretorias envolvidas (enfermagem, anestesia e geral do Instituto);

$\checkmark$ treinamento da equipe multidisciplinar (farmácia, enfermagem e anestesia).

$\checkmark$ planejamento para implantação.

A idéia da montagem de um novo kit foi amadurecida juntamente com as equipes de enfermagem e anestesia, da qual surgiu o projeto de implantação de kits cirúrgicos individualizados(descrito abaixo) dentro dos padrões do PNQ ( Programa Nacional da Qualidade), utilizando como ferramenta de qualidade 5W2H, demonstrada no www.widebiz.com.br/gente/silvio/telegestor.html, consultado no dia 30/11/2005. O projeto foi bem aceito por toda a equipe de saúde, uma vez que já estava caracterizada a inadequação do sistema de distribuição misto (coletivo e individualizado para medicamentos controlados) para atender a demanda de cirurgia, detectado através do levantamento dos produtos vencidos e que venciam periodicamente dentro dos sessenta e seis carros de medicamentos, divididos entre medicamentos para anestesia e parada, distribuídos nas trinta e três salas de cirurgias. Esse fato ocorria devido ao número de funcionários da farmácia não permitir a criação de uma rotina viável de verificação de todos os carros.

Portanto, chegou-se à conclusão de que o kit de anestésicos já existentes poderia ser readequado para solucionar esse problema; além disso, o kit também proporcionaria a racionalização do trabalho e do tempo gasto pela enfermagem, com a atividade ponte de ligação entre a farmácia e a equipe médica.

Segundo Santos Mattos, 2001 28 , para se proporcionar um atendimento de qualidade, foi vista a necessidade de ser montado um sistema de dispensação, em que se controlam todos os medicamentos presentes no elenco da Farmácia Descentralizada do Centro Cirúrgico. Esse novo sistema eliminará as inúmeras vindas da enfermagem à farmácia, proporcionando a maior permanência da auxiliar de enfermagem em sala cirúrgica e melhorando seu atendimento ao corpo clínico atuante. Esses novos kits saem da farmácia acompanhados por duas notas de débito: uma contendo o elenco de psicofármacos e outra com os demais medicamentos distribuídos no Centro Cirúrgico. As notas facilitam o débito na conta do paciente. 
O objetivo dessa nova rotina é otimizar o elenco e racionalizar a quantidade de medicamentos, de modo que durante o procedimento cirúrgico não falte em campo nenhum medicamento essencial, e também evite o disperdício e a perda por vencimento da validade, aumentando a qualidade do serviço prestado pela farmácia junto à equipe de saúde envolvida no atendimento cirúrgico ao paciente; melhorando a qualidade da informação prestada pelas notas de débito relativo ao que foi utilizado no paciente durante o procedimento; além de agilizar o atendimento, fornece um elenco mais variado com excelência em relação à validade e quantidade.

Racionaliza o sistema de dispensação do medicamento, disponibilizando um elenco adequado às necessidades atuais da área; e prestar informações necessárias e mais completas ao faturamento.

Para elaboração e implantação deste projeto, foi necessário:

$\checkmark$ Montagem de uma equipe de trabalho multiprofissional - constituída pela farmácia, enfermagem e anestesia;

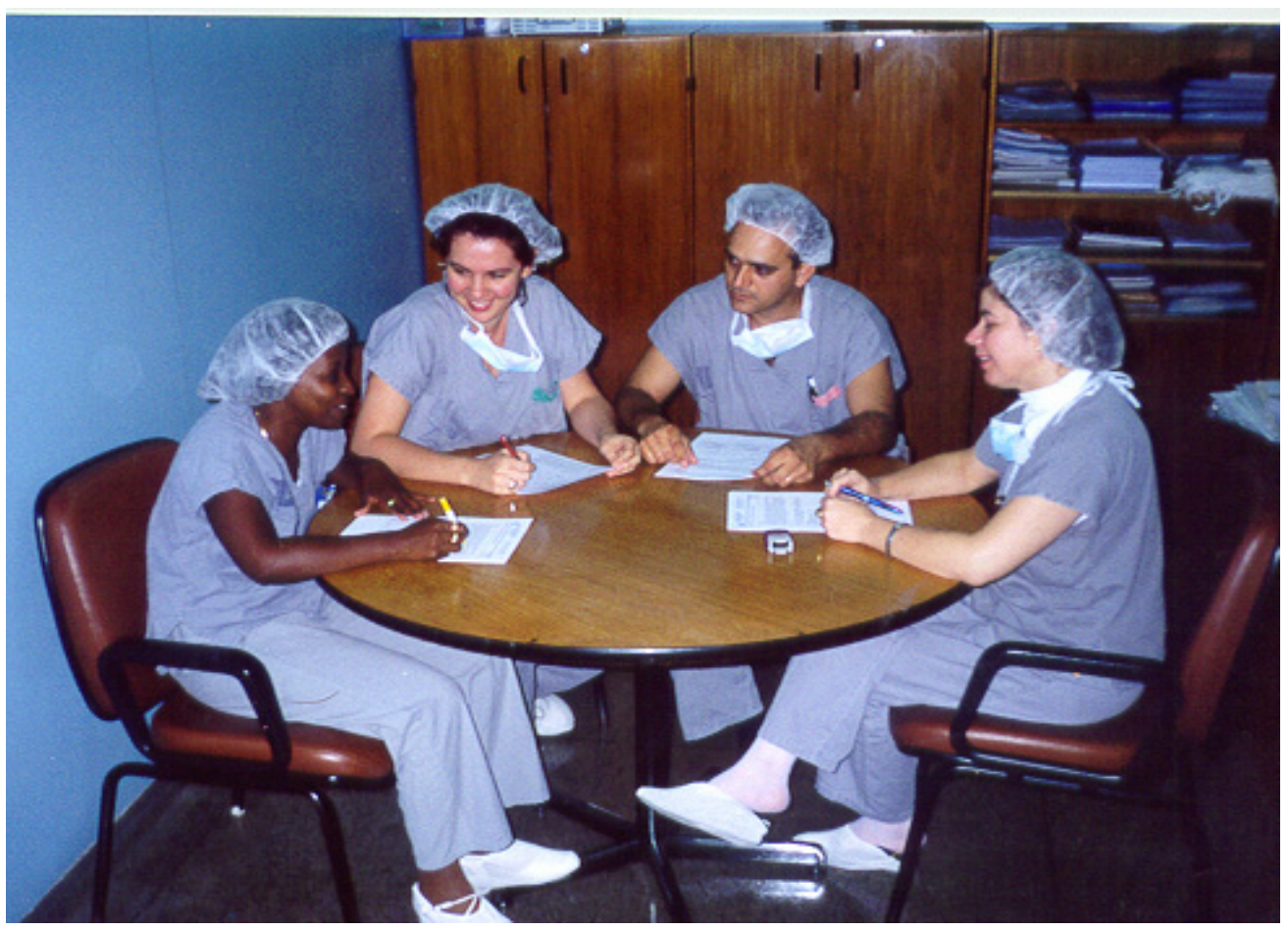

Definição do elenco - efetuou-se um levantamento retrospectivo dos medicamentos consumidos no período de janeiro a fevereiro/2001, através de listas de reposição de estoques das salas cirúrgicas, originando dois kits, que juntos atendem a cada procedimento cirúrgico; 
Kit psicofármacos/entorpecentes padronizados:

\begin{tabular}{|l|c|c|}
\hline Elenco & $\begin{array}{c}\text { Preço } \\
\text { Unitário }\end{array}$ & $\begin{array}{c}\text { Preço } \\
\text { Total * }\end{array}$ \\
\hline 01 ampola de diazepam $5 \mathrm{mg} / \mathrm{ml}-2 \mathrm{ml}$ & 0,17 & 0,17 \\
\hline 01 ampola de etomidato $2 \mathrm{mg} / \mathrm{ml}-10 \mathrm{ml}$ & 3,18 & 3,18 \\
\hline 02 ampolas de fentanil + droperidol $(0,05 \mathrm{mg}+2,5 \mathrm{mg}) / \mathrm{ml}-2 \mathrm{ml}$ & 3,51 & 7,02 \\
\hline 03 ampolas de fentanil $0,05 \mathrm{mg} / \mathrm{ml}-5 \mathrm{ml}$ & 1,8 & 5,4 \\
\hline 01 ampola de midazolam $5 \mathrm{mg} / \mathrm{ml}-3 \mathrm{ml}$ & 2,35 & 2,35 \\
\hline 01 ampola de morfina $2 \mathrm{mg} / \mathrm{ml}-1 \mathrm{ml}$ & 0,41 & 0,41 \\
\hline 01 ampola de petidina $50 \mathrm{mg} / \mathrm{ml}-2 \mathrm{ml}$ & 0,18 & 0,18 \\
\hline 02 ampolas de propofol $10 \mathrm{mg} / \mathrm{ml}-20 \mathrm{ml}$ & 8,51 & 17,02 \\
\hline Valor total do kit & & $\mathbf{3 5 , 7 3}$ \\
\hline
\end{tabular}

Kit medicamentos padronizados:

\begin{tabular}{|c|c|c|}
\hline Elenco & $\begin{array}{c}\text { Preço } \\
\text { Unitário }\end{array}$ & $\begin{array}{c}\text { Preço } \\
\text { Total * }\end{array}$ \\
\hline 06 ampolas de água destilada $-10 \mathrm{ml}$ & 0,1 & 0,6 \\
\hline 01 ampola de aminofilina $24 \mathrm{mg} / \mathrm{ml}-10 \mathrm{ml}$ & 0,05 & 0,05 \\
\hline 06 ampolas de atropina $0,5 \mathrm{mg} / \mathrm{ml}-1 \mathrm{ml}$ & 0,01 & 0,06 \\
\hline 01 frasco de bupivacaína com epinefrina $(5 \mathrm{mg}+9,1 \mathrm{mcg}) / \mathrm{ml}-20 \mathrm{ml}$ & 3,89 & 3,89 \\
\hline 01 frasco de bupivacaína sem epinefrina $0,5 \%-20 \mathrm{ml}$ & 4 & 4 \\
\hline 01 ampola de bupivacaína hiperbárica $0,5 \%-30 \mathrm{~g}$ & 3,59 & 3,59 \\
\hline 02 frascos-ampolas de cefalotina $1 \mathrm{~g}$ & 1,53 & 3,06 \\
\hline 01 frasco-ampola de cetoprofeno $50 \mathrm{mg} / \mathrm{ml}-2 \mathrm{ml}$ & 3,43 & 3,43 \\
\hline 02 ampolas de cloreto de cálcio $100 \mathrm{mg} / \mathrm{ml}-5 \mathrm{ml}$ & 0,38 & 0,76 \\
\hline 06 ampolas de dexametasona $4 \mathrm{mg} / \mathrm{ml}-1 \mathrm{ml}$ & 0,39 & 2,34 \\
\hline 06 ampolas de dipirona $500 \mathrm{mg} / \mathrm{ml}-2 \mathrm{ml}$ & 0,16 & 0,96 \\
\hline 06 ampolas de efedrina $25 \mathrm{mg} / \mathrm{ml}-1 \mathrm{ml}$ & 0,43 & 2,58 \\
\hline 01 ampola de epinefrina $1 \mathrm{mg} / \mathrm{ml}-1 \mathrm{ml}$ & 0,15 & 0,15 \\
\hline 02 ampolas de furosemida $10 \mathrm{mg} / \mathrm{ml}-2 \mathrm{ml}$ & 0,13 & 0,26 \\
\hline 01 ampola de glicose $50 \%-10 \mathrm{ml}$ & 0,16 & 0,16 \\
\hline 01 frasco de heparina IV 5000UI $-5 \mathrm{ml}$ & 3,45 & 3,45 \\
\hline 02 ampolas de hidralazina $20 \mathrm{mg} / \mathrm{ml}-1 \mathrm{ml}$ & 1,5 & 3,0 \\
\hline 02 frascos-ampolas de hidrocortisona 500mg & 2,88 & 5,76 \\
\hline 01 frasco de lidocaína sem epinefrina $2 \%$ - 20ml & 0,68 & 0,68 \\
\hline 01 frasco de lidocaína com epinefrina $(20 \mathrm{mg}+5 \mathrm{mcg}) / \mathrm{ml}-20 \mathrm{ml}$ & 1,31 & 1,31 \\
\hline 01 bisnaga de lidocaína geléia $2 \%$ - 30g & 1,12 & 1,12 \\
\hline 02 ampolas de metaraminol $10 \mathrm{mg} / \mathrm{ml}-1 \mathrm{ml}$ & 1,95 & 3,9 \\
\hline 02 ampolas de metoclopramida $5 \mathrm{mg} / \mathrm{ml}-2 \mathrm{ml}$ & 0,15 & 0,3 \\
\hline 06 ampolas de neostigmina $0,05 \mathrm{mg} / \mathrm{ml}-1 \mathrm{ml}$ & 0,46 & 2,76 \\
\hline 02 ampolas de ranitidina $10 \mathrm{mg} / \mathrm{ml}-5 \mathrm{ml}$ & 0,18 & 0,36 \\
\hline 02 frascos-ampolas de suxametonio $100 \mathrm{mg}$ & 1,53 & 3,06 \\
\hline 01 frasco-ampola de tenoxicam $20 \mathrm{mg}$ & 2,16 & 2,16 \\
\hline Valor total do kit & & 53,75 \\
\hline
\end{tabular}

* valores calculados em 2002, onde a taxa de conversão era de USdólar 2,70, conforme site http: www. portalbrasil.net/índices_dolar02.htm, consultado em $15 / 11 / 2005$. 
Anestésicos Inalatórios:

$\checkmark$ Halothano - frasco $100 \mathrm{ml}$

$\checkmark$ Isoflurano - frasco $100 \mathrm{ml}$

$\checkmark$ Sevoflurano - frasco $250 \mathrm{ml}$

OBS: O anestesista opta por um dos anestésicos inalatórios, na retirada do kit na Farmácia. Este será marcado na ficha de drogas entorpecentes e psicofármacos, no campo (quantidade enviada) em $\mathrm{ml}$, de acordo com o volume apresentado pela escala contida no frasco.

$\checkmark$ Elaboração de impressos de controle/nota de débito de medicamentos e psicofármacos/entorpecentes; 
Nota de débito psicofármacos/entorpecentes:

\begin{tabular}{|c|c|}
\hline $\begin{array}{c}\text { DIVISÃO dE FARMÁCIA } \\
\text { FICHA DE DROGAS ENTORPECENTES E } \\
\text { PSICOFÁRMACOS }\end{array}$ & $\begin{array}{l}\text { HOSPITAL DAS CLÍNICAS } \\
\text { DA } \\
\text { FACULDADE DE MEDICINA DA } \\
\text { UNIVERSIDADE DE SÃO PAULO }\end{array}$ \\
\hline
\end{tabular}

\begin{tabular}{|l|l|l|l|l|l|l|l|l|l|l|}
\hline NÚMERO DA NOTA & SALA / KIT & \multicolumn{3}{|c|}{ ETIQUETA } \\
\hline
\end{tabular}

MÉDICO SOLICITANTE

\begin{tabular}{|c|c|c|c|c|c|}
\hline \multicolumn{3}{|l|}{ NOME } & CRM & \multicolumn{2}{|l|}{ ASSINATURA } \\
\hline CÓDIGO & MEDICAMENTO EXTRA KIT & $\begin{array}{l}\text { KIT Centro } \\
\text { Cirúrgico }\end{array}$ & $\begin{array}{c}\square \\
\text { KIT Centro } \\
\text { Obstétrico }\end{array}$ & $\begin{array}{l}\text { QT. SOLICITADA } \\
\text { EXTRA }\end{array}$ & $\begin{array}{c}\text { QT. TOTAL } \\
\text { UTILIZADA } \\
\text { (KIT+EXTRA) }\end{array}$ \\
\hline \begin{tabular}{|l|}
$1115124-9$ \\
\end{tabular} & Alfentanil $0,5 \mathrm{mg} / \mathrm{ml} 5 \mathrm{ml}$ & 02 & 02 & & \\
\hline $1115440-8$ & Cetamina $10 \mathrm{ml}$ & & 01 & & \\
\hline \begin{tabular}{|l|}
$1115126-2$ \\
\end{tabular} & Clorpromazina $25 \mathrm{mg} / \mathrm{ml} 5 \mathrm{ml}$ & & & & \\
\hline \begin{tabular}{|l|}
$1201136-8$ \\
\end{tabular} & Diazepan $5 \mathrm{mg} / \mathrm{ml} 2 \mathrm{ml}$ & 01 & 01 & & \\
\hline $1115025-7$ & Droperidol + Fentanila $2 \mathrm{ml}$ & 05 & 01 & & \\
\hline \begin{tabular}{|l|}
$1115223-4$ \\
\end{tabular} & Etomidato $2 \mathrm{mg} / \mathrm{ml} 10 \mathrm{ml}$ & 01 & 02 & & \\
\hline 11152539 & Fentanil 2ml & & 01 & & \\
\hline \begin{tabular}{|l|}
$1115251-4$ \\
\end{tabular} & Fentanil $5 \mathrm{ml}$ & 05 & & & \\
\hline 1115252-7 & Fentanil $10 \mathrm{ml}$ & & 02 & & \\
\hline \begin{tabular}{|l|}
$1206217-0$ \\
\end{tabular} & Fenitoína $50 \mathrm{mg} / \mathrm{ml} 5 \mathrm{ml}$ & & & & \\
\hline $1115264-3$ & Flumazenil $0,5 \mathrm{mg} / \mathrm{ml} 5 \mathrm{ml}$ & & & & \\
\hline $1115062-2$ & Haloperidol $5 \mathrm{mg} / \mathrm{ml} 1 \mathrm{ml}$ & & & & \\
\hline 11152953 & Halothano $100 \mathrm{ml}$ & & & & \\
\hline $1115400-7$ & Isoflurano $100 \mathrm{ml}$ & & & & \\
\hline \begin{tabular}{|l|}
$1115120-1$ \\
\end{tabular} & Midazolam $15 \mathrm{mg} / \mathrm{ml} 3 \mathrm{ml}$ & 01 & & & \\
\hline \begin{tabular}{|l|}
$1201516-7$ \\
\end{tabular} & Morfina $2,0 \mathrm{mg} / \mathrm{ml}$ & 01 & 01 & & \\
\hline \multirow{2}{*}{\begin{tabular}{|l}
$1201516-7$ \\
\end{tabular}} & Morfina $10 \mathrm{mg} / \mathrm{ml}$ & & & & \\
\hline & Morfina $0,2 \mathrm{mg} / \mathrm{ml}$ & & 01 & & \\
\hline \begin{tabular}{|l|}
$1115580-2$ \\
\end{tabular} & Nalbufina $10 \mathrm{mg} / \mathrm{ml}$ & & & & \\
\hline $1115570-\bar{X}$ & Naloxona $0,4 \mathrm{mg} / \mathrm{ml} 2 \mathrm{ml}$ & & & & \\
\hline 11155462 & Petidina $50 \mathrm{mg} / \mathrm{ml} 2 \mathrm{ml}$ & 01 & 01 & & \\
\hline \begin{tabular}{|l|}
$1115595-4$ \\
\end{tabular} & Propofol $20 \mathrm{ml}$ & 02 & 02 & & \\
\hline 11155966 & Propofol 50m & & & & \\
\hline 111157008 & Sevoflurano $250 \mathrm{ml}$ & & & & \\
\hline 111151122 & Sufentanil $5 \mathrm{mcg} / \mathrm{ml} 2 \mathrm{ml}$ & & 02 & & \\
\hline \begin{tabular}{|l|}
11151110 \\
\end{tabular} & Sufentanil $50 \mathrm{mcg} / \mathrm{ml} 1 \mathrm{ml}$ & & & & \\
\hline \begin{tabular}{|l|}
$1115774-4$ \\
\end{tabular} & Thionembutal $0,5 \mathrm{~g}$ & & & & \\
\hline \begin{tabular}{|l|}
$1115776-8$ \\
\end{tabular} & Thionembutal $1,0 \mathrm{~g}$ & & & & \\
\hline \begin{tabular}{|l|}
$1115793-8$ \\
\end{tabular} & Tramadol $100 \mathrm{mg} / \mathrm{ml} 2 \mathrm{ml}$ & & & & \\
\hline KIT & Auxiliar de Farm & & & Auxiliar de Enferma & \\
\hline \multicolumn{6}{|l|}{ Retirada } \\
\hline Devolução & & & & & \\
\hline
\end{tabular}


Nota de débito medicamentos:

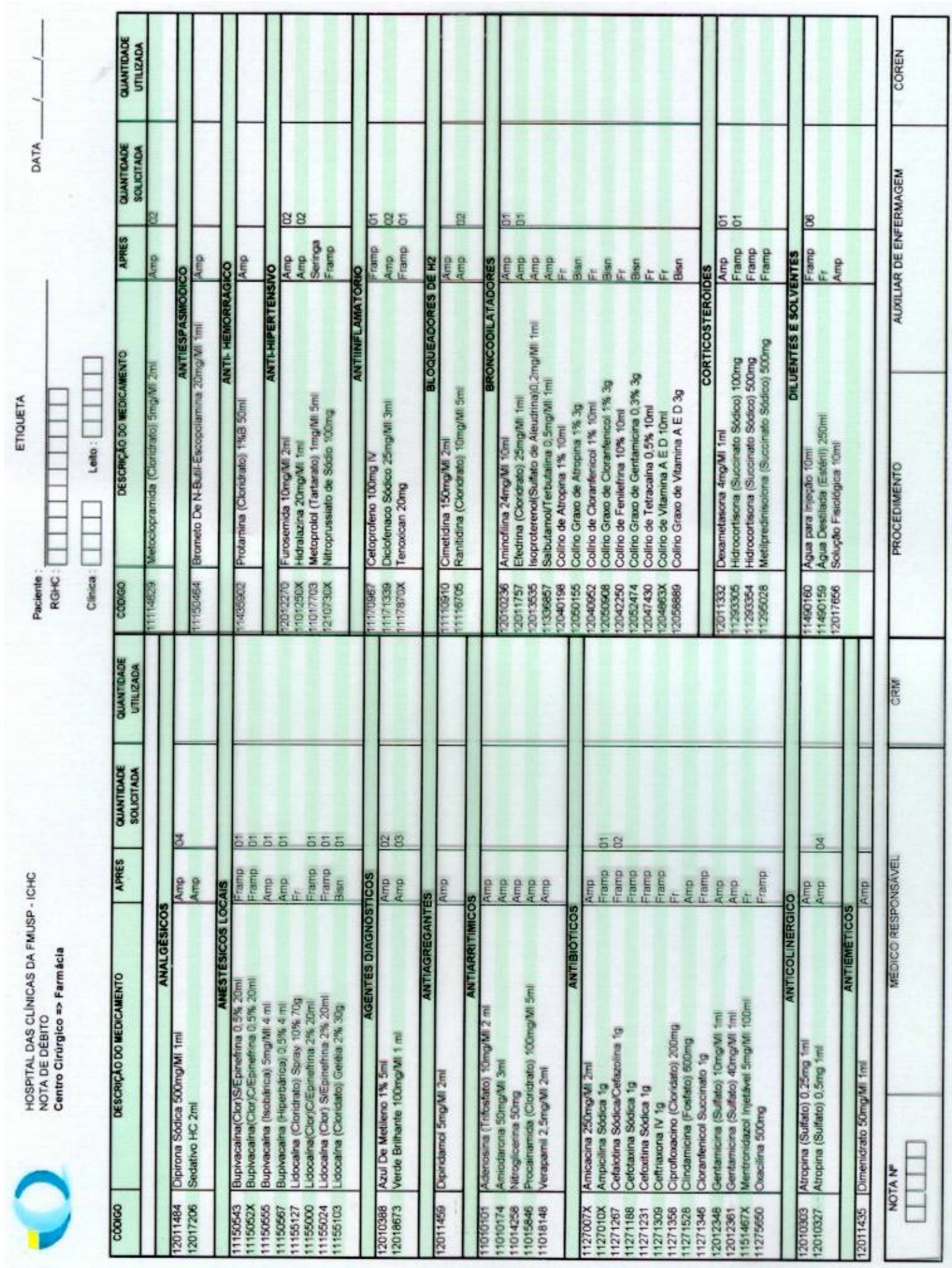


$\checkmark$ Verificação de modelo do recipiente/kit para armazenamento;

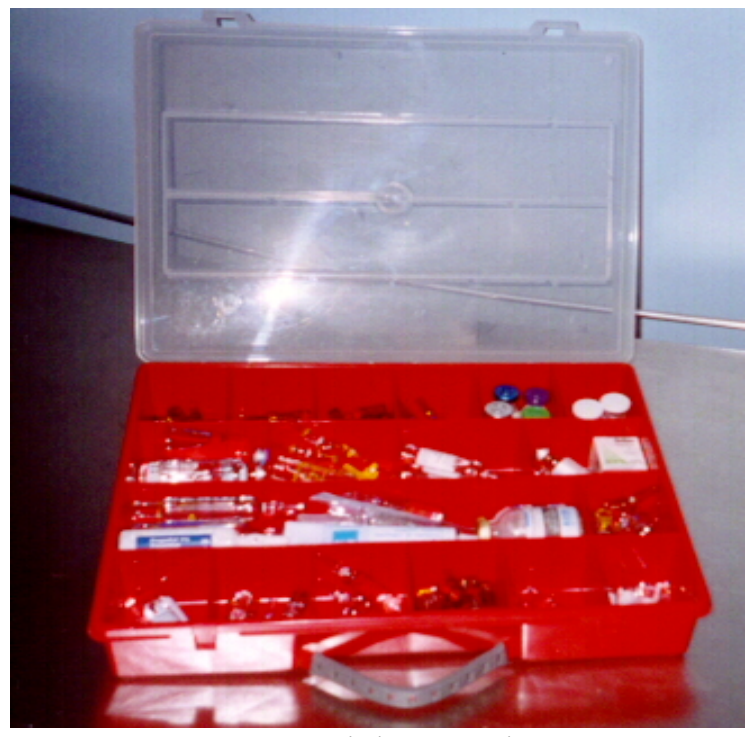

$1^{\circ}$. Modelo testado

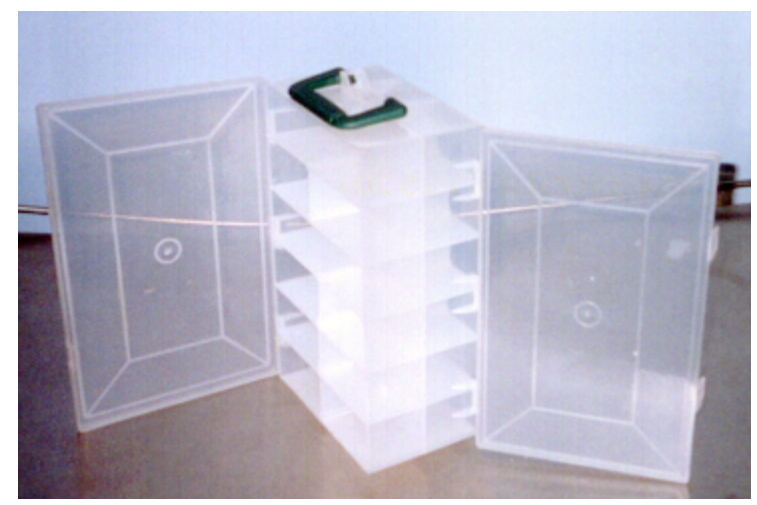

$2^{\circ}$. Modelo testado

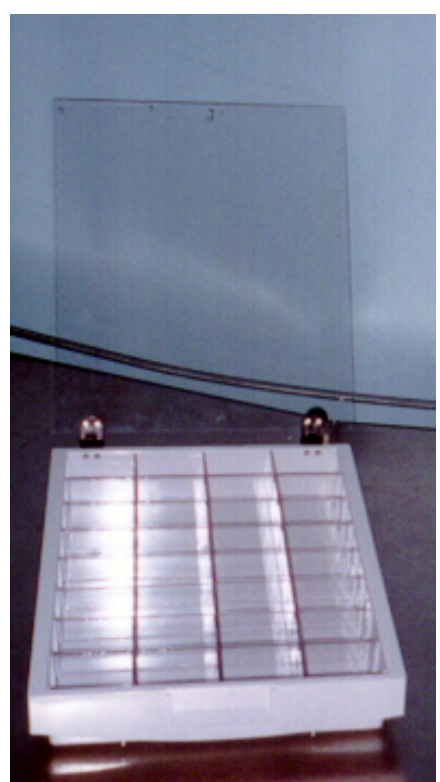

$3^{\circ}$. Modelo testado 
Definição de normas e rotinas operacionais;

Rotina Operacional:

I-) Início de Cirurgia:

\begin{tabular}{|l|l|}
\hline AGENTE & AÇÃO \\
\hline Anestesista & $\begin{array}{l}\text { Solicita verbalmente o kit de psicofarmacos, o } \\
\text { anestésico inalatório e o relaxante muscular } \\
\text { (medicamento termosensível) necessário para o } \\
\text { procedimento cirúrgico }\end{array}$ \\
\hline Auxiliar de Farmácia & $\begin{array}{l}\text { Entrega o kit, o anestésico inalatório, o relaxante } \\
\text { muscular e a nota de débito de psicofármacos/ } \\
\text { entorpecentes ao anestesista, conforme procedimento 1 }\end{array}$ \\
\hline Anestesista & $\begin{array}{l}\text { Confere com o auxiliar da farmácia os medicamentos } \\
\text { controlados do kit e assina o recebimento, conforme } \\
\text { procedimento 2 }\end{array}$ \\
\hline
\end{tabular}

\begin{tabular}{|l|l|}
\hline AGENTE & AÇÃO \\
\hline Auxiliar de Enfermagem & $\begin{array}{l}\text { Faz a solicitação ao Auxiliar de farmácia do kit de } \\
\text { medicamentos, de acordo com o número da sala cirúrgica }\end{array}$ \\
\hline Auxiliar de Farmácia & $\begin{array}{l}\text { Entrega o kit de medicamentos e a nota de débito de } \\
\text { medicamentos ao auxiliar de enfermagem referente ao } \\
\text { número da sala informado }\end{array}$ \\
\hline Auxiliar de Enfermagem & $\begin{array}{l}\text { Recebe o kit lacrado e o entrega ao anestesista da mesma } \\
\text { forma }\end{array}$ \\
\hline
\end{tabular}

II-) Durante a Cirurgia:

\begin{tabular}{|l|l|}
\hline AGENTE & AÇÃO \\
\hline Anestesista & $\begin{array}{l}\text { Verifica a necessidade de algum medicamento } \\
\text { controlado ou não a mais do que o oferecido pelos kits. } \\
\text { Faz a solicitação através das notas de débito, conforme } \\
\text { procedimento 3 }\end{array}$ \\
\hline Auxiliar de Enfermagem & $\begin{array}{l}\text { Solicita à farmácia através da apresentação das notas de } \\
\text { débito }\end{array}$ \\
\hline Auxiliar de Farmácia & $\begin{array}{l}\text { Recebe a nota do circulante e atende, de acordo com o } \\
\text { procedimento 4 }\end{array}$ \\
\hline Auxiliar de Enfermagem & $\begin{array}{l}\text { Confere a solicitação do medicamento, conforme } \\
\text { procedimento 5 }\end{array}$ \\
\hline
\end{tabular}


III-) Final da Cirurgia:

\begin{tabular}{|l|l|}
\hline AGENTE & AÇÃO \\
\hline Anestesista & $\begin{array}{l}\text { Anota todos os medicamentos controlados utilizados na } \\
\text { cirurgia e preenche corretamente os dados, conforme } \\
\text { procedimento 6 }\end{array}$ \\
\hline Auxiliar de Farmácia & $\begin{array}{l}\text { Confere os medicamentos controlados extras e do kit } \\
\text { juntamente com o anestesista no ato da devolução à } \\
\text { farmácia, conforme procedimento 7 }\end{array}$ \\
\hline
\end{tabular}

\begin{tabular}{|l|l|}
\hline AGENTE & AÇÃO \\
\hline Auxiliar de Enfermagem & $\begin{array}{l}\text { Confere se todas as anotações estão certas e devolve } \\
\text { todos os medicamentos não utilizados à farmácia, de } \\
\text { acordo com o procedimento 8 }\end{array}$ \\
\hline Auxiliar de Farmácia & $\begin{array}{l}\text { Recebe o kit de medicamentos e os extras não } \\
\text { controlados. }\end{array}$ \\
\hline
\end{tabular}

IV-) Remontagem do Kit:

\begin{tabular}{|l|l|}
\hline AGENTE & AÇÃO \\
\hline Auxiliar de Farmácia 1 & $\begin{array}{l}\text { Confere todos os kits com as notas de débito e repõe o } \\
\text { que foi utilizado, conforme procedimento 9 }\end{array}$ \\
\hline Auxiliar de Farmácia 2 & $\begin{array}{l}\text { Conferem a montagem e lacram os kits, conforme } \\
\text { procedimento 10 }\end{array}$ \\
\hline Farmacêutico & $\begin{array}{l}\text { Esporadicamente retira amostragem dos kits, conforme } \\
\text { procedimento 11 }\end{array}$ \\
\hline
\end{tabular}

V-) Faturamento:

\begin{tabular}{|l|l|}
\hline AGENTE & AÇÃO \\
\hline Auxiliar de Farmácia 1 & $\begin{array}{l}\text { Ao conferir todos os kits, observa se foi dada } \\
\text { corretamente baixa de todos os medicamentos utilizados } \\
\text { no procedimento cirúrgico nas notas de débito e envia as } \\
\text { notas para o setor de faturamento, conforme } \\
\text { procedimento 12 }\end{array}$ \\
\hline Faturamento & $\begin{array}{l}\text { Devolve as notas de débito para a farmácia após lançá- } \\
\text { las no sistema, conforme procedimento 13 }\end{array}$ \\
\hline Farmacêutico & $\begin{array}{l}\text { Arquiva os documentos por tempo determinado na } \\
\text { farmácia e depois no arquivo morto, conforme } \\
\text { procedimento } 14\end{array}$ \\
\hline
\end{tabular}


Procedimentos:

Procedimento 1:

Item 1: O kit será identificado pelo número da sala acompanhado de uma letra Ponto Crítico: Cada auxiliar de enfermagem deverá retirar o kit referente ao número da sala em que está atendendo.

Item 2: Cada sala terá dois kits, A e B

Ponto Crítico: Estas letras irão facilitar a visualização do tempo necessário para montagem dos kits.

Item 3: Entrega do anestésico inalatório solicitado pelo anestesista ao auxiliar de farmácia.

Ponto crítico: O auxiliar de farmácia deverá marcar a quantidade em $\mathrm{ml}$ contida dentro do frasco, de acordo com o observado na fita graduada colada.

Item 4: O kit é entregue ao anestesista juntamente com a nota de débito psicofarmácos/entorpecentes.

Ponto Crítico: $\mathrm{O}$ auxiliar de farmácia deverá entregar o kit correspondente ao número dasala informada na nota de débito de psicofármacos/entorpecentes e cancelar o campo quantidade solicitada de ambas as vias do documento, caso haja algum medicamento em falta. Assinar a nota de medicamentos psicofármacos/entorpecentes no campo retirada - Farmácia.

Procedimento 2:

Item 1: Ao receber o kit, o anestesista confere os medicamentos controlados e verifica se ele está devidamente lacrado.

Ponto Crítico: Se estiver correto preencherá o campo reservado para a identificação médica (nome/CRM/assinatura); caso contrário, deverá devolvê-lo imediatamente OBS: Não será aceita a informação no final da cirurgia de que estava faltando algum medicamento controlado no kit. Se isso acontecer, o anestesista terá de apresentar um documento de desvio, pois a rotina exige a devolução do kit logo após o rompimento do lacre, antes de utilizá-lo. 
Procedimento 3:

Item 1: Caso no decorrer da cirurgia o anestesista necessite de algum medicamento extra (controlado ou não) ou quantidade maior que a existente nos kits, irá solicitar no campo quantidade solicitada de ambos os documentos.

Ponto crítico: Os documentos devem ser marcados com "pauzinhos" para não gerar dúvidas quanto à quantidade.

Item 2: O auxiliar de enfermagem deve se dirigir à farmácia com a solicitação do médico

Ponto Crítico: Não esquecer de trazer o documento, pois sem a sua apresentação não será atendido.

Procedimento 4:

Item 1: Ao atender a solicitação, o auxiliar de farmácia deve ter atenção para não enviar a quantidade errada.

Ponto Crítico: Devido à marcação ser em "pauzinhos" pode ocorrer de mandar o que já foi mandado anteriormente.

Procedimento 5:

Item 1: $\mathrm{O}$ auxiliar de enfermagem deve conferir o medicamento que está recebendo. Ponto Crítico: Tem de conferir se a quantidade e a dosagem estão de acordo com a solicitada.

Procedimento 6:

Item 1: No término da cirurgia, o anestesista deverá marcar o total de cada medicamento utilizado, no campo quantidade total utilizada de ambas as notas de débito.

Ponto Crítico: Os medicamentos utilizados devem ser todos marcados, independente de fazerem parte ou não do kit (medicamento extra). 
Item 2: Deverá marcar também a quantidade em $\mathrm{ml}$ de anestésico inalatório. Ponto crítico: A quantidade anotada na ficha deve ser correspondente à diferença em mililitros da quantidade enviada com a quantidade devolvida.

Item 3: Essas marcações devem ser feitas pelo médico em algarismos arábicos.

Ponto Crítico: No total, se a quantidade utilizada for marcada com "pauzinhos," poderá gerar dúvidas em quantidades maiores.

\section{Procedimento 7:}

Item 1: $\mathrm{O}$ auxiliar de farmácia confere, juntamente com $\mathrm{o}$ anestesista os medicamentos controlados e se os campos estão devidamente preenchidos.

Ponto Crítico: Se estiver faltando algo, solicitar ao anestesista que anote.

Item 2: Após verificar que está tudo correto, o auxiliar de farmácia poderá dispensar o anestesista e colocar o kit e a nota de débito em cima da bancada da estação de trabalho de montagem dos kits.

\section{Procedimento 8:}

Item 1: $\mathrm{O}$ auxiliar de enfermagem verifica se as baixas foram todas dadas nos campos correspodentes.

Ponto Crítico: Se estiver faltando algo, solicitar ao médico que o faça.

Item 2: $\mathrm{O}$ auxiliar de enfermagem deve colocar todos os medicamentos que não foram utilizados dentro do kit junto com o documento e entregá-lo na farmácia.

Ponto Crítico: Todos os medicamentos extras não utilizados devem ser colocados dentro do kit, pois não deverá ficar nada em sala.

\section{Procedimento 9:}

Item 1: $\mathrm{O}$ auxiliar de farmácia 1 se dirige à estação de trabalho de montagem dos kits e confere todas as notas de débito com os medicamentos que estão nos kits.

Ponto Crítico: Ao conferir, marcar o que não está anotado e reparar os medicamentos extras. 
Item 2: Ir colocando os kits remontados ao lado.

Ponto Crítico: Tomar cuidado para não misturar os kits remontados com os não remontados, pois estarão em cima da mesma bancada.

Procedimento 10:

Item 1: $\mathrm{O}$ auxiliar de farmácia 2 se dirige à estação de trabalho de montagem de kits e confere todos os kits já montados

Ponto Crítico: Se algum kit estiver errado ou com falta de algum medicamento, fazer a correção e anotar.

Item 2: Se estiverem corretos, colocar o lacre e guardar no armário correspondente: kit psicofármaco/entorpecente em armário trancando com chave e kit medicamento estação de trabalho de armazenamento.

Ponto crítico: Não esquecer de lacrar os conferidos e guardá-los corretamente.

Procedimento 11:

Item 1: Esporadicamente, o Farmacêutico colherá amostras dos kits já montados e verificará.

Ponto Crítico: Checar se esse processo possui falhas e corrigi-las se necessário.

Procedimento 12:

Item 1: Se estiver faltando algum medicamento no kit que não foi anotado como utilizado na nota de débito, verificar com o auxiliar de enfermagem da sala de cirurgia se não foi esquecido na ato da devolução.

Ponto Crítico: Esse procedimento atrasa muito a conferência.

Item 2: Se foi utilizado, o auxiliar de farmácia deve anotá-lo no campo de utilizados, para que seja devidamente cobrado.

Ponto Crítico: Anotar corretamente qual o medicamento e a quantidade utilizada OBS: Caso seja medicamento controlado, deverá ser acionado o anestesista responsável pela utilização do kit, pois apenas o médico poderá alterar o documento seguindo os protocolos exigidos pela ANVISA. 
Item 3: Após conferido e consertado, separar todos os documentos de pacientes conveniados e particulares e encaminhar para o setor de faturamento.

Ponto Crítico: Não esquecer de mandar nenhum documento.

Procedimento 13:

Item 1: Após o fechamento da conta do paciente, o faturamento deve devolver as notas de débito para a farmácia.

Ponto Crítico: Não esquecer de devolver nenhuma nota.

Procedimento 14:

Item 1: Ao receber de volta os documentos o farmacêutico, deve conferir e dar baixa no caderno de protocolo de documentos enviados e devolvidos e arquivar conforme a regra abaixo descrita:

Os documentos compreendem via única, que deverá ter seus campos corretamente preenchidos.

Tempo de Arquivo:

FDCC -2 meses

Arquivo morto - 2 anos

Comunicado de Quebra de Medicamento Controlado (não vai para digitação, serve apenas de controle para baixa de estoque na farmácia):

É um documento de via única, utilizado para comunicação de quebra ou extravio de medicamentos controlados por órgãos competentes, durante o procedimento cirúrgico, para fins de baixa e legalização da ocorrência. Este documento deve conter a assinatura e identificação do médico responsável pelo procedimento, circulante de sala e enfermeira chefe do bloco cirúrgico.

Tempo de Arquivo:

FDCC - 2 meses

Arquivo morto - 2 anos

Ponto Crítico: Dar baixa apenas nos já devolvidos. 
$\checkmark$ Desenvolvimento para implantação do kit:

Item 1: Treinamento do Corpo Clínico

Ponto Crítico: Conseguir juntar os anestesistas assistentes para avaliações de todas as modificações desse atendimento.

Item 2: Treinamento da enfermagem

Ponto Crítico: Resultado do treinamento é de médio a longo prazo.

Item 3: Treinamento da Farmácia

Ponto Crítico: Treinamento aos funcionários da farmácia, a longo prazo, para a montagem dos kits.

$\checkmark$ Desenvolvimento do fluxo de documentos e informações;

FARMÁCIA

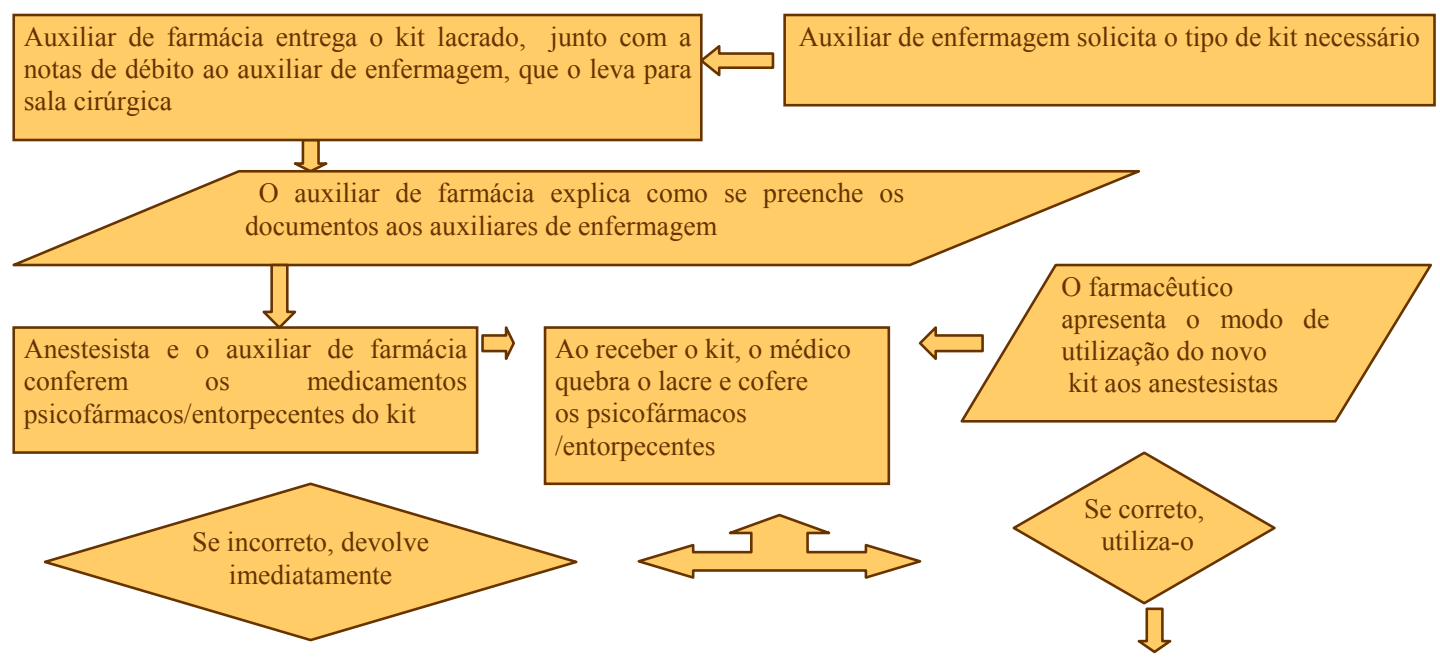

O auxiliar de enfermagem retira o pedido extra com a apresentação dos impressos na farmácia

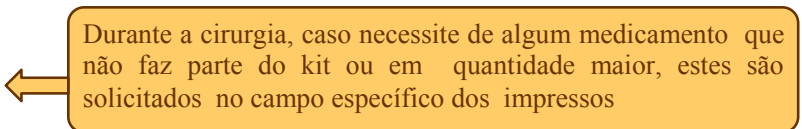

П

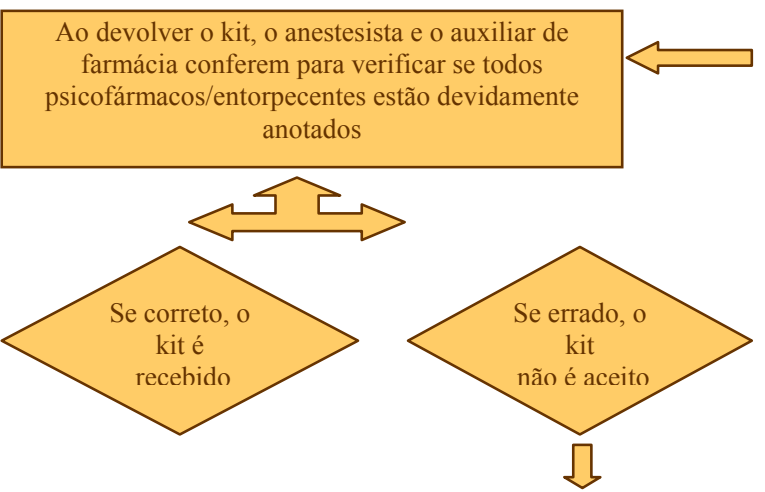

Anestesista anota todos os medicamentos utilizado durante o procedimento, inclusive os extra kit

Ao término da cirurgia, o auxiliar de enfermagem devolve o kit com os medicamentos não utilizados e a nota de débito preenchida 
$\checkmark$ Criação de indicadores:

Controle (Supervisão):

a) Indicadores da Qualidade:

Montagem do kit:

- Em tempo hábil

- Freqüência do uso

- Quantidade de kit x demanda

- Quantidade de correções na conferência

Preenchimento do Impresso:

- Completo/incompleto

- Correto/rasurado

- Legível/ilegível

Utilização do campo quantidade solicitada da ficha de drogas entorpecentes e psicofármacos:

- Freqüente

- Esporádico

- Inexistente

Devolução:

- consumido X devolvido(medicamentos não utilizados)

OBS: Não serão mais devolvidos os cascos

Quebra:

- Freqüente

- Esporádico

- Inexistente

Agente: Farmacêutico da FDCC/Auxiliar Técnico de Saúde

Freqüência: Acompanhamento diário. 
b) Indicadores de Desempenho:
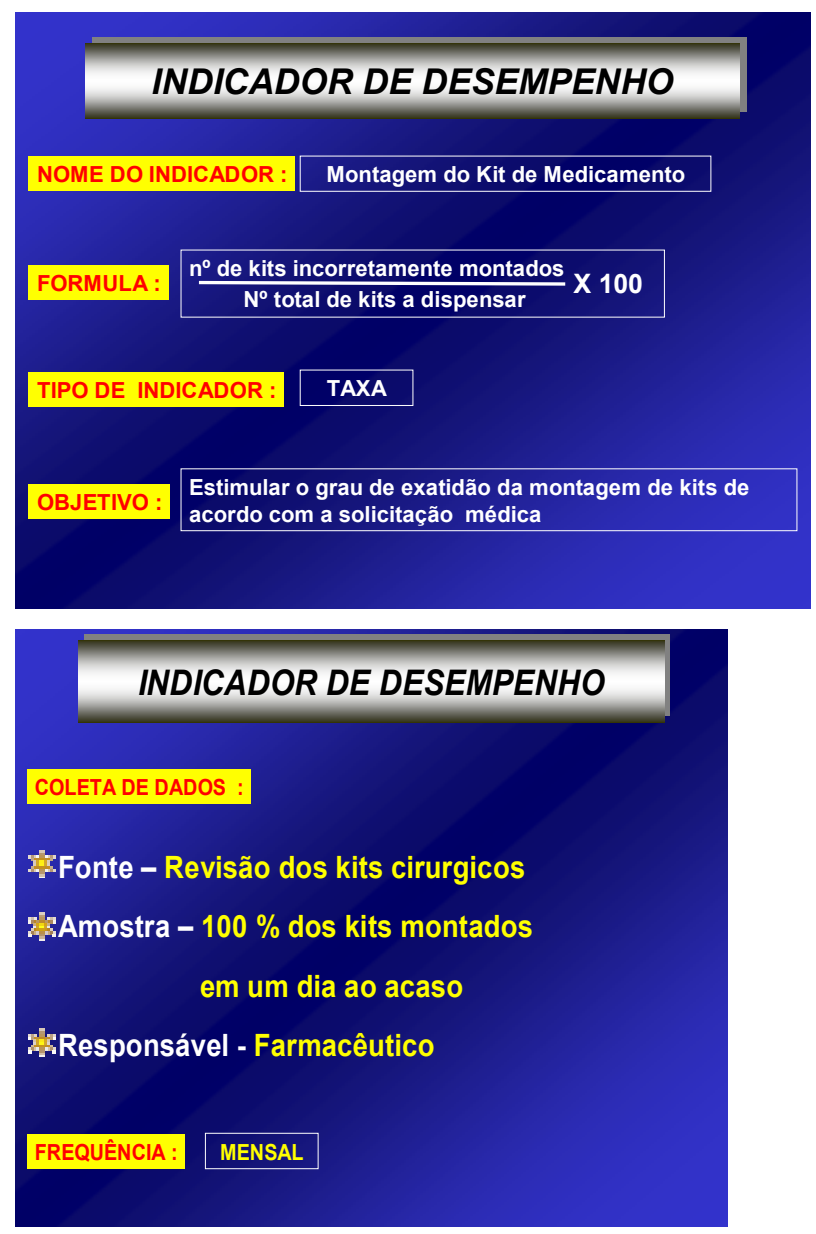

\section{- Teste Piloto}

Foi realizado teste piloto em 20 procedimentos cirúrgicos para validar o kit de dispensação por dose individualizada dos medicamentos em geral, inclusive o de controle especial, obedecendo à portaria 344 da Agência Nacional de Vigilância Sanitária.

Foram aplicados dois testes pilotos, em dez procedimentos cirúrgicos de diversas especialidades cada, abrangendo desde uma cirurgia simples e rápida (Tireoidectomia) até uma mais complexa e demorada (Transplante de Fígado).

Com os resultados obtidos após a observação do número de solicitações extras com relação à quantidade ou elenco contido no kit durante os testes, foi possível estabelecer os ajuntes necessários. Também houve a alteração do impresso específico para medicamentos psicofármacos/entorpecentes, devido à detecção de erros em seu preenchimento. 
Gráfico 1: Apresentação dos dados coletados com referência as alterações do elenco do kit após os dois testes

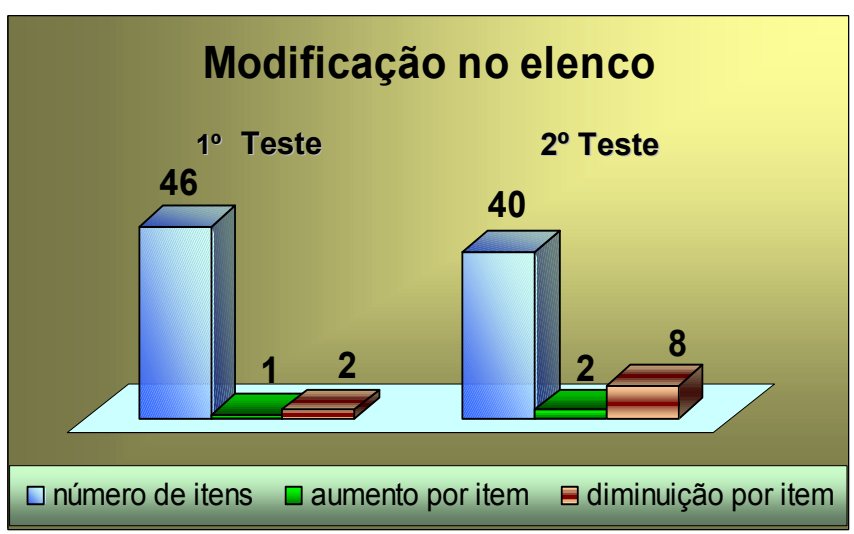

Após os dois testes de validação pudemos acertar o elenco de acordo com as necessidades.

No $1^{\circ}$. Teste, o kit continha 47 itens, houve a inclusão de um e a exclusão de dois medicamentos.

No $2^{\circ}$. Teste, o kit continha 46 itens, houve a inclusão de dois e a exclusão de oito medicamentos.

Gráfico 2: Apresentação dos dados coletados com referência nas alterações necessárias nos campos da nota de débito, devido aos erros no preenchimento.

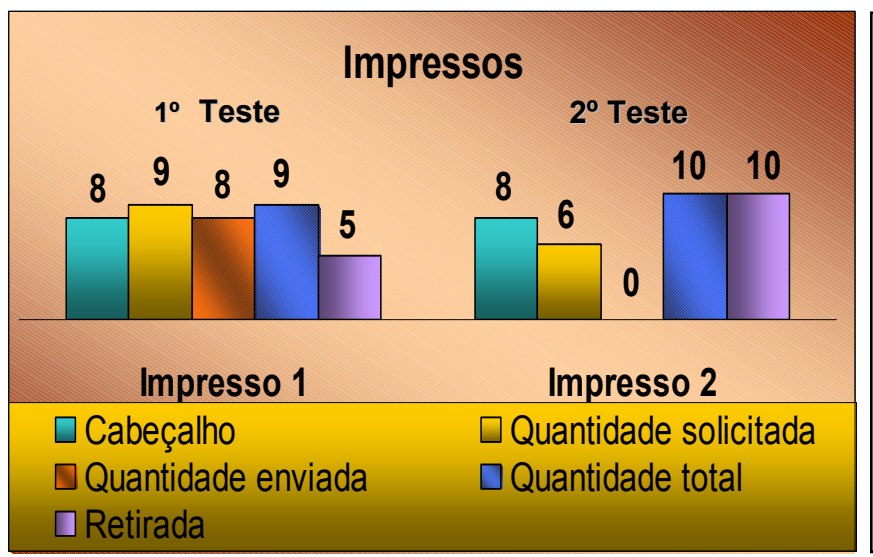

No $1^{\circ}$. Teste, foram encontrados erros em todos os campos de preenchimento da nota de débito. No $2^{\circ}$. Teste, não houve erro no preenchimento da quantidade enviada, diminuindo da quantidade solicitada, mas houve aumento do erro nos campos de retirada e quantidade total.

A conclusão que retiramos da etapa de validação da implantação deste novo sistema de distribuição de medicamentos, realizado por Santos Mattos, $2001^{29}$, foi fundamental para a manutenção do programa com a otimização do elenco e adequação dos documentos. A distribuição de medicamentos é extremamente eficiente, pois atende o maior número de procedimentos de diferentes especialidades cirúrgicas com um único recipiente/kit, diferenciando-se pouco por atender outro centro cirúrgico voltado às gestantes e aos recém nascidos, que foi nosso segundo avanço. 


\subsection{MATERIAL E MÉTODO}

\section{DESENHO EXPERIMENTAL}

O método de pesquisa utilizado foi um estudo de caso qualitativo/quantitativo, sendo que à aplicação do estudo de farmacoeconomia foi realizado no Centro Cirúrgico do Hospital das Clínicas da Faculdade de Medicina da Universidade de São Paulo, localizado no $9^{\circ}$ andar do Prédio dos Ambulatórios (PAMB). A coleta foi realizada no período de 12/05/2002 a 22/07/2002.

Amostra: O Centro Cirúrgico possui trinta e três salas. Para este estudo foram escolhidas como amostra as dez salas do bloco III, onde pudemos acompanhar procedimentos de médio e grande porte de determinadas especialidades médicocirúrgicas.

O estudo foi dividido em três etapas, sendo as duas primeiras experimentais, e a terceira apenas de análise e interpretação dos achados:

$\checkmark 1^{\text {a }}$. Etapa - informações pré-implantação do kit;

$\checkmark 2^{\text {a }}$. Etapa - resultados pós-implantação do kit;

$\checkmark \quad 3^{\text {a }}$. Etapa - comparação dos dados obtidos nas coletas.

Foi realizado o mapeamento do elenco de medicamentos disponibilizados (seja nos carrinhos de drogas, nos kits ou nas solicitações extra) e o levantamento do consumo de três dias de funcionamento de cada sala cirúrgica do Bloco III, nas duas etapas experimentais.

$\mathrm{Na} 1^{\mathrm{a}}$. Etapa, o levantamento foi realizado através da verificação do elenco e das quantidades contidas nos carros de parada e anestesia de cada uma das salas, às 06h30min da manhã, antes do início das cirurgias e no final da tarde, após o término da última, assim, delimitando o consumo/dia/sala. Esses levantamentos eram feitos em dias aleatórios para não induzir a equipe médica ou a enfermagem em modificar seu consumo.

$\mathrm{Na} 2^{\mathrm{a}}$. Etapa realizou-se o levantamento dentro da unidade farmacêutica através da análise dos documentos de dispensação do kit e notas de débito, em que está relacionada a quantidade de medicamentos solicitados pelo auxiliar de 
enfermagem durante a cirurgia e utilizados. A confirmação dessa documentação era feita através da conferência do kit e devolução de medicamentos extras.

Gostaríamos de lembrar que, na $2^{\mathrm{a}}$. Etapa, os carros de medicamentos não estavam sendo utilizados, apenas os kits e os medicamentos extras, que pela rotina estabelecida deviam ser devolvidos após o término de cada cirurgia, não permanecendo nada em sala entre uma cirurgia e outra.

Concomitantemente a ambos os levantamentos, será anotado pelo auxiliar de farmácia em impresso específico, o produto e a quantidade dispensada durante o dia para as determinadas salas cirúrgicas, como registro de retaguarda para conferência dos itens solicitados no decorrer da cirurgia.

Nesse impresso, encontram-se anotações de pedidos extras, o nome dos medicamentos e as quantidades extras que eram solicitadas, para cada sala.

As amostras a serem coletadas correspondem a quarenta e cinco dias de registros de dados, tanto na $1^{\mathrm{a}}$ como na $2^{\mathrm{a}}$ etapas.

Foram elaboradas planilhas para coleta de dados.

Os instrumentos a serem utilizados para coleta de dados serão adequados pela própria relação de medicamentos que forem encontrados em cada uma das salas cirúrgicas, no $1^{\circ}$ dia de levantamento.

$\checkmark$ Apresentação do impresso pré e pós kit:

- Nome de medicamento em ordem alfabética;

- Físico inicial - quantidade de medicamentos antes das cirurgias;

- Extra - quantidade de medicamentos que o médico necessita além daqueles já solicitados;

- Físico final - quantidade de medicamentos que restou após as cirurgias;

- Quantidade utilizada - medicamentos que foram usados durante a cirurgia;

- Preço - gasto com a obtenção de medicamentos pelo hospital 
LEVANTAMENTO DE DADOS KITS INDIVIDUALIZADOS DE MEDICAMENTOS DO C. CIRÚRGICO

DATA:

SALA:

KITS ANTIGO ( )

Novo kit ( )

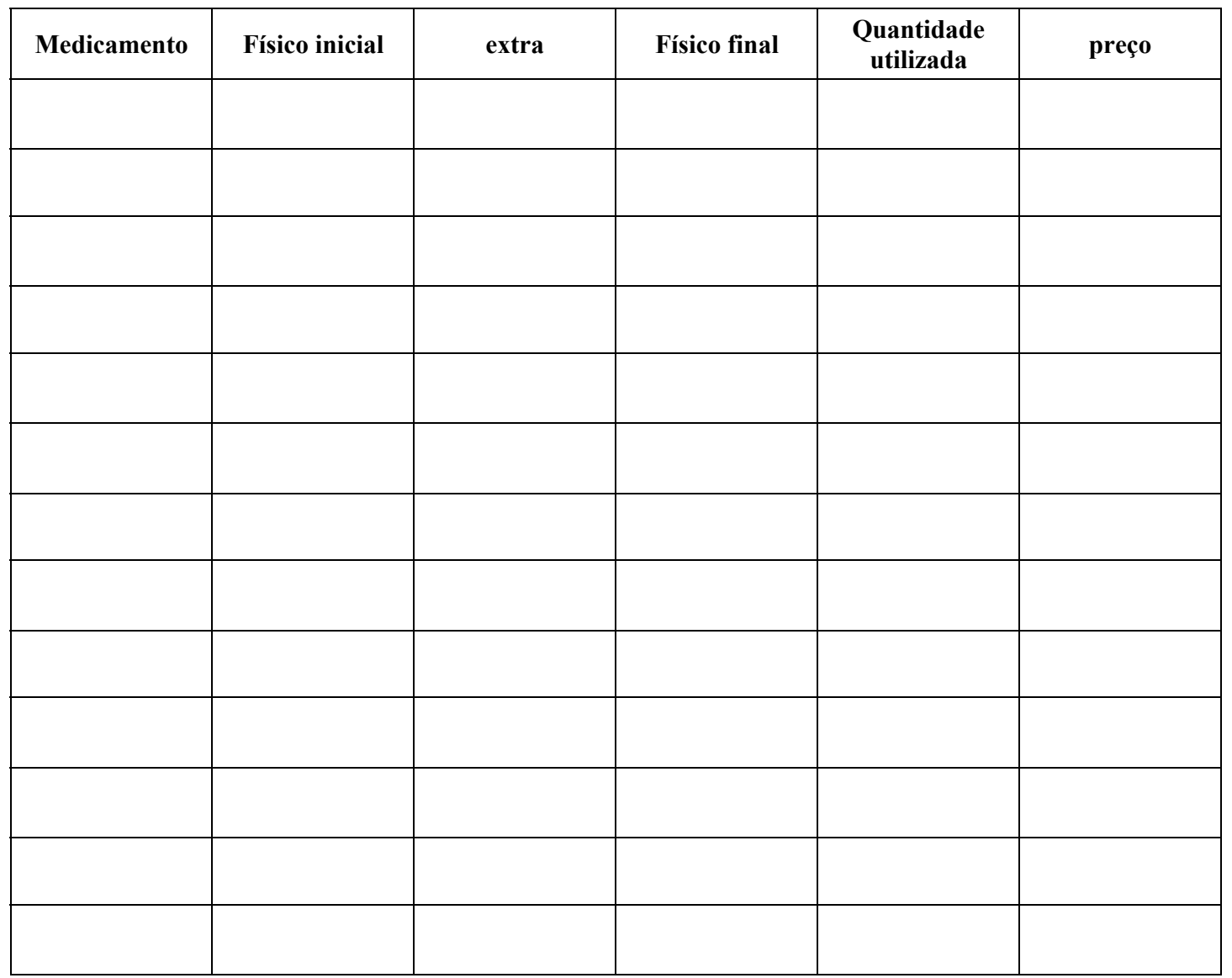


O acompanhamento do consumo de medicamentos no pós-implantação dos kits foi feito em dias consecutivos, devido aos dados serem colhidos das notas de débito da farmácia. Pelo protocolo, foram:

Verificados todos os pacientes que sofreram procedimentos cirúrgicos nas salas do bloco III, através da programação diária do Centro Cirúrgico;

Separados os documentos por sala e anotado todo o elenco de medicamentos solicitados;

$\checkmark$ Conferidos os medicamentos devolvidos identificaram-se que medicamentos haviam sido utilizados por paciente/procedimento cirúrgico;

$\checkmark$ Certificado de que não existia nenhum erro ou desvio nos dados levantados, foi criado um impresso preenchido pela farmácia para marcar as solicitações extras de medicamentos, possibilitando acertos e adaptações à nova rotina;

Anotar os pedidos extras de medicamentos das salas cirúrgicas do bloco III

\begin{tabular}{|l|l|}
\hline Data $L I L$ & Sala \\
\hline Medicamentos & Quantidade solicitada extra \\
\hline & \\
\hline & \\
\hline & \\
\hline & \\
\hline & \\
\hline & \\
\hline & \\
\hline
\end{tabular}

Vistoriadas, ainda, as salas cirúrgicas após o término do último procedimento para comprovar se não ficou nenhum medicamento sem ser devolvido à farmácia. 
Após o fechamento dos dois levantamentos, pré e pós-implantação do kit, procederam-se às seguintes análises dos resultados obtidos pelo programa Excel 2003 (Microsoft Office):

$\checkmark$ Comparação do consumo de medicamentos por sala/dia;

$\checkmark$ Relação de preço de cada medicamento utilizado;

$\checkmark$ Cálculo do valor total gasto por sala/dia;

$\checkmark$ Comparação do valor gasto por sala/dia.

OBS: Informamos que os dados referentes ao preços unitário de cada medicamento foram colhidos do sistema ORACLE 7,0 ( Sistema de Banco de Dados Oracle), que era o sistema de gerenciamento de estoque no momento em que a pesquisa foi realizada.

Vale assinalar que:

$\checkmark$ Os anestésicos inalatórios não entraram no levantamento dos medicamentos utilizados nas cirurgias, pois são utilizados em frações diferentes para cada paciente;

$\checkmark$ No $1^{\circ}$. Dia de mapeamento (pré e pós) das salas cirúrgicas, os medicamentos vencidos encontrados foram recolhidos e considerados como consumidos;

$\checkmark$ Em ambos as fases foram levantados e avaliados itens que poderiam criar viéses no estudo, como: tipo de anestesia e cirurgia, tempo cirúrgico, clínicas envolvidas, e características dos pacientes, por exemplo, sexo e idade. Não foi encontrado nenhuma diferença nestes itens entre as fases pré e pós, que pudessem causar tais intercorrências no estudo.

\section{Análise estatística}

As diferentes variáveis relativas a implantação do kit foram comparadas mediante ao teste " $t$ " de Student bicaldado para valores repetidos. Adotou-se um nível de significância de $5 \%(\mathrm{p}>0,05)$. 


\section{Qualitativos - Aceitação Médica}

Durante todo o processo da implantação e adaptação ao novo sistema de distribuição de medicamentos por kits, não se registrou nenhum incidente, reclamação ou suspensão de procedimento, decorrente de fornecimento medicamentoso inadequado.

Ao contrário, contatos individuais com profissinais da anestesia constataram satisfação com o novo procedimento, apenas havendo sugestões para aprimoramento do impresso e adequação do elenco de medicamentos.

Os resultados principais são apresentados em forma de gráfico, com comparação dos valores pré e pós kits, segundo distintos critérios, sempre evidenciando indiscutíveis benefícios.

O elenco de medicamento com suas respectivas dosagens levantados durante todo o estudo seguiu o padrão de nomenclatura do Guia Farmacoterapêutico do Hospital das Clínicas, realizado por Cipriano et al, $2002^{30}$.

Quantitativos - Dados numéricos coletados

$1^{\mathrm{a}}$. Etapa de coletas - tabelas de um a trinta se referem à fase de préimplantação.

Esses dados foram coletados com o farmacêutico, dentro da sala cirúrgica, após o acompanhamento da cirurgia e na ausência da equipe em dias alternados, de forma que o solicitante não tivesse informação sobre a coleta, para ser induzido à redução de consumo.

Os valores demonstrados nas tabelas abaixo, foram calculados em 2002, onde a taxa de conversão era de USdólar 2,70, conforme site http://www. portalbrasil.net/índices_dolar02.htm, consultado em 15/11/2005. 
Tabela 1: Primeiro dia de consumo na sala 21 fase pré implantação

\begin{tabular}{|c|c|c|c|c|c|c|c|}
\hline \multicolumn{8}{|c|}{ SALA 21 - PRIMEIRO DIA DE CONSUMO } \\
\hline Medicamento & $\begin{array}{l}\text { Físico } \\
\text { Inicial }\end{array}$ & Extra & $\begin{array}{l}\text { Físico } \\
\text { Final }\end{array}$ & $\begin{array}{l}\text { Quantidade } \\
\text { Utilizada }\end{array}$ & $\begin{array}{l}\text { Preço } \\
\text { Unitário }\end{array}$ & $\begin{array}{l}\text { Preço } \\
\text { Final }\end{array}$ & $\begin{array}{l}\text { Valor em } \\
\text { dólar }\end{array}$ \\
\hline amicacina $50 \mathrm{mg} / \mathrm{ml}-2 \mathrm{ml}$ & 6 & & 6 & 0 & & & \\
\hline aminofilina $24 \mathrm{mg} / \mathrm{ml}-10 \mathrm{ml}$ & 5 & & 5 & 0 & & & \\
\hline amiodarona,cloridrato $150 \mathrm{mg}-3 \mathrm{ml}$ & 1 & & 1 & 0 & & & \\
\hline atropina $0,5 \mathrm{mg}-1 \mathrm{ml}$ & 17 & & 16 & 1 & 0,01 & 0,01 & 0,03 \\
\hline bicarbonato de sódio $10 \%-250 \mathrm{ml}$ & 4 & & 4 & 0 & & & \\
\hline bupivacaína isobárica $0,5 \%-20 \mathrm{ml}$ & 1 & & 1 & 0 & & & \\
\hline cetoprofeno $50 \mathrm{mg}-2 \mathrm{ml}$ & 2 & & 2 & 0 & & & \\
\hline cloreto de cálcio $100 \mathrm{mg} / \mathrm{ml}-5 \mathrm{ml}$ & 2 & & 1 & 1 & 0,38 & 0,38 & 1,03 \\
\hline cloreto de sodio $0,9 \%-10 \mathrm{ml}$ & 11 & & 9 & 2 & 0,58 & 1,16 & 3,13 \\
\hline cloreto de sodio $20 \%-20 \mathrm{ml}$ & 12 & & 5 & 7 & 0,38 & 2,66 & 7,18 \\
\hline dexametasona $4 \mathrm{mg} / \mathrm{ml}-1 \mathrm{ml}$ & 2 & & 2 & 0 & & & \\
\hline diazepam $5 \mathrm{mg} / \mathrm{ml}-2 \mathrm{ml}$ & & 2 & 2 & 0 & & & \\
\hline dobutamina $12,5 \mathrm{mg} / \mathrm{ml}-20 \mathrm{ml}$ & 12 & & 12 & 0 & & & \\
\hline dopamina $5 \mathrm{mg} / \mathrm{ml}-10 \mathrm{ml}$ & 6 & & 4 & 2 & 0,34 & 0,68 & 1,84 \\
\hline efedrina $25 \mathrm{mg} / \mathrm{mlo}-1 \mathrm{ml}$ & 5 & & 5 & 0 & & & \\
\hline epinefrina $1 \mathrm{mg} / \mathrm{ml}-1 \mathrm{ml}$ & 45 & & 45 & 0 & & & \\
\hline escopolamina $20 \mathrm{mg} / \mathrm{ml}-1 \mathrm{ml}$ & 3 & & 1 & 2 & 0,72 & 1,44 & 3,89 \\
\hline $\begin{array}{l}\text { fenatanila + droperidol } \\
(0,05 \mathrm{mg}+2,5 \mathrm{mg}) / \mathrm{ml}-2 \mathrm{ml}\end{array}$ & & 4 & 4 & 0 & & & \\
\hline fentanila $0,05 \mathrm{mg} / \mathrm{ml}-5 \mathrm{ml}$ & & 6 & 1 & 5 & 1,8 & 9 & 24,3 \\
\hline fitomenadiona $10 \mathrm{mg} / \mathrm{ml}-1 \mathrm{ml}$ & 4 & & 4 & 0 & & & \\
\hline gentamicina colírio $20 \mathrm{mg} / \mathrm{ml}-10 \mathrm{ml}$ & 2 & & 1 & 1 & 1,34 & 1,34 & 3,62 \\
\hline glicose $50 \%-20 \mathrm{ml}$ & 1 & & 1 & 0 & & & \\
\hline gluconato de cálcio $10 \%-10 \mathrm{ml}$ & 3 & & 3 & 0 & & & \\
\hline hidralazina $20 \mathrm{mg} / \mathrm{ml}-1 \mathrm{ml}$ & 3 & & 3 & 0 & & & \\
\hline isoprenalina $0,2 \mathrm{mg} / \mathrm{ml}-1 \mathrm{ml}$ & 2 & & 1 & 1 & 0,32 & 0,32 & 0,87 \\
\hline metaraminol $10 \mathrm{mg} / \mathrm{ml}-4 \mathrm{ml}$ & 14 & & 14 & 0 & & & \\
\hline metoclopramida $5 \mathrm{mg} / \mathrm{ml}-2 \mathrm{ml}$ & 9 & & 8 & 1 & 0,15 & 0,15 & 0,41 \\
\hline midazolam $5 \mathrm{mg} / \mathrm{ml}-3 \mathrm{ml}$ & & 2 & 1 & 1 & 2,35 & 2,35 & 6,35 \\
\hline morfina $2 \mathrm{mg} / \mathrm{ml}-1 \mathrm{ml}$ & & 2 & 0 & 2 & 0,41 & 0,82 & 2,21 \\
\hline neostigmina $0,5 \mathrm{mg} / \mathrm{ml}-1 \mathrm{ml}$ & 9 & & 8 & 1 & 0,46 & 0,46 & 1,24 \\
\hline noradrenalina $1 \mathrm{mg} / \mathrm{ml}-4 \mathrm{ml}$ & 4 & 11 & 11 & 4 & 1,67 & 6,68 & 18,04 \\
\hline papaverina $50 \mathrm{mg} / \mathrm{ml}-2 \mathrm{ml}$ & 2 & & 2 & 0 & & & \\
\hline petidina $50 \mathrm{mg} / \mathrm{ml}-2 \mathrm{ml}$ & & 2 & 2 & 0 & & & \\
\hline prometazina $25 \mathrm{mg} / \mathrm{ml}-2 \mathrm{ml}$ & 19 & & 19 & 0 & & & \\
\hline propofol $10 \mathrm{mg} / \mathrm{ml}-20 \mathrm{ml}$ & & 4 & 2 & 2 & 8,51 & 17,02 & 45,95 \\
\hline protamina $10 \mathrm{mg} / \mathrm{ml}-5 \mathrm{ml}$ & 7 & & 7 & 0 & & & \\
\hline ranitidina $10 \mathrm{mg} / \mathrm{ml}-5 \mathrm{ml}$ & 11 & & 11 & 0 & & & \\
\hline salbutamol $0,5 \mathrm{mg} / \mathrm{ml}-1 \mathrm{ml}$ & 8 & & 5 & 3 & 0,99 & 2,97 & 8,02 \\
\hline sulfato magnesio $10 \%-10 \mathrm{ml}$ & 10 & & 6 & 4 & 0,45 & 1,8 & 4,86 \\
\hline sulfato magnesio $20 \%-10 \mathrm{ml}$ & 7 & & 5 & 2 & 0,43 & 0,86 & 2,32 \\
\hline tetracaína colírio $0,5 \%-10 \mathrm{ml}$ & 2 & & 2 & 0 & & & \\
\hline verapamil $2,5 \mathrm{mg} / \mathrm{ml}-2 \mathrm{ml}$ & 2 & & 2 & 0 & & & \\
\hline verde brilhante $100 \mathrm{mg} / \mathrm{ml}-1 \mathrm{ml}$ & 7 & & 3 & 4 & 0,36 & 1,44 & 3,89 \\
\hline Total & 260 & 35 & 249 & 46 & 20,75 & 51,54 & 94,16 \\
\hline
\end{tabular}


Tabela 2: Segundo dia de consumo na sala 21 fase pré implantação

\begin{tabular}{|c|c|c|c|c|c|c|c|}
\hline \multicolumn{8}{|c|}{ SALA 21 - SEGUNDO DIA DE CONSUMO } \\
\hline Medicamento & $\begin{array}{l}\text { Físico } \\
\text { Inicial }\end{array}$ & Extra & $\begin{array}{l}\text { Físico } \\
\text { Final }\end{array}$ & $\begin{array}{l}\text { Quantidade } \\
\text { Utilizada }\end{array}$ & \begin{tabular}{|c|} 
Preço \\
Unitário
\end{tabular} & $\begin{array}{l}\text { Preço } \\
\text { Final }\end{array}$ & $\begin{array}{l}\text { Valor em } \\
\text { dólar }\end{array}$ \\
\hline agua destilada $10 \mathrm{ml}$ & 39 & 10 & 30 & 19 & 0,1 & 1,9 & 5,13 \\
\hline álcool etílico $96 \%$ - 10ml & 4 & & 3 & 1 & 0,49 & 0,49 & 1,32 \\
\hline amicacina $50 \mathrm{mg} / \mathrm{ml}-2 \mathrm{ml}$ & 6 & & 6 & 0 & & & \\
\hline amiodarona $50 \mathrm{mg} / \mathrm{ml}-3 \mathrm{ml}$ & 1 & & 1 & 0 & & & \\
\hline aminofilina $24 \mathrm{mg} / \mathrm{ml}-10 \mathrm{ml}$ & 6 & 2 & 6 & 2 & 0,05 & 0,1 & 0,27 \\
\hline atropina $0,5 \mathrm{mg} / \mathrm{ml}-1 \mathrm{ml}$ & 17 & & 13 & 4 & 0,01 & 0,04 & 0,11 \\
\hline bicarbonato de sódio $3 \%-20 \mathrm{ml}$ & 12 & & 9 & 3 & 0,63 & 1,89 & 5,10 \\
\hline bicarbonato de sódio $10 \%-250 \mathrm{ml}$ & 6 & & 4 & 2 & 4,96 & 9,92 & 26,78 \\
\hline bupivacaína isobárica $0,5 \%-20 \mathrm{ml}$ & 2 & 3 & 4 & 1 & 3,07 & 3,07 & 8,29 \\
\hline bupivacaína hiperbárica $0,5 \%$ - $4 \mathrm{ml}$ & 4 & & 4 & 0 & & & \\
\hline $\begin{array}{l}\text { bupivacaína com epinefrina } \\
(5 \mathrm{mg}+9,1 \mathrm{mcg}) / \mathrm{ml}-20 \mathrm{ml}\end{array}$ & 4 & & 2 & 2 & 3,98 & 7,96 & 21,49 \\
\hline $\begin{array}{l}\text { bupivacaína sem epinefrina } 0,5 \% \text { - } \\
20 \mathrm{ml}\end{array}$ & 5 & & 5 & 0 & & & \\
\hline cefalotina $1 \mathrm{~g}$ & 13 & 4 & 9 & 8 & 1,53 & 12,24 & 33,05 \\
\hline cloreto de cálcio $100 \mathrm{mg} / \mathrm{ml}-5 \mathrm{ml}$ & 15 & & 6 & 9 & 0,38 & 3,42 & 9,23 \\
\hline cloreto de potássio $19,1 \%-10 \mathrm{ml}$ & 2 & & 1 & 1 & 0,2 & 0,2 & 0,54 \\
\hline cloreto de sódio $0,9 \%$ - $10 \mathrm{ml}$ & 2 & 5 & 2 & 5 & 0,58 & 2,9 & 7,83 \\
\hline cloreto de sódio $20 \%$ - $20 \mathrm{ml}$ & 11 & & 5 & 6 & 0,38 & 2,28 & 6,16 \\
\hline dexametasona $4 \mathrm{mg} / \mathrm{ml}-1 \mathrm{ml}$ & 22 & & 13 & 9 & 0,39 & 3,51 & 9,48 \\
\hline diazepam $5 \mathrm{mg} / \mathrm{ml}-2 \mathrm{ml}$ & & 3 & 1 & 2 & 0,17 & 0,34 & 0,92 \\
\hline dipirona $500 \mathrm{mg} / \mathrm{ml}-2 \mathrm{ml}$ & 20 & & 15 & 5 & 0,16 & 0,8 & 2,16 \\
\hline dopamina $5 \mathrm{mg} / \mathrm{ml}-10 \mathrm{ml}$ & 3 & 3 & 1 & 5 & 0,34 & 1,7 & 4,59 \\
\hline efedrina $25 \mathrm{mg} / \mathrm{ml}-1 \mathrm{ml}$ & 10 & & 6 & 4 & 0,43 & 1,72 & 4,64 \\
\hline epinefrina $1 \mathrm{mg} / \mathrm{ml} 1 \mathrm{ml}$ & 43 & & 35 & 8 & 0,15 & 1,2 & 3,24 \\
\hline escopolamina $20 \mathrm{mg} / \mathrm{ml}-1 \mathrm{ml}$ & 14 & 10 & 17 & 7 & 0,72 & 5,04 & 13,61 \\
\hline etomidato $2 \mathrm{mg} / \mathrm{ml}-10 \mathrm{ml}$ & & 3 & 2 & 1 & 3,18 & 3,18 & 8,59 \\
\hline $\begin{array}{l}\text { fentanila }+ \text { droperidol }(0,05 \mathrm{mg}+ \\
2,5 \mathrm{mg}) / \mathrm{ml}-2 \mathrm{ml}\end{array}$ & & 6 & 4 & 2 & 3,51 & 7,02 & 18,95 \\
\hline fentanil $0,05 \mathrm{mg} / \mathrm{ml}-5 \mathrm{ml}$ & & 9 & 1 & 8 & 1,8 & 14,4 & 38,9 \\
\hline fitomenadiona $10 \mathrm{mg}-1 \mathrm{ml}$ & 3 & & 3 & 0 & & & \\
\hline furosemida $10 \mathrm{mg} / \mathrm{ml}-2 \mathrm{ml}$ & 12 & & 11 & 1 & 0,13 & 0,13 & 0,35 \\
\hline gentamicina colírio $20 \mathrm{mg} / \mathrm{ml}-10 \mathrm{ml}$ & 1 & & 1 & 0 & & & \\
\hline glicose $50 \%-10 \mathrm{ml}$ & 8 & 3 & 6 & 5 & 0,16 & 0,8 & 2,16 \\
\hline gluconato de cálcio $10 \%-10 \mathrm{ml}$ & 3 & & 3 & 0 & & & \\
\hline heparina IV 5.000UI - $5 \mathrm{ml}$ & 6 & & 5 & 1 & 3,45 & 3,45 & 9,32 \\
\hline hidralazina $20 \mathrm{mg} / \mathrm{ml}-1 \mathrm{ml}$ & 2 & & 1 & 1 & 1,5 & 1,5 & 4,05 \\
\hline hidrocortisona $100 \mathrm{mg}$ & 4 & & 4 & 0 & & & \\
\hline hidrocortisona $500 \mathrm{mg}$ & 3 & & 3 & 0 & & & \\
\hline isoprenalina $0,2 \mathrm{mg} / \mathrm{ml}-1 \mathrm{ml}$ & 13 & & 7 & 6 & 0,32 & 1,92 & 5,18 \\
\hline lidocaína sem epinefrina $2 \%-20 \mathrm{ml}$ & 9 & & 6 & 3 & 0,68 & 2,04 & 5,51 \\
\hline $\begin{array}{l}\text { lidocaína com epinefrina }(2 \%+ \\
50,5 \%) / \mathrm{ml}-20 \mathrm{ml}\end{array}$ & 9 & & 8 & 1 & 1,31 & 1,31 & 3,54 \\
\hline metaraminol 10mg/ml - $1 \mathrm{ml}$ & 18 & & 8 & 10 & 1,95 & 19,5 & 52,65 \\
\hline metoclopramida $5 \mathrm{mg} / \mathrm{ml}-2 \mathrm{ml}$ & 8 & & 8 & 0 & & & \\
\hline midazolam $5 \mathrm{mg} / \mathrm{ml}-3 \mathrm{ml}$ & & 3 & 1 & 2 & 3,53 & 7,05 & 19,04 \\
\hline morfina $2 \mathrm{mg} / \mathrm{ml}-1 \mathrm{ml}$ & & 3 & 1 & 2 & 0,41 & 0,82 & 2,21 \\
\hline
\end{tabular}


SALA 21 - SEGUNDO DIA DE CONSUMO (continuação)

\begin{tabular}{l|c|c|c|c|c|c|c}
\hline Medicamento & $\begin{array}{c}\text { Físico } \\
\text { Inicial }\end{array}$ & Extra & $\begin{array}{c}\text { Físico } \\
\text { Final }\end{array}$ & $\begin{array}{c}\text { Quantidade } \\
\text { Utilizada }\end{array}$ & $\begin{array}{c}\text { Preço } \\
\text { Unitário }\end{array}$ & $\begin{array}{c}\text { Preço } \\
\text { Final }\end{array}$ & $\begin{array}{c}\text { Valor em } \\
\text { dólar }\end{array}$ \\
\hline neostigmina $0,5 \mathrm{mg} / \mathrm{ml}-1 \mathrm{ml}$ & 23 & & 19 & 4 & 0,46 & 1,84 & 4,97 \\
\hline nitroglicerina $50 \mathrm{mg} / 10 \mathrm{ml}$ & 1 & & 1 & 0 & & & \\
\hline noradrenalina $1 \mathrm{mg} / \mathrm{ml}-4 \mathrm{ml}$ & 6 & & 2 & 4 & 1,67 & 6,68 & 18,04 \\
\hline papaverina $50 \mathrm{mg} / \mathrm{ml}-2 \mathrm{ml}$ & 37 & & 27 & 10 & 0,59 & 5,9 & 15,93 \\
\hline petidina $50 \mathrm{mg} / \mathrm{ml}-2 \mathrm{ml}$ & & 3 & 3 & 0 & & & \\
\hline prometazina $25 \mathrm{mg} / \mathrm{ml}-2 \mathrm{ml}$ & 7 & & 7 & 0 & & & \\
\hline propofol $10 \mathrm{mg} / \mathrm{ml}-20 \mathrm{ml}$ & & 6 & 3 & 3 & 8,51 & 25,53 & 68,93 \\
\hline ranitidina $10 \mathrm{mg} / \mathrm{ml}-5 \mathrm{ml}$ & 18 & 5 & 4 & 19 & 0,18 & 3,42 & 9,23 \\
\hline salbutamol $0,5 \mathrm{mg} / \mathrm{ml}-1 \mathrm{ml}$ & 12 & 2 & 8 & 6 & 0,99 & 5,94 & 16,04 \\
\hline sulfato de magnésio $10 \%-10 \mathrm{ml}$ & 5 & & 3 & 2 & 0,45 & 0,9 & 2,43 \\
\hline sulfato de magnésio $20 \%-10 \mathrm{ml}$ & 6 & & 3 & 3 & 0,43 & 1,29 & 3,48 \\
\hline suxametônio $100 \mathrm{mg}$ & 5 & & 5 & 0 & & & \\
\hline tetracaína colírio $0,5 \%-10 \mathrm{ml}$ & 1 & & 1 & 0 & & & \\
\hline verde brilhante $100 \mathrm{mg} / \mathrm{ml}-1 \mathrm{ml}$ & 12 & & 9 & 3 & 0,36 & 1,08 & 2,92 \\
\hline vit A e D colírio - $10 \mathrm{ml}$ & 2 & & 1 & 1 & 4,95 & 4,95 & 13,37 \\
\hline vitamina k3 5mg/ml - 1ml & 4 & & 3 & 1 & 0,56 & 0,56 & 1,51 \\
\hline Total & $\mathbf{4 9 9}$ & $\mathbf{8 3}$ & $\mathbf{4 1 6}$ & $\mathbf{2 0 2}$ & $\mathbf{5 9 , 8}$ & $\mathbf{1 8 0 , 2 1}$ & $\mathbf{4 9 1 , 2 4}$ \\
\hline
\end{tabular}


Tabela 3: Terceiro dia de consumo na sala 21 fase pré implantação

SALA 21 - TERCEIRO DIA DE CONSUMO

\begin{tabular}{|c|c|c|c|c|c|c|c|}
\hline & & & & & & & \\
\hline Medicamento & $\begin{array}{l}\text { Físico } \\
\text { Inicial }\end{array}$ & Extra & $\begin{array}{l}\text { Físico } \\
\text { Final }\end{array}$ & $\begin{array}{l}\text { Quantidade } \\
\text { Utilizada }\end{array}$ & $\begin{array}{c}\text { Preço } \\
\text { Unitário }\end{array}$ & $\begin{array}{l}\text { Preço } \\
\text { Final }\end{array}$ & $\begin{array}{l}\text { Valor em } \\
\text { dólar }\end{array}$ \\
\hline agua destilada $10 \mathrm{ml}$ & 23 & & 18 & 5 & 0,1 & 0,5 & 1,35 \\
\hline álcool etílico $96 \%$ - 10ml & 1 & & 1 & 0 & & & \\
\hline amicacina $50 \mathrm{mg} / \mathrm{ml}-2 \mathrm{ml}$ & 4 & & 4 & 0 & & & \\
\hline ampicilina $1 \mathrm{~g}$ & 3 & & 3 & 0 & & & \\
\hline atropina $0,25 \mathrm{mg} / \mathrm{ml}-1 \mathrm{ml}$ & 14 & & 14 & 0 & & & \\
\hline atropina $0,5 \mathrm{mg} / \mathrm{ml}-1 \mathrm{ml}$ & 16 & & 11 & 5 & 0,01 & 0,05 & 0,14 \\
\hline bupivacaína isobárica $0,5 \%-20 \mathrm{ml}$ & 2 & & 2 & 0 & & & \\
\hline bupivacaína hiperbárica $0,5 \%-4 \mathrm{ml}$ & 2 & & 1 & 1 & 3,59 & 3,59 & 9,69 \\
\hline $\begin{array}{l}\text { bupivacaína com epinefrina } \\
(5 \mathrm{mg}+9,1 \mathrm{mcg}) / \mathrm{ml}-20 \mathrm{ml}\end{array}$ & 5 & & 5 & 0 & & & \\
\hline $\begin{array}{l}\text { bupivacaína sem epinefrina } 0,5 \% \text { - } \\
20 \mathrm{ml}\end{array}$ & 8 & & 3 & 5 & 4 & 20 & 54 \\
\hline cefalotina $1 \mathrm{~g}$ & 4 & & 4 & 0 & & & \\
\hline dexametasona $4 \mathrm{mg} / \mathrm{ml} \mathrm{-} 1 \mathrm{ml}$ & 9 & & 9 & 0 & & & \\
\hline diazepam $5 \mathrm{mg} / \mathrm{ml}-2 \mathrm{ml}$ & & 2 & 1 & 1 & 0,17 & 0,17 & 0,46 \\
\hline $\begin{array}{l}\text { dimenidrato+piridoxina }(50+50 \mathrm{mg}) / \\
\mathrm{ml}-1 \mathrm{ml}\end{array}$ & 1 & & 1 & 0 & & & \\
\hline dipirona $500 \mathrm{mg} / \mathrm{ml}-2 \mathrm{ml}$ & 15 & & 11 & 4 & 0,16 & 0,64 & 1,73 \\
\hline efedrina $25 \mathrm{mg} / \mathrm{ml}-1 \mathrm{ml}$ & 3 & & 3 & 0 & & & \\
\hline epinefrina $1 \mathrm{mg} / \mathrm{ml}-1 \mathrm{ml}$ & 36 & & 36 & 0 & & & \\
\hline escopolamina $20 \mathrm{mg} / \mathrm{ml}-1 \mathrm{ml}$ & 9 & & 7 & 2 & 0,72 & 1,44 & 3,89 \\
\hline etomidato $2 \mathrm{mg} / \mathrm{ml}-10 \mathrm{ml}$ & & 2 & 1 & 1 & 3,18 & 3,18 & 8,59 \\
\hline $\begin{array}{l}\text { fentanila + droperidol } \\
(0,05 \mathrm{mg}+2,5 \mathrm{mg}) / \mathrm{ml}-2 \mathrm{ml}\end{array}$ & & 4 & 2 & 2 & 3,51 & 7,02 & 18,95 \\
\hline fentanil $0,05 \mathrm{mg} / \mathrm{ml}-5 \mathrm{ml}$ & & 6 & 1 & 5 & 1,8 & 9 & 24,3 \\
\hline fitomenadiona $10 \mathrm{mg} / \mathrm{ml}-1 \mathrm{ml}$ & 1 & & 1 & 0 & & & \\
\hline furosemida $10 \mathrm{mg} / \mathrm{ml}-2 \mathrm{ml}$ & 10 & & 10 & 0 & & & \\
\hline gentamicina $10 \mathrm{mg} / \mathrm{ml}-1 \mathrm{ml}$ & 5 & & 5 & 0 & & & \\
\hline gentamicina $40 \mathrm{mg} / \mathrm{ml}-1 \mathrm{ml}$ & 6 & & 6 & 0 & & & \\
\hline gentamicina $80 \mathrm{mg} / \mathrm{ml}-1 \mathrm{ml}$ & 1 & & 1 & 0 & & & \\
\hline gentamicina pomada $0,3 \%-3 \mathrm{~g}$ & 2 & & 2 & 0 & & & \\
\hline heparina IV 5.000UI - $5 \mathrm{ml}$ & 2 & & 2 & 0 & & & \\
\hline hidrocortisona $100 \mathrm{mg}$ & 1 & 2 & 2 & 1 & 0,89 & 0,89 & 2,4 \\
\hline hidrocortisona $500 \mathrm{mg}$ & 4 & & 3 & 1 & 2,88 & 2,88 & 7,78 \\
\hline lidocaína geléia $2 \%$ - 30ml & 1 & & 1 & 0 & & & \\
\hline lidocaína sem epinefrina $2 \%-20 \mathrm{ml}$ & 4 & & 2 & 2 & 0,68 & 1,36 & 3,67 \\
\hline $\begin{array}{l}\text { lidocaína com epinefrina } \\
(20 \mathrm{mg}+5 \mathrm{mcg}) / \mathrm{ml}-20 \mathrm{ml}\end{array}$ & 6 & & 5 & 1 & 1,31 & 1,31 & 3,54 \\
\hline metaraminol $10 \mathrm{mg} / \mathrm{ml}-1 \mathrm{ml}$ & 11 & & 11 & 0 & & & \\
\hline metoclopramida $5 \mathrm{mg} / \mathrm{ml} \mathrm{-} 2 \mathrm{ml}$ & 9 & & 7 & 2 & 0,15 & 0,3 & 0,81 \\
\hline midazolam $5 \mathrm{mg} / \mathrm{ml}-3 \mathrm{ml}$ & & 2 & 1 & 1 & 2,35 & 2,35 & 6,35 \\
\hline morfina $2 \mathrm{mg} / \mathrm{ml}-1 \mathrm{ml}$ & & 2 & 1 & 1 & 0,41 & 0,41 & 1,11 \\
\hline neostigmina $0,5 \mathrm{mg} / \mathrm{ml}-1 \mathrm{ml}$ & 14 & & 12 & 2 & 0,46 & 0,92 & 2,48 \\
\hline noradrenalina $1 \mathrm{mg} / \mathrm{ml}-4 \mathrm{ml}$ & 1 & & 1 & 0 & & & \\
\hline papaverina $50 \mathrm{mg} / \mathrm{ml}-2 \mathrm{ml}$ & 1 & & 1 & 0 & & & \\
\hline petidina $50 \mathrm{mg} / \mathrm{ml} \mathrm{-} 2 \mathrm{ml}$ & & 2 & 2 & 0 & & & \\
\hline prometazina $25 \mathrm{mg} / \mathrm{ml}-2 \mathrm{ml}$ & 1 & & 1 & 0 & & & \\
\hline propofol $10 \mathrm{mg} / \mathrm{ml}-20 \mathrm{ml}$ & & 4 & 2 & 2 & 8,51 & 17,02 & 45,95 \\
\hline
\end{tabular}


SALA 21 - TERCEIRO DIA DE CONSUMO (continuação)

\begin{tabular}{|c|c|c|c|c|c|c|c|}
\hline Medicamento & $\begin{array}{l}\text { Físico } \\
\text { Inicial }\end{array}$ & Extra & $\begin{array}{l}\text { Físico } \\
\text { Final }\end{array}$ & $\begin{array}{l}\text { Quantidade } \\
\text { Utilizada }\end{array}$ & $\begin{array}{c}\text { Preço } \\
\text { Unitário }\end{array}$ & $\begin{array}{l}\text { Preço } \\
\text { Final }\end{array}$ & $\begin{array}{l}\text { Valor em } \\
\text { dólar }\end{array}$ \\
\hline ranitidina $10 \mathrm{mg} / \mathrm{ml}-5 \mathrm{ml}$ & 12 & & 10 & 2 & 0,18 & 036 & 0,97 \\
\hline $\begin{array}{l}\text { salbutamol spray } 100 \mathrm{mcg} / \text { dose - } \\
\text { 200doses }\end{array}$ & 1 & & 1 & 0 & & & \\
\hline suxametônio $100 \mathrm{mg}$ & 1 & & 1 & 0 & & & \\
\hline vaselina $20 \mathrm{ml}$ & 1 & & 1 & 0 & & & \\
\hline verde brilhante $100 \mathrm{mg} / \mathrm{ml}-1 \mathrm{ml}$ & 4 & & 4 & 0 & & & \\
\hline Total & 254 & 26 & 234 & 46 & 35,06 & 73,39 & 198,16 \\
\hline
\end{tabular}


Tabela 4: Primeiro dia de consumo na sala 22 fase pré implantação

SALA 22 - PRIMEIRO DIA DE CONSUMO

\begin{tabular}{|c|c|c|c|c|c|c|c|}
\hline \\
\hline Medicamento & $\begin{array}{l}\text { Físico } \\
\text { Inicial }\end{array}$ & Extra & $\begin{array}{l}\text { Físico } \\
\text { Final }\end{array}$ & $\begin{array}{l}\text { Quantidade } \\
\text { Utilizada }\end{array}$ & $\begin{array}{c}\text { Preço } \\
\text { Unitário }\end{array}$ & $\begin{array}{l}\text { Preço } \\
\text { Final }\end{array}$ & $\begin{array}{c}\text { Valor em } \\
\text { dólar }\end{array}$ \\
\hline agua destilada $10 \mathrm{ml}$ & 18 & & 8 & 10 & 0,1 & 1 & 2,7 \\
\hline álcool etílico $96 \%-10 \mathrm{ml}$ & 1 & & 1 & 0 & & & \\
\hline amicacina $50 \mathrm{mg} / \mathrm{ml}-2 \mathrm{ml}$ & 4 & & 4 & 0 & & & \\
\hline atropina $0,25 \mathrm{mg} / \mathrm{ml}-1 \mathrm{ml}$ & 14 & 20 & 12 & 22 & 0,12 & 2,64 & 7,13 \\
\hline atropina $0,5 \mathrm{mg} / \mathrm{ml}-1 \mathrm{ml}$ & 11 & 15 & 10 & 16 & 0,01 & 0,16 & 0,43 \\
\hline ampicilina $1 \mathrm{~g}$ & 3 & & 3 & 0 & & & \\
\hline azul de metileno $1 \%-5 \mathrm{ml}$ & & 2 & 1 & 1 & 1,02 & 1,02 & 2,75 \\
\hline bupivacaína hiperbárica $0,5 \%-4 \mathrm{ml}$ & 1 & 1 & 1 & 1 & 3,59 & 3,59 & 9,69 \\
\hline bupivacaína isobárica $0,5 \%$ - $20 \mathrm{ml}$ & 2 & & 2 & 0 & & & \\
\hline $\begin{array}{l}\text { bupivacaína com epinefrina } \\
(5 \mathrm{mg}+9,1 \mathrm{mcg}) / \mathrm{ml}-20 \mathrm{ml}\end{array}$ & 3 & 15 & 1 & 17 & 3,98 & 67,66 & 182,68 \\
\hline $\begin{array}{l}\text { bupivacaína sem epinefrina } 0,5 \% \text { - } \\
20 \mathrm{ml}\end{array}$ & 8 & 10 & 7 & 11 & 4 & 44 & 118,8 \\
\hline cefalotina $1 \mathrm{~g}$ & 4 & 2 & 1 & 5 & 1,53 & 7,65 & 20,66 \\
\hline cetoprofeno $50 \mathrm{mg} / \mathrm{ml}-2 \mathrm{ml}$ & & 2 & & 2 & 3,43 & 6,86 & 18,52 \\
\hline dexametasona $4 \mathrm{mg} / \mathrm{ml}-1 \mathrm{ml}$ & 9 & 4 & 9 & 4 & 0,39 & 1,56 & 4,21 \\
\hline diazepam $5 \mathrm{mg} / \mathrm{ml}-2 \mathrm{ml}$ & & 3 & 3 & 0 & & & \\
\hline $\begin{array}{l}\text { Dimenidrato+piridoxina }(50+50 \mathrm{mg}) / \\
\mathrm{ml}-1 \mathrm{ml}\end{array}$ & 1 & & 1 & 0 & & & \\
\hline dipirona $500 \mathrm{mg} / \mathrm{ml}-2 \mathrm{ml}$ & 11 & 11 & 10 & 12 & 0,16 & 1,92 & 5,18 \\
\hline efedrina $25 \mathrm{mg} / \mathrm{ml}-1 \mathrm{ml}$ & 3 & & 2 & 1 & 0,43 & 0,43 & 1,16 \\
\hline epinefrina $1 \mathrm{mg} / \mathrm{ml} 1 \mathrm{ml}$ & 35 & 15 & 35 & 15 & 0,15 & 2,25 & 6,08 \\
\hline escopolamina $20 \mathrm{mg} / \mathrm{ml}-1 \mathrm{ml}$ & 7 & & 7 & 0 & & & \\
\hline etomidato $2 \mathrm{mg} / \mathrm{ml}-10 \mathrm{ml}$ & & 3 & 3 & 0 & & & \\
\hline $\begin{array}{l}\text { fentanila }+ \text { droperidol } \\
(0,05 \mathrm{mg}+2,5 \mathrm{mg}) / \mathrm{ml}-2 \mathrm{ml}\end{array}$ & & 6 & 6 & 0 & & & \\
\hline fentanil $0,05 \mathrm{mg} / \mathrm{ml}-5 \mathrm{ml}$ & & 9 & 4 & 5 & 1,8 & 9 & 24,3 \\
\hline fitomenadiona $10 \mathrm{mg} / \mathrm{ml}-1 \mathrm{ml}$ & 1 & & 1 & 0 & & & \\
\hline furosemida $10 \mathrm{mg} / \mathrm{ml}-2 \mathrm{ml}$ & 10 & & 10 & 0 & & & \\
\hline gentamicina $10 \mathrm{mg} / \mathrm{ml}-1 \mathrm{ml}$ & 5 & & 5 & 0 & & & \\
\hline gentamicina $40 \mathrm{mg} / \mathrm{ml}-1 \mathrm{ml}$ & 6 & 2 & 6 & 2 & 0,19 & 0,38 & 1,03 \\
\hline gentamicina $80 \mathrm{mg} / \mathrm{ml}-1 \mathrm{ml}$ & 1 & & 1 & 0 & & & \\
\hline gentamicina pomada $0,3 \%-3 \mathrm{~g}$ & 2 & & 2 & 0 & & & \\
\hline glicose $50 \%-10 \mathrm{ml}$ & & 1 & & 1 & 0,16 & 0,16 & 0,43 \\
\hline heparina IV 5.000UI - $5 \mathrm{ml}$ & 2 & & 2 & 0 & & & \\
\hline hidrocortisona 100mg & 1 & & 0 & 1 & 0,88 & 0,88 & 2,38 \\
\hline hidrocortisona $500 \mathrm{mg}$ & 4 & & 4 & 0 & & & \\
\hline lidocaína sem epinefrina $2 \%$ - $20 \mathrm{ml}$ & 2 & 4 & 1 & 5 & 0,68 & 3,4 & 9,18 \\
\hline $\begin{array}{l}\text { lidocaína com epinefrina } \\
(20 \mathrm{mg}+5 \mathrm{mcg}) / \mathrm{ml}-20 \mathrm{ml}\end{array}$ & 5 & 4 & 5 & 4 & 1,31 & 5,24 & 14,15 \\
\hline lidocaína spray $10 \%-70 \mathrm{~g}$ & 1 & & 1 & 0 & & & \\
\hline lidocaína geléia $2 \%$ - 30ml & 2 & & 1 & 1 & 1,12 & 1,12 & 3,02 \\
\hline metaraminol $10 \mathrm{mg} / \mathrm{ml}-1 \mathrm{ml}$ & 11 & & 9 & 2 & 1,95 & 3,9 & 10,53 \\
\hline metoclopramida $5 \mathrm{mg} / \mathrm{ml}-2 \mathrm{ml}$ & 7 & 12 & 5 & 14 & 0,15 & 2,1 & 5,67 \\
\hline midazolam $5 \mathrm{mg} / \mathrm{ml}-3 \mathrm{ml}$ & & 3 & 1 & 2 & 2,35 & 4,7 & 12,69 \\
\hline morfina $2 \mathrm{mg} / \mathrm{ml}-1 \mathrm{ml}$ & & 3 & 1 & 2 & 0,41 & 0,82 & 2,21 \\
\hline
\end{tabular}


SALA 22 - PRIMEIRO DIA DE CONSUMO (continuação)

\begin{tabular}{l|c|c|c|c|c|c|c}
\hline Medicamento & $\begin{array}{c}\text { Físico } \\
\text { Inicial }\end{array}$ & Extra & $\begin{array}{c}\text { Físico } \\
\text { Final }\end{array}$ & $\begin{array}{c}\text { Quantidade } \\
\text { Utilizada }\end{array}$ & $\begin{array}{c}\text { Preço } \\
\text { Unitário }\end{array}$ & $\begin{array}{c}\text { Preço } \\
\text { Final }\end{array}$ & $\begin{array}{c}\text { Valor em } \\
\text { dólar }\end{array}$ \\
\hline neostigmina $0,5 \mathrm{mg} / \mathrm{ml}-1 \mathrm{ml}$ & 12 & 2 & 7 & 7 & 0,46 & 3,22 & 8,69 \\
\hline noradrenalina $1 \mathrm{mg} / \mathrm{ml}-4 \mathrm{ml}$ & 1 & 1 & 1 & 1 & 1,67 & 1,67 & 4,51 \\
\hline papaverina $50 \mathrm{mg} / \mathrm{ml}-2 \mathrm{ml}$ & 1 & & 1 & 0 & & & \\
\hline petidina $50 \mathrm{mg} / \mathrm{ml}-2 \mathrm{ml}$ & & 3 & 2 & 1 & 0,18 & 0,18 & 0,49 \\
\hline propofol $10 \mathrm{mg} / \mathrm{ml}-20 \mathrm{ml}$ & & 4 & 0 & 4 & 8,51 & 34,04 & 91,91 \\
\hline ranitidina $10 \mathrm{mg} / \mathrm{ml}-5 \mathrm{ml}$ & 10 & & 8 & 2 & 0,18 & 0,36 & 0,97 \\
\hline salbutamol spray $100 \mathrm{mcg} /$ dose - & 1 & & 1 & 0 & & & \\
200doses & 1 & & 1 & 0 & & & \\
\hline suxametônio $100 \mathrm{mg}$ & 1 & & 1 & 0 & & & \\
\hline vaselina $20 \mathrm{ml}$ & 3 & 2 & 3 & 2 & 0,36 & 0,72 & 1,94 \\
\hline verde brilhante $100 \mathrm{mg} / \mathrm{ml}-1 \mathrm{ml}$ & $\mathbf{2 2 5}$ & $\mathbf{1 5 9}$ & $\mathbf{2 1 0}$ & $\mathbf{1 7 3}$ & $\mathbf{4 1 , 2 7}$ & $\mathbf{2 0 3 , 6 3}$ & $\mathbf{5 7 4 , 0 9}$ \\
\hline Total & & & & & & & \\
\hline
\end{tabular}


Tabela 5: Segundo dia de consumo na sala 22 fase pré implantação

SALA 22 - SEGUNDO DIA DE CONSUMO

\begin{tabular}{|c|c|c|c|c|c|c|c|}
\hline Medicamento & $\begin{array}{l}\text { Físico } \\
\text { Inicial }\end{array}$ & Extra & $\begin{array}{c}\text { Físico } \\
\text { Final }\end{array}$ & $\begin{array}{c}\text { Quantidade } \\
\text { Utilizada }\end{array}$ & $\begin{array}{c}\text { Preço } \\
\text { Unitário }\end{array}$ & $\begin{array}{c}\text { Preço } \\
\text { Final }\end{array}$ & $\begin{array}{c}\text { Valor em } \\
\text { dólar }\end{array}$ \\
\hline água destilada $10 \mathrm{ml}$ & 8 & 13 & 13 & 8 & 0,1 & 0,8 & 2,16 \\
\hline álcool etílico $96 \%$ - 10ml & 1 & & 1 & 0 & & & \\
\hline amicacina $50 \mathrm{mg} / \mathrm{ml}-2 \mathrm{ml}$ & 4 & & 4 & 0 & & & \\
\hline amido hidroxietílico $6 \%-500 \mathrm{ml}$ & 5 & & 2 & 3 & 27,64 & 82,92 & 223,88 \\
\hline ampicilina $1 \mathrm{~g}$ & 3 & & 3 & 0 & & & \\
\hline atropina $0,25 \mathrm{mg} / \mathrm{ml}-1 \mathrm{ml}$ & 12 & & 12 & 0 & & & \\
\hline atropina $0,5 \mathrm{mg} / \mathrm{ml}-1 \mathrm{ml}$ & 10 & & 10 & 0 & & & \\
\hline bupivacaína hiperbárica $0,5 \%$ - 4ml & 6 & 2 & 3 & 5 & 3,59 & 17,95 & 48,47 \\
\hline bupivacaína isobárica $0,5 \%-20 \mathrm{ml}$ & 3 & & 2 & 1 & 3,07 & 3,07 & 8,29 \\
\hline $\begin{array}{l}\text { bupivacaína com epinefrina } \\
(5 \mathrm{mg}+9,1 \mathrm{mcg}) / \mathrm{ml}-20 \mathrm{ml}\end{array}$ & 1 & & 1 & 0 & & & \\
\hline $\begin{array}{l}\text { bupivacaína sem epinefrina } 0,5 \% \text { - } \\
20 \mathrm{ml}\end{array}$ & 8 & & 8 & 0 & & & \\
\hline cefalotina $1 \mathrm{~g}$ & 3 & & 1 & 2 & 1,53 & 3,06 & 8,26 \\
\hline cetoprofeno $50 \mathrm{mg} / \mathrm{ml}-2 \mathrm{ml}$ & & 1 & & 1 & 3,43 & 3,43 & 9,26 \\
\hline dexametasona $4 \mathrm{mg} / \mathrm{ml}-1 \mathrm{ml}$ & 9 & & 9 & 0 & & & \\
\hline diazepam $5 \mathrm{mg} / \mathrm{ml}-2 \mathrm{ml}$ & & 3 & 2 & 1 & 0,17 & 0,17 & 0,46 \\
\hline $\begin{array}{l}\text { Dimenidrato+piridoxina }(50+50 \mathrm{mg}) / \\
\mathrm{ml}-1 \mathrm{ml}\end{array}$ & 1 & & 1 & 0 & & & \\
\hline dipirona $500 \mathrm{mg} / \mathrm{ml}-2 \mathrm{ml}$ & 10 & & 6 & 4 & 0,16 & 0,64 & 1,73 \\
\hline efedrina $25 \mathrm{mg} / \mathrm{ml}-1 \mathrm{ml}$ & 4 & & 2 & 2 & 0,43 & 0,86 & 2,32 \\
\hline epinefrina $1 \mathrm{mg} / \mathrm{ml}-1 \mathrm{ml}$ & 36 & & 26 & 10 & 0,15 & 1,5 & 4,05 \\
\hline escopolamina $20 \mathrm{mg} / \mathrm{ml}-1 \mathrm{ml}$ & 7 & & 6 & 1 & 0,72 & 0,72 & 1,94 \\
\hline etomidato $2 \mathrm{mg} / \mathrm{ml}-10 \mathrm{ml}$ & & 3 & 2 & 1 & 3,18 & 3,18 & 8,59 \\
\hline $\begin{array}{l}\text { fentanila + droperidol } \\
(0,05 \mathrm{mg}+2,5 \mathrm{mg}) / \mathrm{ml}-2 \mathrm{ml}\end{array}$ & & 6 & 4 & 2 & 3,51 & 7,02 & 18,95 \\
\hline fentanil $0,05 \mathrm{mg} / \mathrm{ml}-5 \mathrm{ml}$ & & 9 & 4 & 5 & 1,8 & 9 & 24,3 \\
\hline fitomenadiona $10 \mathrm{mg} / \mathrm{ml}-1 \mathrm{ml}$ & 1 & & 1 & 0 & & & \\
\hline gentamicina $10 \mathrm{mg} / \mathrm{ml}-1 \mathrm{ml}$ & 5 & & 3 & 2 & 0,36 & 0,72 & 1,94 \\
\hline gentamicina $40 \mathrm{mg} / \mathrm{ml}-1 \mathrm{ml}$ & 6 & & 4 & 2 & 0,19 & 0,38 & 1,03 \\
\hline gentamicina $80 \mathrm{mg} / \mathrm{ml}-1 \mathrm{ml}$ & 1 & & 1 & 0 & & & \\
\hline glicose $50 \%-10 \mathrm{ml}$ & 1 & & 1 & 0 & & & \\
\hline heparina IV 5.000UI - 5ml & 6 & & 5 & 1 & 3,45 & 3,45 & 9,32 \\
\hline lidocaína sem epinefrina $2 \%$ - $20 \mathrm{ml}$ & 3 & & 1 & 2 & 0,68 & 1,36 & 3,67 \\
\hline $\begin{array}{l}\text { lidocaína com epinefrina } \\
(20 \mathrm{mg}+5 \mathrm{mcg}) / \mathrm{ml}-20 \mathrm{ml}\end{array}$ & 5 & & 4 & 1 & 1,31 & 1,31 & 3,54 \\
\hline lidocaína geléia $2 \%$ - 30ml & & 2 & & 2 & 1,12 & 2,24 & 6,05 \\
\hline metaraminol $10 \mathrm{mg} / \mathrm{ml}-1 \mathrm{ml}$ & 9 & & 8 & 1 & 1,95 & 1,95 & 5,27 \\
\hline midazolam $5 \mathrm{mg} / \mathrm{ml}-3 \mathrm{ml}$ & & 3 & 1 & 2 & 2,35 & 4,7 & 12,69 \\
\hline morfina $2 \mathrm{mg} / \mathrm{ml}-1 \mathrm{ml}$ & & 3 & 2 & 1 & 0,41 & 0,41 & 1,11 \\
\hline neostigmina $0,5 \mathrm{mg} / \mathrm{ml}-1 \mathrm{ml}$ & 8 & & 8 & 0 & & & \\
\hline noradrenalina $1 \mathrm{mg} / \mathrm{ml}-4 \mathrm{ml}$ & 1 & & 1 & 0 & & & \\
\hline papaverina $50 \mathrm{mg} / \mathrm{ml}-2 \mathrm{ml}$ & 1 & & 1 & 0 & & & \\
\hline petidina $50 \mathrm{mg} / \mathrm{ml}-2 \mathrm{ml}$ & & 3 & 2 & 1 & 0,18 & 0,18 & 0,49 \\
\hline prometazina $25 \mathrm{mg} / \mathrm{ml}-2 \mathrm{ml}$ & 3 & & 1 & 2 & 0,29 & 0,58 & 1,57 \\
\hline propofol $10 \mathrm{mg} / \mathrm{ml}-20 \mathrm{ml}$ & & 6 & 1 & 5 & 8,51 & 42,55 & 114,89 \\
\hline ranitidina $10 \mathrm{mg} / \mathrm{ml}-5 \mathrm{ml}$ & 9 & & 6 & 3 & 0,18 & 0,54 & 1,46 \\
\hline
\end{tabular}


SALA 22 - SEGUNDO DIA DE CONSUMO (contnuação)

\begin{tabular}{l|c|c|c|c|c|c|c}
\hline Medicamento & $\begin{array}{c}\text { Físico } \\
\text { Inicial }\end{array}$ & Extra & $\begin{array}{c}\text { Físico } \\
\text { Final }\end{array}$ & $\begin{array}{c}\text { Quantidade } \\
\text { Utilizada }\end{array}$ & $\begin{array}{c}\text { Preço } \\
\text { Unitário }\end{array}$ & $\begin{array}{c}\text { Preço } \\
\text { Final }\end{array}$ & $\begin{array}{c}\text { Valor em } \\
\text { dólar }\end{array}$ \\
\hline salbutamol $0,5 \mathrm{mg} / \mathrm{ml}-1 \mathrm{ml}$ & 1 & & 1 & 0 & & & \\
\hline suxametônio $100 \mathrm{mg}$ & 1 & & 1 & 0 & & & \\
\hline vaselina $20 \mathrm{ml}$ & 1 & & 1 & 0 & & & \\
\hline verde brilhante $100 \mathrm{mg} / \mathrm{ml}-1 \mathrm{ml}$ & 4 & & 3 & 1 & 0,36 & 0,36 & 0,97 \\
\hline Total & $\mathbf{1 9 7}$ & $\mathbf{5 4}$ & $\mathbf{1 7 9}$ & $\mathbf{7 2}$ & $\mathbf{7 5 , 7 7}$ & $\mathbf{1 9 5 , 0 5}$ & $\mathbf{5 2 6 , 6 6}$ \\
\hline
\end{tabular}


Tabela 6: Terceiro dia de consumo na sala 22 fase pré implantação

SALA 22 - TERCEIRO DIA DE CONSUMO

\begin{tabular}{|c|c|c|c|c|c|c|c|}
\hline & & & & & & & \\
\hline Medicamento & $\begin{array}{l}\text { Físico } \\
\text { Inicial }\end{array}$ & Extra & $\begin{array}{l}\text { Físico } \\
\text { Final }\end{array}$ & $\begin{array}{l}\text { Quantidade } \\
\text { Utilizada }\end{array}$ & $\begin{array}{c}\text { Preço } \\
\text { Unitário }\end{array}$ & $\begin{array}{l}\text { Preço } \\
\text { Final }\end{array}$ & $\begin{array}{l}\text { Valor em } \\
\text { dólar }\end{array}$ \\
\hline agua destilada $10 \mathrm{ml}$ & 1 & & 0 & 1 & 0,1 & 0,1 & 0,27 \\
\hline álcool etílico $96 \%$ - 10ml & 2 & & 1 & 1 & 0,49 & 0,49 & 1,32 \\
\hline amicacina $50 \mathrm{mg} / \mathrm{ml}-2 \mathrm{ml}$ & 1 & & 0 & 1 & 0,49 & 0,49 & 1,32 \\
\hline aminofilina $24 \mathrm{mg} / \mathrm{ml}-10 \mathrm{ml}$ & 3 & & 3 & 0 & & & \\
\hline amiodarona $50 \mathrm{mg} / \mathrm{ml}-3 \mathrm{ml}$ & 4 & & 3 & 1 & 0,74 & 0,74 & 2 \\
\hline ampicilina $1 \mathrm{~g}$ & 2 & & 2 & 0 & & & \\
\hline atropina $0,25 \mathrm{mg} / \mathrm{ml}-1 \mathrm{ml}$ & 1 & & 1 & 0 & & & \\
\hline atropina $0,5 \mathrm{mg} / \mathrm{ml}-1 \mathrm{ml}$ & 3 & & 0 & 3 & 0,01 & 0,03 & 0,08 \\
\hline azul de metileno $1 \%-5 \mathrm{ml}$ & 1 & & 1 & 0 & & & \\
\hline bicarbonato de sódio $3 \%-20 \mathrm{ml}$ & 5 & & 4 & 1 & 0,63 & 0,63 & 1,7 \\
\hline bicarbonato de sódio $10 \%-250 \mathrm{ml}$ & 6 & & 6 & 0 & & & \\
\hline bupivacaína hiperbárica $0,5 \%$ - $4 \mathrm{ml}$ & 1 & & 1 & 0 & & & \\
\hline $\begin{array}{l}\text { bupivacaína com epinefrina } \\
(5 \mathrm{mg}+9,1 \mathrm{mcg}) / \mathrm{ml}-20 \mathrm{ml}\end{array}$ & 11 & 8 & 9 & 10 & 3,98 & 39,8 & 107,46 \\
\hline $\begin{array}{l}\text { bupivacaína sem epinefrina } 0,5 \% \text { - } \\
20 \mathrm{ml}\end{array}$ & 6 & & 6 & 0 & & & \\
\hline cefalotina $1 \mathrm{~g}$ & 8 & 2 & 7 & 3 & 1,53 & 4,59 & 12,39 \\
\hline ceftriaxona $1 \mathrm{~g}$ & 1 & & 1 & 0 & & & \\
\hline cetoprofeno $50 \mathrm{mg} / \mathrm{ml}-2 \mathrm{ml}$ & & 1 & & 1 & 3,43 & 3,43 & 9,26 \\
\hline cloranfenicol 1g & 3 & & 3 & 0 & & & \\
\hline cloreto de cálcio $100 \mathrm{mg} / \mathrm{ml}-5 \mathrm{ml}$ & 5 & & 4 & 1 & 0,38 & 0,38 & 1,03 \\
\hline cloreto de sódio $20 \%$ - $20 \mathrm{ml}$ & 7 & & 1 & 6 & 0,38 & 2,28 & 6,16 \\
\hline deslanosido $0,2 \mathrm{mg} / \mathrm{ml}-2 \mathrm{ml}$ & 6 & & 6 & 0 & & & \\
\hline dexametasona $4 \mathrm{mg} / \mathrm{ml}-1 \mathrm{ml}$ & 2 & 2 & 2 & 2 & 0,39 & 0,78 & 2,11 \\
\hline diazepam $5 \mathrm{mg} / \mathrm{ml}-2 \mathrm{ml}$ & & 3 & 2 & 1 & 0,17 & 0,17 & 0,46 \\
\hline $\begin{array}{l}\text { dimenidrato+piridoxina } \\
(50+50 \mathrm{mg}) / \mathrm{ml}\end{array}$ & 5 & & 4 & 1 & 1 & 1 & 2,7 \\
\hline dipirona $500 \mathrm{mg} / \mathrm{ml}-2 \mathrm{ml}$ & 10 & 10 & 8 & 12 & 0,16 & 1,92 & 5,18 \\
\hline dobutamina $12,5 \mathrm{mg} / \mathrm{ml}-20 \mathrm{ml}$ & 2 & & 1 & 1 & 4,52 & 4,52 & 12,2 \\
\hline dopamina $5 \mathrm{mg} / \mathrm{ml}-10 \mathrm{ml}$ & 3 & & 3 & 0 & & & \\
\hline efedrina $25 \mathrm{mg} / \mathrm{ml}-1 \mathrm{ml}$ & 5 & & 0 & 5 & 0,43 & 2,15 & 5,81 \\
\hline epinefrina $1 \mathrm{mg} / \mathrm{ml}-1 \mathrm{ml}$ & 31 & 20 & 16 & 35 & 0,15 & 5,25 & 14,18 \\
\hline escopolamina $20 \mathrm{mg} / \mathrm{ml}-1 \mathrm{ml}$ & 14 & & 13 & 1 & 0,46 & 0,46 & 1,24 \\
\hline etomidato $2 \mathrm{mg} / \mathrm{ml}-10 \mathrm{ml}$ & & 3 & 2 & 1 & 3,18 & 3,18 & 8,59 \\
\hline $\begin{array}{l}\text { fentanila + droperidol } \\
(0,05 \mathrm{mg}+2,5 \mathrm{mg}) / \mathrm{ml}-2 \mathrm{ml}\end{array}$ & & 6 & 4 & 2 & 3,51 & 7,02 & 18,95 \\
\hline fentanil $0,05 \mathrm{mg} / \mathrm{ml}-5 \mathrm{ml}$ & & 9 & 3 & 6 & 1,8 & 10,80 & 29,16 \\
\hline furosemida $10 \mathrm{mg} / \mathrm{ml}-2 \mathrm{ml}$ & 3 & & 3 & 0 & & & \\
\hline galamina & 4 & & 4 & 0 & & & \\
\hline gentamicina $40 \mathrm{mg} / \mathrm{ml}-1 \mathrm{ml}$ & 12 & 2 & 10 & 4 & 0,19 & 0,76 & 2,05 \\
\hline gentamicina $80 \mathrm{mg} / \mathrm{ml}-1 \mathrm{ml}$ & 4 & & 4 & 0 & & & \\
\hline gentamicina colírio $20 \mathrm{mg} / \mathrm{ml}-10 \mathrm{ml}$ & 2 & & 2 & 0 & & & \\
\hline gentamicina pomada $0,3 \%-3 \mathrm{~g}$ & 5 & & 4 & 1 & 1,99 & 1,99 & 5,4 \\
\hline glicose $50 \%-10 \mathrm{ml}$ & 2 & & 1 & 1 & 0,16 & 0,16 & 0,43 \\
\hline gluconato de cálcio $10 \%-10 \mathrm{ml}$ & 9 & & 8 & 1 & 0,48 & 0,48 & 1,3 \\
\hline heparina 5.000ui $-0,25 \mathrm{ml}$ & 7 & & 5 & 2 & 0,74 & 1,48 & 3,4 \\
\hline heparina IV 5.000UI - 5ml & 5 & & 4 & 1 & 3,45 & 3,45 & 9,32 \\
\hline
\end{tabular}


SALA 22 - TERCEIRO DIA DE CONSUMO (continuação)

\begin{tabular}{|c|c|c|c|c|c|c|c|}
\hline Medicamento & $\begin{array}{l}\text { Físico } \\
\text { Inicial }\end{array}$ & Extra & $\begin{array}{r}\text { Físico } \\
\text { Final }\end{array}$ & $\begin{array}{l}\text { Quantidade } \\
\text { Utilizada }\end{array}$ & $\begin{array}{c}\text { Preço } \\
\text { Unitário } \\
\end{array}$ & $\begin{array}{l}\text { Preço } \\
\text { Final }\end{array}$ & $\begin{array}{l}\text { Valor em } \\
\text { dólar }\end{array}$ \\
\hline hidrocortisona $100 \mathrm{mg}$ & 2 & & 2 & 0 & & & \\
\hline hidrocortisona $500 \mathrm{mg}$ & 3 & & 3 & 0 & & & \\
\hline lidocaína sem epinefrina $2 \%$ - $20 \mathrm{ml}$ & 8 & 4 & 7 & 5 & 0,68 & 3,4 & 9,18 \\
\hline $\begin{array}{l}\text { lidocaína com epinefrina } \\
(20 \mathrm{mg}+5 \mathrm{mcg}) / \mathrm{ml}-20 \mathrm{ml}\end{array}$ & 20 & 10 & 30 & 0 & & & \\
\hline lidocaína geléia $2 \%-30 \mathrm{ml}$ & 13 & & 5 & 8 & 1,12 & 8,96 & 24,2 \\
\hline metaraminol 10mg/ml - $1 \mathrm{ml}$ & 13 & 3 & 15 & 1 & 1,95 & 1,95 & 5,27 \\
\hline midazolam $5 \mathrm{mg} / \mathrm{ml}-3 \mathrm{ml}$ & & 3 & & 3 & 2,35 & 7,05 & 19,04 \\
\hline morfina $2 \mathrm{mg} / \mathrm{ml}-1 \mathrm{ml}$ & & 3 & 2 & 1 & 0,41 & 0,41 & 1,11 \\
\hline metoclopramida $5 \mathrm{mg} / \mathrm{ml}-2 \mathrm{ml}$ & 15 & 10 & 14 & 11 & 0,15 & 1,65 & 4,46 \\
\hline neostigmina $0,5 \mathrm{mg} / \mathrm{ml}-1 \mathrm{ml}$ & 14 & & 13 & 1 & 0,46 & 0,46 & 1,24 \\
\hline noradrenalina $1 \mathrm{mg} / \mathrm{ml}$ - $4 \mathrm{ml}$ & 4 & & 4 & 0 & & & \\
\hline petidina $50 \mathrm{mg} / \mathrm{ml}-2 \mathrm{ml}$ & & 3 & 3 & 0 & & & \\
\hline propofol $10 \mathrm{mg} / \mathrm{ml}-20 \mathrm{ml}$ & & 6 & 2 & 4 & 8,51 & 34,04 & 91,91 \\
\hline protamina $10 \mathrm{mg} / \mathrm{ml}-5 \mathrm{ml}$ & 7 & & 6 & 1 & 1,35 & 1,35 & 3,65 \\
\hline ranitidina $10 \mathrm{mg} / \mathrm{ml}-5 \mathrm{ml}$ & 3 & 2 & 1 & 4 & 0,23 & 0,92 & 2,48 \\
\hline sulfato de magnésio $10 \%-10 \mathrm{ml}$ & 2 & & 2 & 0 & & & \\
\hline sulfato de magnésio $20 \%-10 \mathrm{ml}$ & 3 & & 2 & 1 & 0,43 & 0,43 & 1,16 \\
\hline suxametônio $100 \mathrm{mg}$ & 10 & & 8 & 2 & 7,12 & 14,24 & 38,45 \\
\hline vaselina $20 \mathrm{ml}$ & 3 & & 3 & 0 & & & \\
\hline verde brilhante $100 \mathrm{mg} / \mathrm{ml}-1 \mathrm{ml}$ & 6 & 2 & 6 & 2 & 0,36 & 0,72 & 1,94 \\
\hline vitamina C $100 \mathrm{mg} / \mathrm{ml}-5 \mathrm{ml}$ & 5 & & 3 & 2 & 0,39 & 0,78 & 2,11 \\
\hline Total & 322 & 112 & 282 & 149 & 60,45 & 174,43 & 471,67 \\
\hline
\end{tabular}


Tabela 7: Primeiro dia de consumo na sala 23 fase pré implantação

\begin{tabular}{|c|c|c|c|c|c|c|c|}
\hline \multicolumn{8}{|c|}{ SALA 23 - PRIMEIRO DIA DE CONSUMO } \\
\hline Medicamento & $\begin{array}{l}\text { Físico } \\
\text { Inicial }\end{array}$ & Extra & $\begin{array}{l}\text { Físico } \\
\text { Final }\end{array}$ & $\begin{array}{l}\text { Quantidade } \\
\text { Utilizada }\end{array}$ & \begin{tabular}{|c|} 
Preço \\
Unitário
\end{tabular} & $\begin{array}{l}\text { Preço } \\
\text { Final }\end{array}$ & $\begin{array}{l}\text { Valor em } \\
\text { dólar }\end{array}$ \\
\hline agua destilada $10 \mathrm{ml}$ & 22 & & 14 & 8 & 0,1 & 0,8 & 2,16 \\
\hline álcool etílico $96 \%$ - 10ml & 5 & & 5 & 0 & & & \\
\hline amicacina $50 \mathrm{mg} / \mathrm{ml}-2 \mathrm{ml}$ & 6 & & 6 & 0 & & & \\
\hline aminofilina $24 \mathrm{mg} / \mathrm{ml}-10 \mathrm{ml}$ & 3 & & 3 & 0 & & & \\
\hline amiodarona $50 \mathrm{mg} / \mathrm{ml}-3 \mathrm{ml}$ & 4 & & 4 & 0 & & & \\
\hline atropina $0,25 \mathrm{mg} / \mathrm{ml}-1 \mathrm{ml}$ & 20 & & 17 & 3 & 0,12 & 0,36 & 0,97 \\
\hline atropina $0,5 \mathrm{mg} / \mathrm{ml}-1 \mathrm{ml}$ & 14 & & 13 & 1 & 0,01 & 0,01 & 0,03 \\
\hline azul de metileno $1 \%-5 \mathrm{ml}$ & 3 & 2 & 1 & 4 & 1,02 & 4,08 & 11,02 \\
\hline bicarbonato de odio $3 \%-20 \mathrm{ml}$ & 5 & & 5 & 0 & & & \\
\hline bicarbonato de sódio $10 \%-250 \mathrm{ml}$ & 6 & & 6 & 0 & & & \\
\hline bupivacaína hiperbárica $0,5 \%-4 \mathrm{ml}$ & 5 & & 4 & 1 & 3,59 & 3,59 & 9,69 \\
\hline $\begin{array}{l}\text { bupivacaína com epinefrina } \\
(5 \mathrm{mg}+9,1 \mathrm{mcg}) / \mathrm{ml}-20 \mathrm{ml}\end{array}$ & 5 & 3 & 5 & 3 & 3,98 & 11,94 & 32,24 \\
\hline $\begin{array}{l}\text { bupivacaína sem epinefrina } 0,5 \% \text { - } \\
20 \mathrm{ml}\end{array}$ & 6 & & 6 & 0 & & & \\
\hline cefalotina $1 \mathrm{~g}$ & 8 & & 7 & 1 & 1,53 & 1,53 & 4,13 \\
\hline cetoprofeno $50 \mathrm{mg} / \mathrm{ml}-2 \mathrm{ml}$ & 1 & & 1 & 0 & & & \\
\hline cloranfenicol $1 \mathrm{~g}$ & 3 & & 1 & 2 & 9,3 & 18,6 & 50,22 \\
\hline cloreto de cálcio $100 \mathrm{mg} / \mathrm{ml}-5 \mathrm{ml}$ & 5 & & 5 & 0 & & & \\
\hline cloreto de potássio $19,1 \%-10 \mathrm{ml}$ & 2 & & 2 & 0 & & & \\
\hline cloreto de sódio $0,9 \%-10 \mathrm{ml}$ & 1 & & 0 & 1 & 0,58 & 0,58 & 1,57 \\
\hline cloreto de sódio $20 \%$ - $20 \mathrm{ml}$ & 7 & & 5 & 2 & 0,38 & 0,76 & 2,05 \\
\hline dexametasona $4 \mathrm{mg} / \mathrm{ml}-1 \mathrm{ml}$ & 7 & & 7 & 0 & & & \\
\hline diazepam $5 \mathrm{mg} / \mathrm{ml}-2 \mathrm{ml}$ & & 2 & 2 & 0 & & & \\
\hline $\begin{array}{l}\text { dimenidrato+piridoxina }(50+50 \mathrm{mg}) / \\
\mathrm{ml}-1 \mathrm{ml}\end{array}$ & 13 & & 12 & 1 & 1 & 1 & 2,7 \\
\hline dipirona $500 \mathrm{mg} / \mathrm{ml}-2 \mathrm{ml}$ & 14 & 10 & 6 & 18 & 0,16 & 2,88 & 7,78 \\
\hline dobutamina $12,5 \mathrm{mg} / \mathrm{ml}-20 \mathrm{ml}$ & 1 & & 1 & 0 & & & \\
\hline dopamina $5 \mathrm{mg} / \mathrm{ml}-10 \mathrm{ml}$ & 3 & & 3 & 0 & & & \\
\hline efedrina $25 \mathrm{mg} / \mathrm{ml}-1 \mathrm{ml}$ & 5 & 5 & 5 & 5 & 0,43 & 2,15 & 5,81 \\
\hline epinefrina $1 \mathrm{mg} / \mathrm{ml} 1 \mathrm{ml}$ & 22 & & 17 & 5 & 0,15 & 0,75 & 2,03 \\
\hline escopolamina $20 \mathrm{mg} / \mathrm{ml}-1 \mathrm{ml}$ & 3 & & 3 & 0 & & & \\
\hline etomidato $2 \mathrm{mg} / \mathrm{ml}-10 \mathrm{ml}$ & & 2 & 2 & 0 & & & \\
\hline $\begin{array}{l}\text { fentanila + droperidol } \\
(0,05 \mathrm{mg}+2,5 \mathrm{mg}) / \mathrm{ml}-2 \mathrm{ml}\end{array}$ & & 3 & 2 & 1 & 3,51 & 3,51 & 9,48 \\
\hline fentanil $0,05 \mathrm{mg} / \mathrm{ml}-5 \mathrm{ml}$ & & 9 & 5 & 4 & 1,8 & 7,2 & 19,44 \\
\hline furosemida $10 \mathrm{mg} / \mathrm{ml}-2 \mathrm{ml}$ & 3 & & 3 & 0 & & & \\
\hline gentamicina colírio $20 \mathrm{mg} / \mathrm{ml}-10 \mathrm{ml}$ & 1 & & 1 & 0 & & & \\
\hline gentamicina pomada $0,3 \%-3 g$ & 1 & & 1 & 0 & & & \\
\hline glicose $50 \%-10 \mathrm{ml}$ & 6 & & 5 & 1 & 0,16 & 0,16 & 0,43 \\
\hline gluconato de cálcio $10 \%-10 \mathrm{ml}$ & 10 & & 9 & 1 & 0,48 & 0,48 & 1,3 \\
\hline hidrocortisona $100 \mathrm{mg}$ & 2 & & 2 & 0 & & & \\
\hline hidrocortisona $500 \mathrm{mg}$ & 3 & 1 & 2 & 2 & 2,88 & 5,76 & 15,55 \\
\hline lidocaína sem epinefrina $2 \%-20 \mathrm{ml}$ & 5 & 3 & 7 & 1 & 1,31 & 1,31 & 3,54 \\
\hline $\begin{array}{l}\text { lidocaína com epinefrina } \\
(20 \mathrm{mg}+5 \mathrm{mcg}) / \mathrm{ml}-20 \mathrm{ml}\end{array}$ & 9 & & 8 & 1 & 0,68 & 0,68 & 1,84 \\
\hline lidocaína geléia $2 \%$ - $30 \mathrm{ml}$ & & 5 & 5 & 0 & & & \\
\hline
\end{tabular}


SALA 23 - PRIMEIRO DIA DE CONSUMO (cotinuação)

\begin{tabular}{l|c|c|c|c|c|c|c}
\hline Medicamento & $\begin{array}{c}\text { Físico } \\
\text { Inicial }\end{array}$ & Extra & $\begin{array}{c}\text { Físico } \\
\text { Final }\end{array}$ & $\begin{array}{c}\text { Quantidade } \\
\text { Utilizada }\end{array}$ & $\begin{array}{c}\text { Preço } \\
\text { Unitário }\end{array}$ & $\begin{array}{c}\text { Preço } \\
\text { Final }\end{array}$ & $\begin{array}{c}\text { Valor em } \\
\text { dólar }\end{array}$ \\
\hline metaraminol $10 \mathrm{mg} / \mathrm{ml}-1 \mathrm{ml}$ & 14 & & 5 & 9 & 1,95 & 17,55 & 47,39 \\
\hline metoclopramida $5 \mathrm{mg} / \mathrm{ml}-2 \mathrm{ml}$ & 17 & 5 & 17 & 5 & 0,15 & 0,75 & 2,03 \\
\hline midazolam $5 \mathrm{mg} / \mathrm{ml}-3 \mathrm{ml}$ & & 3 & 1 & 2 & 2,35 & 4,7 & 12,69 \\
\hline morfina $2 \mathrm{mg} / \mathrm{ml}-1 \mathrm{ml}$ & & 2 & 2 & 0 & & & \\
\hline n-butilescopolamina & 3 & & 3 & 0 & & & \\
\hline noradrenalina $1 \mathrm{mg} / \mathrm{ml}-4 \mathrm{ml}$ & 4 & & 4 & 0 & & & \\
\hline oxitocina $5 \mathrm{ui} / \mathrm{ml}-1 \mathrm{ml}$ & 4 & & 2 & 2 & 0,48 & 0,96 & 2,59 \\
\hline petidina $50 \mathrm{mg} / \mathrm{ml}-2 \mathrm{ml}$ & & 2 & 2 & 0 & & & \\
\hline propofol $10 \mathrm{mg} / \mathrm{ml}-20 \mathrm{ml}$ & & 6 & 4 & 2 & 8,51 & 17,02 & 45,95 \\
\hline protamina $10 \mathrm{mg} / \mathrm{ml}-5 \mathrm{ml}$ & 7 & & 7 & 0 & & & \\
\hline ranitidina $10 \mathrm{mg} / \mathrm{ml}-5 \mathrm{ml}$ & 7 & 5 & 5 & 7 & 0,18 & 1,26 & 3,4 \\
\hline salbutamol $0,5 \mathrm{mg} / \mathrm{ml}-1 \mathrm{ml}$ & 3 & & 3 & 0 & & & \\
\hline sulfato de magnésio $10 \%-10 \mathrm{ml}$ & 5 & & 5 & 0 & & & \\
\hline suxametônio $100 \mathrm{mg}$ & 4 & & 4 & 0 & & & \\
\hline vaselina $20 \mathrm{ml}$ & 3 & & 3 & 0 & & & \\
\hline verde brilhante $100 \mathrm{mg} / \mathrm{ml}-1 \mathrm{ml}$ & 5 & & 4 & 1 & 0,36 & 0,36 & 0,97 \\
\hline vitamina C $100 \mathrm{mg} / \mathrm{ml}-5 \mathrm{ml}$ & 3 & & 3 & 0 & & & \\
\hline Total & $\mathbf{3 3 4}$ & $\mathbf{6 8}$ & $\mathbf{3 0 7}$ & $\mathbf{9 7}$ & $\mathbf{4 6 , 9 4}$ & $\mathbf{1 1 2 , 1 1}$ & $\mathbf{2 9 9}$ \\
\hline
\end{tabular}


Tabela 8: Segundo dia de consumo na sala 23 fase pré implantação

SALA 23 - SEGUNDO DIA DE CONSUMO

\begin{tabular}{|c|c|c|c|c|c|c|c|}
\hline \\
\hline Medicamento & $\begin{array}{l}\text { Físico } \\
\text { Inicial }\end{array}$ & Extra & $\begin{array}{l}\text { Físico } \\
\text { Final }\end{array}$ & $\begin{array}{l}\text { Quantidade } \\
\text { Utilizada }\end{array}$ & $\begin{array}{c}\text { Preço } \\
\text { Unitário }\end{array}$ & $\begin{array}{l}\text { Preço } \\
\text { Final }\end{array}$ & $\begin{array}{l}\text { Valor em } \\
\text { dólar }\end{array}$ \\
\hline agua destilada $10 \mathrm{ml}$ & 28 & 20 & 31 & 17 & 0,1 & 1,7 & 4,59 \\
\hline álcool etílico $96 \%$ - 10ml & 5 & & 5 & 0 & & & \\
\hline amicacina $50 \mathrm{mg} / \mathrm{ml}-2 \mathrm{ml}$ & 6 & & 6 & 0 & & & \\
\hline aminofilina $24 \mathrm{mg} / \mathrm{ml}-10 \mathrm{ml}$ & 3 & & 3 & 0 & & & \\
\hline amiodarona $50 \mathrm{mg} / \mathrm{ml}-3 \mathrm{ml}$ & 4 & & 4 & 0 & & & \\
\hline ampicilina $1 \mathrm{~g}$ & & 2 & 0 & 2 & 0,9 & 1,8 & 4,86 \\
\hline atropina $0,25 \mathrm{mg} / \mathrm{ml}-1 \mathrm{ml}$ & 20 & & 19 & 1 & 0,12 & 0,12 & 0,32 \\
\hline atropina $0,5 \mathrm{mg} / \mathrm{ml}-1 \mathrm{ml}$ & 13 & & 13 & 0 & & & \\
\hline azul de metileno $1 \%-5 \mathrm{ml}$ & 3 & & 1 & 2 & 1,02 & 2,04 & 5,51 \\
\hline bicarbonato de sódio $3 \%-20 \mathrm{ml}$ & 5 & & 5 & 0 & & & \\
\hline bicarbonato de sódio $10 \%-250 \mathrm{ml}$ & 6 & & 6 & 0 & & & \\
\hline bupivacaína isobárica $0,5 \%$ - 20ml & 4 & & 3 & 1 & 3,07 & 3,07 & 8,29 \\
\hline bupivacaína hiperbárica $0,5 \%$ - $4 \mathrm{ml}$ & & 2 & 0 & 2 & 3,59 & 7,18 & 19,39 \\
\hline $\begin{array}{l}\text { bupivacaína com epinefrina } \\
(5 \mathrm{mg}+9,1 \mathrm{mcg}) / \mathrm{ml}-20 \mathrm{ml}\end{array}$ & 7 & & 6 & 1 & 3,98 & 3,98 & 10,75 \\
\hline $\begin{array}{l}\text { bupivacaína sem epinefrina } 0,5 \% \text { - } \\
20 \mathrm{ml}\end{array}$ & 6 & & 5 & 1 & 4 & 4 & 10,8 \\
\hline cefalotina $1 \mathrm{~g}$ & 12 & & 6 & 6 & 1,53 & 9,18 & 24,79 \\
\hline cetoprofeno $50 \mathrm{mg} / \mathrm{ml}-2 \mathrm{ml}$ & & 1 & 0 & 1 & 3,43 & 3,43 & 9,26 \\
\hline cloranfenicol $1 \mathrm{~g}$ & 3 & & 2 & 1 & 0,93 & 0,93 & 2,51 \\
\hline cloreto de cálcio $100 \mathrm{mg} / \mathrm{ml}-5 \mathrm{ml}$ & 5 & & 5 & 0 & & & \\
\hline cloreto de potássio $19,1 \%-10 \mathrm{ml}$ & 2 & & 2 & 0 & & & \\
\hline cloreto de sódio $20 \%$ - $20 \mathrm{ml}$ & 7 & & 7 & 0 & & & \\
\hline deslanosido $0,2 \mathrm{mg} / \mathrm{ml}-2 \mathrm{ml}$ & 6 & & 6 & 0 & & & \\
\hline dexametasona $4 \mathrm{mg} / \mathrm{ml} \mathrm{-} 1 \mathrm{ml}$ & 7 & & 7 & 0 & & & \\
\hline diazepam $5 \mathrm{mg} / \mathrm{ml}-2 \mathrm{ml}$ & & 2 & 2 & 0 & & & \\
\hline $\begin{array}{l}\text { dimenidrato+piridoxina }(50+50 \mathrm{mg}) / \\
\mathrm{ml}-1 \mathrm{ml}\end{array}$ & 1 & & 1 & 0 & & & \\
\hline dipirona $500 \mathrm{mg} / \mathrm{ml}-2 \mathrm{ml}$ & 10 & 10 & 6 & 14 & 0,16 & 2,24 & 6,05 \\
\hline dobutamina $12,5 \mathrm{mg} / \mathrm{ml}-20 \mathrm{ml}$ & 1 & & 1 & 0 & & & \\
\hline dopamina $5 \mathrm{mg} / \mathrm{ml}-10 \mathrm{ml}$ & 3 & & 3 & 0 & & & \\
\hline efedrina $25 \mathrm{mg} / \mathrm{ml}-1 \mathrm{ml}$ & 9 & & 8 & 1 & 0,43 & 0,43 & 1,16 \\
\hline epinefrina $1 \mathrm{mg} / \mathrm{ml} 1 \mathrm{ml}$ & 22 & & 20 & 2 & 0,15 & 0,3 & 0,81 \\
\hline etomidato $2 \mathrm{mg} / \mathrm{ml}-10 \mathrm{ml}$ & & 2 & 1 & 1 & 3,51 & 3,51 & 9,48 \\
\hline $\begin{array}{l}\text { fentanila + droperidol } \\
(0,05 \mathrm{mg}+2,5 \mathrm{mg}) / \mathrm{ml}-2 \mathrm{ml}\end{array}$ & & 4 & 4 & 0 & & & \\
\hline fentanil $0,05 \mathrm{mg} / \mathrm{ml}-5 \mathrm{ml}$ & & 6 & 3 & 3 & 1,8 & 5,4 & 14,58 \\
\hline furosemida $10 \mathrm{mg} / \mathrm{ml}-2 \mathrm{ml}$ & 2 & & 2 & 0 & & & \\
\hline galamina & 4 & & 4 & 0 & & & \\
\hline gentamicina pomada $0,3 \%-3 \mathrm{~g}$ & 1 & & 1 & 0 & & & \\
\hline gentamicina $40 \mathrm{mg} / \mathrm{ml}-1 \mathrm{ml}$ & 20 & & 15 & 5 & 0,19 & 0,95 & 2,57 \\
\hline gentamicina $80 \mathrm{mg} / \mathrm{ml}-1 \mathrm{ml}$ & 5 & & 5 & 0 & & & \\
\hline glicose $50 \%-10 \mathrm{ml}$ & 7 & & 7 & 0 & & & \\
\hline gluconato de cálcio $10 \%-10 \mathrm{ml}$ & 9 & & 9 & 0 & & & \\
\hline
\end{tabular}


SALA 23 - SEGUNDO DIA DE CONSUMO (continuação)

\begin{tabular}{|c|c|c|c|c|c|c|c|}
\hline Medicamento & $\begin{array}{l}\text { Físico } \\
\text { Inicial }\end{array}$ & Extra & $\begin{array}{c}\text { Físico } \\
\text { Final }\end{array}$ & $\begin{array}{l}\text { Quantidade } \\
\text { Utilizada }\end{array}$ & $\begin{array}{c}\text { Preço } \\
\text { Unitário }\end{array}$ & $\begin{array}{l}\text { Preço } \\
\text { Final }\end{array}$ & $\begin{array}{c}\text { Valor em } \\
\text { dólar }\end{array}$ \\
\hline heparina 5.000ui $-0,25 \mathrm{ml}$ & 1 & & 1 & 0 & & & \\
\hline heparina IV 5.000UI - 5ml & 1 & & 1 & 0 & & & \\
\hline hidrocortisona $100 \mathrm{mg}$ & 2 & & 2 & 0 & & & \\
\hline hidrocortisona $500 \mathrm{mg}$ & 2 & & 2 & 0 & & & \\
\hline lidocaína geléia $2 \%$ - $30 \mathrm{ml}$ & 4 & 3 & 4 & 3 & 1,12 & 3,36 & 9,07 \\
\hline lidocaína sem epinefrina $2 \%$ - $20 \mathrm{ml}$ & 3 & 4 & 4 & 3 & 1,31 & 3,93 & 10,61 \\
\hline $\begin{array}{l}\text { lidocaína com epinefrina } \\
(20 \mathrm{mg}+5 \mathrm{mcg}) / \mathrm{ml}-20 \mathrm{ml}\end{array}$ & 5 & 2 & 6 & 1 & 0,68 & 0,68 & 1,84 \\
\hline metaraminol 10mg/ml - $1 \mathrm{ml}$ & 14 & & 14 & 0 & & & \\
\hline metoclopramida $5 \mathrm{mg} / \mathrm{ml}-2 \mathrm{ml}$ & 19 & & 16 & 3 & 0,15 & 0,45 & 1,22 \\
\hline midazolam $5 \mathrm{mg} / \mathrm{ml}-3 \mathrm{ml}$ & & 2 & 0 & 2 & 2,35 & 4,7 & 12,69 \\
\hline morfina $2 \mathrm{mg} / \mathrm{ml}-1 \mathrm{ml}$ & & 2 & 2 & 0 & & & \\
\hline neostigmina $0,5 \mathrm{mg} / \mathrm{ml}-1 \mathrm{ml}$ & 22 & & 22 & 0 & & & \\
\hline noradrenalina $1 \mathrm{mg} / \mathrm{ml}-4 \mathrm{ml}$ & 4 & & 4 & 0 & & & \\
\hline oxitocina $5 \mathrm{ui} / \mathrm{ml}-1 \mathrm{ml}$ & 2 & & 2 & 0 & & & \\
\hline petidina $50 \mathrm{mg} / \mathrm{ml}-2 \mathrm{ml}$ & & 2 & 2 & 0 & & & \\
\hline propofol $10 \mathrm{mg} / \mathrm{ml}-20 \mathrm{ml}$ & & 4 & 3 & 1 & 8,51 & 8,51 & 22,98 \\
\hline protamina $10 \mathrm{mg} / \mathrm{ml}-5 \mathrm{ml}$ & 7 & & 7 & 0 & & & \\
\hline ranitidina $10 \mathrm{mg} / \mathrm{ml}-5 \mathrm{ml}$ & 10 & & 7 & 3 & 0,18 & 0,54 & 1,46 \\
\hline sulfato de magnésio $10 \%-10 \mathrm{ml}$ & 2 & & 2 & 0 & & & \\
\hline sulfato de magnésio $20 \%-10 \mathrm{ml}$ & 3 & & 2 & 1 & 0,43 & 0,43 & 1,16 \\
\hline suxametônio $100 \mathrm{mg}$ & 4 & & 4 & 0 & & & \\
\hline terbutalina $0,5 \mathrm{mg} / \mathrm{ml}-1 \mathrm{ml}$ & 3 & & 3 & 0 & & & \\
\hline vaselina $20 \mathrm{ml}$ & 3 & & 3 & 0 & & & \\
\hline verde brilhante $100 \mathrm{mg} / \mathrm{ml}-1 \mathrm{ml}$ & 4 & & 4 & 0 & & & \\
\hline vitamina c $100 \mathrm{mg} / \mathrm{ml}-5 \mathrm{ml}$ & 5 & & 5 & 0 & & & \\
\hline Total & 341 & 68 & 356 & 78 & 43,64 & 72,86 & 196,75 \\
\hline
\end{tabular}


Tabela 9: Terceiro dia de consumo na sala 23 fase pré implantação

\begin{tabular}{|c|c|c|c|c|c|c|c|}
\hline \multicolumn{8}{|c|}{ SALA 23 - TERCEIRO DIA DE CONSUMO } \\
\hline Medicamento & $\begin{array}{l}\text { Físico } \\
\text { Inicial }\end{array}$ & Extra & $\begin{array}{l}\text { Físico } \\
\text { Final }\end{array}$ & $\begin{array}{l}\text { Quantidade } \\
\text { Utilizada }\end{array}$ & \begin{tabular}{|c|} 
Preço \\
Unitário
\end{tabular} & $\begin{array}{l}\text { Preço } \\
\text { Final }\end{array}$ & $\begin{array}{l}\text { Valor em } \\
\text { dólar }\end{array}$ \\
\hline agua destilada $10 \mathrm{ml}$ & 20 & & 19 & 1 & 0,1 & 0,1 & 0,27 \\
\hline álcool etílico $96 \%$ - 10ml & 1 & & 1 & 0 & & & \\
\hline amicacina $50 \mathrm{mg} / \mathrm{ml}-2 \mathrm{ml}$ & 4 & & 4 & 0 & & & \\
\hline aminofilina $24 \mathrm{mg} / \mathrm{ml}-10 \mathrm{ml}$ & 1 & & 1 & 0 & & & \\
\hline atropina $0,25 \mathrm{mg} / \mathrm{ml}-1 \mathrm{ml}$ & 15 & & 12 & 3 & 0,12 & 0,36 & 0,97 \\
\hline atropina $0,5 \mathrm{mg} / \mathrm{ml}-1 \mathrm{ml}$ & 5 & & 4 & 1 & 0,01 & 0,01 & 0,03 \\
\hline bicarbonato de sódio $3 \%-20 \mathrm{ml}$ & 4 & & 4 & 0 & & & \\
\hline $\begin{array}{l}\text { bupivacaína com epinefrina } \\
(5 \mathrm{mg}+9,1 \mathrm{mcg}) / \mathrm{ml}-20 \mathrm{ml}\end{array}$ & 3 & & 3 & 0 & & & \\
\hline $\begin{array}{l}\text { bupivacaína sem epinefrina } 0,5 \% \text { - } \\
20 \mathrm{ml}\end{array}$ & 8 & & 8 & 0 & & & \\
\hline bupivacaína isobárica $0,5 \%$ - $20 \mathrm{ml}$ & 6 & & 5 & 1 & 3,07 & 3,07 & 8,29 \\
\hline bupivacaína hiperbárica $0,5 \%$ - $4 \mathrm{ml}$ & 4 & & 2 & 2 & 3,59 & 7,18 & 19,39 \\
\hline cefalotina $1 \mathrm{~g}$ & 6 & & 3 & 3 & 1,02 & 3,06 & 8,26 \\
\hline cloreto de sódio $20 \%$ - $20 \mathrm{ml}$ & 1 & & 1 & 0 & & & \\
\hline deslanosido $0,2 \mathrm{mg} / \mathrm{ml}-2 \mathrm{ml}$ & 1 & & 1 & 0 & & & \\
\hline dexametasona $4 \mathrm{mg} / \mathrm{ml}-1 \mathrm{ml}$ & 29 & & 27 & 2 & 0,39 & 0,78 & 2,11 \\
\hline diazepam $5 \mathrm{mg} / \mathrm{ml}-2 \mathrm{ml}$ & & 2 & 2 & 0 & & & \\
\hline diclofenaco de sódio $25 \mathrm{mg} / \mathrm{ml}-3 \mathrm{ml}$ & 2 & & 1 & 1 & 0,15 & 0,15 & 0,41 \\
\hline dipirona $500 \mathrm{mg} / \mathrm{ml}-2 \mathrm{ml}$ & 14 & & 10 & 4 & 0,16 & 0,64 & 1,73 \\
\hline dopamina $5 \mathrm{mg} / \mathrm{ml}-10 \mathrm{ml}$ & 10 & & 9 & 1 & 0,34 & 0,34 & 0,92 \\
\hline efedrina $25 \mathrm{mg} / \mathrm{ml}-1 \mathrm{ml}$ & 2 & & 1 & 1 & 0,43 & 0,43 & 1,16 \\
\hline epinefrina $1 \mathrm{mg} / \mathrm{ml} 1 \mathrm{ml}$ & 42 & & 41 & 1 & 0,15 & 0,15 & 0,41 \\
\hline etomidato $2 \mathrm{mg} / \mathrm{ml}-10 \mathrm{ml}$ & & 2 & 2 & 0 & & & \\
\hline $\begin{array}{l}\text { fentanila+droperidol } \\
(0,05+2,5 \mathrm{mg}) / \mathrm{ml}-2 \mathrm{ml}\end{array}$ & & 6 & 5 & 1 & 3,51 & 3,51 & 9,48 \\
\hline fentanil $0,05 \mathrm{mg} / \mathrm{ml}-5 \mathrm{ml}$ & & 9 & 4 & 5 & 1,8 & 9 & 24,3 \\
\hline furosemida $10 \mathrm{mg} / \mathrm{ml}-2 \mathrm{ml}$ & 17 & & 16 & 1 & 0,13 & 0,13 & 0,35 \\
\hline gentamicina $40 \mathrm{mg} / \mathrm{ml}-1 \mathrm{ml}$ & 26 & & 24 & 2 & 0,19 & 0,38 & 1,03 \\
\hline heparina IV 5.000UI - 5ml & 2 & & 2 & 0 & & & \\
\hline hidralazina $20 \mathrm{mg} / \mathrm{ml}-1 \mathrm{ml}$ & 1 & & 1 & 0 & & & \\
\hline hidrocortisona $500 \mathrm{mg}$ & 3 & & 3 & 0 & & & \\
\hline lidocaína sem epinefrina $2 \%$ - $20 \mathrm{ml}$ & 5 & & 4 & 1 & 0,68 & 0,68 & 1,84 \\
\hline $\begin{array}{l}\text { lidocaína com } \\
\text { epinefrina }(20 \mathrm{mg}+5 \mathrm{mcg}) / \mathrm{ml}-20 \mathrm{ml}\end{array}$ & 8 & & 8 & 0 & & & \\
\hline metaraminol $10 \mathrm{mg} / \mathrm{ml}-1 \mathrm{ml}$ & 1 & & 1 & 0 & & & \\
\hline metoclopramida $5 \mathrm{mg} / \mathrm{ml}-2 \mathrm{ml}$ & 15 & & 12 & 3 & 0,15 & 0,45 & 1,22 \\
\hline metoprolol $1 \mathrm{mg} / \mathrm{ml}-5 \mathrm{ml}$ & 1 & & 1 & 0 & & & \\
\hline midazolam $5 \mathrm{mg} / \mathrm{ml}-3 \mathrm{ml}$ & & 3 & 2 & 1 & 2,35 & 2,35 & 6,35 \\
\hline morfina $2 \mathrm{mg} / \mathrm{ml}-1 \mathrm{ml}$ & & 3 & 2 & 1 & 0,41 & 0,41 & 1,11 \\
\hline neostigmina $0,5 \mathrm{mg} / \mathrm{ml}-1 \mathrm{ml}$ & 20 & & 18 & 2 & 0,46 & 0,92 & 2,48 \\
\hline nitroprussiato de sódio $100 \mathrm{mg}$ & 1 & & 1 & 0 & & & \\
\hline petidina $50 \mathrm{mg} / \mathrm{ml}-2 \mathrm{ml}$ & & 3 & 2 & 1 & 0,18 & 0,18 & 0,49 \\
\hline prometazina $25 \mathrm{mg} / \mathrm{ml}-2 \mathrm{ml}$ & 2 & & 2 & 0 & & & \\
\hline propofol $10 \mathrm{mg} / \mathrm{ml}-20 \mathrm{ml}$ & & 6 & 3 & 3 & 8,51 & 25,53 & 68,93 \\
\hline ranitidina $10 \mathrm{mg} / \mathrm{ml}-5 \mathrm{ml}$ & 4 & & 2 & 2 & 0,18 & 0,36 & 0,97 \\
\hline
\end{tabular}


SALA 23 - TERCEIRO DIA DE CONSUMO (continuação)

\begin{tabular}{l|c|c|c|c|c|c|c}
\hline Medicamento & $\begin{array}{c}\text { Físico } \\
\text { Inicial }\end{array}$ & Extra & $\begin{array}{c}\text { Físico } \\
\text { Final }\end{array}$ & $\begin{array}{c}\text { Quantidade } \\
\text { Utilizada }\end{array}$ & $\begin{array}{c}\text { Preço } \\
\text { Unitário }\end{array}$ & $\begin{array}{c}\text { Preço } \\
\text { Final }\end{array}$ & $\begin{array}{c}\text { Valor em } \\
\text { dólar }\end{array}$ \\
\hline terbutalina $0,5 \mathrm{mg} / \mathrm{ml}-1 \mathrm{ml}$ & 2 & & 2 & 0 & & & \\
\hline verde brilhante $100 \mathrm{mg} / \mathrm{ml}-1 \mathrm{ml}$ & 1 & & 1 & 0 & & & \\
\hline vit A e D colírio $-10 \mathrm{ml}$ & 1 & & 1 & 0 & & & \\
\hline Total & $\mathbf{2 8 9}$ & $\mathbf{3 4}$ & $\mathbf{2 7 8}$ & $\mathbf{4 4}$ & $\mathbf{2 8 , 0 8}$ & $\mathbf{6 0 , 1 7}$ & $\mathbf{1 6 2 , 5}$ \\
\hline
\end{tabular}


Tabela 10: Primeiro dia de consumo na sala 24 fase pré implantação

SALA 24 - PRIMEIRO DIA DE CONSUMO

\begin{tabular}{|c|c|c|c|c|c|c|c|}
\hline & & & & & & & \\
\hline Medicamento & $\begin{array}{l}\text { Físico } \\
\text { Inicial }\end{array}$ & Extra & $\begin{array}{l}\text { Físico } \\
\text { Final }\end{array}$ & $\begin{array}{l}\text { Quantidade } \\
\text { Utilizada }\end{array}$ & $\begin{array}{c}\text { Preço } \\
\text { Unitário }\end{array}$ & $\begin{array}{l}\text { Preço } \\
\text { Final }\end{array}$ & $\begin{array}{c}\text { Valor em } \\
\text { dólar }\end{array}$ \\
\hline água destilada $10 \mathrm{ml}$ & 9 & & 2 & 7 & 0,1 & 0,7 & 1,89 \\
\hline álcool etílico 96\% - 10ml & 1 & & 1 & 0 & & & \\
\hline amicacina $50 \mathrm{mg} / \mathrm{ml}-2 \mathrm{ml}$ & 5 & & 5 & 0 & & & \\
\hline atropina $0,25 \mathrm{mg} / \mathrm{ml}-1 \mathrm{ml}$ & 10 & & 9 & 1 & 0,12 & 0,12 & 0,33 \\
\hline atropina $0,5 \mathrm{mg} / \mathrm{ml}-1 \mathrm{ml}$ & 7 & & 6 & 1 & 0,01 & 0,01 & 0,03 \\
\hline azul de metileno $1 \%-5 \mathrm{ml}$ & 1 & & 1 & 0 & & & \\
\hline bicarbonato de sódio $3 \%-20 \mathrm{ml}$ & 4 & & 4 & 0 & & & \\
\hline bupivacaína hiperbárica $0,5 \%-4 \mathrm{ml}$ & 10 & & 6 & 4 & 3,59 & 14,36 & 38,77 \\
\hline bupivacaína isobárica $0,5 \%$ - $20 \mathrm{ml}$ & 2 & 8 & 6 & 4 & 3,07 & 12,28 & 33,16 \\
\hline $\begin{array}{l}\text { bupivacaína com epinefrina } \\
(5 \mathrm{mg}+9,1 \mathrm{mcg}) / \mathrm{ml}-20 \mathrm{ml}\end{array}$ & 2 & & 2 & 0 & & & \\
\hline cloreto de sódio $20 \%$ - $20 \mathrm{ml}$ & 1 & & 1 & 0 & & & \\
\hline dexametasona $4 \mathrm{mg} / \mathrm{ml}-1 \mathrm{ml}$ & 29 & & 26 & 3 & 0,39 & 1,17 & 3,16 \\
\hline diazepam $5 \mathrm{mg} / \mathrm{ml}-2 \mathrm{ml}$ & & 2 & 2 & 0 & & & \\
\hline diclofenaco de sódio $25 \mathrm{mg} / \mathrm{ml}-3 \mathrm{ml}$ & 2 & & 2 & 0 & & & \\
\hline $\begin{array}{l}\text { dimenidrato+piridoxina }(50+50 \mathrm{mg}) / \\
\mathrm{ml}-1 \mathrm{ml}\end{array}$ & 1 & & 1 & 0 & & & \\
\hline dipirona $500 \mathrm{mg} / \mathrm{ml}-2 \mathrm{ml}$ & 6 & & 2 & 4 & 0,16 & 0,64 & 1,73 \\
\hline dobutamina $12,5 \mathrm{mg} / \mathrm{ml}-20 \mathrm{ml}$ & 2 & & 2 & 0 & & & \\
\hline dopamina $5 \mathrm{mg} / \mathrm{ml}-10 \mathrm{ml}$ & 10 & & 10 & 0 & & & \\
\hline efedrina $25 \mathrm{mg} / \mathrm{ml}-1 \mathrm{ml}$ & 10 & & 8 & 2 & 0,43 & 0,86 & 2,32 \\
\hline epinefrina $1 \mathrm{mg} / \mathrm{ml} 1 \mathrm{ml}$ & 26 & 29 & 29 & 26 & 0,15 & 3,9 & 10,53 \\
\hline etomidato $2 \mathrm{mg} / \mathrm{ml}-10 \mathrm{ml}$ & & 2 & 2 & 0 & & & \\
\hline $\begin{array}{l}\text { fentanila }+ \text { droperidol } \\
(0,05 \mathrm{mg}+2,5 \mathrm{mg}) / \mathrm{ml}-2 \mathrm{ml}\end{array}$ & & 4 & 2 & 2 & 3,51 & 7,02 & 18,95 \\
\hline fentanil $0,05 \mathrm{mg} / \mathrm{ml}-5 \mathrm{ml}$ & & 6 & 3 & 3 & 1,8 & 5,4 & 14,58 \\
\hline furosemida $10 \mathrm{mg} / \mathrm{ml}-2 \mathrm{ml}$ & 17 & & 17 & 0 & & & \\
\hline gentamicina $40 \mathrm{mg} / \mathrm{ml}-1 \mathrm{ml}$ & 16 & & 12 & 4 & 0,19 & 0,76 & 2,05 \\
\hline heparina IV 5.000UI - 5ml & 2 & & 2 & 0 & & & \\
\hline hidrocortisona $100 \mathrm{mg}$ & 1 & & 1 & 0 & & & \\
\hline hidrocortisona $500 \mathrm{mg}$ & 3 & & 2 & 1 & 2,88 & 2,88 & 7,78 \\
\hline lidocaína geléia $2 \%$ - 30ml & 2 & & 2 & 0 & & & \\
\hline metoclopramida $5 \mathrm{mg} / \mathrm{ml}-2 \mathrm{ml}$ & 10 & & 7 & 3 & 0,15 & 0,45 & 1,22 \\
\hline metoprolol $1 \mathrm{mg} / \mathrm{ml}-5 \mathrm{ml}$ & 1 & & 1 & 0 & & & \\
\hline midazolam $5 \mathrm{mg} / \mathrm{ml}-3 \mathrm{ml}$ & & 2 & 1 & 1 & 2,35 & 2,35 & 6,35 \\
\hline morfina $2 \mathrm{mg} / \mathrm{ml}-1 \mathrm{ml}$ & & 2 & 1 & 1 & 0,41 & 0,41 & 1,11 \\
\hline neostigmina $0,5 \mathrm{mg} / \mathrm{ml}-1 \mathrm{ml}$ & 18 & & 17 & 1 & 0,46 & 0,46 & 1,24 \\
\hline petidina $50 \mathrm{mg} / \mathrm{ml}-2 \mathrm{ml}$ & & 2 & 2 & 0 & & & \\
\hline prometazina $25 \mathrm{mg} / \mathrm{ml}-2 \mathrm{ml}$ & 2 & & 2 & 0 & & & \\
\hline propofol $10 \mathrm{mg} / \mathrm{ml}-20 \mathrm{ml}$ & & 6 & 0 & 6 & 8,51 & 51,06 & 137,86 \\
\hline ranitidina $10 \mathrm{mg} / \mathrm{ml}-5 \mathrm{ml}$ & 8 & & 5 & 3 & 0,18 & 0,54 & 1,46 \\
\hline terbutalina $0,5 \mathrm{mg} / \mathrm{ml}-1 \mathrm{ml}$ & 2 & & 2 & 0 & & & \\
\hline verde brilhante $100 \mathrm{mg} / \mathrm{ml}-1 \mathrm{ml}$ & 3 & & 1 & 2 & 0,36 & 0,72 & 1,94 \\
\hline Total & 223 & 63 & 207 & 79 & 20,29 & 106,09 & 286,46 \\
\hline
\end{tabular}


Tabela 11: Segundo dia de consumo na sala 24 fase pré implantação

\begin{tabular}{|c|c|c|c|c|c|c|c|}
\hline \multicolumn{8}{|c|}{ SALA 24 - SEGUNDO DIA DE CONSUMO } \\
\hline Medicamento & $\begin{array}{l}\text { Físico } \\
\text { Inicial }\end{array}$ & Extra & $\begin{array}{l}\text { Físico } \\
\text { Final }\end{array}$ & $\begin{array}{l}\text { Quantidade } \\
\text { Utilizada }\end{array}$ & $\begin{array}{c}\text { Preço } \\
\text { Unitário }\end{array}$ & $\begin{array}{l}\text { Preço } \\
\text { Final }\end{array}$ & $\begin{array}{l}\text { Valor em } \\
\text { dólar }\end{array}$ \\
\hline água destilada $10 \mathrm{ml}$ & 11 & & 8 & 3 & 0,1 & 0,3 & 0,81 \\
\hline álcool etílico $96 \%$ - 10ml & 1 & & 1 & 0 & & & \\
\hline amicacina $50 \mathrm{mg} / \mathrm{ml}-2 \mathrm{ml}$ & 4 & & 4 & 0 & & & \\
\hline aminofilina $24 \mathrm{mg} / \mathrm{ml}-10 \mathrm{ml}$ & 1 & & 1 & 0 & & & \\
\hline atropina $0,25 \mathrm{mg} / \mathrm{ml}-1 \mathrm{ml}$ & 5 & & 4 & 1 & 0,12 & 0,12 & 0,32 \\
\hline atropina $0,5 \mathrm{mg} / \mathrm{ml}-1 \mathrm{ml}$ & 7 & & 7 & 0 & & & \\
\hline azul de metileno $1 \%-5 \mathrm{ml}$ & 1 & & 0 & 1 & 1,02 & 1,02 & 2,75 \\
\hline bicarbonato de sódio $3 \%-20 \mathrm{ml}$ & 4 & & 4 & 0 & & & \\
\hline $\begin{array}{l}\text { bupivacaína com epinefrina } \\
(5 \mathrm{mg}+9,1 \mathrm{mcg}) / \mathrm{ml}-20 \mathrm{ml}\end{array}$ & 2 & & 2 & 0 & & & \\
\hline $\begin{array}{l}\text { bupivacaína sem epinefrina } 0,5 \% \text { - } \\
20 \mathrm{ml}\end{array}$ & 10 & & 7 & 3 & 4 & 12 & 32,4 \\
\hline bupivacaína isobárica $0,5 \%$ - $20 \mathrm{ml}$ & 5 & & 5 & 0 & & & \\
\hline bupivacaína hiperbárica $0,5 \%-4 \mathrm{ml}$ & 6 & & 5 & 1 & 3,59 & 3,59 & 9,69 \\
\hline cefalotina $1 \mathrm{~g}$ & 3 & & 5 & 2 & 1,53 & 3,06 & 8,26 \\
\hline cloreto de sódio $20 \%$ - $20 \mathrm{ml}$ & 1 & & 1 & 0 & & & \\
\hline dexametasona $4 \mathrm{mg} / \mathrm{ml}-1 \mathrm{ml}$ & 28 & & 27 & 1 & 0,39 & 0,39 & 1,05 \\
\hline diazepam $5 \mathrm{mg} / \mathrm{ml}-2 \mathrm{ml}$ & & 2 & 2 & 0 & & & \\
\hline diclofenaco de sódio $25 \mathrm{mg} / \mathrm{ml}-3 \mathrm{ml}$ & 2 & & 1 & 1 & 0,15 & 0,15 & 0,41 \\
\hline $\begin{array}{l}\text { dimenidrato+piridoxina }(50+50 \mathrm{mg}) / \\
\mathrm{ml}-1 \mathrm{ml}\end{array}$ & 1 & & 1 & 0 & & & \\
\hline dipirona $500 \mathrm{mg} / \mathrm{ml}-2 \mathrm{ml}$ & 9 & & 7 & 2 & 0,16 & 0,32 & 0,86 \\
\hline dobutamina $12,5 \mathrm{mg} / \mathrm{ml}-20 \mathrm{ml}$ & 2 & & 2 & 0 & & & \\
\hline dopamina $5 \mathrm{mg} / \mathrm{ml}-10 \mathrm{ml}$ & 10 & & 10 & 0 & & & \\
\hline efedrina $25 \mathrm{mg} / \mathrm{ml}-1 \mathrm{ml}$ & 13 & & 11 & 2 & 0,43 & 0,86 & 2,32 \\
\hline epinefrina $1 \mathrm{mg} / \mathrm{ml} 1 \mathrm{ml}$ & 30 & & 29 & 1 & 0,15 & 0,15 & 0,41 \\
\hline etomidato $2 \mathrm{mg} / \mathrm{ml}-10 \mathrm{ml}$ & & 2 & 2 & 0 & & & \\
\hline $\begin{array}{l}\text { fentanila + droperidol } \\
(0,05 \mathrm{mg}+2,5 \mathrm{mg}) / \mathrm{ml}-2 \mathrm{ml}\end{array}$ & & 4 & 4 & 0 & & & \\
\hline fentanil $0,05 \mathrm{mg} / \mathrm{ml}-5 \mathrm{ml}$ & & 9 & 7 & 2 & 1,8 & 3,6 & 9,72 \\
\hline furosemida $10 \mathrm{mg} / \mathrm{ml}-2 \mathrm{ml}$ & 17 & & 17 & 0 & & & \\
\hline gentamicina $40 \mathrm{mg} / \mathrm{ml}-1 \mathrm{ml}$ & 16 & & 16 & 0 & & & \\
\hline gentamicina pomada $0,3 \%-3 \mathrm{~g}$ & 2 & & 1 & 1 & 1,99 & 1,99 & 5,37 \\
\hline heparina IV 5.000UI - 5ml & 1 & & 1 & 0 & & & \\
\hline hidralazina $20 \mathrm{mg} / \mathrm{ml}-1 \mathrm{ml}$ & 1 & & 1 & 0 & & & \\
\hline hidrocortisona 500mg & 1 & & 1 & 0 & & & \\
\hline lidocaína geléia $2 \%$ - 30ml & 4 & & 1 & 3 & 1,12 & 3,36 & 9,07 \\
\hline lidocaína sem epinefrina $2 \%$ - $20 \mathrm{ml}$ & 4 & & 4 & 0 & & & \\
\hline $\begin{array}{l}\text { lidocaína com epinefrina } \\
(20 \mathrm{mg}+5 \mathrm{mcg}) / \mathrm{ml}-20 \mathrm{ml}\end{array}$ & 8 & & 8 & 0 & & & \\
\hline metaraminol $10 \mathrm{mg} / \mathrm{ml}-1 \mathrm{ml}$ & 1 & & 1 & 0 & & & \\
\hline metoclopramida $5 \mathrm{mg} / \mathrm{ml}-2 \mathrm{ml}$ & 10 & & 9 & 1 & 0,15 & 0,15 & 0,41 \\
\hline metoprolol $1 \mathrm{mg} / \mathrm{ml}-5 \mathrm{ml}$ & 1 & & 1 & 0 & & & \\
\hline midazolam $5 \mathrm{mg} / \mathrm{ml}-3 \mathrm{ml}$ & & 3 & 1 & 2 & 2,35 & 4,7 & 12,69 \\
\hline morfina $2 \mathrm{mg} / \mathrm{ml}-1 \mathrm{ml}$ & & 2 & 2 & 0 & & & \\
\hline neostigmina $0,5 \mathrm{mg} / \mathrm{ml}-1 \mathrm{ml}$ & 18 & & 13 & 5 & 0,46 & 2,3 & 6,21 \\
\hline petidina $50 \mathrm{mg} / \mathrm{ml}-2 \mathrm{ml}$ & & 2 & 2 & 0 & & & \\
\hline
\end{tabular}


SALA 24 - SEGUNDO DIA DE CONSUMO (continuação)

\begin{tabular}{l|c|c|c|c|c|c|c}
\hline Medicamento & $\begin{array}{c}\text { Físico } \\
\text { Inicial }\end{array}$ & Extra & $\begin{array}{c}\text { Físico } \\
\text { Final }\end{array}$ & $\begin{array}{c}\text { Quantidade } \\
\text { Utilizada }\end{array}$ & $\begin{array}{c}\text { Preço } \\
\text { Unitário }\end{array}$ & $\begin{array}{c}\text { Preço } \\
\text { Final }\end{array}$ & $\begin{array}{c}\text { Valor em } \\
\text { dólar }\end{array}$ \\
\hline prometazina $25 \mathrm{mg} / \mathrm{ml}-2 \mathrm{ml}$ & 2 & & 2 & 0 & & & \\
\hline propofol $10 \mathrm{mg} / \mathrm{ml}-20 \mathrm{ml}$ & & 6 & 5 & 1 & 8,51 & 8,51 & 22,98 \\
\hline ranitidina $10 \mathrm{mg} / \mathrm{ml}-5 \mathrm{ml}$ & 6 & & 5 & 1 & 0,18 & 0,18 & 0,49 \\
\hline terbutalina0,5mg/ml $-1 \mathrm{ml}$ & 2 & & 2 & 0 & & & \\
\hline vit A e D colírio $-10 \mathrm{ml}$ & 1 & & 1 & 0 & & & \\
\hline Total & $\mathbf{2 5 1}$ & $\mathbf{3 0}$ & $\mathbf{2 4 9}$ & $\mathbf{3 4}$ & $\mathbf{2 8 , 2}$ & $\mathbf{4 6 , 7 5}$ & $\mathbf{1 2 6 , 2 2}$ \\
\hline
\end{tabular}


Tabela 12: Terceiro dia de consumo na sala 24 fase pré implantação

\begin{tabular}{|c|c|c|c|c|c|c|c|}
\hline \multicolumn{8}{|c|}{ SALA 24 - TERCEIRO DIA DE CONSUMO } \\
\hline Medicamento & $\begin{array}{l}\text { Físico } \\
\text { Inicial }\end{array}$ & Extra & $\begin{array}{l}\text { Físico } \\
\text { Final }\end{array}$ & $\begin{array}{l}\text { Quantidade } \\
\text { Utilizada }\end{array}$ & \begin{tabular}{|c|} 
Preço \\
Unitário
\end{tabular} & $\begin{array}{l}\text { Preço } \\
\text { Final }\end{array}$ & $\begin{array}{l}\text { Valor em } \\
\text { dólar }\end{array}$ \\
\hline água destilada $10 \mathrm{ml}$ & 3 & 33 & 33 & 3 & 0,1 & 0,3 & 0,81 \\
\hline álcool etílico $96 \%$ - 10ml & 1 & & 1 & 0 & & & \\
\hline amicacina $50 \mathrm{mg} / \mathrm{ml}-2 \mathrm{ml}$ & 6 & & 6 & 0 & & & \\
\hline aminofilina $24 \mathrm{mg} / \mathrm{ml}-10 \mathrm{ml}$ & 6 & & 6 & 0 & & & \\
\hline amiodarona $50 \mathrm{mg} / \mathrm{ml}-3 \mathrm{ml}$ & 3 & & 3 & 0 & & & \\
\hline ampicilina $1 \mathrm{~g}$ & 4 & & 4 & 0 & & & \\
\hline atropina $0,25 \mathrm{mg} / \mathrm{ml}-1 \mathrm{ml}$ & 17 & & 17 & 0 & & & \\
\hline atropina $0,5 \mathrm{mg} / \mathrm{ml}-1 \mathrm{ml}$ & 15 & & 15 & 0 & & & \\
\hline azul de metileno $1 \%-5 \mathrm{ml}$ & 4 & & 4 & 0 & & & \\
\hline bicarbonato de sódio $3 \%-20 \mathrm{ml}$ & 4 & 5 & 5 & 4 & 0,45 & 1,8 & 4,86 \\
\hline bicarbonato de sódio $10 \%-250 \mathrm{ml}$ & 4 & & 4 & 0 & & & \\
\hline n-butilescopolamina & 7 & & 7 & 0 & & & \\
\hline $\begin{array}{l}\text { bupivacaína com epinefrina } \\
(5 \mathrm{mg}+9,1 \mathrm{mcg}) / \mathrm{ml}-20 \mathrm{ml}\end{array}$ & 3 & & 3 & 0 & & & \\
\hline $\begin{array}{l}\text { bupivacaína sem epinefrina } 0,5 \% \text { - } \\
20 \mathrm{ml}\end{array}$ & 8 & & 8 & 0 & & & \\
\hline bupivacaína hiperbárica $0,5 \%-4 \mathrm{ml}$ & 1 & & 1 & 0 & & & \\
\hline bupivacaína isobárica $0,5 \%-20 \mathrm{ml}$ & 2 & & 2 & 0 & & & \\
\hline cefalotina $1 \mathrm{~g}$ & 5 & & 3 & 2 & 1,53 & 3,06 & 8,26 \\
\hline cloreto de cálcio $100 \mathrm{mg} / \mathrm{ml}-5 \mathrm{ml}$ & 10 & & 8 & 2 & 0,38 & 0,76 & 2,05 \\
\hline cloreto de potássio $19,1 \%$ - $10 \mathrm{ml}$ & 8 & & 8 & 0 & & & \\
\hline cloreto de sódio $20 \%$ - $20 \mathrm{ml}$ & 8 & & 8 & 0 & & & \\
\hline complexo $\mathrm{b}-3 \mathrm{ml}$ & 2 & & 2 & 0 & & & \\
\hline deslanosido $0,2 \mathrm{mg} / \mathrm{ml}-2 \mathrm{ml}$ & 5 & & 5 & 0 & & & \\
\hline dexametasona $4 \mathrm{mg} / \mathrm{ml}-1 \mathrm{ml}$ & 2 & & 1 & 1 & 0,39 & 0,39 & 1,05 \\
\hline diazepam $5 \mathrm{mg} / \mathrm{ml}-2 \mathrm{ml}$ & & 2 & 2 & 0 & & & \\
\hline dipirona $500 \mathrm{mg} / \mathrm{ml}-2 \mathrm{ml}$ & 23 & & 20 & 3 & 0,16 & 0,48 & 1,3 \\
\hline dopamina $5 \mathrm{mg} / \mathrm{ml}-10 \mathrm{ml}$ & 1 & & 1 & 0 & & & \\
\hline efedrina $25 \mathrm{mg} / \mathrm{ml}-1 \mathrm{ml}$ & 8 & & 8 & 0 & & & \\
\hline epinefrina $1 \mathrm{mg} / \mathrm{ml}-1 \mathrm{ml}$ & 18 & & 17 & 1 & 0,15 & 0,15 & 0,41 \\
\hline etomidato $2 \mathrm{mg} / \mathrm{ml}-10 \mathrm{ml}$ & & 2 & 2 & 0 & & & \\
\hline $\begin{array}{l}\text { fentanila + droperidol } \\
(0,05 \mathrm{mg}+2,5 \mathrm{mg}) / \mathrm{ml}-2 \mathrm{ml}\end{array}$ & & 4 & 4 & 0 & & & \\
\hline fentanil $0,05 \mathrm{mg} / \mathrm{ml}-5 \mathrm{ml}$ & & 6 & 2 & 4 & 1,95 & 7,8 & 21,06 \\
\hline furosemida $10 \mathrm{mg} / \mathrm{ml}-2 \mathrm{ml}$ & 15 & & 15 & 0 & & & \\
\hline gentamicina $40 \mathrm{mg} / \mathrm{ml}-1 \mathrm{ml}$ & 22 & & 22 & 0 & & & \\
\hline glicose $50 \%-10 \mathrm{ml}$ & 5 & & 5 & 0 & & & \\
\hline heparina IV 5.000UI $-5 \mathrm{ml}$ & 2 & & 1 & 1 & 3,45 & 3,45 & 9,32 \\
\hline hidralazina $20 \mathrm{mg} / \mathrm{ml}-1 \mathrm{ml}$ & 10 & & 1 & 9 & 1,5 & 13,5 & 36,45 \\
\hline isoprenalina $0,2 \mathrm{mg} / \mathrm{ml}-1 \mathrm{ml}$ & 15 & & 15 & 0 & & & \\
\hline $\begin{array}{l}\text { lidocaína com epinefrina } \\
(20 \mathrm{mg}+5 \mathrm{mcg}) / \mathrm{ml}-20 \mathrm{ml}\end{array}$ & 9 & & 8 & 1 & 0,68 & 0,68 & 1,84 \\
\hline lidocaína geléia $2 \%$ - 30ml & 3 & & 2 & 1 & 1,12 & 1,12 & 3,02 \\
\hline metaraminol $10 \mathrm{mg} / \mathrm{ml}-1 \mathrm{ml}$ & 13 & & 12 & 1 & 1,95 & 1,95 & 5,27 \\
\hline metilergotamina $0,2 \mathrm{mg} / \mathrm{ml}-1 \mathrm{ml}$ & 2 & & 2 & 0 & & & \\
\hline metoclopramida $5 \mathrm{mg} / \mathrm{ml}-2 \mathrm{ml}$ & 24 & & 24 & 0 & & & \\
\hline midazolam $5 \mathrm{mg} / \mathrm{ml}-3 \mathrm{ml}$ & & 2 & 0 & 2 & 2,35 & 4,7 & 12,69 \\
\hline
\end{tabular}


SALA 24 - TERCEIRO DIA DE CONSUMO (continuação)

\begin{tabular}{|c|c|c|c|c|c|c|c|}
\hline Medicamento & $\begin{array}{l}\text { Físico } \\
\text { Inicial }\end{array}$ & Extra & $\begin{array}{c}\text { Físico } \\
\text { Final }\end{array}$ & $\begin{array}{l}\text { Quantidade } \\
\text { Utilizada }\end{array}$ & \begin{tabular}{|c|} 
Preço \\
Unitário
\end{tabular} & $\begin{array}{l}\text { Preço } \\
\text { Final }\end{array}$ & $\begin{array}{c}\text { Valor em } \\
\text { dólar }\end{array}$ \\
\hline morfina $2 \mathrm{mg} / \mathrm{ml}-1 \mathrm{ml}$ & & 2 & 2 & 0 & & & \\
\hline neostigmina $0,5 \mathrm{mg} / \mathrm{ml}-1 \mathrm{ml}$ & 13 & & 11 & 2 & 0,46 & 0,92 & 2,48 \\
\hline noradrenalina $1 \mathrm{mg} / \mathrm{ml}-4 \mathrm{ml}$ & 2 & & 2 & 0 & & & \\
\hline oxitocina $5 \mathrm{ui} / \mathrm{ml}-1 \mathrm{ml}$ & 4 & & 4 & 0 & & & \\
\hline petidina $50 \mathrm{mg} / \mathrm{ml}-2 \mathrm{ml}$ & & 2 & 2 & 0 & & & \\
\hline prometazina $25 \mathrm{mg} / \mathrm{ml}-2 \mathrm{ml}$ & 14 & & 14 & 0 & & & \\
\hline propofol $10 \mathrm{mg} / \mathrm{ml}-20 \mathrm{ml}$ & & 4 & 2 & 2 & 8,51 & 17,02 & 45,95 \\
\hline protamina $10 \mathrm{mg} / \mathrm{ml}-5 \mathrm{ml}$ & 5 & & 5 & 0 & & & \\
\hline ranitidina $10 \mathrm{mg} / \mathrm{ml}-5 \mathrm{ml}$ & 10 & & 4 & 6 & 0,18 & 1,08 & 2,92 \\
\hline salbutamol $0,5 \mathrm{mg} / \mathrm{ml}-1 \mathrm{ml}$ & 3 & & 3 & 0 & & & \\
\hline sedativo $-2 \mathrm{ml}$ & 3 & & 3 & 0 & & & \\
\hline sulfato de magnésio $10 \%-10 \mathrm{ml}$ & 5 & 6 & 6 & 5 & 0,43 & 2,15 & 5,81 \\
\hline vaselina $20 \mathrm{ml}$ & 3 & & 3 & 0 & & & \\
\hline vecurônio $250 \mathrm{mg} / \mathrm{ml}-1 \mathrm{ml}$ & 1 & & 1 & 0 & & & \\
\hline verapamil $2,5 \mathrm{mg} / \mathrm{ml}-2 \mathrm{ml}$ & 5 & & 5 & 0 & & & \\
\hline verde brilhante $100 \mathrm{mg} / \mathrm{ml}-1 \mathrm{ml}$ & 1 & 2 & 2 & 1 & 0,36 & 0,36 & 0,97 \\
\hline vitamina c $100 \mathrm{mg} / \mathrm{ml}-5 \mathrm{ml}$ & 2 & & 2 & 0 & & & \\
\hline Total & 369 & 70 & 391 & 51 & 26,1 & 61,67 & 166,52 \\
\hline
\end{tabular}


Tabela 13: Primeiro dia de consumo na sala 25 fase pré implantação

SALA 25 - PRIMEIRO DIA DE CONSUMO

\begin{tabular}{|c|c|c|c|c|c|c|c|}
\hline \\
\hline Medicamento & $\begin{array}{l}\text { Físico } \\
\text { Inicial }\end{array}$ & Extra & $\begin{array}{l}\text { Físico } \\
\text { Final }\end{array}$ & $\begin{array}{c}\text { Quantidade } \\
\text { Utilizada }\end{array}$ & $\begin{array}{c}\text { Preço } \\
\text { Unitário }\end{array}$ & $\begin{array}{l}\text { Preço } \\
\text { Final }\end{array}$ & $\begin{array}{l}\text { Valor em } \\
\text { dólar }\end{array}$ \\
\hline agua destilada $10 \mathrm{ml}$ & 18 & & 11 & 7 & 0,1 & 0,7 & 1,89 \\
\hline álcool etílico $96 \%$ - 10ml & 1 & & 1 & 0 & & & \\
\hline amicacina $50 \mathrm{mg} / \mathrm{ml}-2 \mathrm{ml}$ & 6 & & 6 & 0 & & & \\
\hline aminofilina $24 \mathrm{mg} / \mathrm{ml}-10 \mathrm{ml}$ & 6 & & 6 & 0 & & & \\
\hline amiodarona $50 \mathrm{mg} / \mathrm{ml}-3 \mathrm{ml}$ & 3 & & 3 & 0 & & & \\
\hline ampicilina $1 \mathrm{~g}$ & 4 & & 4 & 0 & & & \\
\hline atropina $0,25 \mathrm{mg} / \mathrm{ml}-1 \mathrm{ml}$ & 9 & & 9 & 0 & & & \\
\hline azul de metileno $1 \%-5 \mathrm{ml}$ & 4 & & 4 & 0 & & & \\
\hline bicarbonato de sodio $3 \%-20 \mathrm{ml}$ & 5 & & 4 & 1 & 0,45 & 0,45 & 1,22 \\
\hline bicarbonato de sódio $10 \%-250 \mathrm{ml}$ & 4 & & 4 & 0 & & & \\
\hline bupivacaína isobárica $0,5 \%-20 \mathrm{ml}$ & 3 & & 2 & 1 & 3,07 & 3,07 & 8,29 \\
\hline bupivacaína hiperbárica $0,5 \%$ - $4 \mathrm{ml}$ & 3 & & 2 & 1 & 3,59 & 3,59 & 9,69 \\
\hline cefalotina $1 \mathrm{~g}$ & 2 & & 1 & 1 & 1,53 & 1,53 & 4,13 \\
\hline cetoprofeno $50 \mathrm{mg} / \mathrm{ml}-2 \mathrm{ml}$ & 1 & & 1 & 0 & & & \\
\hline cloreto de cálcio $100 \mathrm{mg} / \mathrm{ml}-5 \mathrm{ml}$ & 10 & & 8 & 2 & 0,38 & 0,76 & 2,05 \\
\hline cloreto de potássio $19,1 \%-10 \mathrm{ml}$ & 8 & & 8 & 0 & & & \\
\hline cloreto de sódio $20 \%-20 \mathrm{ml}$ & 8 & & 8 & 0 & & & \\
\hline complexo B - $2 \mathrm{ml}$ & 2 & & 2 & 0 & & & \\
\hline deslanosido $0,2 \mathrm{mg} / \mathrm{ml}-2 \mathrm{ml}$ & 8 & & 8 & 0 & & & \\
\hline dexametasona $4 \mathrm{mg} / \mathrm{ml}-1 \mathrm{ml}$ & 11 & & 6 & 5 & 0,39 & 1,95 & 5,27 \\
\hline diazepam $5 \mathrm{mg} / \mathrm{ml}-2 \mathrm{ml}$ & & 2 & 2 & 0 & & & \\
\hline dipirona $500 \mathrm{mg} / \mathrm{ml}-2 \mathrm{ml}$ & 27 & & 25 & 2 & 0,16 & 0,32 & 0,86 \\
\hline dopamina $5 \mathrm{mg} / \mathrm{ml}-10 \mathrm{ml}$ & 1 & & 1 & 0 & & & \\
\hline efedrina $25 \mathrm{mg} / \mathrm{ml}-1 \mathrm{ml}$ & 8 & & 8 & 0 & & & \\
\hline epinefrina $1 \mathrm{mg} / \mathrm{ml} 1 \mathrm{ml}$ & 18 & & 17 & 1 & 0,15 & 0,15 & 0,41 \\
\hline escopolamina $20 \mathrm{mg} / \mathrm{ml}-1 \mathrm{ml}$ & 7 & & 0 & 7 & 0,72 & 5,04 & 13,61 \\
\hline etomidato $2 \mathrm{mg} / \mathrm{ml}-10 \mathrm{ml}$ & & 2 & 2 & 0 & & & \\
\hline $\begin{array}{l}\text { fentanila + droperidol } \\
(0,05 \mathrm{mg}+2,5 \mathrm{mg}) / \mathrm{ml}-2 \mathrm{ml}\end{array}$ & & 4 & 4 & 0 & & & \\
\hline fentanil $0,05 \mathrm{mg} / \mathrm{ml}-5 \mathrm{ml}$ & & 6 & 3 & 3 & 1,8 & 5,4 & 14,58 \\
\hline furosemida $10 \mathrm{mg} / \mathrm{ml}-2 \mathrm{ml}$ & 14 & & 14 & 0 & & & \\
\hline gentamicina colírio $20 \mathrm{mg} / \mathrm{ml}-10 \mathrm{ml}$ & 1 & & 1 & 0 & & & \\
\hline gentamicina $10 \mathrm{mg} / \mathrm{ml}-1 \mathrm{ml}$ & 1 & & 1 & 0 & & & \\
\hline gentamicina $40 \mathrm{mg} / \mathrm{ml}-1 \mathrm{ml}$ & 20 & & 16 & 4 & 0,19 & 0,76 & 2,05 \\
\hline heparina $5.000 \mathrm{ui}-0,25 \mathrm{ml}$ & 1 & & 1 & 0 & & & \\
\hline heparina iv 5.000ui $-5 \mathrm{ml}$ & 1 & & 1 & 0 & & & \\
\hline hidralazina $20 \mathrm{mg} / \mathrm{ml}-1 \mathrm{ml}$ & 11 & & 10 & 1 & 1,5 & 1,5 & 4,05 \\
\hline lidocaína sem epinefrina $2 \%$ - $20 \mathrm{ml}$ & 5 & & 4 & 1 & 1,31 & 1,31 & 3,54 \\
\hline $\begin{array}{l}\text { lidocaína com epinefrina } \\
(20 \mathrm{mg}+5 \mathrm{mcg}) / \mathrm{ml}-20 \mathrm{ml}\end{array}$ & 9 & & 9 & 0 & & & \\
\hline lidocaína geléia $2 \%$ - 30ml & 3 & & 3 & 0 & & & \\
\hline metaraminol $10 \mathrm{mg} / \mathrm{ml}-1 \mathrm{ml}$ & 12 & & 12 & 0 & & & \\
\hline metilergotamina $0,2 \mathrm{mg} / \mathrm{ml}-1 \mathrm{ml}$ & 2 & & 1 & 1 & 5,82 & 5,82 & 15,71 \\
\hline metoclopramida $5 \mathrm{mg} / \mathrm{ml}-2 \mathrm{ml}$ & 13 & & 12 & 1 & 0,15 & 0,15 & 0,41 \\
\hline midazolam $5 \mathrm{mg} / \mathrm{ml}-3 \mathrm{ml}$ & & 2 & 0 & 2 & 2,35 & 4,7 & 12,69 \\
\hline morfina $2 \mathrm{mg} / \mathrm{ml}-1 \mathrm{ml}$ & & 2 & 1 & 1 & 0,41 & 0,41 & 1,11 \\
\hline
\end{tabular}


SALA 25 - PRIMEIRO DIA DE CONSUMO (continuação)

\begin{tabular}{l|c|c|c|c|c|c|c}
\hline Medicamento & $\begin{array}{c}\text { Físico } \\
\text { Inicial }\end{array}$ & Extra & $\begin{array}{c}\text { Físico } \\
\text { Final }\end{array}$ & $\begin{array}{c}\text { Quantidade } \\
\text { Utilizada }\end{array}$ & $\begin{array}{c}\text { Preço } \\
\text { Unitário }\end{array}$ & $\begin{array}{c}\text { Preço } \\
\text { Final }\end{array}$ & $\begin{array}{c}\text { Valor em } \\
\text { dólar }\end{array}$ \\
\hline neostigmina $0,5 \mathrm{mg} / \mathrm{ml}-1 \mathrm{ml}$ & 21 & & 20 & 1 & 0,46 & 0,46 & 1,24 \\
\hline petidina $50 \mathrm{mg} / \mathrm{ml}-2 \mathrm{ml}$ & & 2 & 2 & 0 & & & \\
\hline propofol $10 \mathrm{mg} / \mathrm{ml}-20 \mathrm{ml}$ & & 4 & 2 & 2 & 8,51 & 17,02 & 45,95 \\
\hline protamina $10 \mathrm{mg} / \mathrm{ml}-5 \mathrm{ml}$ & 14 & & 14 & 0 & & & \\
\hline ranitidina $10 \mathrm{mg} / \mathrm{ml}-5 \mathrm{ml}$ & 12 & & 12 & 0 & & & \\
\hline salbutamol $0,5 \mathrm{mg} / \mathrm{ml}-1 \mathrm{ml}$ & 3 & & 3 & 0 & & & \\
\hline vaselina $20 \mathrm{ml}$ & 3 & & 3 & 0 & & & \\
\hline vecurônio $250 \mathrm{mg} / \mathrm{ml}-1 \mathrm{ml}$ & 1 & & 1 & 0 & & & \\
\hline verapamil $2,5 \mathrm{mg} / \mathrm{ml}-2 \mathrm{ml}$ & 5 & & 5 & 0 & & & \\
\hline verde brilhante $100 \mathrm{mg} / \mathrm{ml}-1 \mathrm{ml}$ & 2 & & 2 & 0 & & & \\
\hline Total & $\mathbf{3 3 1}$ & $\mathbf{2 4}$ & $\mathbf{3 1 0}$ & $\mathbf{4 5}$ & $\mathbf{3 3 , 0 4}$ & $\mathbf{5 5 , 0 9}$ & $\mathbf{1 4 8 , 7 5}$ \\
\hline
\end{tabular}


Tabela 14: Segundo dia de consumo na sala 25 fase pré implantação

SALA 25 - SEGUNDO DIA DE CONSUMO

\begin{tabular}{|c|c|c|c|c|c|c|c|}
\hline \\
\hline Medicamento & $\begin{array}{l}\text { Físico } \\
\text { Inicial }\end{array}$ & Extra & $\begin{array}{l}\text { Físico } \\
\text { Final }\end{array}$ & $\begin{array}{c}\text { Quantidade } \\
\text { Utilizada }\end{array}$ & $\begin{array}{c}\text { Preço } \\
\text { Unitário }\end{array}$ & $\begin{array}{l}\text { Preço } \\
\text { Final }\end{array}$ & $\begin{array}{l}\text { Valor em } \\
\text { dólar }\end{array}$ \\
\hline agua destilada $10 \mathrm{ml}$ & 19 & & 14 & 5 & 0,1 & 0,5 & 1,35 \\
\hline álcool etílico $96 \%$ - 10ml & 2 & & 2 & 0 & & & \\
\hline amicacina $50 \mathrm{mg} / \mathrm{ml}-2 \mathrm{ml}$ & 6 & & 6 & 0 & & & \\
\hline aminofilina $24 \mathrm{mg} / \mathrm{ml}-10 \mathrm{ml}$ & 6 & & 6 & 0 & & & \\
\hline amiodarona $50 \mathrm{mg} / \mathrm{ml}-3 \mathrm{ml}$ & 4 & & 4 & 0 & & & \\
\hline ampicilina $1 \mathrm{~g}$ & 4 & & 4 & 0 & & & \\
\hline atropina $0,25 \mathrm{mg} / \mathrm{ml}-1 \mathrm{ml}$ & 10 & & 9 & 1 & 0,12 & 0,12 & 0,32 \\
\hline azul de metileno $1 \%-5 \mathrm{ml}$ & 3 & & 3 & 0 & & & \\
\hline bicarbonato de sodio $3 \%-20 \mathrm{ml}$ & 6 & & 5 & 1 & 0,45 & 0,45 & 1,22 \\
\hline bicarbonato de sódio $10 \%-250 \mathrm{ml}$ & 4 & & 4 & 0 & & & \\
\hline bupivacaína isobárica $0,5 \%$ - $20 \mathrm{ml}$ & 3 & & 2 & 1 & 3,07 & 3,07 & 8,29 \\
\hline bupivacaína hiperbárica $0,5 \%$ - $4 \mathrm{ml}$ & 3 & & 2 & 1 & 3,59 & 3,59 & 9,69 \\
\hline cefalotina $1 \mathrm{~g}$ & 2 & & 1 & 1 & 1,53 & 1,53 & 4,13 \\
\hline cetoprofeno $50 \mathrm{mg} / \mathrm{ml}-2 \mathrm{ml}$ & 1 & & 0 & 1 & 3,43 & 3,43 & 9,26 \\
\hline cloreto de cálcio $100 \mathrm{mg} / \mathrm{ml}-5 \mathrm{ml}$ & 11 & & 7 & 4 & 0,38 & 1,52 & 4,1 \\
\hline cloreto de potássio $19,1 \%-10 \mathrm{ml}$ & 9 & & 6 & 3 & 0,2 & 0,6 & 1,62 \\
\hline cloreto de sódio $20 \%$ - $20 \mathrm{ml}$ & 4 & & 4 & 0 & & & \\
\hline dexametasona $4 \mathrm{mg} / \mathrm{ml}-1 \mathrm{ml}$ & 18 & & 12 & 6 & 0,39 & 2,34 & 6,32 \\
\hline diazepam $5 \mathrm{mg} / \mathrm{ml}-2 \mathrm{ml}$ & & 2 & 2 & 0 & & & \\
\hline dipirona $500 \mathrm{~g} / \mathrm{ml}-2 \mathrm{ml}$ & 28 & & 26 & 2 & 0,32 & 0,32 & 0,86 \\
\hline dopamina $5 \mathrm{mg} / \mathrm{ml}-10 \mathrm{ml}$ & 1 & & 1 & 0 & & & \\
\hline efedrina $25 \mathrm{mg} / \mathrm{ml}-1 \mathrm{ml}$ & 7 & & 7 & 0 & & & \\
\hline epinefrina $1 \mathrm{mg} / \mathrm{ml} 1 \mathrm{ml}$ & 18 & & 17 & 1 & 0,15 & 0,15 & 0,41 \\
\hline escopolamina $20 \mathrm{mg} / \mathrm{ml}-1 \mathrm{ml}$ & 5 & & 0 & 5 & 0,72 & 3,6 & 9,72 \\
\hline etomidato $2 \mathrm{mg} / \mathrm{ml}-10 \mathrm{ml}$ & & 2 & 2 & 0 & & & \\
\hline $\begin{array}{l}\text { fentanila }+ \text { droperidol } \\
(0,05 \mathrm{mg}+2,5 \mathrm{mg}) / \mathrm{ml}-2 \mathrm{ml}\end{array}$ & & 4 & 4 & 0 & & & \\
\hline fentanil $0,05 \mathrm{mg} / \mathrm{ml}-5 \mathrm{ml}$ & & 7 & 0 & 7 & 1,8 & 12,60 & 34,02 \\
\hline furosemida $10 \mathrm{mg} / \mathrm{ml}-2 \mathrm{ml}$ & 15 & & 14 & 1 & 0,13 & 0,13 & 0,35 \\
\hline gentamicina colírio $20 \mathrm{mg} / \mathrm{ml}-10 \mathrm{ml}$ & 1 & & 1 & 0 & & & \\
\hline gentamicina $10 \mathrm{mg} / \mathrm{ml}-1 \mathrm{ml}$ & 1 & & 1 & 0 & & & \\
\hline glicose $50 \%-10 \mathrm{ml}$ & 4 & & 4 & 0 & & & \\
\hline heparina $5.000 \mathrm{ui}-0,25 \mathrm{ml}$ & 1 & & 1 & 0 & & & \\
\hline heparina IV 5.000UI $-5 \mathrm{ml}$ & 1 & & 1 & 0 & & & \\
\hline hidralazina $20 \mathrm{mg} / \mathrm{ml}-1 \mathrm{ml}$ & 12 & & 8 & 4 & 1,5 & 6 & 16,2 \\
\hline deslanosido $0,2 \mathrm{mg} / \mathrm{ml}-2 \mathrm{ml}$ & 8 & & 8 & 0 & & & \\
\hline lidocaína sem epinefrina $2 \%-20 \mathrm{ml}$ & 5 & & 4 & 1 & 1,31 & 1,31 & 3,54 \\
\hline $\begin{array}{l}\text { lidocaína com epinefrina } \\
(20 \mathrm{mg}+5 \mathrm{mcg}) / \mathrm{ml}-20 \mathrm{ml}\end{array}$ & 8 & & 8 & 0 & & & \\
\hline lidocaína geléia $2 \%$ - 30ml & 3 & & 3 & 0 & & & \\
\hline metaraminol $10 \mathrm{mg} / \mathrm{ml}-1 \mathrm{ml}$ & 10 & & 10 & 0 & & & \\
\hline metilergometrina $0,2 \mathrm{mg} / \mathrm{ml}-1 \mathrm{ml}$ & 2 & & 1 & 1 & 0,15 & 0,15 & 0,41 \\
\hline metoclopramida $5 \mathrm{mg} / \mathrm{ml}-2 \mathrm{ml}$ & 13 & & 12 & 1 & 0,15 & 0,15 & 0,41 \\
\hline midazolam $5 \mathrm{mg} / \mathrm{ml}-3 \mathrm{ml}$ & & 2 & 2 & 0 & & & \\
\hline morfina $2 \mathrm{mg} / \mathrm{ml}-1 \mathrm{ml}$ & & 2 & 2 & 0 & & & \\
\hline
\end{tabular}


SALA 25 - SEGUNDO DIA DE CONSUMO (continuação)

\begin{tabular}{l|c|c|c|c|c|c|c}
\hline Medicamento & $\begin{array}{c}\text { Físico } \\
\text { Inicial }\end{array}$ & Extra & $\begin{array}{c}\text { Físico } \\
\text { Final }\end{array}$ & $\begin{array}{c}\text { Quantidade } \\
\text { Utilizada }\end{array}$ & $\begin{array}{c}\text { Preço } \\
\text { Unitário }\end{array}$ & $\begin{array}{c}\text { Preço } \\
\text { Final }\end{array}$ & $\begin{array}{c}\text { Valor em } \\
\text { dólar }\end{array}$ \\
\hline neostigmina $0,5 \mathrm{mg} / \mathrm{ml}-1 \mathrm{ml}$ & 21 & & 20 & 1 & 0,46 & 0,46 & 1,24 \\
\hline noradrenalina $1 \mathrm{mg} / \mathrm{ml}-4 \mathrm{ml}$ & 3 & & 3 & 0 & & & \\
\hline rocurônio $10 \mathrm{mg} / \mathrm{ml}-5 \mathrm{ml}$ & 1 & & 1 & 0 & & & \\
\hline petidina $50 \mathrm{mg} / \mathrm{ml}-2 \mathrm{ml}$ & & 2 & 2 & 0 & & & \\
\hline prometazina $25 \mathrm{mg} / \mathrm{ml}-2 \mathrm{ml}$ & 14 & & 12 & 2 & 0,29 & 0,58 & 1,57 \\
\hline propofol $10 \mathrm{mg} / \mathrm{ml}-20 \mathrm{ml}$ & & 7 & 0 & 7 & 8,51 & 59,57 & 160,84 \\
\hline protamina $10 \mathrm{mg} / \mathrm{ml}-5 \mathrm{ml}$ & 5 & & 4 & 1 & 1,35 & 1,35 & 3,65 \\
\hline ranitidina $10 \mathrm{mg} / \mathrm{ml}-5 \mathrm{ml}$ & 15 & & 12 & 3 & 0,18 & 0,54 & 1,46 \\
\hline salbutamol $0,5 \mathrm{mg} / \mathrm{ml}-1 \mathrm{ml}$ & 3 & & 3 & 0 & & & \\
\hline vaselina $20 \mathrm{ml}$ & 4 & & 4 & 0 & & & \\
\hline verapamil $2,5 \mathrm{mg} / \mathrm{ml}-2 \mathrm{ml}$ & 4 & & 3 & 1 & 0,67 & 0,67 & 1,81 \\
\hline verde brilhante $100 \mathrm{mg} / \mathrm{ml}-1 \mathrm{ml}$ & 3 & & 2 & 1 & 0,36 & 0,36 & 0,97 \\
\hline vitamina c $100 \mathrm{mg} / \mathrm{ml} \mathrm{-5ml}$ & 2 & & 2 & 0 & & & \\
\hline Total & $\mathbf{3 3 3}$ & $\mathbf{2 8}$ & $\mathbf{3 1 2}$ & $\mathbf{6 3}$ & $\mathbf{3 1 , 3 1}$ & $\mathbf{1 0 5 , 0 9}$ & $\mathbf{2 8 3 , 7 6}$ \\
\hline
\end{tabular}


Tabela 15: Terceiro dia de consumo na sala 25 fase pré implantação

\begin{tabular}{|c|c|c|c|c|c|c|c|}
\hline \multicolumn{8}{|c|}{ SALA 25 - TERCEIRO DIA DE CONSUMO } \\
\hline Medicamento & $\begin{array}{l}\text { Físico } \\
\text { Inicial }\end{array}$ & Extra & $\begin{array}{l}\text { Físico } \\
\text { Final }\end{array}$ & $\begin{array}{l}\text { Quantidade } \\
\text { Utilizada }\end{array}$ & $\begin{array}{l}\text { Preço } \\
\text { Unitário }\end{array}$ & $\begin{array}{l}\text { Preço } \\
\text { Final }\end{array}$ & $\begin{array}{l}\text { Valor em } \\
\text { dólar }\end{array}$ \\
\hline agua destilada $10 \mathrm{ml}$ & 24 & & 18 & 6 & 0,1 & 0,6 & 1,62 \\
\hline álcool etílico $96 \%-10 \mathrm{ml}$ & 1 & & 1 & 0 & & & \\
\hline amiodarona $50 \mathrm{mg} / \mathrm{ml}-3 \mathrm{ml}$ & 2 & 1 & 1 & 2 & 0,74 & 1,48 & 4 \\
\hline ampicilina $1 \mathrm{~g}$ & 1 & & 1 & 0 & & & \\
\hline azul de metileno $1 \%-5 \mathrm{ml}$ & 1 & 2 & 2 & 1 & 1,02 & 1,02 & 2,75 \\
\hline bicarbonato de sódio $10 \%-250 \mathrm{ml}$ & 3 & & 1 & 2 & 4,96 & 9,92 & 25,78 \\
\hline $\begin{array}{l}\text { bupivacaína com epinefrina } \\
(5 \mathrm{mg}+9,1 \mathrm{mcg}) / \mathrm{ml}-20 \mathrm{ml}\end{array}$ & 3 & & 3 & 0 & & & \\
\hline $\begin{array}{l}\text { bupivacaína sem epinefrina } 0,5 \% \text { - } \\
20 \mathrm{ml}\end{array}$ & 3 & & 3 & 0 & & & \\
\hline bupivacaína isobárica $0,5 \%-20 \mathrm{ml}$ & 1 & & 1 & 0 & & & \\
\hline cefoxitina $1 \mathrm{~g}$ & 1 & & 1 & 0 & & & \\
\hline cetoprofeno $50 \mathrm{mg} / \mathrm{ml}-2 \mathrm{ml}$ & 2 & & 1 & 1 & 3,43 & 3,43 & 9,26 \\
\hline cloreto de sódio $20 \%-20 \mathrm{ml}$ & 1 & & 1 & 0 & & & \\
\hline Deslanosido $0,2 \mathrm{mg} / \mathrm{ml}-2 \mathrm{ml}$ & 8 & & 8 & 0 & & & \\
\hline diazepam $5 \mathrm{mg} / \mathrm{ml}-2 \mathrm{ml}$ & 3 & & 1 & 2 & 0,17 & 0,34 & 0,92 \\
\hline $\begin{array}{l}\text { dimenidrato+piridoxina } \\
(50+50 \mathrm{mg}) / \mathrm{ml}-1 \mathrm{ml} \\
\end{array}$ & 1 & & 1 & 0 & & & \\
\hline dobutamina $12,5 \mathrm{mg} / \mathrm{ml}-20 \mathrm{ml}$ & 3 & & 3 & 0 & & & \\
\hline dopamina $5 \mathrm{mg} / \mathrm{ml}-10 \mathrm{ml}$ & 3 & & 3 & 0 & & & \\
\hline efedrina $25 \mathrm{mg} / \mathrm{ml}-1 \mathrm{ml}$ & 27 & & 25 & 2 & 0,43 & 0,86 & 2,32 \\
\hline esmolol $250 \mathrm{mg} / \mathrm{ml}-1 \mathrm{ml}$ & 2 & & 1 & 1 & 105,11 & 105,11 & 283,8 \\
\hline etomidato $2 \mathrm{mg} / \mathrm{ml}-10 \mathrm{ml}$ & & 3 & 1 & 2 & 3,51 & 7,02 & 18,95 \\
\hline $\begin{array}{l}\text { fentanila }+ \text { droperidol } \\
(0,05 \mathrm{mg}+2,5 \mathrm{mg}) / \mathrm{ml}-2 \mathrm{ml}\end{array}$ & & 6 & 2 & 4 & 3,51 & 14,04 & 37,91 \\
\hline fentanil $0,05 \mathrm{mg} / \mathrm{ml}-5 \mathrm{ml}$ & & 10 & 0 & 10 & 1,8 & 18 & 48,6 \\
\hline furosemida $10 \mathrm{mg} / \mathrm{ml}-2 \mathrm{ml}$ & 30 & & 30 & 0 & & & \\
\hline$\underline{\text { gentamicina pomada } 0,3 \%-3 \mathrm{~g}}$ & 1 & & 1 & 0 & & & \\
\hline$\underline{\text { gentamicina colírio } 20 \mathrm{mg} / \mathrm{ml}-10 \mathrm{ml}}$ & 1 & & 1 & 0 & & & \\
\hline glicose $50 \%-10 \mathrm{ml}$ & 1 & & 1 & 0 & & & \\
\hline gluconato de cálcio $10 \%-10 \mathrm{ml}$ & 1 & & 1 & 0 & & & \\
\hline heparina IV 5.000UI - 5ml & 2 & & 2 & 0 & & & \\
\hline hidralazina $20 \mathrm{mg} / \mathrm{ml}-1 \mathrm{ml}$ & 3 & & 3 & 0 & & & \\
\hline lidocaína geléia $2 \%$ - $30 \mathrm{ml}$ & 10 & & 2 & 8 & 1,12 & 8,96 & 24,19 \\
\hline lidocaína sem epinefrina $2 \%$ - $20 \mathrm{ml}$ & 1 & & 0 & 1 & 1,31 & 1,31 & 3,54 \\
\hline $\begin{array}{l}\text { lidocaína c/epinefrina } \\
(20 \mathrm{mg}+5 \mathrm{mcg}) / \mathrm{ml}-20 \mathrm{ml}\end{array}$ & 8 & & 7 & 1 & 0,68 & 0,68 & 1,84 \\
\hline metaraminol $10 \mathrm{mg} / \mathrm{ml}-1 \mathrm{ml}$ & 4 & & 3 & 1 & 1,95 & 1,95 & 5,27 \\
\hline midazolam $5 \mathrm{mg} / \mathrm{ml}-3 \mathrm{ml}$ & & 3 & 0 & 3 & 0,18 & 0,54 & 1,46 \\
\hline morfina $2 \mathrm{mg} / \mathrm{ml}-1 \mathrm{ml}$ & & 3 & 3 & 0 & & & \\
\hline neostigmina $0,5 \mathrm{mg} / \mathrm{ml}-1 \mathrm{ml}$ & 29 & & 27 & 2 & 0,46 & 0,92 & 2,48 \\
\hline noradrenalina $1 \mathrm{mg} / \mathrm{ml}-4 \mathrm{ml}$ & 5 & & 2 & 3 & 1,67 & 5,01 & 13,53 \\
\hline petidina $50 \mathrm{mg} / \mathrm{ml}-2 \mathrm{ml}$ & & 2 & 0 & 2 & 0,18 & 0,36 & 0,97 \\
\hline prometazina $25 \mathrm{mg} / \mathrm{ml}-2 \mathrm{ml}$ & 1 & & 1 & 0 & & & \\
\hline propofol $10 \mathrm{mg} / \mathrm{ml}-20 \mathrm{ml}$ & & 30 & 0 & 30 & 8,51 & 255,30 & 689,31 \\
\hline
\end{tabular}


SALA 25 - TERCEIRO DIA DE CONSUMO (continuação)

\begin{tabular}{l|c|c|c|c|c|c|c}
\hline Medicamento & $\begin{array}{c}\text { Físico } \\
\text { Inicial }\end{array}$ & Extra & $\begin{array}{c}\text { Físico } \\
\text { Final }\end{array}$ & $\begin{array}{c}\text { Quantidade } \\
\text { Utilizada }\end{array}$ & $\begin{array}{c}\text { Preço } \\
\text { Unitário }\end{array}$ & $\begin{array}{c}\text { Preço } \\
\text { Final }\end{array}$ & $\begin{array}{c}\text { Valor em } \\
\text { dólar }\end{array}$ \\
\hline sulfato de magnésio $10 \%-10 \mathrm{ml}$ & 4 & & 4 & 0 & & & \\
\hline sulfato de terbutalina $0,5 \mathrm{mg} / \mathrm{ml}-1 \mathrm{ml}$ & 9 & & 4 & 5 & 0,99 & 4,95 & 13,36 \\
\hline suxametônio $100 \mathrm{mg}$ & 2 & & 1 & 1 & 7,12 & 7,12 & 19,22 \\
\hline tenoxicam $20 \mathrm{mg}$ & 1 & & 1 & 0 & & & \\
\hline verde brilhante $100 \mathrm{mg} / \mathrm{ml}-1 \mathrm{ml}$ & 1 & & 1 & 0 & & & \\
\hline Total & $\mathbf{2 0 4}$ & $\mathbf{6 0}$ & $\mathbf{1 9 2}$ & $\mathbf{9 0}$ & $\mathbf{1 4 8 , 9 5}$ & $\mathbf{4 4 8 , 9 2}$ & $\mathbf{1 2 1 1 , 0 8}$ \\
\hline
\end{tabular}


Tabela 16: Primeiro dia de consumo na sala 26 fase pré implantação

\begin{tabular}{|c|c|c|c|c|c|c|c|}
\hline \multicolumn{8}{|c|}{ SALA 26 - PRIMEIRO DIA DE CONSUMO } \\
\hline Medicamento & $\begin{array}{l}\text { Físico } \\
\text { Inicial }\end{array}$ & Extra & $\begin{array}{l}\text { Físico } \\
\text { Final }\end{array}$ & $\begin{array}{l}\text { Quantidade } \\
\text { Utilizada }\end{array}$ & $\begin{array}{c}\text { Preço } \\
\text { Unitário }\end{array}$ & $\begin{array}{l}\text { Preço } \\
\text { Final }\end{array}$ & $\begin{array}{l}\text { Valor em } \\
\text { dólar }\end{array}$ \\
\hline agua destilada $10 \mathrm{ml}$ & 24 & & 18 & 6 & 0,1 & 0,6 & 1,62 \\
\hline álcool etílico $96 \%$ - 10ml & 1 & & 1 & 0 & & & \\
\hline amiodarona $50 \mathrm{mg} / \mathrm{ml}-3 \mathrm{ml}$ & 2 & 1 & 1 & 2 & 0,74 & 1,48 & 4 \\
\hline ampicilina $1 \mathrm{~g}$ & 1 & & 1 & 0 & & & \\
\hline azul de metileno $1 \%-5 \mathrm{ml}$ & 1 & 1 & 2 & 0 & & & \\
\hline bicarbonato de sódio $10 \%-250 \mathrm{ml}$ & 3 & & 1 & 2 & 4,96 & 9,92 & 26,78 \\
\hline bupivacaína isobárica $0,5 \%-20 \mathrm{ml}$ & 1 & & 1 & 0 & & & \\
\hline $\begin{array}{l}\text { bupivacaína com epinefrina } \\
(5 \mathrm{mg}+9,1 \mathrm{mcg}) / \mathrm{ml}-20 \mathrm{ml}\end{array}$ & 3 & & 3 & 0 & & & \\
\hline bupivacaína s/ epinefrina $0,5 \%-20 \mathrm{ml}$ & 3 & & 3 & 0 & & & \\
\hline cefoxitina $1 \mathrm{~g}$ & 1 & & 1 & 0 & & & \\
\hline cetoprofeno $50 \mathrm{mg} / \mathrm{ml}-2 \mathrm{ml}$ & 2 & & 1 & 1 & 3,43 & 3,43 & 9,26 \\
\hline cloreto de sódio $20 \%-20 \mathrm{ml}$ & 1 & & 1 & 0 & & & \\
\hline diazepam $5 \mathrm{mg} / \mathrm{ml}-2 \mathrm{ml}$ & & 3 & 3 & 0 & & & \\
\hline dimenidrato+piridoxina $(50+50 \mathrm{mg}) / \mathrm{ml}-1 \mathrm{ml}$ & 1 & & 1 & 0 & & & \\
\hline dobutamina $12,5 \mathrm{mg} / \mathrm{ml}-20 \mathrm{ml}$ & 3 & & 3 & 0 & & & \\
\hline dopamina $5 \mathrm{mg} / \mathrm{ml}-10 \mathrm{ml}$ & 3 & & 3 & 0 & & & \\
\hline esmolol $250 \mathrm{mg} / \mathrm{ml}-1 \mathrm{ml}$ & 2 & & 1 & 1 & 105,11 & 105,11 & 283,8 \\
\hline escopolamina $20 \mathrm{mg} / \mathrm{ml}-1 \mathrm{ml}$ & 2 & & 0 & 2 & 0,72 & 1,44 & 3,89 \\
\hline etomidato $2 \mathrm{mg} / \mathrm{ml}-10 \mathrm{ml}$ & & 3 & 2 & 1 & 3,18 & 3,18 & 8,59 \\
\hline $\begin{array}{l}\text { fentanila }+ \text { droperidol }(0,05 \mathrm{mg}+2,5 \mathrm{mg}) / \mathrm{ml} \\
-2 \mathrm{ml}\end{array}$ & & 6 & 4 & 2 & 3,51 & 7,02 & 18,95 \\
\hline fentanil $0,05 \mathrm{mg} / \mathrm{ml}-5 \mathrm{ml}$ & & 9 & 2 & 7 & 1,8 & 12,60 & 34,02 \\
\hline furosemida $10 \mathrm{mg} / \mathrm{ml}-2 \mathrm{ml}$ & 30 & & 30 & 0 & & & \\
\hline gentamicina colírio $20 \mathrm{mg} / \mathrm{ml}-10 \mathrm{ml}$ & 1 & & 1 & 0 & & & \\
\hline gentamicina pomada $0,3 \%-3 g$ & 1 & & 1 & 0 & & & \\
\hline glicose $50 \%-10 \mathrm{ml}$ & 1 & & 1 & 0 & & & \\
\hline gluconato de cálcio $10 \%-10 \mathrm{ml}$ & 1 & & 1 & 0 & & & \\
\hline heparina IV 5.000UI $-5 \mathrm{ml}$ & 2 & & 2 & 0 & & & \\
\hline hidralazina $20 \mathrm{mg} / \mathrm{ml}-1 \mathrm{ml}$ & 3 & & 3 & 0 & & & \\
\hline lidocaína geléia $2 \%$ - 30ml & 10 & & 2 & 8 & 1,12 & 8,96 & 24,19 \\
\hline lidocaína sem epinefrina $2 \%-20 \mathrm{ml}$ & 1 & & 0 & 1 & 1,31 & 1,31 & 3,54 \\
\hline $\begin{array}{l}\text { lidocaína com epinefrina }(20 \mathrm{mg}+5 \mathrm{mcg}) / \mathrm{ml} \\
-20 \mathrm{ml}\end{array}$ & 8 & & 7 & 1 & 0,68 & 0,68 & 1,84 \\
\hline metaraminol $10 \mathrm{mg} / \mathrm{ml}-1 \mathrm{ml}$ & 4 & & 3 & 1 & 1,95 & 1,95 & 5,27 \\
\hline midazolam $5 \mathrm{mg} / \mathrm{ml}-3 \mathrm{ml}$ & & 3 & 3 & 0 & & & \\
\hline morfina $2 \mathrm{mg} / \mathrm{ml}-1 \mathrm{ml}$ & & 3 & 0 & 3 & 0,41 & 1,23 & 3,32 \\
\hline neostigmina $0,5 \mathrm{mg} / \mathrm{ml}-1 \mathrm{ml}$ & 29 & & 27 & 2 & 0,46 & 0,92 & 2,48 \\
\hline noradrenalina $1 \mathrm{mg} / \mathrm{ml}-4 \mathrm{ml}$ & 5 & & 2 & 3 & 1,67 & 5,01 & 13,53 \\
\hline petidina $50 \mathrm{mg} / \mathrm{ml}-2 \mathrm{ml}$ & & 3 & 3 & 0 & & & \\
\hline prometazina $25 \mathrm{mg} / \mathrm{ml}-2 \mathrm{ml}$ & 1 & & 1 & 0 & & & \\
\hline propofol $10 \mathrm{mg} / \mathrm{ml}-20 \mathrm{ml}$ & & 24 & 0 & 24 & 8,51 & 204,24 & 551,45 \\
\hline sulfato de magnésio $10 \%-10 \mathrm{ml}$ & 4 & & 4 & 0 & & & \\
\hline suxametônio $100 \mathrm{mg}$ & 2 & & 1 & 1 & 7,12 & 7,12 & 19,22 \\
\hline terbutalina $0,5 \mathrm{mg} / \mathrm{ml}-1 \mathrm{ml}$ & 9 & & 4 & 5 & 0,99 & 4,95 & 13,37 \\
\hline tenoxicam $20 \mathrm{mg}$ & 1 & & 1 & 0 & & & \\
\hline verde brilhante $100 \mathrm{mg} / \mathrm{ml}-1 \mathrm{ml}$ & 1 & & 1 & 0 & & & \\
\hline Total & 168 & 56 & 151 & 73 & 147,77 & 381,15 & 1029,12 \\
\hline
\end{tabular}


Tabela 17: Segundo dia de consumo na sala 26 fase pré implantação

SALA 26 - SEGUNDO DIA DE CONSUMO

\begin{tabular}{|c|c|c|c|c|c|c|c|}
\hline \multicolumn{8}{|c|}{ SALA 26 - SEGUNDO DIA DE CONSUMO } \\
\hline Medicamento & $\begin{array}{l}\text { Físico } \\
\text { Inicial }\end{array}$ & Extra & $\begin{array}{c}\text { Físico } \\
\text { Final }\end{array}$ & $\begin{array}{l}\text { Quantidade } \\
\text { Utilizada }\end{array}$ & $\begin{array}{c}\text { Preço } \\
\text { Unitário }\end{array}$ & $\begin{array}{l}\text { Preço } \\
\text { Final }\end{array}$ & $\begin{array}{c}\text { Valor em } \\
\text { dólar }\end{array}$ \\
\hline atropina $0,25 \mathrm{mg} / \mathrm{ml}-1 \mathrm{ml}$ & 30 & & 26 & 4 & 0,48 & 1,92 & 5,18 \\
\hline atropina $0,5 \mathrm{mg} / \mathrm{ml}-1 \mathrm{ml}$ & 23 & & 23 & 0 & & & \\
\hline cefalotina $1 \mathrm{~g}$ & 28 & & 26 & 2 & 1,53 & 3,06 & 8,26 \\
\hline cloreto de potássio $19,1 \%-10 \mathrm{ml}$ & 5 & & 5 & 0 & & & \\
\hline deslanosido $0,2 \mathrm{mg} / \mathrm{ml}-2 \mathrm{ml}$ & 1 & & 1 & 0 & & & \\
\hline dexametasona $4 \mathrm{mg} / \mathrm{ml}-1 \mathrm{ml}$ & 42 & & 42 & 0 & & & \\
\hline diazepam $5 \mathrm{mg} / \mathrm{ml}-2 \mathrm{ml}$ & & 2 & 2 & 0 & & & \\
\hline dipirona $500 \mathrm{mg} / \mathrm{ml}-2 \mathrm{ml}$ & 12 & & 9 & 3 & 0,16 & 0,48 & 1,3 \\
\hline epinefrina $1 \mathrm{mg} / \mathrm{ml}-1 \mathrm{ml}$ & 51 & & 49 & 2 & 0,15 & 0,3 & 0,81 \\
\hline etomidato $2 \mathrm{mg} / \mathrm{ml}-10 \mathrm{ml}$ & & 2 & 2 & 0 & & & \\
\hline $\begin{array}{l}\text { fentanila }+ \text { droperidol } \\
(0,05 \mathrm{mg}+2,5 \mathrm{mg}) / \mathrm{ml}-2 \mathrm{ml}\end{array}$ & & 4 & 4 & 0 & & & \\
\hline fentanil $0,05 \mathrm{mg} / \mathrm{ml}-5 \mathrm{ml}$ & & 8 & 0 & 8 & 1,8 & 14,4 & 38,9 \\
\hline gentamicina $40 \mathrm{mg} / \mathrm{ml}-1 \mathrm{ml}$ & 27 & & 27 & 0 & & & \\
\hline gentamicina $80 \mathrm{mg} / \mathrm{ml}-1 \mathrm{ml}$ & 2 & & 2 & 0 & & & \\
\hline isoprenalina $0,2 \mathrm{mg} / \mathrm{ml}-1 \mathrm{ml}$ & 5 & & 3 & 2 & 0,32 & 0,64 & 1,73 \\
\hline metilpredinisona $500 \mathrm{mg}$ & 1 & & 1 & 0 & & & \\
\hline metoclopramida $5 \mathrm{mg} / \mathrm{ml}-2 \mathrm{ml}$ & 5 & & 5 & 0 & & & \\
\hline midazolam $5 \mathrm{mg} / \mathrm{ml}-3 \mathrm{ml}$ & & 2 & 0 & 2 & 2,35 & 4,7 & 12,69 \\
\hline morfina $2 \mathrm{mg} / \mathrm{ml}-1 \mathrm{ml}$ & & 2 & 0 & 2 & 0,41 & 0,82 & 2,21 \\
\hline petidina $50 \mathrm{mg} / \mathrm{ml}-2 \mathrm{ml}$ & & 2 & 2 & 0 & & & \\
\hline propofol $10 \mathrm{mg} / \mathrm{ml}-20 \mathrm{ml}$ & & 7 & 2 & 5 & 8,51 & 42,55 & 114,89 \\
\hline ranitidina $10 \mathrm{mg} / \mathrm{ml}-5 \mathrm{ml}$ & 17 & & 16 & 1 & 0,18 & 0,18 & 0,49 \\
\hline $\begin{array}{l}\text { salbutamol spray } 100 \mathrm{mcg} / \mathrm{dose}- \\
200 \text { doses }\end{array}$ & 3 & & 3 & 0 & & & \\
\hline verapamil $2,5 \mathrm{mg} / \mathrm{ml}-2 \mathrm{ml}$ & 3 & & 2 & 1 & 0,67 & 0,67 & 1,81 \\
\hline Total & 255 & 29 & 252 & 32 & 16,56 & 69,72 & 188,27 \\
\hline
\end{tabular}


Tabela 18: Terceiro dia de consumo na sala 26 fase pré implantação

\begin{tabular}{|c|c|c|c|c|c|c|c|}
\hline \multicolumn{8}{|c|}{ SALA 26 - TERCEIRO DIA DE CONSUMO } \\
\hline Medicamento & $\begin{array}{l}\text { Físico } \\
\text { Inicial }\end{array}$ & Extra & $\begin{array}{l}\text { Físico } \\
\text { Final }\end{array}$ & $\begin{array}{l}\text { Quantidade } \\
\text { Utilizada }\end{array}$ & $\begin{array}{l}\text { Preço } \\
\text { Unitário }\end{array}$ & $\begin{array}{l}\text { Preço } \\
\text { Final }\end{array}$ & $\begin{array}{l}\text { Valor em } \\
\text { dólar }\end{array}$ \\
\hline água destilada $10 \mathrm{ml}$ & 20 & & 11 & 9 & 0,1 & 0,9 & 2,43 \\
\hline álcool etílico $96 \%$ - 10ml & 1 & & 1 & 0 & & & \\
\hline amicacina $50 \mathrm{mg} / \mathrm{ml}-2 \mathrm{ml}$ & 5 & & 4 & 1 & 0,49 & 0,49 & 1,32 \\
\hline amiodarona $50 \mathrm{mg} / \mathrm{ml}-3 \mathrm{ml}$ & 3 & & 2 & 1 & 0,74 & 0,74 & 2 \\
\hline ampicilina $1 \mathrm{~g}$ & 1 & & 1 & 0 & & & \\
\hline atropina $0,25 \mathrm{mg} / \mathrm{ml}-1 \mathrm{ml}$ & 18 & & 13 & 5 & 0,12 & 0,6 & 1,62 \\
\hline atropina $0,5 \mathrm{mg} / \mathrm{ml}-1 \mathrm{ml}$ & 31 & & 27 & 4 & 0,01 & 0,04 & 0,11 \\
\hline azul de metileno $1 \%-5 \mathrm{ml}$ & 2 & & 2 & 0 & & & \\
\hline bicarbonato de sódio $3 \%-20 \mathrm{ml}$ & 1 & & 1 & 0 & & & \\
\hline $\begin{array}{l}\text { bupivacaína com epinefrina } \\
(5 \mathrm{mg}+9,1 \mathrm{mcg}) / \mathrm{ml}-20 \mathrm{ml}\end{array}$ & 1 & & 1 & 0 & & & \\
\hline $\begin{array}{l}\text { bupivacaína sem epinefrina } 0,5 \% \text { - } \\
20 \mathrm{ml}\end{array}$ & 1 & & 1 & 0 & & & \\
\hline bupivacaína isobárica $0,5 \%$ - 20ml & 1 & & 1 & 0 & & & \\
\hline bupivacaína hiperbárica $0,5 \%-4 \mathrm{ml}$ & 1 & & 1 & 0 & & & \\
\hline cefalotina $1 \mathrm{~g}$ & 1 & & 1 & 0 & & & \\
\hline cloreto de potássio $19,1 \%-10 \mathrm{ml}$ & 5 & & 5 & 0 & & & \\
\hline cloreto de sódio $20 \%$ - $20 \mathrm{ml}$ & 2 & & 1 & 1 & 0,38 & 0,38 & 1,03 \\
\hline deslanosido $0,2 \mathrm{mg} / \mathrm{ml} \mathrm{-} 2 \mathrm{ml}$ & 2 & & 1 & 1 & 0,57 & 0,57 & 1,54 \\
\hline dexametasona $4 \mathrm{mg} / \mathrm{ml}-1 \mathrm{ml}$ & 40 & & 38 & 2 & 0,39 & 0,78 & 2,11 \\
\hline diazepam $5 \mathrm{mg} / \mathrm{ml}-2 \mathrm{ml}$ & & 2 & 2 & 0 & & & \\
\hline $\begin{array}{l}\text { dimenidrato+piridoxina }(50+50 \mathrm{mg}) / \\
\mathrm{ml}-1 \mathrm{ml}\end{array}$ & 1 & & 1 & 0 & & & \\
\hline dipirona $500 \mathrm{mg} / \mathrm{ml}-2 \mathrm{ml}$ & 30 & & 27 & 3 & 0,16 & 0,48 & 1,3 \\
\hline dobutamina $12,5 \mathrm{mg} / \mathrm{ml}-20 \mathrm{ml}$ & 3 & & 2 & 1 & 4,52 & 4,52 & 12,2 \\
\hline dopamina $5 \mathrm{mg} / \mathrm{ml}-10 \mathrm{ml}$ & 3 & & 1 & 2 & 0,34 & 0,68 & 1,84 \\
\hline efedrina $25 \mathrm{mg} / \mathrm{ml}-1 \mathrm{ml}$ & 22 & & 17 & 5 & 0,43 & 2,15 & 5,81 \\
\hline epinefrina $1 \mathrm{mg} / \mathrm{ml} 1 \mathrm{ml}$ & 52 & 4 & 54 & 2 & 0,15 & 0,3 & 0,81 \\
\hline esmolol $250 \mathrm{mg} / \mathrm{ml}-1 \mathrm{ml}$ & 2 & & 2 & 0 & & & \\
\hline etomidato $2 \mathrm{mg} / \mathrm{ml}-10 \mathrm{ml}$ & & 2 & 2 & 0 & & & \\
\hline $\begin{array}{l}\text { fentanila }+ \text { droperidol }(0,05 \mathrm{mg}+ \\
2,5 \mathrm{mg}) / \mathrm{ml}-2 \mathrm{ml}\end{array}$ & & 4 & 2 & 2 & 3,51 & 7,02 & 25,97 \\
\hline fentanil $0,05 \mathrm{mg} / \mathrm{ml}-5 \mathrm{ml}$ & & 6 & 0 & 6 & 1,8 & 10,8 & 29,16 \\
\hline furosemida $10 \mathrm{mg} / \mathrm{ml}-2 \mathrm{ml}$ & 29 & & 27 & 2 & 0,13 & 0,26 & 0,7 \\
\hline gentamicina $10 \mathrm{mg} / \mathrm{ml}-1 \mathrm{ml}$ & 27 & & 27 & 0 & & & \\
\hline gentamicina $40 \mathrm{mg} / \mathrm{ml}-1 \mathrm{ml}$ & 2 & & 2 & 0 & & & \\
\hline glicose $50 \%-10 \mathrm{ml}$ & 1 & & 1 & 0 & & & \\
\hline heparina IV 5.000UI - 5ml & 2 & & 2 & 0 & & & \\
\hline hidralazina $20 \mathrm{mg} / \mathrm{ml}-1 \mathrm{ml}$ & 5 & & 4 & 1 & 1,5 & 1,5 & 4,05 \\
\hline isoprenalina $0,2 \mathrm{mg} / \mathrm{ml}-1 \mathrm{ml}$ & 3 & & 3 & 0 & & & \\
\hline $\begin{array}{l}\text { lidocaína com epinefrina (20mg+ } \\
5 \mathrm{mcg}) / \mathrm{ml}-20 \mathrm{ml}\end{array}$ & 7 & & 6 & 1 & 0,68 & 0,68 & 1,84 \\
\hline lidocaína geléia $2 \%$ - 30ml & 11 & & 1 & 10 & 1,12 & 11,2 & 30,24 \\
\hline metaraminol $10 \mathrm{mg} / \mathrm{ml}-1 \mathrm{ml}$ & 3 & & 2 & 1 & 1,95 & 1,95 & 5,27 \\
\hline Metilpredinisona 500mg & 1 & & 1 & 0 & & & \\
\hline metoclopramida $5 \mathrm{mg} / \mathrm{ml}-2 \mathrm{ml}$ & 17 & & 16 & 1 & 0,15 & 0,15 & 0,41 \\
\hline midazolam $5 \mathrm{mg} / \mathrm{ml}-3 \mathrm{ml}$ & & 2 & 0 & 2 & 2,35 & 4,7 & 12,69 \\
\hline
\end{tabular}


SALA 26 - TERCEIRO DIA DE CONSUMO (continuação)

\begin{tabular}{l|c|c|c|c|c|c|c}
\hline Medicamento & $\begin{array}{c}\text { Físico } \\
\text { Inicial }\end{array}$ & Extra & $\begin{array}{c}\text { Físico } \\
\text { Final }\end{array}$ & $\begin{array}{c}\text { Quantidade } \\
\text { Utilizada }\end{array}$ & $\begin{array}{c}\text { Preço } \\
\text { Unitário }\end{array}$ & $\begin{array}{c}\text { Preço } \\
\text { Final }\end{array}$ & $\begin{array}{c}\text { Valor em } \\
\text { dólar }\end{array}$ \\
\hline morfina $2 \mathrm{mg} / \mathrm{ml}-1 \mathrm{ml}$ & & 2 & 2 & 0 & & & \\
\hline neostigmina $0,5 \mathrm{mg} / \mathrm{ml}-1 \mathrm{ml}$ & 15 & & 13 & 2 & 0,46 & 0,92 & 2,48 \\
\hline noradrenalina $1 \mathrm{mg} / \mathrm{ml}-4 \mathrm{ml}$ & 5 & & 1 & 4 & 1,67 & 6,68 & 18,04 \\
\hline petidina $50 \mathrm{mg} / \mathrm{ml}-2 \mathrm{ml}$ & & 2 & 2 & 0 & & & \\
\hline prometazina $25 \mathrm{mg} / \mathrm{ml}-2 \mathrm{ml}$ & 3 & & 1 & 2 & 0,29 & 0,58 & 1,57 \\
\hline propofol $10 \mathrm{mg} / \mathrm{ml}-20 \mathrm{ml}$ & & 4 & 1 & 3 & 8,51 & 25,53 & 68,93 \\
\hline ranitidina $10 \mathrm{mg} / \mathrm{ml}-5 \mathrm{ml}$ & 14 & & 10 & 4 & 0,18 & 0,72 & 1,94 \\
\hline salbutamol spray $100 \mathrm{mcg} / \mathrm{dose}-$ & 2 & & 2 & 0 & & & \\
200doses & 4 & & 3 & 1 & 0,43 & 0,43 & 1,16 \\
\hline sulfato de magnésio $10 \%-10 \mathrm{ml}$ & 9 & & 4 & 5 & 0,99 & 4,95 & 13,37 \\
\hline terbutalina $0,5 \mathrm{mg} / \mathrm{ml}-1 \mathrm{ml}$ & 1 & & 1 & 0 & & & \\
\hline tenoxicam $20 \mathrm{mg}$ & 3 & & 3 & 0 & & & \\
\hline verapamil 2,5mg/ml - 2ml & 1 & & 0 & 1 & 0,36 & 0,36 & 0,97 \\
\hline verde brilhante $100 \mathrm{mg} / \mathrm{ml}-1 \mathrm{ml}$ & $\mathbf{4 1 4}$ & $\mathbf{2 8}$ & $\mathbf{3 5 7}$ & $\mathbf{8 5}$ & $\mathbf{3 4 , 4 8}$ & $\mathbf{5 1 , 0 6}$ & $\mathbf{1 6 2 , 9 6}$ \\
\hline Total & & & & & &
\end{tabular}


Tabela 19: Primeiro dia de consumo na sala 27 fase pré implantação

SALA 27 - PRIMEIRO DIA DE CONSUMO

\begin{tabular}{|c|c|c|c|c|c|c|c|}
\hline \multicolumn{8}{|c|}{ DA DE CONSUMO } \\
\hline Medicamento & $\begin{array}{l}\text { Físico } \\
\text { Inicial }\end{array}$ & Extra & $\begin{array}{l}\text { Físico } \\
\text { Final }\end{array}$ & $\begin{array}{l}\text { Quantidade } \\
\text { Utilizada }\end{array}$ & $\begin{array}{c}\text { Preço } \\
\text { Unitário }\end{array}$ & $\begin{array}{l}\text { Preço } \\
\text { Final }\end{array}$ & $\begin{array}{l}\text { Valor em } \\
\text { dólar }\end{array}$ \\
\hline agua destilada $10 \mathrm{ml}$ & 15 & & 8 & 7 & 0,1 & 0,7 & 1,89 \\
\hline amicacina $50 \mathrm{mg} / \mathrm{ml}-2 \mathrm{ml}$ & 12 & & 12 & 0 & & & \\
\hline aminofilina $24 \mathrm{mg} / \mathrm{ml}-10 \mathrm{ml}$ & 1 & & 1 & 0 & & & \\
\hline amiodarona $50 \mathrm{mg} / \mathrm{ml}-3 \mathrm{ml}$ & 5 & & 5 & 0 & & & \\
\hline ampicilina $1 \mathrm{~g}$ & 1 & & 1 & 0 & & & \\
\hline atropina $0,25 \mathrm{mg} / \mathrm{ml}-1 \mathrm{ml}$ & 11 & & 11 & 0 & & & \\
\hline atropina $0,5 \mathrm{mg} / \mathrm{ml}-1 \mathrm{ml}$ & 20 & & 20 & 0 & & & \\
\hline bicarbonato de sodio $3 \%-20 \mathrm{ml}$ & 5 & & 5 & 0 & & & \\
\hline bicarbonato de sódio $10 \%-250 \mathrm{ml}$ & 3 & & 3 & 0 & & & \\
\hline $\begin{array}{l}\text { bupivacaína com epinefrina } \\
(5 \mathrm{mg}+9,1 \mathrm{mcg}) / \mathrm{ml}-20 \mathrm{ml}\end{array}$ & 2 & & 2 & 0 & & & \\
\hline $\begin{array}{l}\text { bupivacaína sem epinefrina } 0,5 \% \text { - } \\
20 \mathrm{ml}\end{array}$ & 3 & & 3 & 0 & & & \\
\hline bupivacaína hiperbárica $0,5 \%-4 \mathrm{ml}$ & 1 & & 1 & 0 & & & \\
\hline bupivacaína isobárica $0,5 \%-20 \mathrm{ml}$ & 3 & & 3 & 0 & & & \\
\hline cefalotina $1 \mathrm{~g}$ & 4 & & 4 & 0 & & & \\
\hline cimetidina & 1 & & 1 & 0 & & & \\
\hline cloranfenicol 1g & 3 & & 3 & 0 & & & \\
\hline cloreto de potássio $19,1 \%-10 \mathrm{ml}$ & 1 & & 1 & 0 & & & \\
\hline cloreto de sódio $20 \%$ - $20 \mathrm{ml}$ & 5 & & 5 & 0 & & & \\
\hline dexametasona $4 \mathrm{mg} / \mathrm{ml}-1 \mathrm{ml}$ & 25 & 30 & 51 & 4 & 0,39 & 1,56 & 4,21 \\
\hline diazepam $5 \mathrm{mg} / \mathrm{ml}-2 \mathrm{ml}$ & & 2 & 2 & 0 & & & \\
\hline dipirona $500 \mathrm{mg} / \mathrm{ml}-2 \mathrm{ml}$ & 14 & & 10 & 4 & 0,15 & 0,6 & 1,62 \\
\hline dopamina $5 \mathrm{mg} / \mathrm{ml}-10 \mathrm{ml}$ & 2 & & 2 & 0 & & & \\
\hline epinefrina $1 \mathrm{mg} / \mathrm{ml}-1 \mathrm{ml}$ & 23 & & 23 & 0 & & & \\
\hline escopolamina $20 \mathrm{mg} / \mathrm{ml}-1 \mathrm{ml}$ & 2 & & 2 & 0 & & & \\
\hline etomidato $2 \mathrm{mg} / \mathrm{ml}-10 \mathrm{ml}$ & & 2 & 2 & 0 & & & \\
\hline $\begin{array}{l}\text { fentanila }+ \text { droperidol }(0,05 \mathrm{mg}+ \\
2,5 \mathrm{mg}) / \mathrm{ml}-2 \mathrm{ml}\end{array}$ & & 4 & 4 & 0 & & & \\
\hline fentanil $0,05 \mathrm{mg} / \mathrm{ml}-5 \mathrm{ml}$ & & 6 & 3 & 3 & 1,8 & 5,4 & 14,58 \\
\hline furosemida $10 \mathrm{mg} / \mathrm{ml}-2 \mathrm{ml}$ & 4 & 4 & 4 & 4 & 0,13 & 0,52 & 1,4 \\
\hline gentamicina $10 \mathrm{mg} / \mathrm{ml}-1 \mathrm{ml}$ & 2 & & 2 & 0 & & & \\
\hline gentamicina $40 \mathrm{mg} / \mathrm{ml}-1 \mathrm{ml}$ & 14 & & 14 & 0 & & & \\
\hline gentamicina $80 \mathrm{mg} / \mathrm{ml}-1 \mathrm{ml}$ & 12 & 2 & 14 & 0 & & & \\
\hline heparina 5.000ui $-0,25 \mathrm{ml}$ & 6 & & 1 & 5 & 0,74 & 3,7 & 9,99 \\
\hline heparina IV 5.000UI $-5 \mathrm{ml}$ & 6 & & 6 & 0 & & & \\
\hline hidralazina $20 \mathrm{mg} / \mathrm{ml}-1 \mathrm{ml}$ & 10 & 6 & 8 & 8 & 1,5 & 12 & 32,4 \\
\hline hidrocortisona $100 \mathrm{mg}$ & 1 & & 1 & 0 & & & \\
\hline hidrocortisona 500mg & 4 & & 3 & 1 & 2,88 & 2,88 & 7,78 \\
\hline isoprenalina $0,2 \mathrm{mg} / \mathrm{ml}-1 \mathrm{ml}$ & 5 & & 5 & 0 & & & \\
\hline lidocaína sem epinefrina $2 \%$ - $20 \mathrm{ml}$ & 2 & & 2 & 0 & & & \\
\hline $\begin{array}{l}\text { lidocaína com epinefrina (20mg+ } \\
5 \mathrm{mcg}) / \mathrm{ml}-20 \mathrm{ml}\end{array}$ & 9 & & 8 & 1 & 0,68 & 0,68 & 1,84 \\
\hline metoclopramida $5 \mathrm{mg} / \mathrm{ml}-2 \mathrm{ml}$ & 15 & & 11 & 4 & 0,15 & 0,6 & 1,62 \\
\hline midazolam $5 \mathrm{mg} / \mathrm{ml}-3 \mathrm{ml}$ & & 2 & 0 & 2 & 2,35 & 4,7 & 12,69 \\
\hline morfina $2 \mathrm{mg} / \mathrm{ml}-1 \mathrm{ml}$ & & 2 & 2 & 0 & & & \\
\hline
\end{tabular}


SALA 27 - PRIMEIRO DIA DE CONSUMO (continuação)

\begin{tabular}{l|c|c|c|c|c|c|c}
\hline Medicamento & $\begin{array}{c}\text { Físico } \\
\text { Inicial }\end{array}$ & Extra & $\begin{array}{c}\text { Físico } \\
\text { Final }\end{array}$ & $\begin{array}{c}\text { Quantidade } \\
\text { Utilizada }\end{array}$ & $\begin{array}{c}\text { Preço } \\
\text { Unitário }\end{array}$ & $\begin{array}{c}\text { Preço } \\
\text { Final }\end{array}$ & $\begin{array}{c}\text { Valor em } \\
\text { dólar }\end{array}$ \\
\hline neostigmina $0,5 \mathrm{mg} / \mathrm{ml}-1 \mathrm{ml}$ & 6 & & 6 & 0 & & & \\
\hline noradrenalina $1 \mathrm{mg} / \mathrm{ml}-4 \mathrm{ml}$ & 12 & & 12 & 0 & & & \\
\hline petidina $50 \mathrm{mg} / \mathrm{ml}-2 \mathrm{ml}$ & & 2 & 2 & 0 & & & \\
\hline prometazina $25 \mathrm{mg} / \mathrm{ml}-2 \mathrm{ml}$ & 5 & 1 & 5 & 1 & 0,29 & 0,29 & 0,78 \\
\hline propofol $10 \mathrm{mg} / \mathrm{ml}-20 \mathrm{ml}$ & & 4 & 1 & 3 & 8,51 & 25,53 & 68,93 \\
\hline protamina $10 \mathrm{mg} / \mathrm{ml}-5 \mathrm{ml}$ & 5 & & 5 & 0 & & & \\
\hline ranitidina $10 \mathrm{mg} / \mathrm{ml}-5 \mathrm{ml}$ & 6 & & 5 & 1 & 0,18 & 0,18 & 0,49 \\
\hline Salbutamol $0,5 \mathrm{mg} / \mathrm{ml}-1 \mathrm{ml}$ & 5 & & 5 & 0 & & & \\
\hline $\begin{array}{l}\text { sulfametoxazol+ } \\
\text { trimetropina(400+800mg)-5ml }\end{array}$ & 5 & & 4 & 1 & 0,56 & 0,56 & 1,51 \\
\hline suxametônio $100 \mathrm{mg}$ & & 1 & & 1 & 7,12 & 7,12 & 19,22 \\
\hline tetracaína colírio $0,5 \%-10 \mathrm{ml}$ & 1 & & 1 & 0 & & & \\
\hline vaselina $20 \mathrm{ml}$ & 1 & & 1 & 0 & & & \\
\hline verapamil $2,5 \mathrm{mg} / \mathrm{ml}-2 \mathrm{ml}$ & 6 & & 5 & 1 & 0,67 & 0,67 & 1,81 \\
\hline verde brilhante $100 \mathrm{mg} / \mathrm{ml}-1 \mathrm{ml}$ & 4 & & 4 & 0 & & & \\
\hline Vit A e D colírio - $10 \mathrm{ml}$ & 1 & & 1 & 0 & & &
\end{tabular}


Tabela 20: Segundo dia de consumo na sala 27 fase pré implantação

SALA 27 - SEGUNDO DIA DE CONSUMO

\begin{tabular}{|c|c|c|c|c|c|c|c|}
\hline \\
\hline Medicamento & $\begin{array}{l}\text { Físico } \\
\text { Inicial }\end{array}$ & Extra & $\begin{array}{l}\text { Físico } \\
\text { Final }\end{array}$ & $\begin{array}{l}\text { Quantidade } \\
\text { Utilizada }\end{array}$ & $\begin{array}{c}\text { Preço } \\
\text { Unitário }\end{array}$ & $\begin{array}{l}\text { Preço } \\
\text { Final }\end{array}$ & $\begin{array}{l}\text { Valor em } \\
\text { dólar }\end{array}$ \\
\hline agua destilada $10 \mathrm{ml}$ & 6 & & 5 & 1 & 0,1 & 0,1 & 0,27 \\
\hline álcool etílico $96 \%$ - 10ml & 2 & & 2 & 0 & & & \\
\hline amicacina $50 \mathrm{mg} / \mathrm{ml}-2 \mathrm{ml}$ & 17 & & 11 & 6 & 0,49 & 2,94 & 7,94 \\
\hline aminofilina $24 \mathrm{mg} / \mathrm{ml}-10 \mathrm{ml}$ & 2 & & 1 & 1 & 0,01 & 0,05 & 0,14 \\
\hline Amiodarona $50 \mathrm{mg} / \mathrm{ml}-3 \mathrm{ml}$ & 5 & & 5 & 0 & & & \\
\hline ampicilina $1 \mathrm{~g}$ & 1 & & 1 & 0 & & & \\
\hline atropina $0,25 \mathrm{mg} / \mathrm{ml}-1 \mathrm{ml}$ & 25 & 7 & 11 & 21 & 0,12 & 2,52 & 6,8 \\
\hline atropina $0,5 \mathrm{mg} / \mathrm{ml}-1 \mathrm{ml}$ & 39 & 8 & 20 & 27 & 0,01 & 0,27 & 0,73 \\
\hline azul de metileno $1 \%-5 \mathrm{ml}$ & & 2 & 0 & 2 & 1,02 & 2,04 & 5,51 \\
\hline bicarbonato de sódio $3 \%-20 \mathrm{ml}$ & 6 & & 5 & 1 & 0,63 & 0,63 & 1,7 \\
\hline bicarbonato de sódio $10 \%-250 \mathrm{ml}$ & 3 & & 3 & 0 & & & \\
\hline bupivacaína isobárica $0,5 \%-20 \mathrm{ml}$ & 2 & & 2 & 0 & & & \\
\hline bupivacaína hiperbárica $0,5 \%$ - $4 \mathrm{ml}$ & 11 & & 7 & 4 & 3,59 & 14,36 & 38,77 \\
\hline $\begin{array}{l}\text { bupivacaína com epinefrina } \\
(5 \mathrm{mg}+9,1 \mathrm{mcg}) / \mathrm{ml}-20 \mathrm{ml}\end{array}$ & 5 & 2 & 3 & 4 & 3,98 & 15,92 & 42,98 \\
\hline $\begin{array}{l}\text { bupivacaína sem epinefrina } 0,5 \% \text { - } \\
20 \mathrm{ml}\end{array}$ & 6 & & 3 & 3 & 4 & 12 & 44,4 \\
\hline cefalotina $1 \mathrm{~g}$ & 4 & 2 & 4 & 2 & 1,53 & 3,06 & 8,26 \\
\hline cetoprofeno $50 \mathrm{mg} / \mathrm{ml}-2 \mathrm{ml}$ & 1 & 1 & 1 & 1 & 3,43 & 3,43 & 9,26 \\
\hline cloreto de cálcio $100 \mathrm{mg} / \mathrm{ml}-5 \mathrm{ml}$ & 2 & & 1 & 1 & 0,38 & 0,38 & 1,03 \\
\hline cloreto de potássio $19,1 \%-10 \mathrm{ml}$ & 2 & & 1 & 1 & 0,2 & 0,2 & 0,54 \\
\hline cloreto de sódio $20 \%$ - $20 \mathrm{ml}$ & 11 & & 10 & 1 & 0,38 & 0,38 & 1,03 \\
\hline dexametasona $4 \mathrm{mg} / \mathrm{ml}$ - $1 \mathrm{ml}$ & 35 & 2 & 21 & 16 & 0,39 & 6,24 & 16,85 \\
\hline diazepam $5 \mathrm{mg} / \mathrm{ml}-2 \mathrm{ml}$ & & 4 & 4 & 0 & & & \\
\hline dipirona $500 \mathrm{mg} / \mathrm{ml} \mathrm{-} 2 \mathrm{ml}$ & 14 & 12 & 7 & 19 & 0,16 & 3,04 & 8,21 \\
\hline dopamina $5 \mathrm{mg} / \mathrm{ml}-10 \mathrm{ml}$ & 3 & 2 & 4 & 1 & 0,34 & 0,34 & 0,92 \\
\hline efedrina $25 \mathrm{mg} / \mathrm{ml}-1 \mathrm{ml}$ & 21 & & 13 & 8 & 0,43 & 3,44 & 9,3 \\
\hline epinefrina $1 \mathrm{mg} / \mathrm{ml} 1 \mathrm{ml}$ & 36 & 21 & 26 & 31 & 0,15 & 4,65 & 12,56 \\
\hline escopolamina $20 \mathrm{mg} / \mathrm{ml}-1 \mathrm{ml}$ & 6 & & 2 & 4 & 0,72 & 2,88 & 7,78 \\
\hline etomidato $2 \mathrm{mg} / \mathrm{ml}-10 \mathrm{ml}$ & & 4 & 2 & 2 & 3,18 & 6,36 & 17,17 \\
\hline $\begin{array}{l}\text { fentanila + droperidol } \\
(0,05 \mathrm{mg}+2,5 \mathrm{mg}) / \mathrm{ml}-2 \mathrm{ml}\end{array}$ & & 8 & 5 & 3 & 2,35 & 7,05 & 19,04 \\
\hline fentanil $0,05 \mathrm{mg} / \mathrm{ml}-5 \mathrm{ml}$ & & 12 & 0 & 12 & 1,8 & 21,6 & 58,32 \\
\hline fitomenadiona $10 \mathrm{mg} / \mathrm{ml}-1 \mathrm{ml}$ & 1 & & 1 & 0 & & & \\
\hline furosemida $10 \mathrm{mg} / \mathrm{ml}-2 \mathrm{ml}$ & 12 & & 6 & 6 & 0,13 & 0,78 & 2,11 \\
\hline gentamicina colírio $20 \mathrm{mg} / \mathrm{ml}-10 \mathrm{ml}$ & 1 & 2 & 1 & 2 & 1,34 & 2,68 & 7,24 \\
\hline gentamicina $10 \mathrm{mg} / \mathrm{ml}-1 \mathrm{ml}$ & 19 & & 13 & 6 & 0,36 & 2,16 & 5,83 \\
\hline gentamicina $40 \mathrm{mg} / \mathrm{ml}-1 \mathrm{ml}$ & 7 & & 4 & 3 & 0,19 & 0,57 & 1,54 \\
\hline glicose $50 \%-10 \mathrm{ml}$ & 2 & & 1 & 1 & 0,16 & 0,16 & 0,43 \\
\hline heparina IV 5.000UI - 5ml & 6 & & 6 & 0 & & & \\
\hline heparina $5.000 \mathrm{UI}-0,25 \mathrm{ml}$ & 6 & & 6 & 0 & & & \\
\hline hidrocortisona $100 \mathrm{mg}$ & 2 & 8 & 8 & 2 & 0,89 & 1,78 & 4,81 \\
\hline hidrocortisona $500 \mathrm{mg}$ & 17 & & 6 & 11 & 2,88 & 31,68 & 85,54 \\
\hline isoprenalina $0,2 \mathrm{mg} / \mathrm{ml}-1 \mathrm{ml}$ & 7 & & 5 & 2 & 0,32 & 0,64 & 1,73 \\
\hline $\begin{array}{l}\text { lidocaína com epinefrina (20mg+ } \\
5 \mathrm{mcg}) / \mathrm{ml}-20 \mathrm{ml}\end{array}$ & 7 & 4 & 6 & 5 & 0,68 & 3,4 & 9,18 \\
\hline
\end{tabular}


SALA 27 - SEGUNDO DIA DE CONSUMO (continuação)

\begin{tabular}{|c|c|c|c|c|c|c|c|}
\hline Medicamento & $\begin{array}{l}\text { Físico } \\
\text { Inicial }\end{array}$ & Extra & $\begin{array}{l}\text { Físico } \\
\text { Final }\end{array}$ & $\begin{array}{l}\text { Quantidade } \\
\text { Utilizada }\end{array}$ & $\begin{array}{l}\text { Preço } \\
\text { Unitário }\end{array}$ & $\begin{array}{l}\text { Preço } \\
\text { Final }\end{array}$ & $\begin{array}{l}\text { Valor em } \\
\text { dólar }\end{array}$ \\
\hline metaraminol $10 \mathrm{mg} / \mathrm{ml}-1 \mathrm{ml}$ & 1 & & 1 & 0 & & & \\
\hline metoclopramida $5 \mathrm{mg} / \mathrm{ml}-2 \mathrm{ml}$ & 15 & 10 & 8 & 17 & 0,15 & 2,55 & 6,89 \\
\hline midazolam $5 \mathrm{mg} / \mathrm{ml}-3 \mathrm{ml}$ & & 4 & 0 & 4 & 2,35 & 9,4 & 25,38 \\
\hline morfina $2 \mathrm{mg} / \mathrm{ml}-1 \mathrm{ml}$ & & 4 & 2 & 2 & 0,81 & 1,62 & 4,37 \\
\hline neostigmina $0,5 \mathrm{mg} / \mathrm{ml}-1 \mathrm{ml}$ & 23 & 10 & 8 & 25 & 0,46 & 11,5 & 31,05 \\
\hline noradrenalina $1 \mathrm{mg} / \mathrm{ml}-4 \mathrm{ml}$ & 6 & & 6 & 0 & & & \\
\hline papaverina $50 \mathrm{mg} / \mathrm{ml}-2 \mathrm{ml}$ & 4 & & 4 & 0 & & & \\
\hline petidina $50 \mathrm{mg} / \mathrm{ml}-2 \mathrm{ml}$ & & 4 & 2 & 2 & 0,18 & 0,36 & 0,97 \\
\hline prometazina $25 \mathrm{mg} / \mathrm{ml} \mathrm{-} 2 \mathrm{ml}$ & 4 & & 4 & 0 & & & \\
\hline propofol $10 \mathrm{mg} / \mathrm{ml}-20 \mathrm{ml}$ & & 19 & 3 & 16 & 3,51 & 56,16 & 151,63 \\
\hline protamina $10 \mathrm{mg} / \mathrm{ml}-5 \mathrm{ml}$ & 9 & & 9 & 0 & & & \\
\hline ranitidina $10 \mathrm{mg} / \mathrm{ml}-5 \mathrm{ml}$ & 11 & 2 & 6 & 7 & 0,18 & 1,26 & 3,4 \\
\hline rocuronio $10 \mathrm{mg} / \mathrm{ml}-5 \mathrm{ml}$ & 1 & & 1 & 0 & & & \\
\hline $\begin{array}{l}\text { salbutamol spray } 100 \mathrm{mcg} / \text { dose - } \\
\text { 200doses }\end{array}$ & 2 & & 2 & 0 & & & \\
\hline salbutamol $0,5 \mathrm{mg} / \mathrm{ml}-1 \mathrm{ml}$ & 5 & & 5 & 0 & & & \\
\hline $\begin{array}{l}\text { sulfametoxazol+trimetropina }(400+8 \\
0 \mathrm{mg})-5 \mathrm{ml}\end{array}$ & 5 & & 5 & 0 & & & \\
\hline suxametônio $100 \mathrm{mg}$ & 4 & & 3 & 1 & 7,12 & 7,12 & 19,22 \\
\hline tetracaína colírio $0,5 \%-10 \mathrm{ml}$ & 1 & & 1 & 0 & & & \\
\hline vaselina $20 \mathrm{ml}$ & 1 & & 1 & 0 & & & \\
\hline verapamil $2,5 \mathrm{mg} / \mathrm{ml}-2 \mathrm{ml}$ & 3 & & 3 & 0 & & & \\
\hline verde brilhante $100 \mathrm{mg} / \mathrm{ml}-1 \mathrm{ml}$ & 7 & 2 & 3 & 6 & 0,36 & 2,16 & 5,83 \\
\hline vit A e D colírio $-10 \mathrm{ml}$ & 2 & & 2 & 0 & & & \\
\hline vitamina $\mathrm{K} 35 \mathrm{mg} / \mathrm{ml}-1 \mathrm{ml}$ & 2 & & 0 & 2 & 0,56 & 1,12 & 3,02 \\
\hline Total & 460 & 156 & 322 & 302 & 52,02 & 250,62 & 689,64 \\
\hline
\end{tabular}


Tabela 21: Terceiro dia de consumo na sala 27 fase pré implantação

SALA 27 - TERCEIRO DIA DE CONSUMO

\begin{tabular}{|c|c|c|c|c|c|c|c|}
\hline \\
\hline Medicamento & $\begin{array}{l}\text { Físico } \\
\text { Inicial }\end{array}$ & Extra & $\begin{array}{r}\text { Físico } \\
\text { Final }\end{array}$ & \begin{tabular}{|c|} 
Quantidade \\
Utilizada \\
\end{tabular} & \begin{tabular}{|c|} 
Preço \\
Unitário
\end{tabular} & $\begin{array}{r}\text { Preço } \\
\text { Final }\end{array}$ & $\begin{array}{l}\text { Valor em } \\
\text { dólar }\end{array}$ \\
\hline agua destilada $10 \mathrm{ml}$ & 5 & & 0 & 5 & 0,1 & 0,5 & 1,35 \\
\hline amicacina $50 \mathrm{mg} / \mathrm{ml}-2 \mathrm{ml}$ & 11 & & 11 & 0 & & & \\
\hline amido hidroxietílico $6 \%-500 \mathrm{ml}$ & 8 & & 7 & 1 & 27,64 & 27,64 & 74,63 \\
\hline aminofilina $24 \mathrm{mg} / \mathrm{ml}-10 \mathrm{ml}$ & 1 & & 1 & 0 & & & \\
\hline Amiodarona $50 \mathrm{mg} / \mathrm{ml}-3 \mathrm{ml}$ & 5 & & 5 & 0 & & & \\
\hline ampicilina $1 \mathrm{~g}$ & 1 & & 1 & 0 & & & \\
\hline atropina $0, .25 \mathrm{mg} / \mathrm{ml}-1 \mathrm{ml}$ & 9 & & 4 & 5 & 0,12 & 0,6 & 1,62 \\
\hline atropina $0,5 \mathrm{mg} / \mathrm{ml}-1 \mathrm{ml}$ & 20 & & 15 & 5 & 0,01 & 0,05 & 0,14 \\
\hline bicarbonato de sódio $3 \%-20 \mathrm{ml}$ & 5 & & 5 & 0 & & & \\
\hline bicarbonato de sódio $10 \%-250 \mathrm{ml}$ & 3 & & 3 & 0 & & & \\
\hline bupivacaína isobárica $0,5 \%$ - $20 \mathrm{ml}$ & 2 & & 2 & 0 & & & \\
\hline bupivacaína hiperbárica $0,5 \%$ - $4 \mathrm{ml}$ & 3 & 1 & 2 & 2 & 3,59 & 7,18 & 19,39 \\
\hline $\begin{array}{l}\text { bupivacaína com epinefrina } \\
(5 \mathrm{mg}+9,1 \mathrm{mcg}) / \mathrm{ml}-20 \mathrm{ml}\end{array}$ & 2 & & 2 & 0 & & & \\
\hline $\begin{array}{l}\text { bupivacaína sem epinefrina } 0,5 \% \text { - } \\
20 \mathrm{ml}\end{array}$ & 3 & & 3 & 0 & & & \\
\hline cefalotina $1 \mathrm{~g}$ & 6 & & 5 & 1 & 1,53 & 1,53 & 4,13 \\
\hline cetoprofeno $50 \mathrm{mg} / \mathrm{ml}-2 \mathrm{ml}$ & & 1 & 0 & 1 & 3,43 & 3,43 & 9,26 \\
\hline cloreto de potássio $19,1 \%-10 \mathrm{ml}$ & 1 & & 1 & 0 & & & \\
\hline cloreto de sódio $20 \%$ - $20 \mathrm{ml}$ & 5 & & 5 & 0 & & & \\
\hline dexametasona $4 \mathrm{mg} / \mathrm{ml} \mathrm{-} 1 \mathrm{ml}$ & 22 & & 22 & 0 & & & \\
\hline diazepam $5 \mathrm{mg} / \mathrm{ml}-2 \mathrm{ml}$ & & 2 & 2 & 0 & & & \\
\hline dipirona $500 \mathrm{mg} / \mathrm{ml}-2 \mathrm{ml}$ & 13 & & 11 & 2 & 0,16 & 0,32 & 0,86 \\
\hline dopamina $5 \mathrm{mg} / \mathrm{ml}-10 \mathrm{ml}$ & 2 & & 2 & 0 & & & \\
\hline efedrina $25 \mathrm{mg} / \mathrm{ml}-1 \mathrm{ml}$ & 13 & & 13 & 0 & & & \\
\hline epinefrina $1 \mathrm{mg} / \mathrm{ml}-1 \mathrm{ml}$ & 20 & & 6 & 14 & 0,15 & 2,1 & 5,67 \\
\hline escopolamina $20 \mathrm{mg} / \mathrm{ml}-1 \mathrm{ml}$ & 2 & & 2 & 0 & & & \\
\hline etomidato $2 \mathrm{mg} / \mathrm{ml}-10 \mathrm{ml}$ & & 2 & 2 & 0 & & & \\
\hline $\begin{array}{l}\text { fentanila }+ \\
\text { droperidol }(0,05 \mathrm{mg}+2,5 \mathrm{mg}) / \mathrm{ml}-2 \mathrm{ml}\end{array}$ & & 4 & 4 & 0 & & & \\
\hline Fentanil $0,05 \mathrm{mg} / \mathrm{ml}-5 \mathrm{ml}$ & & 6 & 6 & 0 & & & \\
\hline furosemida $10 \mathrm{mg} / \mathrm{ml}-2 \mathrm{ml}$ & 6 & & 5 & 1 & 0,13 & 0,13 & 0,35 \\
\hline gentamicina $10 \mathrm{mg} / \mathrm{ml}-1 \mathrm{ml}$ & 2 & & 2 & 0 & & & \\
\hline gentamicina $40 \mathrm{mg} / \mathrm{ml}-1 \mathrm{ml}$ & 13 & & 12 & 1 & 0,19 & 0,19 & 0,51 \\
\hline Heparina 5000UI - 0,25ml & 6 & & 6 & 0 & & & \\
\hline heparina IV 5.000UI - 5ml & 8 & & 7 & 1 & 3,45 & 3,45 & 9,32 \\
\hline hidralazina $20 \mathrm{mg} / \mathrm{ml}-1 \mathrm{ml}$ & 10 & & 10 & 0 & & & \\
\hline hidrocortisona $500 \mathrm{mg}$ & 3 & & 2 & 1 & 2,88 & 2,88 & 7,78 \\
\hline isoprenalina $0,2 \mathrm{mg} / \mathrm{ml}-1 \mathrm{ml}$ & 5 & & 5 & 0 & & & \\
\hline lidocaína geléia $2 \%$ - 30ml & & 2 & 0 & 2 & 1,12 & 2,24 & 6,05 \\
\hline $\begin{array}{l}\text { lidocaína com } \\
\text { epinefrina }(20 \mathrm{mg}+5 \mathrm{mcg}) / \mathrm{ml}-20 \mathrm{ml}\end{array}$ & 6 & & 6 & 0 & & & \\
\hline midazolam $5 \mathrm{mg} / \mathrm{ml}-3 \mathrm{ml}$ & & 2 & 0 & 2 & 2,35 & 4,7 & 12,69 \\
\hline morfina $2 \mathrm{mg} / \mathrm{ml}-1 \mathrm{ml}$ & & 2 & 0 & 2 & 0,41 & 0,82 & 2,21 \\
\hline neostigmina $0,5 \mathrm{mg} / \mathrm{ml}-1 \mathrm{ml}$ & 6 & & 6 & 0 & & & \\
\hline noradrenalina $1 \mathrm{mg} / \mathrm{ml}-4 \mathrm{ml}$ & 10 & & 9 & 1 & 1,67 & 1,67 & 4,5 \\
\hline
\end{tabular}


SALA 27 - TERCEIRO DIA DE CONSUMO (continuação)

\begin{tabular}{l|c|c|c|c|c|c|c}
\hline Medicamento & $\begin{array}{c}\text { Físico } \\
\text { Inicial }\end{array}$ & Extra & $\begin{array}{c}\text { Físico } \\
\text { Final }\end{array}$ & $\begin{array}{c}\text { Quantidade } \\
\text { Utilizada }\end{array}$ & $\begin{array}{c}\text { Preço } \\
\text { Unitário }\end{array}$ & $\begin{array}{c}\text { Preço } \\
\text { Final }\end{array}$ & $\begin{array}{c}\text { Valor em } \\
\text { dólar }\end{array}$ \\
\hline petidina $50 \mathrm{mg} / \mathrm{ml}-2 \mathrm{ml}$ & & 2 & 2 & 0 & & & \\
\hline prometazina $25 \mathrm{mg} / \mathrm{ml}-2 \mathrm{ml}$ & 4 & & 1 & 3 & 0,29 & 0,87 & 2,35 \\
\hline propofol $10 \mathrm{mg} / \mathrm{ml}-20 \mathrm{ml}$ & & 4 & 2 & 2 & 8,51 & 17,02 & 45,95 \\
\hline protamina $10 \mathrm{mg} / \mathrm{ml}-5 \mathrm{ml}$ & 5 & & 5 & 0 & & & \\
\hline ranitidina $10 \mathrm{mg} / \mathrm{ml}-5 \mathrm{ml}$ & 3 & & 3 & 0 & & & \\
\hline salbutamol 0,5mg/ml - 1ml & 5 & & 5 & 0 & & & \\
\hline $\begin{array}{l}\text { sulfametoxazol+trimetropina(400+8 } \\
\text { 00mg)/ }\end{array}$ & 5 & & 5 & 0 & & & \\
\hline tetracaína colírio 0,5\% - 10ml & 1 & & 1 & 0 & & & \\
\hline vaselina 20ml & 1 & & 1 & 0 & & & \\
\hline verapamil 2,5mg/ml - 2ml & 3 & & 1 & 2 & 0,67 & 1,34 & 3,62 \\
\hline verde brilhante $100 \mathrm{mg} / \mathrm{ml} \mathrm{-} \mathrm{1ml}$ & 4 & & 3 & 1 & 0,36 & 0,36 & 0,97 \\
\hline vit A e D colírio & 1 & & 1 & 0 & & & \\
\hline Total & $\mathbf{2 6 9}$ & $\mathbf{2 8}$ & $\mathbf{2 4 2}$ & $\mathbf{5 5}$ & $\mathbf{5 8 , 7 6}$ & $\mathbf{7 9 , 0 2}$ & $\mathbf{2 1 3 , 3 5}$ \\
\hline
\end{tabular}


Tabela 22: Primeiro dia de consumo na sala 28 fase pré implantação

SALA 28 - PRIMERO DIA DE CONSUMO

\begin{tabular}{|c|c|c|c|c|c|c|c|}
\hline & & & & & & & \\
\hline Medicamento & $\begin{array}{l}\text { Físico } \\
\text { Inicial }\end{array}$ & Extra & $\begin{array}{l}\text { Físico } \\
\text { Final }\end{array}$ & $\begin{array}{l}\text { Quantidade } \\
\text { Utilizada }\end{array}$ & $\begin{array}{c}\text { Preço } \\
\text { Unitário }\end{array}$ & $\begin{array}{l}\text { Preço } \\
\text { Final }\end{array}$ & $\begin{array}{l}\text { Valor em } \\
\text { dólar }\end{array}$ \\
\hline agua destilada $10 \mathrm{ml}$ & 14 & & 10 & 4 & 0,1 & 0,4 & 1,08 \\
\hline aminofilina $24 \mathrm{mg} / \mathrm{ml}-10 \mathrm{ml}$ & 12 & & 11 & 1 & 0,01 & 0,05 & 0,14 \\
\hline amiodarona $50 \mathrm{mg} / \mathrm{ml} \mathrm{-} 3 \mathrm{ml}$ & 2 & & 2 & 0 & & & \\
\hline atropina $0,25 \mathrm{mg} / \mathrm{ml}-1 \mathrm{ml}$ & 10 & & 7 & 3 & 0,12 & 0,36 & 0,97 \\
\hline atropina $0,5 \mathrm{mg} / \mathrm{ml}-1 \mathrm{ml}$ & 9 & & 9 & 0 & & & \\
\hline azul de metileno $1 \%-5 \mathrm{ml}$ & 9 & & 7 & 2 & 1,02 & 2,04 & 5,51 \\
\hline bicarbonato de sódio $3 \%$ - 20ml & 5 & & 4 & 1 & 0,63 & 0,63 & 1,7 \\
\hline bicarbonato de sódio $10 \%-250 \mathrm{ml}$ & 1 & & 1 & 0 & & & \\
\hline bupivacaína hiperbárica $0,5 \%$ - $4 \mathrm{ml}$ & 1 & & 1 & 0 & & & \\
\hline $\begin{array}{l}\text { bupivacaína com epinefrina } \\
(5 \mathrm{mg}+9,1 \mathrm{mcg}) / \mathrm{ml}-20 \mathrm{ml}\end{array}$ & 3 & & 0 & 3 & 3,98 & 11,94 & 32,24 \\
\hline $\begin{array}{l}\text { bupivacaína sem epinefrina } 0,5 \% \text { - } \\
20 \mathrm{ml}\end{array}$ & 3 & & 3 & 0 & & & \\
\hline cefalotina $1 \mathrm{~g}$ & 4 & & 2 & 2 & 1,53 & 3,06 & 8,26 \\
\hline cloranfenicol 1g & 7 & & 6 & 1 & 0,93 & 0,93 & 2,51 \\
\hline cloreto de cálcio $100 \mathrm{mg} / \mathrm{ml}-5 \mathrm{ml}$ & 3 & & 3 & 0 & & & \\
\hline cloreto de potássio $19,1 \%-10 \mathrm{ml}$ & 7 & & 7 & 0 & & & \\
\hline Deslanosideo $0,2 \mathrm{mg} / \mathrm{ml}-2 \mathrm{ml}$ & 1 & & 1 & 0 & & & \\
\hline dexametasona $4 \mathrm{mg} / \mathrm{ml}-1 \mathrm{ml}$ & 10 & & 10 & 0 & & & \\
\hline diazepam $5 \mathrm{mg} / \mathrm{ml}-2 \mathrm{ml}$ & & 1 & 1 & 0 & & & \\
\hline diclofenaco $25 \mathrm{mg} / \mathrm{ml}-3 \mathrm{ml}$ & 1 & & 1 & 0 & & & \\
\hline $\begin{array}{l}\text { dimenidrato+piridoxina } \\
(50 \mathrm{mg}+50 \mathrm{mg}) / 1 \mathrm{ml}\end{array}$ & 7 & & 1 & 6 & 1 & 6 & 16,2 \\
\hline dipirona $500 \mathrm{mg} / \mathrm{ml}-2 \mathrm{ml}$ & 4 & & 3 & 1 & 0,16 & 0,16 & 0,43 \\
\hline dobutamina $12,5 \mathrm{mg} / \mathrm{ml}-20 \mathrm{ml}$ & 4 & & 1 & 3 & 4,52 & 13,56 & 36,61 \\
\hline dopamina $5 \mathrm{mg} / \mathrm{ml}-10 \mathrm{ml}$ & 8 & & 8 & 0 & & & \\
\hline efedrina $25 \mathrm{mg} / \mathrm{ml}-1 \mathrm{ml}$ & 2 & & 2 & 0 & & & \\
\hline epinefrina $1 \mathrm{mg} / \mathrm{ml} 1 \mathrm{ml}$ & 60 & & 58 & 2 & 0,15 & 0,3 & 0,81 \\
\hline escopolamina $20 \mathrm{mg} / \mathrm{ml}-1 \mathrm{ml}$ & 17 & & 14 & 3 & 0,72 & 2,16 & 5,83 \\
\hline etomidato $2 \mathrm{mg} / \mathrm{ml}-10 \mathrm{ml}$ & & 1 & 1 & 0 & & & \\
\hline $\begin{array}{l}\text { fentanila }+ \text { droperidol }(0,05 \mathrm{mg}+ \\
2,5 \mathrm{mg}) / \mathrm{ml}-2 \mathrm{ml}\end{array}$ & & 2 & 2 & 0 & & & \\
\hline fentanil $0,05 \mathrm{mg} / \mathrm{ml}-5 \mathrm{ml}$ & & 6 & 5 & 10 & 0,18 & 1,8 & 4,86 \\
\hline fitomenadiona $10 \mathrm{mg} / \mathrm{ml}-1 \mathrm{ml}$ & 3 & & 3 & 0 & & & \\
\hline furosemida $10 \mathrm{mg} / \mathrm{ml}-2 \mathrm{ml}$ & 10 & & 9 & 1 & 0,13 & 0,13 & 0,35 \\
\hline gentamicina $10 \mathrm{mgml}-1 \mathrm{ml}$ & 1 & & 1 & 0 & & & \\
\hline gentamicina $40 \mathrm{mg} / \mathrm{ml}-1 \mathrm{ml}$ & 11 & & 10 & 1 & 0,19 & 0,19 & 0,51 \\
\hline gentamicina $80 \mathrm{mg} / \mathrm{ml}-1 \mathrm{ml}$ & 2 & & 2 & 0 & & & \\
\hline gluconato de cálcio $10 \%-10 \mathrm{ml}$ & 4 & & 3 & 1 & 0,48 & 0,48 & 1,3 \\
\hline heparina IV 5.000UI - 5ml & 1 & & 1 & 0 & & & \\
\hline hidralazina $20 \mathrm{mg} / \mathrm{ml}-1 \mathrm{ml}$ & 2 & & 2 & 0 & & & \\
\hline hidrocortisona $500 \mathrm{mg}$ & 1 & & 1 & 0 & & & \\
\hline isoprenalina $0,2 \mathrm{mg} / \mathrm{ml}-1 \mathrm{ml}$ & 12 & & 12 & 0 & & & \\
\hline lidocaína sem epinefrina $2 \%$ - $20 \mathrm{ml}$ & 4 & & 3 & 1 & 1,31 & 1,31 & 3,54 \\
\hline $\begin{array}{l}\text { lidocaína com epinefrina } \\
(20 \mathrm{mg}+5 \mathrm{mcg}) / \mathrm{ml}-20 \mathrm{ml}\end{array}$ & 5 & & 5 & 0 & & & \\
\hline lidocaína geléia $2 \%$ - 30ml & 2 & & 1 & 1 & 1,12 & 1,12 & 3,02 \\
\hline
\end{tabular}


SALA 28 - PRIMEIRO DIA DE CONSUMO (continuação)

\begin{tabular}{l|c|c|c|c|c|c|c}
\hline Medicamento & $\begin{array}{c}\text { Físico } \\
\text { Inicial }\end{array}$ & Extra & $\begin{array}{c}\text { Físico } \\
\text { Final }\end{array}$ & $\begin{array}{c}\text { Quantidade } \\
\text { Utilizada }\end{array}$ & $\begin{array}{c}\text { Preço } \\
\text { Unitário }\end{array}$ & $\begin{array}{c}\text { Preço } \\
\text { Final }\end{array}$ & $\begin{array}{c}\text { Valor em } \\
\text { dólar }\end{array}$ \\
\hline metoclopramida $5 \mathrm{mg} / \mathrm{ml}-2 \mathrm{ml}$ & 11 & & 7 & 4 & 0,15 & 0,6 & 1,62 \\
\hline midazolam $5 \mathrm{mg} / \mathrm{ml}-3 \mathrm{ml}$ & & 2 & 1 & 1 & 2,35 & 2,35 & 6,35 \\
\hline morfina $2 \mathrm{mg} / \mathrm{ml}-1 \mathrm{ml}$ & & 1 & 1 & 0 & & & \\
\hline neostigmina $0,5 \mathrm{mg} / \mathrm{ml}-1 \mathrm{ml}$ & 1 & & 1 & 0 & & & \\
\hline nitroglicerina $50 \mathrm{mg} / 10 \mathrm{ml}$ & 1 & & 0 & 1 & 0,59 & 0,59 & 1,59 \\
\hline papaverina $50 \mathrm{mg} / \mathrm{ml}-2 \mathrm{ml}$ & & 1 & 1 & 0 & & & \\
\hline petidina $50 \mathrm{mg} / \mathrm{ml}-2 \mathrm{ml}$ & 7 & & 6 & 1 & 0,29 & 0,29 & 0,78 \\
\hline prometazina $25 \mathrm{mg} / \mathrm{ml}-2 \mathrm{ml}$ & & 4 & 2 & 2 & 8,51 & 17,02 & 45,95 \\
\hline propofol $10 \mathrm{mg} / \mathrm{ml}-20 \mathrm{ml}$ & 7 & & 7 & 0 & & & \\
\hline protamina $10 \mathrm{mg} / \mathrm{ml}-5 \mathrm{ml}$ & 12 & & 11 & 1 & 0,18 & 0,18 & 0,49 \\
\hline ranitidina $10 \mathrm{mg} / \mathrm{ml}-5 \mathrm{ml}$ & 1 & & 1 & 0 & & & \\
\hline salbutamol $0,5 \mathrm{mg} / \mathrm{ml}-1 \mathrm{ml}$ & 5 & & 5 & 0 & & & \\
\hline sulfato de magnésio $10 \%-10 \mathrm{ml}$ & 3 & & 3 & 0 & & & \\
\hline sulfato de magnésio $20 \%-10 \mathrm{ml}$ & 8 & & 5 & 3 & 0,99 & 2,97 & 8,02 \\
\hline sulfato de terbutalina $0,5 \mathrm{mg} / \mathrm{ml} \mathrm{-} \mathrm{1ml}$ & 2 & & 2 & 0 & & & \\
\hline vaselina $20 \mathrm{ml}$ & 10 & & 9 & 1 & 0,36 & 0,36 & 0,97 \\
\hline verde brilhante $100 \mathrm{mg} / \mathrm{ml}-1 \mathrm{ml}$ & 1 & & 1 & 0 & & & \\
\hline vit A e D colírio & $\mathbf{3 3 2}$ & $\mathbf{1 8}$ & $\mathbf{2 9 8}$ & $\mathbf{5 2}$ & $\mathbf{3 1 , 7}$ & $\mathbf{7 0 , 9 8}$ & $\mathbf{1 9 1 , 6 4}$ \\
\hline Total & & & & & & \\
\hline
\end{tabular}


Tabela 23: Segundo dia de consumo na sala 28 fase pré implantação

\begin{tabular}{|c|c|c|c|c|c|c|c|}
\hline \multicolumn{8}{|c|}{ SALA 28- SEGUNDO DIA DE CONSUMO } \\
\hline Medicamento & $\begin{array}{l}\text { Físico } \\
\text { Inicial }\end{array}$ & Extra & $\begin{array}{l}\text { Físico } \\
\text { Final }\end{array}$ & $\begin{array}{l}\text { Quantidade } \\
\text { Utilizada }\end{array}$ & $\begin{array}{c}\text { Preço } \\
\text { Unitário }\end{array}$ & $\begin{array}{l}\text { Preço } \\
\text { Final }\end{array}$ & $\begin{array}{l}\text { Valor em } \\
\text { dólar }\end{array}$ \\
\hline água destilada $10 \mathrm{ml}$ & 26 & & 16 & 10 & 0,1 & 1 & 2,7 \\
\hline amicacina $50 \mathrm{mg} / \mathrm{ml}-2 \mathrm{ml}$ & 6 & & 6 & 0 & & & \\
\hline amiodarona $50 \mathrm{mg} / \mathrm{ml}-3 \mathrm{ml}$ & 8 & & 8 & 0 & & & \\
\hline atropina $0, .25 \mathrm{mg} / \mathrm{ml}-1 \mathrm{ml}$ & 15 & & 15 & 0 & & & \\
\hline atropina $0,5 \mathrm{mg} / \mathrm{ml}-1 \mathrm{ml}$ & 13 & & 12 & 1 & 0,01 & 0,01 & 0,03 \\
\hline azul de metileno $1 \%-5 \mathrm{ml}$ & 9 & & 9 & 0 & & & \\
\hline bicarbonato de sódio $3 \%-20 \mathrm{ml}$ & 5 & 3 & 5 & 3 & 0,63 & 1,89 & 5,1 \\
\hline bicarbonato de sódio $10 \%-250 \mathrm{ml}$ & 1 & & 1 & 0 & & & \\
\hline bupivacaína hiperbárica $0,5 \%$ - $4 \mathrm{ml}$ & 2 & & 2 & 0 & & & \\
\hline $\begin{array}{l}\text { bupivacaína com epinefrina } \\
(5 \mathrm{mg}+9,1 \mathrm{mcg}) / \mathrm{ml}-20 \mathrm{ml}\end{array}$ & 3 & & 3 & 0 & & & \\
\hline $\begin{array}{l}\text { bupivacaína sem epinefrina } 0,5 \% \text { - } \\
20 \mathrm{ml}\end{array}$ & 3 & & 3 & 0 & & & \\
\hline cefalotina $1 \mathrm{~g}$ & 11 & & 7 & 4 & 1,53 & 6,12 & 16,52 \\
\hline cetoprofeno $50 \mathrm{mg} / \mathrm{ml}-2 \mathrm{ml}$ & 1 & & 1 & 0 & & & \\
\hline cloranfenicol colirio $-10 \mathrm{ml}$ & 6 & & 6 & 0 & & & \\
\hline cloreto de potássio $19,1 \%-10 \mathrm{ml}$ & 7 & & 7 & 0 & & & \\
\hline dexametasona $4 \mathrm{mg} / \mathrm{ml}-1 \mathrm{ml}$ & 9 & & 9 & 0 & & & \\
\hline diazepam $5 \mathrm{mg} / \mathrm{ml}-2 \mathrm{ml}$ & & 2 & 2 & 0 & & & \\
\hline diclofenaco $25 \mathrm{mg} / \mathrm{ml}-3 \mathrm{ml}$ & 1 & & 1 & 0 & & & \\
\hline difenidramina $25 \mathrm{mg} / \mathrm{ml}-2 \mathrm{ml}$ & 1 & & 1 & 0 & & & \\
\hline dobutamina $12,5 \mathrm{mg} / \mathrm{ml}-20 \mathrm{ml}$ & 4 & & 4 & 0 & & & \\
\hline dopamina $5 \mathrm{mg} / \mathrm{ml}-10 \mathrm{ml}$ & 8 & & 8 & 0 & & & \\
\hline efedrina $25 \mathrm{mg} / \mathrm{ml}-1 \mathrm{ml}$ & 12 & & 11 & 1 & 0,43 & 0,43 & 1,16 \\
\hline epinefrina $1 \mathrm{mg} / \mathrm{ml}-1 \mathrm{ml}$ & 62 & & 62 & 0 & & & \\
\hline escopolamina $20 \mathrm{mg} / \mathrm{ml}-1 \mathrm{ml}$ & 17 & & 17 & 0 & & & \\
\hline etomidato $2 \mathrm{mg} / \mathrm{ml}-10 \mathrm{ml}$ & & 2 & 0 & 2 & 3,18 & 6,36 & 17,17 \\
\hline $\begin{array}{l}\text { fentanila }+ \text { droperidol } \\
(0,05 \mathrm{mg}+2,5 \mathrm{mg}) / \mathrm{ml}-2 \mathrm{ml}\end{array}$ & & 4 & 2 & 2 & 2,35 & 4,7 & 12,69 \\
\hline fentanil $0,05 \mathrm{mg} / \mathrm{ml}-5 \mathrm{ml}$ & & 9 & 1 & 8 & 1,8 & 14,4 & 38,9 \\
\hline fitomenadiona $10 \mathrm{mg} / \mathrm{ml}-1 \mathrm{ml}$ & 3 & & 3 & 0 & & & \\
\hline furosemida $10 \mathrm{mg} / \mathrm{ml}-2 \mathrm{ml}$ & 20 & & 20 & 0 & & & \\
\hline gentamicina $10 \mathrm{mg} / \mathrm{ml}-1 \mathrm{ml}$ & 1 & & 1 & 0 & & & \\
\hline gentamicina $40 \mathrm{mg} / \mathrm{ml}-1 \mathrm{ml}$ & 11 & & 11 & 0 & & & \\
\hline gentamicina $80 \mathrm{mg} / \mathrm{ml}-1 \mathrm{ml}$ & 2 & & 2 & 0 & & & \\
\hline gluconato de cálcio $10 \%-10 \mathrm{ml}$ & 4 & & 4 & 0 & & & \\
\hline heparina IV 5.000UI - 5ml & 1 & & 1 & 0 & & & \\
\hline hidralazina $20 \mathrm{mg} / \mathrm{ml}-1 \mathrm{ml}$ & 2 & & 2 & 0 & & & \\
\hline hidrocortisona 100mg & 2 & & 2 & 0 & & & \\
\hline hidrocortisona $500 \mathrm{mg}$ & 3 & & 3 & 0 & & & \\
\hline lidocaína sem epinefrina $2 \%$ - $20 \mathrm{ml}$ & 3 & & 2 & 1 & 0,68 & 0,68 & 1,84 \\
\hline $\begin{array}{l}\text { lidocaína com epinefrina } \\
(20 \mathrm{mg}+5 \mathrm{mcg}) / \mathrm{ml}-20 \mathrm{ml}\end{array}$ & 4 & & 4 & 0 & & & \\
\hline lidocaína geléia $2 \%$ - 30ml & 4 & & 3 & 1 & 1,12 & 1,12 & 3,02 \\
\hline metoclopramida $5 \mathrm{mg} / \mathrm{ml}-2 \mathrm{ml}$ & 30 & & 29 & 1 & 0,15 & 0,15 & 0,41 \\
\hline midazolam $5 \mathrm{mg} / \mathrm{ml}-3 \mathrm{ml}$ & & 3 & 0 & 3 & 2,35 & 7,05 & 19,04 \\
\hline morfina $2 \mathrm{mg} / \mathrm{ml}-1 \mathrm{ml}$ & & 2 & 0 & 2 & 0,41 & 0,81 & 2,19 \\
\hline
\end{tabular}


SALA 28- SEGUNDO DIA DE CONSUMO (continuação)

\begin{tabular}{l|c|c|c|c|c|c|c}
\hline Medicamento & $\begin{array}{c}\text { Físico } \\
\text { Inicial }\end{array}$ & Extra & $\begin{array}{c}\text { Físico } \\
\text { Final }\end{array}$ & $\begin{array}{c}\text { Quantidade } \\
\text { Utilizada }\end{array}$ & $\begin{array}{c}\text { Preço } \\
\text { Unitário }\end{array}$ & $\begin{array}{c}\text { Preço } \\
\text { Final }\end{array}$ & $\begin{array}{c}\text { Valor em } \\
\text { dólar }\end{array}$ \\
\hline neostigmina $0,5 \mathrm{mg} / \mathrm{ml}-1 \mathrm{ml}$ & 14 & & 14 & 0 & & & \\
\hline nitroglicerina $50 \mathrm{mg} / 10 \mathrm{ml}$ & 1 & & 1 & 0 & & & \\
\hline papaverina $50 \mathrm{mg} / \mathrm{ml}-2 \mathrm{ml}$ & 1 & & 1 & 0 & & & \\
\hline petidina $50 \mathrm{mg} / \mathrm{ml}-2 \mathrm{ml}$ & & 2 & 2 & 0 & & & \\
\hline prometazina $25 \mathrm{mg} / \mathrm{ml}-2 \mathrm{ml}$ & 7 & & 7 & 0 & & & \\
\hline propofol $10 \mathrm{mg} / \mathrm{ml}-20 \mathrm{ml}$ & & 4 & 4 & 0 & & & \\
\hline protamina $10 \mathrm{mg} / \mathrm{ml}-5 \mathrm{ml}$ & 7 & & 7 & 0 & & & \\
\hline ranitidina $10 \mathrm{mg} / \mathrm{ml}-5 \mathrm{ml}$ & 12 & & 10 & 2 & 0,19 & 0,38 & 1,03 \\
\hline salbutamol spray $100 \mathrm{mcg} / \mathrm{dose}-$ & 1 & & 1 & 0 & & & \\
200doses & 3 & & 3 & 0 & & & \\
\hline sulfato de magnésio $10 \%-10 \mathrm{ml}$ & 6 & & 3 & 3 & 0,43 & 1,29 & 3,48 \\
\hline sulfato de magnésio $20 \%-10 \mathrm{ml}$ & 5 & & 5 & 0 & & & \\
\hline terbutalina $0,5 \mathrm{mg} / \mathrm{ml}-1 \mathrm{ml}$ & 2 & & 2 & 0 & & & \\
\hline vaselina $20 \mathrm{ml}$ & 10 & 12 & 16 & 6 & 0,36 & 2,16 & 5,83 \\
\hline verde brilhante $100 \mathrm{mg} / \mathrm{ml}-1 \mathrm{ml}$ & 1 & & 1 & 0 & & & \\
\hline vit A e D colírio - $10 \mathrm{ml}$ & $\mathbf{3 9 0}$ & $\mathbf{4 3}$ & $\mathbf{3 8 3}$ & $\mathbf{5 0}$ & $\mathbf{1 5 , 7 2}$ & $\mathbf{4 8 , 5 5}$ & $\mathbf{1 3 1 , \mathbf { 1 1 }}$ \\
\hline Total & & & & & \\
\hline
\end{tabular}


Tabela 24: Terceiro dia de consumo na sala 28 fase pré implantação

SALA 28- TERCEIRO DIA DE CONSUMO

\begin{tabular}{|c|c|c|c|c|c|c|c|}
\hline \\
\hline Medicamento & $\begin{array}{l}\text { Físico } \\
\text { Inicial }\end{array}$ & Extra & $\begin{array}{c}\text { Físico } \\
\text { Final }\end{array}$ & $\begin{array}{l}\text { Quantidade } \\
\text { Utilizada }\end{array}$ & $\begin{array}{c}\text { Preço } \\
\text { Unitário }\end{array}$ & $\begin{array}{c}\text { Preço } \\
\text { Final }\end{array}$ & $\begin{array}{c}\text { Valor em } \\
\text { dólar }\end{array}$ \\
\hline água destilada $10 \mathrm{ml}$ & 17 & & 15 & 2 & 0,1 & 0,2 & 0,54 \\
\hline álcool etílico $96 \%$ - 10ml & 1 & & 1 & 0 & & & \\
\hline amicacina $50 \mathrm{mg} / \mathrm{ml}-2 \mathrm{ml}$ & 5 & & 5 & 0 & & & \\
\hline amiodarona $50 \mathrm{mg} / \mathrm{ml}-3 \mathrm{ml}$ & 3 & 5 & 5 & 3 & 0,74 & 2,22 & 5,99 \\
\hline ampicilina $1 \mathrm{~g}$ & 1 & & 1 & 0 & & & \\
\hline atropina $0,25 \mathrm{mg} / \mathrm{ml}-1 \mathrm{ml}$ & 30 & & 26 & 4 & 0,12 & 0,48 & 1,3 \\
\hline atropina $0,5 \mathrm{mg} / \mathrm{ml}-1 \mathrm{ml}$ & 23 & & 21 & 2 & 0,01 & 0,02 & 0,05 \\
\hline azul de metileno $1 \%-5 \mathrm{ml}$ & 2 & & 2 & 0 & & & \\
\hline bicarbonato de sódio $3 \%-20 \mathrm{ml}$ & 1 & & 1 & 0 & & & \\
\hline $\begin{array}{l}\text { bupivacaína com epinefrina } \\
(5 \mathrm{mg}+9,1 \mathrm{mcg}) / \mathrm{ml}-20 \mathrm{ml}\end{array}$ & 2 & & 2 & 0 & & & \\
\hline $\begin{array}{l}\text { bupivacaína sem epinefrina } 0,5 \% \text { - } \\
20 \mathrm{ml}\end{array}$ & 3 & & 3 & 0 & & & \\
\hline bupivacaína isobárica $0,5 \%$ - $20 \mathrm{ml}$ & 1 & & 1 & 0 & & & \\
\hline cloreto de sódio $20 \%$ - $20 \mathrm{ml}$ & 4 & & 2 & 2 & 0,38 & 0,76 & 2,05 \\
\hline cloreto de potássio $19,1 \%-10 \mathrm{ml}$ & 5 & & 4 & 1 & 0,2 & 0,2 & 0,54 \\
\hline dexametasona $4 \mathrm{mg} / \mathrm{ml}-1 \mathrm{ml}$ & 42 & & 38 & 4 & 0,39 & 1,56 & 4,2 \\
\hline diazepam $5 \mathrm{mg} / \mathrm{ml}-2 \mathrm{ml}$ & & 3 & 3 & 0 & & & \\
\hline $\begin{array}{l}\text { dimenidrato }+ \text { piridoxina } \\
(50 \mathrm{mg}+50 \mathrm{mg}) / \mathrm{ml}-1 \mathrm{ml}\end{array}$ & 2 & & 1 & 1 & 1 & 1 & 2,7 \\
\hline dipirona $500 \mathrm{mg} / \mathrm{ml}-2 \mathrm{ml}$ & 5 & 30 & 30 & 5 & 0,13 & 0,66 & 1,78 \\
\hline dobutamina $12,5 \mathrm{mg} / \mathrm{ml}-20 \mathrm{ml}$ & 3 & & 2 & 1 & 4,52 & 4,52 & 12,2 \\
\hline dopamina $5 \mathrm{mg} / \mathrm{ml}-10 \mathrm{ml}$ & 3 & & 3 & 0 & & & \\
\hline efedrina $25 \mathrm{mg} / \mathrm{ml}-1 \mathrm{ml}$ & 24 & & 20 & 4 & 0,36 & 1,44 & 3,89 \\
\hline epinefrina $1 \mathrm{mg} / \mathrm{ml} 1 \mathrm{ml}$ & 52 & & 52 & 0 & & & \\
\hline etomidato $2 \mathrm{mg} / \mathrm{ml}-10 \mathrm{ml}$ & & 3 & 3 & 0 & & & \\
\hline $\begin{array}{l}\text { fentanila + droperidol } \\
(0,05 \mathrm{mg}+2,5 \mathrm{mg}) / \mathrm{ml}-2 \mathrm{ml}\end{array}$ & & 6 & 4 & 2 & 3,51 & 7,02 & 18,95 \\
\hline fentanil $0,05 \mathrm{mg} / \mathrm{ml}-5 \mathrm{ml}$ & & 9 & 1 & 8 & 1,8 & 14,4 & 38,89 \\
\hline furosemida $10 \mathrm{mg} / \mathrm{ml}-2 \mathrm{ml}$ & 31 & & 26 & 5 & 0,13 & 0,65 & 1,76 \\
\hline gentamicina colírio $20 \mathrm{mg} / \mathrm{ml}-10 \mathrm{ml}$ & 1 & & 1 & 0 & & & \\
\hline gentamicina pomada $0,3 \%-3 \mathrm{~g}$ & 1 & & 1 & 0 & & & \\
\hline gentamicina $10 \mathrm{mg} / \mathrm{ml}-1 \mathrm{ml}$ & 2 & & 2 & 0 & & & \\
\hline gentamicina $40 \mathrm{mg} / \mathrm{ml}-1 \mathrm{ml}$ & 27 & & 25 & 2 & 0,19 & 0,38 & 1,03 \\
\hline heparina IV 5.000UI $-5 \mathrm{ml}$ & 2 & & 1 & 1 & 3,45 & 3,45 & 9,32 \\
\hline hidralazina $20 \mathrm{mg} / \mathrm{ml}-1 \mathrm{ml}$ & 2 & & 2 & 0 & & & \\
\hline hidrocortisona $100 \mathrm{mg}$ & 2 & & 2 & 0 & & & \\
\hline isoprenalina $0,2 \mathrm{mg} / \mathrm{ml}-1 \mathrm{ml}$ & 3 & & 3 & 0 & & & \\
\hline cedilanide & 2 & & 2 & 0 & & & \\
\hline $\begin{array}{l}\text { lidocaína com epinefrina } \\
(20 \mathrm{mg}+5 \mathrm{mcg}) / \mathrm{ml}-20 \mathrm{ml}\end{array}$ & 7 & & 7 & 0 & & & \\
\hline lidocaína geléia $2 \%$ - 30ml & 10 & & 4 & 6 & 1,12 & 6,72 & 18,14 \\
\hline metaraminol 10mg/ml - $1 \mathrm{ml}$ & 3 & & 3 & 0 & & & \\
\hline metilpredinizolona $100 \mathrm{mg}$ & 1 & & 1 & 0 & & & \\
\hline metoclopramida $5 \mathrm{mg} / \mathrm{ml}-2 \mathrm{ml}$ & 20 & & 18 & 2 & 0,15 & 0,3 & 0,81 \\
\hline midazolam $5 \mathrm{mg} / \mathrm{ml}-3 \mathrm{ml}$ & & 3 & 0 & 3 & 2,35 & 7,05 & 19,04 \\
\hline morfina $2 \mathrm{mg} / \mathrm{ml}-1 \mathrm{ml}$ & & 3 & 1 & 2 & 0,41 & 0,82 & 2,21 \\
\hline
\end{tabular}


SALA 28- TERCEIRO DIA DE CONSUMO (continuação)

\begin{tabular}{l|c|c|c|c|c|c|c}
\hline Medicamento & $\begin{array}{c}\text { Físico } \\
\text { Inicial }\end{array}$ & Extra & $\begin{array}{c}\text { Físico } \\
\text { Final }\end{array}$ & $\begin{array}{c}\text { Quantidade } \\
\text { Utilizada }\end{array}$ & $\begin{array}{c}\text { Preço } \\
\text { Unitário }\end{array}$ & $\begin{array}{c}\text { Preço } \\
\text { Final }\end{array}$ & $\begin{array}{c}\text { Valor em } \\
\text { dólar }\end{array}$ \\
\hline neostigmina $0,5 \mathrm{mg} / \mathrm{ml}-1 \mathrm{ml}$ & 29 & & 22 & 7 & 0,46 & 3,22 & 8,69 \\
\hline noradrenalina $1 \mathrm{mg} / \mathrm{ml}-4 \mathrm{ml}$ & 5 & & 4 & 1 & 1,67 & 1,67 & 4,51 \\
\hline petidina $50 \mathrm{mg} / \mathrm{ml}-2 \mathrm{ml}$ & & 3 & 3 & 0 & & & \\
\hline propofol $10 \mathrm{mg} / \mathrm{ml}-20 \mathrm{ml}$ & & 6 & 3 & 3 & 8,51 & 25,53 & 68,93 \\
\hline prometazina $25 \mathrm{mg} / \mathrm{ml}-2 \mathrm{ml}$ & 3 & & 0 & 3 & 0,29 & 0,87 & 2,35 \\
\hline ranitidina $10 \mathrm{mg} / \mathrm{ml}-5 \mathrm{ml}$ & 15 & & 14 & 1 & 0,18 & 0,18 & 0,49 \\
\hline rocurônio $10 \mathrm{mg} / \mathrm{ml}-5 \mathrm{ml}$ & 2 & & 2 & 0 & & & \\
\hline $\begin{array}{l}\text { salbutamol spray } 100 \mathrm{mcg} / \mathrm{dose}- \\
\text { 200doses }\end{array}$ & 3 & & 2 & 1 & 7,17 & 7,17 & 19,36 \\
\hline sulfato de magnésio $10 \%-10 \mathrm{ml}$ & 4 & & 4 & 0 & & & \\
\hline $\begin{array}{l}\text { sulfato de terbutalina } 0,5 \mathrm{mg} / \mathrm{ml}- \\
\text { 1ml }\end{array}$ & 11 & & 10 & 1 & 0,99 & 0,99 & 2,67 \\
\hline suxametônio $100 \mathrm{mg}$ & 1 & & 1 & 0 & & & \\
\hline tenoxican $20 \mathrm{mg}$ & 1 & & 1 & 0 & & & \\
\hline verapamil 2,5mg/ml - 2ml & 3 & & 2 & 1 & 0,67 & 0,67 & 1,81 \\
\hline verde brilhante $100 \mathrm{mg} / \mathrm{ml}-1 \mathrm{ml}$ & 1 & & 1 & 0 & & & \\
\hline Total & $\mathbf{4 2 1}$ & $\mathbf{7 1}$ & $\mathbf{4 1 4}$ & $\mathbf{7 8}$ & $\mathbf{4 1}$ & $\mathbf{9 4 , 1 5}$ & $\mathbf{2 5 4 , 2}$ \\
\hline
\end{tabular}


Tabela 25: Primeiro dia de consumo na sala 29 fase pré implantação

SALA 29- PRIMEIRO DIA DE CONSUMO

\begin{tabular}{|c|c|c|c|c|c|c|c|}
\hline \\
\hline Medicamento & $\begin{array}{l}\text { Físico } \\
\text { Inicial }\end{array}$ & Extra & $\begin{array}{c}\text { Físico } \\
\text { Final }\end{array}$ & $\begin{array}{c}\text { Quantidade } \\
\text { Utilizada }\end{array}$ & $\begin{array}{c}\text { Preço } \\
\text { Unitário }\end{array}$ & $\begin{array}{l}\text { Preço } \\
\text { Final }\end{array}$ & $\begin{array}{c}\text { Valor em } \\
\text { dólar }\end{array}$ \\
\hline agua destilada $10 \mathrm{ml}$ & 13 & & 6 & 7 & 0,01 & 0,7 & 1,89 \\
\hline aminofilina $24 \mathrm{mg} / \mathrm{ml}-10 \mathrm{ml}$ & 14 & & 12 & 2 & 0,05 & 0,1 & 0,27 \\
\hline amiodarona $50 \mathrm{mg} / \mathrm{ml}-3 \mathrm{ml}$ & 3 & & 3 & 0 & & & \\
\hline ampicilina $1 \mathrm{~g}$ & 3 & & 3 & 0 & & & \\
\hline atropina $0,25 \mathrm{mg} / \mathrm{ml} \mathrm{-} 1 \mathrm{ml}$ & 19 & & 17 & 2 & 0,12 & 0,24 & 0,65 \\
\hline atropina $0,5 \mathrm{mg} / \mathrm{ml}-1 \mathrm{ml}$ & 7 & & 6 & 1 & 0,01 & 0,01 & 0,03 \\
\hline azul de metileno $1 \%-5 \mathrm{ml}$ & 5 & & 5 & 0 & & & \\
\hline bicarbonato de sódio $3 \%-20 \mathrm{ml}$ & 2 & 3 & 2 & 3 & 0,63 & 1,89 & 5,1 \\
\hline bicarbonato de sódio $10 \%-250 \mathrm{ml}$ & 2 & 4 & 2 & 4 & 4,96 & 19,84 & 53,57 \\
\hline bicarbonato de sódio $10 \%-20 \mathrm{ml}$ & 1 & & 1 & 0 & & & \\
\hline $\begin{array}{l}\text { bupivacaína com epinefrina } \\
(5 \mathrm{mg}+9,1 \mathrm{mcg}) / \mathrm{ml}-20 \mathrm{ml}\end{array}$ & 7 & & 6 & 1 & 3,98 & 3,98 & 10,75 \\
\hline $\begin{array}{l}\text { bupivacaína sem epinefrina } 0,5 \% \text { - } \\
20 \mathrm{ml}\end{array}$ & 7 & & 7 & 0 & & & \\
\hline bupivacaína hiperbárica $0,5 \%$ - $4 \mathrm{ml}$ & 4 & & 4 & 0 & & & \\
\hline bupivacaína isobárica $0,5 \%-20 \mathrm{ml}$ & 1 & & 1 & 0 & & & \\
\hline cefalotina $1 \mathrm{~g}$ & 4 & & 3 & 1 & 1,53 & 1,53 & 4,13 \\
\hline cetoprofeno $50 \mathrm{mg} / \mathrm{ml} \mathrm{-} 2 \mathrm{ml}$ & 1 & & 1 & 0 & & & \\
\hline cloreto de cálcio $100 \mathrm{mg} / \mathrm{ml}-5 \mathrm{ml}$ & 9 & & 9 & 0 & & & \\
\hline cloreto de potássio $19,1 \%-10 \mathrm{ml}$ & 5 & & 4 & 1 & 0,2 & 0,2 & 0,54 \\
\hline cloreto de sódio $20 \%$ - $20 \mathrm{ml}$ & 7 & & 5 & 2 & 0,38 & 0,76 & 2,05 \\
\hline cloreto de sódio $0,9 \%-10 \mathrm{ml}$ & 4 & & 4 & 0 & & & \\
\hline deslanosido $0,2 \mathrm{mg} / \mathrm{ml}-2 \mathrm{ml}$ & 5 & & 5 & 0 & & & \\
\hline dexametasona $4 \mathrm{mg} / \mathrm{ml}$ - 1ml & 12 & & 12 & 0 & & & \\
\hline diazepam $5 \mathrm{mg} / \mathrm{ml}-2 \mathrm{ml}$ & & 3 & 3 & 0 & & & \\
\hline $\begin{array}{l}\text { dimenidrato }+ \text { piridoxina } \\
(50 \mathrm{mg}+50 \mathrm{mg}) / \mathrm{ml}-1 \mathrm{ml}\end{array}$ & 1 & & 1 & 0 & & & \\
\hline dipirona $500 \mathrm{mg} / \mathrm{ml} \mathrm{-} 2 \mathrm{ml}$ & 3 & 5 & 3 & 5 & 0,16 & 0,8 & 2,16 \\
\hline dobutamina $12,5 \mathrm{mg} / \mathrm{ml}-20 \mathrm{ml}$ & 6 & & 5 & 1 & 4,52 & 4,52 & 12,2 \\
\hline dopamina $5 \mathrm{mg} / \mathrm{ml}-10 \mathrm{ml}$ & 3 & & 3 & 0 & & & \\
\hline efedrina $25 \mathrm{mg} / \mathrm{ml}-1 \mathrm{ml}$ & 18 & & 16 & 2 & 0,43 & 0,86 & 2,32 \\
\hline epinefrina $1 \mathrm{mg} / \mathrm{ml} 1 \mathrm{ml}$ & 43 & 4 & 42 & 5 & 0,15 & 0,75 & 2,03 \\
\hline escopolamina $20 \mathrm{mg} / \mathrm{ml}-1 \mathrm{ml}$ & 1 & & 1 & 0 & & & \\
\hline etomidato $2 \mathrm{mg} / \mathrm{ml}-10 \mathrm{ml}$ & & 3 & 0 & 3 & 3,18 & 9,54 & 25,76 \\
\hline $\begin{array}{l}\text { fentanila + droperidol } \\
(0,05 \mathrm{mg}+2,5 \mathrm{mg}) / \mathrm{ml}-2 \mathrm{ml}\end{array}$ & & 6 & 1 & 5 & 3,51 & 17,55 & 47,39 \\
\hline Fentanil $0,05 \mathrm{mg} / \mathrm{ml}-5 \mathrm{ml}$ & & 9 & 0 & 9 & 1,8 & 16,2 & 43,74 \\
\hline furosemida $10 \mathrm{mg} / \mathrm{ml}-2 \mathrm{ml}$ & 10 & & 8 & 2 & 0,13 & 0,26 & 0,7 \\
\hline gel contacto $30 \mathrm{~g}$ & 1 & & 1 & 0 & & & \\
\hline gentamicina $40 \mathrm{mg} / \mathrm{ml}-1 \mathrm{ml}$ & 15 & & 14 & 1 & 0,29 & 0,29 & 0,78 \\
\hline gentamicina colírio $20 \mathrm{mg} / \mathrm{ml}-10 \mathrm{ml}$ & 1 & & 1 & 0 & & & \\
\hline glicose $50 \%-10 \mathrm{ml}$ & 3 & & 2 & 1 & 0,16 & 0,16 & 0,43 \\
\hline gluconato de cálcio $10 \%-10 \mathrm{ml}$ & 5 & & 5 & 0 & & & \\
\hline heparina IV 5.000UI - 5ml & 9 & & 8 & 1 & 3,45 & 3,45 & 9,32 \\
\hline hidralazina $20 \mathrm{mg} / \mathrm{ml}-1 \mathrm{ml}$ & 2 & & 2 & 0 & & & \\
\hline lidocaína sem epinefrina $2 \%$ - $20 \mathrm{ml}$ & 6 & & 5 & 1 & 1,31 & 1,31 & 3,54 \\
\hline $\begin{array}{l}\text { lidocaína com epinefrina } \\
(20 \mathrm{mg}+5 \mathrm{mcg}) / \mathrm{ml}-20 \mathrm{ml}\end{array}$ & 7 & & 7 & 0 & & & \\
\hline
\end{tabular}


SALA 29- PRIMEIRO DIA DE CONSUMO (coninuação)

\begin{tabular}{l|c|c|c|c|c|c|c}
\hline Medicamento & $\begin{array}{c}\text { Físico } \\
\text { Inicial }\end{array}$ & Extra & $\begin{array}{c}\text { Físico } \\
\text { Final }\end{array}$ & $\begin{array}{c}\text { Quantidade } \\
\text { Utilizada }\end{array}$ & $\begin{array}{c}\text { Preço } \\
\text { Unitário }\end{array}$ & $\begin{array}{c}\text { Preço } \\
\text { Final }\end{array}$ & $\begin{array}{c}\text { Valor em } \\
\text { dólar }\end{array}$ \\
\hline metaraminol $10 \mathrm{mg} / \mathrm{ml}-1 \mathrm{ml}$ & 1 & & 1 & 0 & & & \\
\hline metilpredinisolona $100 \mathrm{mg}$ & 1 & & 1 & 0 & & & \\
\hline metoprolol $1 \mathrm{mg} / \mathrm{ml}-5 \mathrm{ml}$ & 1 & & 1 & 0 & & & \\
\hline midazolam $5 \mathrm{mg} / \mathrm{ml}-3 \mathrm{ml}$ & & 3 & 0 & 3 & 2,35 & 7,05 & 19,04 \\
\hline morfina $2 \mathrm{mg} / \mathrm{ml}-1 \mathrm{ml}$ & & 3 & 3 & 0 & & & \\
\hline neostigmina $0,5 \mathrm{mg} / \mathrm{ml}-1 \mathrm{ml}$ & 10 & & 10 & 0 & & & \\
\hline noradrenalina $1 \mathrm{mg} / \mathrm{ml}-4 \mathrm{ml}$ & 10 & & 9 & 1 & 1,67 & 1,67 & 4,51 \\
\hline papaverina $50 \mathrm{mg} / \mathrm{ml}-2 \mathrm{ml}$ & 8 & & 8 & 0 & & & \\
\hline petidina $50 \mathrm{mg} / \mathrm{ml} \mathrm{-} \mathrm{2ml}$ & & 3 & 3 & 0 & & & \\
\hline propofol $10 \mathrm{mg} / \mathrm{ml} \mathrm{-} \mathrm{20ml}$ & & 6 & 0 & 6 & 8,51 & 51,06 & 137,86 \\
\hline protamina $10 \mathrm{mg} / \mathrm{ml}-5 \mathrm{ml}$ & 5 & & 5 & 0 & & & \\
\hline ranitidina $10 \mathrm{mg} / \mathrm{ml}-5 \mathrm{ml}$ & 20 & & 16 & 4 & 0,36 & 0,72 & 1,94 \\
\hline sulfato de magnésio $10 \%-10 \mathrm{ml}$ & 4 & & 4 & 0 & & & \\
\hline suxametônio $100 \mathrm{mg}$ & 9 & & 9 & 0 & & & \\
\hline vaselina $20 \mathrm{ml}$ & 1 & & 1 & 0 & & & \\
\hline verde brilhante $100 \mathrm{mg} / \mathrm{ml} \mathrm{-} \mathrm{1ml}$ & 8 & & 7 & 1 & 0,36 & 0,36 & 0,97 \\
\hline Total & $\mathbf{3 4 7}$ & $\mathbf{5 2}$ & $\mathbf{3 2 4}$ & $\mathbf{7 5}$ & $\mathbf{4 4 , 0 3}$ & $\mathbf{1 2 9 , 8 9}$ & $\mathbf{3 9 3 , 6 7}$ \\
\hline
\end{tabular}


Tabela 26: Segundo dia de consumo na sala 29 fase pré implantação

SALA 29- SEGUNDO DIA DE CONSUMO

\begin{tabular}{|c|c|c|c|c|c|c|c|}
\hline & & & & & & & \\
\hline Medicamento & $\begin{array}{l}\text { Físico } \\
\text { Inicial }\end{array}$ & Extra & $\begin{array}{l}\text { Físico } \\
\text { Final }\end{array}$ & $\begin{array}{l}\text { Quantidade } \\
\text { Utilizada }\end{array}$ & $\begin{array}{c}\text { Preço } \\
\text { Unitário }\end{array}$ & $\begin{array}{l}\text { Preço } \\
\text { Final }\end{array}$ & $\begin{array}{c}\text { Valor em } \\
\text { dólar }\end{array}$ \\
\hline água destilada $10 \mathrm{ml}$ & 25 & 28 & 28 & 25 & 0,1 & 2,5 & 6,75 \\
\hline álcool etílico $96 \%$ - 10ml & 2 & & 2 & 0 & & & \\
\hline aminofilina $24 \mathrm{mg} / \mathrm{ml}-10 \mathrm{ml}$ & 3 & & 3 & 0 & & & \\
\hline amiodarona $50 \mathrm{mg} / \mathrm{ml}-3 \mathrm{ml}$ & 3 & & 3 & 0 & & & \\
\hline ampicilina $1 \mathrm{~g}$ & 3 & & 3 & 0 & & & \\
\hline atropina $0,25 \mathrm{mg} / \mathrm{ml}-1 \mathrm{ml}$ & 18 & & 18 & 0 & & & \\
\hline atropina $0,5 \mathrm{mg} / \mathrm{ml}-1 \mathrm{ml}$ & 18 & & 18 & 0 & & & \\
\hline azul de metileno $1 \%-5 \mathrm{ml}$ & 5 & & 5 & 0 & & & \\
\hline bicarbonato sódio $3 \%-20 \mathrm{ml}$ & 4 & & 4 & 0 & & & \\
\hline $\begin{array}{l}\text { bupivacaína com epinefrina } \\
(5 \mathrm{mg}+9,1 \mathrm{mcg}) / \mathrm{ml}-20 \mathrm{ml}\end{array}$ & 6 & & 5 & 1 & 3,98 & 3,98 & 10,75 \\
\hline $\begin{array}{l}\text { bupivacaína sem epinefrina } 0,5 \% \text { - } \\
20 \mathrm{ml}\end{array}$ & 6 & & 6 & 0 & & & \\
\hline bupivacaína isobárica $0,5 \%-20 \mathrm{ml}$ & 14 & & 1 & 0 & & & \\
\hline bupivacaína hiperbárica $0,5 \%$ - $4 \mathrm{ml}$ & 4 & & 4 & 0 & & & \\
\hline cefalotina $1 \mathrm{~g}$ & 8 & & 6 & 2 & 1,53 & 3,06 & 9,72 \\
\hline cloreto de potássio $19,1 \%-10 \mathrm{ml}$ & 4 & & 4 & 0 & & & \\
\hline cloreto de cálcio $100 \mathrm{mg} / \mathrm{ml}-5 \mathrm{ml}$ & 4 & 7 & 7 & 4 & 0,38 & 1,52 & 4,1 \\
\hline cloreto de sódio $0,9 \%$ - $10 \mathrm{ml}$ & 4 & 10 & 9 & 5 & 0,58 & 2,9 & 7,83 \\
\hline cloreto sódio $20 \%-20 \mathrm{ml}$ & 9 & & 9 & 0 & & & \\
\hline deslanosido $0,2 \mathrm{mg} / \mathrm{ml}-2 \mathrm{ml}$ & 4 & & 4 & 0 & & & \\
\hline dexametasona $4 \mathrm{mg} / \mathrm{ml}$ - $1 \mathrm{ml}$ & 8 & & 2 & 6 & 0,39 & 2,34 & 6,32 \\
\hline diazepam $5 \mathrm{mg} / \mathrm{ml}-2 \mathrm{ml}$ & & 2 & 0 & 2 & 0,17 & 0,34 & 0,92 \\
\hline $\begin{array}{l}\text { dimenidrato+piridoxina } \\
(50 \mathrm{mg}+50 \mathrm{mg}) / \mathrm{ml}-1 \mathrm{ml}\end{array}$ & 1 & & 1 & 0 & & & \\
\hline dipirona $500 \mathrm{mg} / \mathrm{ml}-2 \mathrm{ml}$ & 20 & 29 & 29 & 20 & 0,16 & 3,2 & 8,64 \\
\hline dobutamina $12,5 \mathrm{mg} / \mathrm{ml}-20 \mathrm{ml}$ & 4 & 5 & 5 & 4 & 4,52 & 18,08 & 48,82 \\
\hline dopamina $5 \mathrm{mg} / \mathrm{ml}-10 \mathrm{ml}$ & 3 & & 3 & 0 & & & \\
\hline efedrina $25 \mathrm{mg} / \mathrm{ml}-1 \mathrm{ml}$ & 13 & & 12 & 1 & 0,43 & 0,43 & 1,16 \\
\hline epinefrina $1 \mathrm{mg} / \mathrm{ml} 1 \mathrm{ml}$ & 43 & & 42 & 1 & 0,15 & 0,15 & 0,41 \\
\hline escopolamina $20 \mathrm{mg} / \mathrm{ml}-1 \mathrm{ml}$ & 1 & & 1 & 0 & & & \\
\hline etomidato $2 \mathrm{mg} / \mathrm{ml}-10 \mathrm{ml}$ & & 2 & 2 & 0 & & & \\
\hline $\begin{array}{l}\text { fentanila }+ \text { droperidol } \\
(0,05 \mathrm{mg}+2,5 \mathrm{mg}) / \mathrm{ml}-2 \mathrm{ml}\end{array}$ & & 4 & 0 & 4 & 3,51 & 14,04 & 37,91 \\
\hline fentanil $0,05 \mathrm{mg} / \mathrm{ml}-5 \mathrm{ml}$ & & 6 & 0 & 6 & 1,8 & 10,8 & 29,16 \\
\hline furosemida $10 \mathrm{mg} / \mathrm{ml}-2 \mathrm{ml}$ & 23 & & 13 & 10 & 0,13 & 1,3 & 3,51 \\
\hline gel contacto $30 \mathrm{~g}$ & 1 & & 1 & 0 & & & \\
\hline gentamicina pomada $0,3 \%-3 g$ & 1 & & 1 & 0 & & & \\
\hline gentamicina colírio $20 \mathrm{mg} / \mathrm{ml}-10 \mathrm{ml}$ & 1 & & 1 & 0 & & & \\
\hline gentamicina $40 \mathrm{mg} / \mathrm{ml}-1 \mathrm{ml}$ & 14 & & 14 & 0 & & & \\
\hline gluconato de cálcio $10 \%-10 \mathrm{ml}$ & 5 & & 5 & 0 & & & \\
\hline heparina IV 5.000UI $-5 \mathrm{ml}$ & 8 & & 7 & 1 & 3,45 & 3,45 & 9,32 \\
\hline hidralazina $20 \mathrm{mg} / \mathrm{ml}-1 \mathrm{ml}$ & 2 & & 1 & 1 & 1,5 & 1,5 & 4,05 \\
\hline lidocaína sem epinefrina $2 \%-20 \mathrm{ml}$ & 6 & & 5 & 1 & 1,31 & 1,31 & 3,54 \\
\hline metaraminol $10 \mathrm{mg} / \mathrm{ml}-1 \mathrm{ml}$ & 1 & & 1 & 0 & & & \\
\hline metoclopramida $5 \mathrm{mg} / \mathrm{ml}-2 \mathrm{ml}$ & 11 & & 10 & 1 & 0,15 & 0,15 & 0,41 \\
\hline midazolam $5 \mathrm{mg} / \mathrm{ml}-3 \mathrm{ml}$ & & 2 & 2 & 0 & & & \\
\hline
\end{tabular}


SALA 29- SEGUNDO DIA DE CONSUMO (continuação)

\begin{tabular}{l|c|c|c|c|c|c|c}
\hline Medicamento & $\begin{array}{c}\text { Físico } \\
\text { Inicial }\end{array}$ & Extra & $\begin{array}{c}\text { Físico } \\
\text { Final }\end{array}$ & $\begin{array}{c}\text { Quantidade } \\
\text { Utilizada }\end{array}$ & $\begin{array}{c}\text { Preço } \\
\text { Unitário }\end{array}$ & $\begin{array}{c}\text { Preço } \\
\text { Final }\end{array}$ & $\begin{array}{c}\text { Valor em } \\
\text { dólar }\end{array}$ \\
\hline morfina $2 \mathrm{mg} / \mathrm{ml}-1 \mathrm{ml}$ & & 2 & 2 & 0 & & & \\
\hline neostigmina $0,5 \mathrm{mg} / \mathrm{ml}-1 \mathrm{ml}$ & 20 & & 19 & 1 & 0,46 & 0,46 & 1,24 \\
\hline noradrenalina $1 \mathrm{mg} / \mathrm{ml}-4 \mathrm{ml}$ & 9 & & 8 & 1 & 1,67 & 1,67 & 4,51 \\
\hline papaverina $50 \mathrm{mg} / \mathrm{ml}-2 \mathrm{ml}$ & 8 & & 8 & 0 & & & \\
\hline petidina $50 \mathrm{mg} / \mathrm{ml}-2 \mathrm{ml}$ & & 2 & 2 & 0 & & & \\
\hline propofol $10 \mathrm{mg} / \mathrm{ml}-20 \mathrm{ml}$ & & 4 & 0 & 4 & 8,51 & 34,04 & 91,91 \\
\hline protamina $10 \mathrm{mg} / \mathrm{ml}-5 \mathrm{ml}$ & 5 & & 5 & 0 & & & \\
\hline ranitidina $10 \mathrm{mg} / \mathrm{ml}-5 \mathrm{ml}$ & 14 & & 14 & 0 & & & \\
\hline sulfato de $\mathrm{magnésio} 10 \%-10 \mathrm{ml}$ & 4 & & 4 & 0 & & & \\
\hline suxametônio $100 \mathrm{mg}$ & 9 & & 9 & 0 & & & \\
\hline vaselina $20 \mathrm{ml}$ & 2 & & 2 & 0 & & & \\
\hline verde brilhante $100 \mathrm{mg} / \mathrm{ml}-1 \mathrm{ml}$ & 6 & & 5 & 1 & 0,36 & 0,36 & 0,97 \\
\hline Total & $\mathbf{3 7 4}$ & $\mathbf{1 0 3}$ & $\mathbf{3 7 5}$ & $\mathbf{1 0 2}$ & $\mathbf{3 5 , 2 4}$ & $\mathbf{1 0 7 , 5 8}$ & $\mathbf{2 9 1 , 9 5}$ \\
\hline
\end{tabular}


Tabela 27: Terceiro dia de consumo na sala 29 fase pré implantação

SALA 29 - TERCEIRO DIA DE CONSUMO

\begin{tabular}{|c|c|c|c|c|c|c|c|}
\hline & & & & & & & \\
\hline Medicamento & $\begin{array}{l}\text { Físico } \\
\text { Inicial }\end{array}$ & Extra & $\begin{array}{l}\text { Físico } \\
\text { Final }\end{array}$ & $\begin{array}{l}\text { Quantidade } \\
\text { Utilizada }\end{array}$ & $\begin{array}{c}\text { Preço } \\
\text { Unitário }\end{array}$ & $\begin{array}{l}\text { Preço } \\
\text { Final }\end{array}$ & $\begin{array}{l}\text { Valor em } \\
\text { dólar }\end{array}$ \\
\hline agua destilada $10 \mathrm{ml}$ & 21 & & 21 & 0 & & & \\
\hline álcool etílico $96 \%$ - 10ml & 2 & & 2 & 0 & & & \\
\hline amido hidroxietílico $6 \%-500 \mathrm{ml}$ & 8 & & 8 & 0 & & & \\
\hline aminofilina $24 \mathrm{mg} / \mathrm{ml}-10 \mathrm{ml}$ & 3 & & 3 & 0 & & & \\
\hline amiodarona $50 \mathrm{mg} / \mathrm{ml}-3 \mathrm{ml}$ & 3 & & 3 & 0 & & & \\
\hline ampicilina $1 \mathrm{~g}$ & 3 & & 3 & 0 & & & \\
\hline atropina $0,25 \mathrm{mg} / \mathrm{ml}-1 \mathrm{ml}$ & 14 & & 14 & 0 & & & \\
\hline atropina $0,5 \mathrm{mg} / \mathrm{ml}-1 \mathrm{ml}$ & 5 & & 3 & 2 & 0,01 & 0,02 & 0,05 \\
\hline azul de metileno $1 \%-5 \mathrm{ml}$ & 5 & & 5 & 0 & & & \\
\hline bicarbonato de sódio $3 \%-20 \mathrm{ml}$ & 2 & & 2 & 0 & & & \\
\hline bicarbonato de sódio $10 \%-250 \mathrm{ml}$ & 2 & & 2 & 0 & & & \\
\hline bupivacaína isobárica $0,5 \%-20 \mathrm{ml}$ & 1 & & 1 & 0 & & & \\
\hline bupivacaína hiperbárica $0,5 \%$ - $4 \mathrm{ml}$ & 4 & & 4 & 0 & & & \\
\hline $\begin{array}{l}\text { bupivacaína com epinefrina } \\
(5 \mathrm{mg}+9,1 \mathrm{mcg}) / \mathrm{ml}-20 \mathrm{ml}\end{array}$ & 6 & & 4 & 2 & 3,98 & 7,96 & 21,49 \\
\hline $\begin{array}{l}\text { bupivacaína sem epinefrina } 0,5 \% \text { - } \\
20 \mathrm{ml}\end{array}$ & 7 & & 6 & 1 & 4 & 4 & 10,8 \\
\hline cloreto de cálcio $100 \mathrm{mg} / \mathrm{ml}-5 \mathrm{ml}$ & 16 & & 16 & 0 & & & \\
\hline cloreto potássio $19,1 \%$ - $10 \mathrm{ml}$ & 4 & & 4 & 0 & & & \\
\hline cloreto de sódio $0,9 \%-10 \mathrm{ml}$ & 4 & & 4 & 0 & & & \\
\hline deslantosido $0,2 \mathrm{mg} / \mathrm{ml}-2 \mathrm{ml}$ & 4 & & 4 & 0 & & & \\
\hline dexametasona $4 \mathrm{mg} / \mathrm{ml}-1 \mathrm{ml}$ & 12 & & 10 & 2 & 0,39 & 0,78 & 2,11 \\
\hline diazepam $5 \mathrm{mg} / \mathrm{ml}-2 \mathrm{ml}$ & & 3 & 0 & 3 & 0,17 & 0,51 & 1,38 \\
\hline $\begin{array}{l}\text { dimenidrato }+ \text { piridoxina } \\
(50 \mathrm{mg}+50 \mathrm{mg}) / \mathrm{ml}-10 \mathrm{ml}\end{array}$ & 1 & & 1 & 0 & & & \\
\hline dobutamina $12,5 \mathrm{mg} / \mathrm{ml}-20 \mathrm{ml}$ & 4 & & 4 & 0 & & & \\
\hline dopamina $5 \mathrm{mg} / \mathrm{ml}-10 \mathrm{ml}$ & 3 & & 3 & 0 & & & \\
\hline efedrina $25 \mathrm{mg} / \mathrm{ml}-1 \mathrm{ml}$ & 15 & & 14 & 1 & 0,43 & 0,43 & 1,16 \\
\hline epinefrina $1 \mathrm{mg} / \mathrm{ml} 1 \mathrm{ml}$ & 43 & & 43 & 0 & & & \\
\hline escopolamina $20 \mathrm{mg} / \mathrm{ml}-1 \mathrm{ml}$ & 1 & & 1 & 0 & & & \\
\hline etomidato $2 \mathrm{mg} / \mathrm{ml}-10 \mathrm{ml}$ & & 3 & 3 & 0 & & & \\
\hline $\begin{array}{l}\text { fentanila + droperidol } \\
(0,05 \mathrm{mg}+2,5 \mathrm{mg}) / \mathrm{ml}-2 \mathrm{ml}\end{array}$ & & 6 & 6 & 0 & & & \\
\hline fentanil $0,05 \mathrm{mg} / \mathrm{ml}-5 \mathrm{ml}$ & & 9 & 0 & 9 & 1,8 & 16,2 & 43,74 \\
\hline furosemida $10 \mathrm{mg} / \mathrm{ml}-2 \mathrm{ml}$ & 8 & & 8 & 0 & & & \\
\hline gel contacto $30 \mathrm{~g}$ & 1 & & 1 & 0 & & & \\
\hline gluconato de cálcio $10 \%-10 \mathrm{ml}$ & 5 & & 5 & 0 & & & \\
\hline heparina IV 5.000UI - 5ml & 8 & & 8 & 0 & & & \\
\hline hidralazina $20 \mathrm{mg} / \mathrm{ml}$ - $1 \mathrm{ml}$ & 2 & & 2 & 0 & & & \\
\hline lidocaína sem epinefrina $2 \%-20 \mathrm{ml}$ & 3 & & 3 & 0 & & & \\
\hline $\begin{array}{l}\text { lidocaína com epinefrina } \\
(20 \mathrm{mg}+5 \mathrm{mcg}) / \mathrm{ml}-20 \mathrm{ml}\end{array}$ & 7 & & 7 & 0 & & & \\
\hline midazolam $5 \mathrm{mg} / \mathrm{ml}-3 \mathrm{ml}$ & & 4 & 0 & 4 & 2,35 & 9,4 & 25,38 \\
\hline morfina $2 \mathrm{mg} / \mathrm{ml}-1 \mathrm{ml}$ & & 3 & 0 & 3 & 0,41 & 1,23 & 3,32 \\
\hline neostigmina $0,5 \mathrm{mg} / \mathrm{ml}-1 \mathrm{ml}$ & 5 & & 5 & 0 & & & \\
\hline noradrenalina $1 \mathrm{mg} / \mathrm{ml}-4 \mathrm{ml}$ & 9 & & 9 & 0 & & & \\
\hline papaverina $50 \mathrm{mg} / \mathrm{ml} \mathrm{-} 2 \mathrm{ml}$ & 8 & & 8 & 0 & & & \\
\hline petidina $50 \mathrm{mg} / \mathrm{ml}-2 \mathrm{ml}$ & & 3 & 0 & 3 & 0,18 & 0,54 & 1,46 \\
\hline
\end{tabular}


SALA 29 - TERCEIRO DIA DE CONSUMO (continuação)

\begin{tabular}{l|c|c|c|c|c|c|c}
\hline Medicamento & $\begin{array}{c}\text { Físico } \\
\text { Inicial }\end{array}$ & Extra & $\begin{array}{c}\text { Físico } \\
\text { Final }\end{array}$ & $\begin{array}{c}\text { Quantidade } \\
\text { Utilizada }\end{array}$ & $\begin{array}{c}\text { Preço } \\
\text { Unitário }\end{array}$ & $\begin{array}{c}\text { Preço } \\
\text { Final }\end{array}$ & $\begin{array}{c}\text { Valor em } \\
\text { dólar }\end{array}$ \\
\hline propofol $10 \mathrm{mg} / \mathrm{ml}-20 \mathrm{ml}$ & & 13 & 0 & 13 & 8,51 & 110,63 & 298,7 \\
\hline protamina $10 \mathrm{mg} / \mathrm{ml}-5 \mathrm{ml}$ & 5 & & 5 & 0 & & & \\
\hline ranitidina $10 \mathrm{mg} / \mathrm{ml}-5 \mathrm{ml}$ & 16 & & 10 & 6 & 0,18 & 1,08 & 2,92 \\
\hline suxametônio $100 \mathrm{mg}$ & 9 & & 9 & 0 & & & \\
\hline vaselina $20 \mathrm{ml}$ & 2 & & 2 & 0 & & & \\
\hline verde brilhante $100 \mathrm{mg} / \mathrm{ml}-1 \mathrm{ml}$ & 7 & & 6 & 1 & 0,36 & 0,36 & 0,97 \\
\hline Total & $\mathbf{2 8 8}$ & $\mathbf{4 4}$ & $\mathbf{2 7 4}$ & $\mathbf{5 0}$ & $\mathbf{2 2 , 7 7}$ & $\mathbf{1 5 3 , 1 4}$ & $\mathbf{4 1 3 , 4 8}$ \\
\hline
\end{tabular}


Tabela 28: Primeiro dia de consumo na sala 30 fase pré implantação

SALA 30 - PRIMEIRO DIA DE CONSUMO

\begin{tabular}{|c|c|c|c|c|c|c|c|}
\hline \\
\hline Medicamento & $\begin{array}{l}\text { Físico } \\
\text { Inicial }\end{array}$ & Extra & $\begin{array}{l}\text { Físico } \\
\text { Final }\end{array}$ & $\begin{array}{l}\text { Quantidade } \\
\text { Utilizada }\end{array}$ & $\begin{array}{c}\text { Preço } \\
\text { Unitário }\end{array}$ & $\begin{array}{l}\text { Preço } \\
\text { Final }\end{array}$ & $\begin{array}{c}\text { Valor em } \\
\text { dólar }\end{array}$ \\
\hline agua destilada $10 \mathrm{ml}$ & 21 & & 18 & 3 & 0,1 & 0,3 & 0,81 \\
\hline amicacina $50 \mathrm{mg} / \mathrm{ml}-2 \mathrm{ml}$ & 2 & & 2 & 0 & & & \\
\hline amiodarona $50 \mathrm{mg} / \mathrm{ml} \mathrm{-} \mathrm{3ml}$ & 3 & & 3 & 0 & & & \\
\hline ampicilina $1 \mathrm{~g}$ & 2 & & 1 & 1 & 0,9 & 0,9 & 2,43 \\
\hline atropina $0, .25 \mathrm{mg} / \mathrm{ml}-1 \mathrm{ml}$ & 14 & & 13 & 1 & 0,12 & 0,12 & 0,32 \\
\hline atropina $0,5 \mathrm{mg} / \mathrm{ml}-1 \mathrm{ml}$ & 20 & & 18 & 2 & 0,01 & 0,02 & 0,05 \\
\hline bicarbonato de sódio $3 \%-20 \mathrm{ml}$ & 4 & & 4 & 0 & & & \\
\hline bupivacaína hiperbárica $0,5 \%$ - $4 \mathrm{ml}$ & 3 & & 3 & 0 & & & \\
\hline $\begin{array}{l}\text { bupivacaína com epinefrina } \\
(5 \mathrm{mg}+9,1 \mathrm{mcg}) / \mathrm{ml}-20 \mathrm{ml}\end{array}$ & 8 & & 6 & 2 & 3,98 & 7,96 & 21,49 \\
\hline $\begin{array}{l}\text { bupivacaína sem epinefrina } 0,5 \% \text { - } \\
20 \mathrm{ml}\end{array}$ & 8 & & 3 & 5 & 4 & 20 & 54 \\
\hline cefalotina $1 \mathrm{~g}$ & 6 & 3 & 4 & 5 & 1,53 & 7,65 & 20,66 \\
\hline cetoprofeno $50 \mathrm{mg} / \mathrm{ml}-2 \mathrm{ml}$ & 3 & & 2 & 1 & 1,43 & 1,43 & 3,86 \\
\hline cimetidina $150 \mathrm{mg} / \mathrm{ml}-2 \mathrm{ml}$ & 2 & & 1 & 1 & 0,17 & 0,17 & 0,46 \\
\hline cloreto de potássio $19,1 \%-10 \mathrm{ml}$ & 5 & & 5 & 0 & & & \\
\hline cloreto de sódio $20 \%$ - $20 \mathrm{ml}$ & 5 & & 5 & 0 & & & \\
\hline dexametasona $4 \mathrm{mg} / \mathrm{ml} \mathrm{-} 1 \mathrm{ml}$ & 14 & & 12 & 2 & 0,78 & 0,78 & 2,11 \\
\hline diazepam $5 \mathrm{mg} / \mathrm{ml}-2 \mathrm{ml}$ & & 2 & 2 & 0 & & & \\
\hline $\begin{array}{l}\text { dimenidrato+piridoxina } \\
(50 \mathrm{mg}+50 \mathrm{mg}) / \mathrm{ml}-1 \mathrm{ml}\end{array}$ & 3 & & 0 & 3 & 3 & 3 & 8,1 \\
\hline dipiridamol $5 \mathrm{mg} / \mathrm{ml}-2 \mathrm{ml}$ & 2 & & 1 & 1 & 0,36 & 0,36 & 0,97 \\
\hline dipirona $500 \mathrm{mg} / \mathrm{ml} \mathrm{-} 2 \mathrm{ml}$ & 36 & & 33 & 3 & 0,16 & 0,48 & 1,3 \\
\hline dobutamina $12,5 \mathrm{mg} / \mathrm{ml}-20 \mathrm{ml}$ & 5 & & 5 & 0 & & & \\
\hline dopamina $5 \mathrm{mg} / \mathrm{ml}-10 \mathrm{ml}$ & 4 & 1 & 3 & 2 & 0,34 & 0,68 & 1,84 \\
\hline efedrina $25 \mathrm{mg} / \mathrm{ml}-1 \mathrm{ml}$ & 19 & & 16 & 3 & 0,43 & 1,29 & 3,48 \\
\hline enoxaparina $40 \mathrm{mg}-0,4 \mathrm{ml}$ & 1 & & 1 & 0 & & & \\
\hline epinefrina $1 \mathrm{mg} / \mathrm{ml} 1 \mathrm{ml}$ & 31 & & 30 & 1 & 0,15 & 0,15 & 0,41 \\
\hline escopolamina $20 \mathrm{mg} / \mathrm{ml}-1 \mathrm{ml}$ & 1 & & 1 & 0 & & & \\
\hline etomidato $2 \mathrm{mg} / \mathrm{ml}-10 \mathrm{ml}$ & & 2 & 2 & 0 & & & \\
\hline $\begin{array}{l}\text { fentanila }+ \text { droperidol } \\
(0,05 \mathrm{mg}+2,5 \mathrm{mg}) / \mathrm{ml}-2 \mathrm{ml}\end{array}$ & & 4 & 3 & 1 & 3,51 & 3,51 & 9,48 \\
\hline fentanil $0,05 \mathrm{mg} / \mathrm{ml}-5 \mathrm{ml}$ & & 6 & 2 & 4 & 1,8 & 7,2 & 19,44 \\
\hline fitomenadiona $10 \mathrm{mg} / \mathrm{ml}-1 \mathrm{ml}$ & 1 & & 1 & 0 & & & \\
\hline furosemida $10 \mathrm{mg} / \mathrm{ml}-2 \mathrm{ml}$ & 17 & & 14 & 3 & 0,13 & 0,39 & 1,05 \\
\hline gentamicina pomada $0,3 \%-3 \mathrm{~g}$ & 1 & & 1 & 0 & & & \\
\hline gentamicina colírio $20 \mathrm{mg} / \mathrm{ml}-10 \mathrm{ml}$ & 2 & & 1 & 1 & 1,34 & 1,34 & 3,62 \\
\hline gentamicina $10 \mathrm{mg} / \mathrm{ml}-1 \mathrm{ml}$ & 3 & & 3 & 0 & & & \\
\hline gentamicina $40 \mathrm{mg} / \mathrm{ml}-1 \mathrm{ml}$ & 17 & & 12 & 5 & 0,19 & 0,95 & 2,57 \\
\hline glicose $50 \%-10 \mathrm{ml}$ & & 2 & & 2 & 0,19 & 0,38 & 1,03 \\
\hline gluconato de cálcio $10 \%-10 \mathrm{ml}$ & 3 & & 3 & 0 & & & \\
\hline heparina IV 5.000UI - 5ml & 2 & & 2 & 0 & & & \\
\hline heparina $5.000 \mathrm{UI}-0,25 \mathrm{ml}$ & 1 & & 0 & 1 & 0,74 & 0,74 & 2 \\
\hline hidrocortisona $100 \mathrm{mg}$ & 3 & & 3 & 0 & & & \\
\hline hidrocortisona $500 \mathrm{mg}$ & 2 & & 0 & 2 & 2,88 & 5,76 & 15,55 \\
\hline lidocaína geléia $2 \%$ - 30ml & 3 & & 3 & 0 & & & \\
\hline lidocaína sem epinefrina $2 \%$ - $20 \mathrm{ml}$ & 8 & 1 & 6 & 3 & 1,31 & 3,93 & 10,61 \\
\hline
\end{tabular}


SALA 30 - PRIMEIRO DIA DE CONSUMO (continuação)

\begin{tabular}{|c|c|c|c|c|c|c|c|}
\hline Medicamento & $\begin{array}{l}\text { Físico } \\
\text { Inicial }\end{array}$ & Extra & $\begin{array}{l}\text { Físico } \\
\text { Final }\end{array}$ & $\begin{array}{c}\text { Quantidade } \\
\text { Utilizada }\end{array}$ & $\begin{array}{c}\text { Preço } \\
\text { Unitário }\end{array}$ & $\begin{array}{l}\text { Preço } \\
\text { Final }\end{array}$ & $\begin{array}{l}\text { Valor em } \\
\text { dólar }\end{array}$ \\
\hline $\begin{array}{l}\text { lidocaína com epinefrina } \\
(20 \mathrm{mg}+5 \mathrm{mcg}) / \mathrm{ml}-20 \mathrm{ml}\end{array}$ & 9 & 1 & 5 & 5 & 0,68 & 3,4 & 9,18 \\
\hline metaraminol $10 \mathrm{mg} / \mathrm{ml}-1 \mathrm{ml}$ & 12 & & 11 & 1 & 1,95 & 1,95 & 5,27 \\
\hline metilpredinisolona $500 \mathrm{mg}$ & 1 & & 1 & 0 & & & \\
\hline metoclopramida $5 \mathrm{mg} / \mathrm{ml}-2 \mathrm{ml}$ & 18 & 4 & 16 & 6 & 0,15 & 0,9 & 2,43 \\
\hline midazolam $5 \mathrm{mg} / \mathrm{ml}-3 \mathrm{ml}$ & & 2 & 1 & 1 & 2,35 & 2,35 & 6,35 \\
\hline morfina $2 \mathrm{mg} / \mathrm{ml}-1 \mathrm{ml}$ & & 2 & 1 & 1 & 0,41 & 0,41 & 1,11 \\
\hline neostigmina $0,5 \mathrm{mg} / \mathrm{ml}-1 \mathrm{ml}$ & 27 & & 27 & 0 & & & \\
\hline papaverina $50 \mathrm{mg} / \mathrm{ml}-2 \mathrm{ml}$ & 1 & & 0 & 1 & 0,59 & 0,59 & 1,59 \\
\hline petidina $50 \mathrm{mg} / \mathrm{ml}-2 \mathrm{ml}$ & & 2 & 2 & 0 & & & \\
\hline prometazina $25 \mathrm{mg} / \mathrm{ml}-2 \mathrm{ml}$ & 4 & & 2 & 2 & 0,29 & 0,58 & 1,57 \\
\hline propofol $10 \mathrm{mg} / \mathrm{ml}-20 \mathrm{ml}$ & & 4 & 2 & 2 & 8,51 & 17,02 & 45,95 \\
\hline protamina $10 \mathrm{mg} / \mathrm{ml}-5 \mathrm{ml}$ & 15 & & 14 & 1 & 1,35 & 1,35 & 3,65 \\
\hline ranitidina $10 \mathrm{mg} / \mathrm{ml}-5 \mathrm{ml}$ & 2 & 6 & 0 & 8 & 0,19 & 1,52 & 4,1 \\
\hline sedativo $-2 \mathrm{ml}$ & 1 & & 1 & 0 & & & \\
\hline sulfato de terbutalina $0,5 \mathrm{mg} / \mathrm{ml}-1 \mathrm{ml}$ & 10 & & 0 & 10 & 0,99 & 9,9 & 26,73 \\
\hline suxametônio $100 \mathrm{mg}$ & 3 & & 3 & 0 & & & \\
\hline tenoxican $20 \mathrm{mg}$ & 2 & & 0 & 2 & 2,16 & 4,32 & 11,66 \\
\hline vaselina $-20 \mathrm{ml}$ & 1 & & 1 & 0 & & & \\
\hline verapamil $2,5 \mathrm{mg} / \mathrm{ml}-2 \mathrm{ml}$ & 19 & & 1 & 18 & 0,67 & 12,06 & 32,56 \\
\hline verde brilhante $100 \mathrm{mg} / \mathrm{ml}-1 \mathrm{ml}$ & 20 & & 18 & 2 & 0,36 & 0,72 & 1,94 \\
\hline vit A e D colírio $-10 \mathrm{ml}$ & 1 & & 0 & 1 & 4,95 & 4,95 & 13,37 \\
\hline vitamina C $100 \mathrm{mg} / \mathrm{ml}-5 \mathrm{ml}$ & 2 & & 1 & 1 & 0,39 & 0,39 & 1,05 \\
\hline Total & 437 & 42 & 338 & 120 & 55,54 & 191,69 & 355,11 \\
\hline
\end{tabular}


Tabela 29: Segundo dia de consumo na sala 30 fase pré implantação

SALA 30 - SEGUNDO DIA DE CONSUMO

\begin{tabular}{|c|c|c|c|c|c|c|c|}
\hline \\
\hline Medicamento & $\begin{array}{l}\text { Físico } \\
\text { Inicial }\end{array}$ & Extra & $\begin{array}{c}\text { Físico } \\
\text { Final }\end{array}$ & \begin{tabular}{|l} 
Quantidade \\
Utilizada \\
\end{tabular} & \begin{tabular}{|c|} 
Preço \\
Unitário
\end{tabular} & $\begin{array}{r}\text { Preço } \\
\text { Final }\end{array}$ & $\begin{array}{c}\text { Valor em } \\
\text { dólar }\end{array}$ \\
\hline água destilada $10 \mathrm{ml}$ & 15 & & 13 & 2 & 0,1 & 0,2 & 0,54 \\
\hline aminofilina $24 \mathrm{mg} / \mathrm{ml}-10 \mathrm{ml}$ & 15 & & 13 & 2 & 0,05 & 0,1 & 0,27 \\
\hline amiodarona $50 \mathrm{mg} / \mathrm{ml}-3 \mathrm{ml}$ & 3 & & 3 & 0 & & & \\
\hline amicacina $50 \mathrm{mg} / \mathrm{ml}-2 \mathrm{ml}$ & 1 & & 1 & 0 & & & \\
\hline ampicilina $1 \mathrm{~g}$ & 2 & & 2 & 0 & & & \\
\hline atropina $0,25 \mathrm{mg} / \mathrm{ml}-1 \mathrm{ml}$ & 13 & & 10 & 3 & 0,12 & 0,36 & 0,97 \\
\hline atropina $0,5 \mathrm{mg} / \mathrm{ml}-1 \mathrm{ml}$ & 19 & & 18 & 1 & 0,01 & 0,01 & 0,03 \\
\hline bicarbonato de sódio $10 \%-250 \mathrm{ml}$ & 4 & & 4 & 0 & & & \\
\hline bupivacaína hiperbárica $0,5 \%-4 \mathrm{ml}$ & 2 & & 0 & 2 & 3,59 & 7,18 & 19,39 \\
\hline cefalotina $1 \mathrm{~g}$ & 2 & & 0 & 2 & 1,53 & 3,06 & 8,26 \\
\hline cetoprofeno $50 \mathrm{mg} / \mathrm{ml}-2 \mathrm{ml}$ & 2 & & 1 & 1 & 1,43 & 1,43 & 3,86 \\
\hline cloreto de potássio $19,1 \%$ - $10 \mathrm{ml}$ & 5 & & 5 & 0 & & & \\
\hline cloreto de sódio $20 \%$ - $20 \mathrm{ml}$ & 5 & & 5 & 0 & & & \\
\hline dexametasona $4 \mathrm{mg} / \mathrm{ml}-1 \mathrm{ml}$ & 13 & & 11 & 2 & 0,39 & 0,78 & 2,11 \\
\hline diazepam $5 \mathrm{mg} / \mathrm{ml}-2 \mathrm{ml}$ & & 2 & 2 & 0 & & & \\
\hline $\begin{array}{l}\text { dimenidrato+piridoxina } \\
(50 \mathrm{mg}+50 \mathrm{mg}) / \mathrm{ml}-1 \mathrm{ml}\end{array}$ & 3 & & 1 & 2 & 1 & 2 & 5,4 \\
\hline dipirona $500 \mathrm{mg} / \mathrm{ml}-2 \mathrm{ml}$ & 28 & & 26 & 2 & 0,16 & 0,32 & 0,86 \\
\hline dobutamina $12,5 \mathrm{mg} / \mathrm{ml}-20 \mathrm{ml}$ & 5 & & 5 & 0 & & & \\
\hline dopamina $5 \mathrm{mg} / \mathrm{ml}-10 \mathrm{ml}$ & 3 & & 3 & 0 & & & \\
\hline efedrina $25 \mathrm{mg} / \mathrm{ml}-1 \mathrm{ml}$ & 18 & & 17 & 1 & 0,43 & 0,43 & 1,16 \\
\hline epinefrina $1 \mathrm{mg} / \mathrm{ml} 1 \mathrm{ml}$ & 27 & & 25 & 2 & 0,15 & 0,3 & 0,81 \\
\hline escopolamina $20 \mathrm{mg} / \mathrm{ml}-1 \mathrm{ml}$ & 1 & & 1 & 0 & & & \\
\hline etomidato $2 \mathrm{mg} / \mathrm{ml}-10 \mathrm{ml}$ & & 2 & 2 & 0 & & & \\
\hline $\begin{array}{l}\text { fentanila + droperidol } \\
(0,05 \mathrm{mg}+2,5 \mathrm{mg}) / \mathrm{ml}-2 \mathrm{ml}\end{array}$ & & 4 & 4 & 0 & & & \\
\hline fentanil $0,05 \mathrm{mg} / \mathrm{ml}-5 \mathrm{ml}$ & & 6 & 4 & 2 & 1,8 & 3,6 & 9,72 \\
\hline fitomenadiona $10 \mathrm{mg} / \mathrm{ml}-1 \mathrm{ml}$ & 1 & & 1 & 0 & & & \\
\hline furosemida $10 \mathrm{mg} / \mathrm{ml}-2 \mathrm{ml}$ & 15 & & 14 & 1 & 0,13 & 0,13 & 0,35 \\
\hline gentamicina $10 \mathrm{mg} / \mathrm{ml}-1 \mathrm{ml}$ & 3 & & 3 & 0 & & & \\
\hline gentamicina $40 \mathrm{mg} / \mathrm{ml}-1 \mathrm{ml}$ & 12 & & 0 & 12 & 0,19 & 2,28 & 6,16 \\
\hline gluconato de cálcio $10 \%-10 \mathrm{ml}$ & 3 & & 3 & 0 & & & \\
\hline heparina IV 5.000UI $-5 \mathrm{ml}$ & 3 & & 3 & 0 & & & \\
\hline hidrocortisona $100 \mathrm{mg}$ & 3 & & 3 & 0 & & & \\
\hline lidocaína geléia $2 \%$ - 30ml & 3 & & 1 & 2 & 1,12 & 2,24 & 6,05 \\
\hline lidocaína sem epinefrina $2 \%-20 \mathrm{ml}$ & 7 & & 6 & 1 & 1,31 & 1,31 & 3,54 \\
\hline $\begin{array}{l}\text { lidocaína com epinefrina } \\
(20 \mathrm{mg}+5 \mathrm{mcg}) / \mathrm{ml}-20 \mathrm{ml}\end{array}$ & 5 & & 4 & 1 & 0,68 & 0,68 & 1,84 \\
\hline metaraminol $10 \mathrm{mg} / \mathrm{ml}-1 \mathrm{ml}$ & 12 & & 11 & 1 & 1,95 & 1,95 & 5,27 \\
\hline metoclopramida $5 \mathrm{mg} / \mathrm{ml}-2 \mathrm{ml}$ & 1 & & 1 & 0 & & & \\
\hline midazolam $5 \mathrm{mg} / \mathrm{ml}-3 \mathrm{ml}$ & & 2 & 0 & 2 & 2,35 & 4,7 & 12,69 \\
\hline morfina $2 \mathrm{mg} / \mathrm{ml}-1 \mathrm{ml}$ & & 2 & 2 & 0 & & & \\
\hline neostigmina $0,5 \mathrm{mg} / \mathrm{ml}-1 \mathrm{ml}$ & 31 & & 27 & 4 & 0,12 & 0,46 & 1,24 \\
\hline petidina $50 \mathrm{mg} / \mathrm{ml}-2 \mathrm{ml}$ & & 2 & 1 & 1 & 0,18 & 0,18 & 0,49 \\
\hline prometazina $25 \mathrm{mg} / \mathrm{ml}-2 \mathrm{ml}$ & 2 & & 2 & 0 & & & \\
\hline propofol $10 \mathrm{mg} / \mathrm{ml}-20 \mathrm{ml}$ & & 4 & 2 & 2 & 8,51 & 17,02 & 45,95 \\
\hline protamina $10 \mathrm{mg} / \mathrm{ml}-5 \mathrm{ml}$ & 14 & & 14 & 0 & & & \\
\hline
\end{tabular}


SALA 30 - SEGUNDO DIA DE CONSUMO (continuação)

\begin{tabular}{l|c|c|c|c|c|c|c}
\hline Medicamento & $\begin{array}{c}\text { Físico } \\
\text { Inicial }\end{array}$ & Extra & $\begin{array}{c}\text { Físico } \\
\text { Final }\end{array}$ & $\begin{array}{c}\text { Quantidade } \\
\text { Utilizada }\end{array}$ & $\begin{array}{c}\text { Preço } \\
\text { Unitário }\end{array}$ & $\begin{array}{c}\text { Preço } \\
\text { Final }\end{array}$ & $\begin{array}{c}\text { Valor em } \\
\text { dólar }\end{array}$ \\
\hline suxametônio 100mg & 3 & & 3 & 0 & & & \\
\hline tenoxican $20 \mathrm{mg}$ & 2 & & 2 & 0 & & & \\
\hline vaselina $20 \mathrm{ml}$ & 1 & & 1 & 0 & & & \\
\hline verapamil $2,5 \mathrm{mg} / \mathrm{ml}-2 \mathrm{ml}$ & 1 & & 1 & 0 & & & \\
\hline verde brilhante $100 \mathrm{mg} / \mathrm{ml}-1 \mathrm{ml}$ & 15 & & 12 & 3 & 0,36 & 1,08 & 2,92 \\
\hline Vitamina C $100 \mathrm{mg} / \mathrm{ml}-5 \mathrm{ml}$ & 1 & & 1 & 0 & & & \\
\hline Total & $\mathbf{3 2 4}$ & $\mathbf{2 4}$ & $\mathbf{2 9 4}$ & $\mathbf{5 2}$ & $\mathbf{2 9 , 2 5}$ & $\mathbf{5 3 , 1 8}$ & $\mathbf{1 3 9 , 8 8}$ \\
\hline
\end{tabular}


Tabela 30: Terceiro dia de consumo na sala 30 fase pré implantação

SALA 30 - TERCEIRO DIA DE CONSUMO

\begin{tabular}{|c|c|c|c|c|c|c|c|}
\hline \\
\hline Medicamento & $\begin{array}{l}\text { Físico } \\
\text { Inicial }\end{array}$ & Extra & $\begin{array}{c}\text { Físico } \\
\text { Final }\end{array}$ & $\begin{array}{l}\text { Quantidade } \\
\text { Utilizada }\end{array}$ & \begin{tabular}{|c|} 
Preço \\
Unitário
\end{tabular} & $\begin{array}{c}\text { Preço } \\
\text { Final }\end{array}$ & $\begin{array}{c}\text { Valor em } \\
\text { dólar }\end{array}$ \\
\hline agua destilada $10 \mathrm{ml}$ & 18 & & 15 & 3 & 0,1 & 0,3 & 0,81 \\
\hline amicacina $50 \mathrm{mg} / \mathrm{ml}-2 \mathrm{ml}$ & 1 & & 1 & 0 & & & \\
\hline amiodarona $50 \mathrm{mg} / \mathrm{ml} \mathrm{-} 3 \mathrm{ml}$ & 3 & & 3 & 0 & & & \\
\hline ampicilina $1 \mathrm{~g}$ & 4 & & 4 & 0 & & & \\
\hline atropina $0,25 \mathrm{mg} / \mathrm{ml}-1 \mathrm{ml}$ & 14 & 29 & 29 & 14 & 0,12 & 1,68 & 4,54 \\
\hline atropina $0,5 \mathrm{mg} / \mathrm{ml}-1 \mathrm{ml}$ & 17 & & 16 & 1 & 0,01 & 0,01 & 0,027 \\
\hline bicarbonato de sódio $3 \%-20 \mathrm{ml}$ & 4 & & 4 & 0 & & & \\
\hline $\begin{array}{l}\text { bupivacaína com epinefrina } \\
(5 \mathrm{mg}+9,1 \mathrm{mcg}) / \mathrm{ml}-20 \mathrm{ml}\end{array}$ & 6 & & 6 & 0 & & & \\
\hline $\begin{array}{l}\text { bupivacaína sem epinefrina } 0,5 \% \text { - } \\
20 \mathrm{ml}\end{array}$ & 6 & & 6 & 0 & & & \\
\hline cefalotina $1 \mathrm{~g}$ & 6 & & 4 & 2 & 1,53 & 3,06 & 8,26 \\
\hline cloranfenicol colírio $1 \%-10 \mathrm{ml}$ & 1 & & 1 & 0 & & & \\
\hline cloreto de potássio $19,1 \%$ - $10 \mathrm{ml}$ & 5 & & 5 & 0 & & & \\
\hline cloreto de sódio $20 \%-20 \mathrm{ml}$ & 5 & & 5 & 0 & & & \\
\hline dexametasona $4 \mathrm{mg} / \mathrm{ml}-1 \mathrm{ml}$ & 9 & & 8 & 1 & 0,39 & 0,39 & 1,05 \\
\hline diazepam $5 \mathrm{mg} / \mathrm{ml}-2 \mathrm{ml}$ & & 2 & 2 & 0 & & & \\
\hline $\begin{array}{l}\text { dimenidrato }+ \text { piridoxina } \\
(50 \mathrm{mg}+50 \mathrm{mg})-1 \mathrm{ml}\end{array}$ & 1 & & 1 & 0 & & & \\
\hline dobutamina $12,5 \mathrm{mg} / \mathrm{ml}-20 \mathrm{ml}$ & 5 & & 5 & 0 & & & \\
\hline dopamina $5 \mathrm{mg} / \mathrm{ml}-10 \mathrm{ml}$ & 3 & & 3 & 0 & & & \\
\hline efedrina $25 \mathrm{mg} / \mathrm{ml}-1 \mathrm{ml}$ & 17 & 15 & 19 & 13 & 0,25 & 3,25 & 8,78 \\
\hline enoxeparina $20 \mathrm{mg}-0,2 \mathrm{ml}$ & 1 & & 1 & 0 & & & \\
\hline epinefrina $1 \mathrm{mg} / \mathrm{ml} 1 \mathrm{ml}$ & 28 & & 25 & 3 & 0,15 & 0,45 & 1,22 \\
\hline etomidato $2 \mathrm{mg} / \mathrm{ml}-10 \mathrm{ml}$ & & 2 & 2 & 0 & & & \\
\hline $\begin{array}{l}\text { fentanila + droperidol } \\
(0,05 \mathrm{mg}+2,5 \mathrm{mg}) / \mathrm{ml}-2 \mathrm{ml}\end{array}$ & & 6 & 5 & 1 & 3,51 & 3,51 & 9,48 \\
\hline fentanil $-5 \mathrm{ml}$ & & 9 & 8 & 1 & 1,8 & 1,8 & 4,86 \\
\hline fitomenadiona $10 \mathrm{mg} / \mathrm{ml}-1 \mathrm{ml}$ & 1 & & 1 & 0 & & & \\
\hline furosemida $10 \mathrm{mg} / \mathrm{ml}-2 \mathrm{ml}$ & 15 & & 14 & 1 & 0,13 & 0,13 & 0,35 \\
\hline gentamicina $40 \mathrm{mg} / \mathrm{ml} \mathrm{-} 1 \mathrm{ml}$ & 23 & & 22 & 1 & 0,19 & 0,19 & 0,51 \\
\hline gluconato de cálcio $10 \%-10 \mathrm{ml}$ & 3 & & 3 & 0 & & & \\
\hline heparina IV 5.000UI - 5ml & 4 & & 3 & 1 & 3,45 & 3,45 & 9,32 \\
\hline hidrocortisona $100 \mathrm{mg}$ & 3 & & 3 & 0 & & & \\
\hline hidrocortisona $500 \mathrm{mg}$ & 1 & & 1 & 0 & & & \\
\hline $\begin{array}{l}\text { lidocaína com epinefrina ( } 2 \%+ \\
0,5 \%) / \mathrm{ml}-20 \mathrm{ml}\end{array}$ & 6 & & 6 & 0 & & & \\
\hline lidocaína geléia $2 \%$ - 30ml & 3 & & 2 & 1 & 1,12 & 1,12 & 3,02 \\
\hline metaraminol 10mg/ml - $1 \mathrm{ml}$ & 12 & & 12 & 0 & & & \\
\hline metilpredinisolona $-500 \mathrm{mg}$ & 1 & 2 & 2 & 1 & 15,83 & 15,83 & 42,74 \\
\hline metoclopramida $5 \mathrm{mg} / \mathrm{ml}-2 \mathrm{ml}$ & 18 & & 16 & 2 & 0,15 & 0,3 & 0,81 \\
\hline midazolam $5 \mathrm{mg} / \mathrm{ml}-3 \mathrm{ml}$ & & 3 & 1 & 2 & 2,35 & 4,7 & 12,69 \\
\hline morfina $2 \mathrm{mg} / \mathrm{ml}-1 \mathrm{ml}$ & & 2 & 2 & 0 & & & \\
\hline neostigmina $0,5 \mathrm{mg} / \mathrm{ml} \mathrm{-} 1 \mathrm{ml}$ & 29 & & 28 & 1 & 0,46 & 0,46 & 1,24 \\
\hline petidina $50 \mathrm{mg} / \mathrm{ml}-2 \mathrm{ml}$ & & 3 & 3 & 0 & & & \\
\hline prometazina $25 \mathrm{mg} / \mathrm{ml} \mathrm{-} 2 \mathrm{ml}$ & 2 & & 2 & 0 & & & \\
\hline propofol $10 \mathrm{mg} / \mathrm{ml}-20 \mathrm{ml}$ & & 11 & 0 & 11 & 8,51 & 93,61 & 252,75 \\
\hline protamina $10 \mathrm{mg} / \mathrm{ml}-5 \mathrm{ml}$ & 14 & & 14 & 0 & & & \\
\hline
\end{tabular}


SALA 30 - TERCEIRO DIA DE CONSUMO (continuação)

\begin{tabular}{l|c|c|c|c|c|c|c}
\hline Medicamento & $\begin{array}{c}\text { Físico } \\
\text { Inicial }\end{array}$ & Extra & $\begin{array}{c}\text { Físico } \\
\text { Final }\end{array}$ & $\begin{array}{c}\text { Quantidade } \\
\text { Utilizada }\end{array}$ & $\begin{array}{c}\text { Preço } \\
\text { Unitário }\end{array}$ & $\begin{array}{c}\text { Preço } \\
\text { Final }\end{array}$ & $\begin{array}{c}\text { Valor em } \\
\text { dólar }\end{array}$ \\
\hline suxametônio 100mg & 3 & & 3 & 0 & & & \\
\hline tenoxican - 20mg & 2 & & 2 & 0 & & & \\
\hline vaselina - 20ml & 1 & & 1 & 0 & & & \\
\hline verapamil 2,5mg/ml - 2ml & 1 & & 1 & 0 & & & \\
\hline verde brilhante 100mg/ml - 1ml & 14 & & 1 & 13 & 0,36 & 4,68 & 12,64 \\
\hline vitamina c $100 \mathrm{mg} / \mathrm{ml} \mathrm{-} \mathrm{5ml}$ & 2 & & 1 & 1 & 0,39 & 0,39 & 1,05 \\
\hline Total & $\mathbf{3 1 2}$ & $\mathbf{8 4}$ & $\mathbf{3 2 2}$ & $\mathbf{6 4}$ & $\mathbf{4 0 , 8}$ & $\mathbf{1 3 9 , 3 1}$ & $\mathbf{3 7 6 , 1 4 7}$ \\
\hline
\end{tabular}


As tabelas de trinta e um à sessenta se referem à fase de pós implantação.

Esses dados foram coletados com o farmacêutico dentro da sala cirúrgica e após o acompanhamento da cirurgia e na ausência em dias alternados, de forma que o solicitante não tivesse informação sobre a coleta, para não ser induzido à redução de consumo.

Tabela 31: Primeiro dia de consumo na sala 21 fase pós implantação

SALA 21 - PRIMEIRO DIA DE CONSUMO

\begin{tabular}{|c|c|c|c|c|c|c|}
\hline Medicamento & $\begin{array}{l}\text { Físico Inicial } \\
\text { (elenco kit) }\end{array}$ & Extra & \begin{tabular}{|c|} 
Quantidade \\
Utilizada
\end{tabular} & \begin{tabular}{|c|} 
Preço \\
Unitário
\end{tabular} & $\begin{array}{l}\text { Preço } \\
\text { Final }\end{array}$ & $\begin{array}{l}\text { Valor em } \\
\text { dólar }\end{array}$ \\
\hline agua destilada $-10 \mathrm{ml}$ & 12 & & & & & \\
\hline aminofilina $24 \mathrm{mg} / \mathrm{ml}-10 \mathrm{ml}$ & 2 & & & & & \\
\hline atropina $0,5 \mathrm{mg} / \mathrm{ml}-1 \mathrm{ml}$ & 12 & & & & & \\
\hline $\begin{array}{l}\text { bupivacaína com } \\
\text { epinefrina }(5 \mathrm{mg}+9,1 \mathrm{mcg}) / \mathrm{ml}-20 \mathrm{ml}\end{array}$ & 2 & & & & & \\
\hline bupivacaína sem epinefrina $0,5 \%-20 \mathrm{ml}$ & 2 & & & & & \\
\hline bupivacaína hiperbárica $0,5 \%-30 \mathrm{~g}$ & 2 & & & & & \\
\hline cefalotina $1 \mathrm{~g}$ & 4 & & & & & \\
\hline cetoprofeno $50 \mathrm{mg} / \mathrm{ml}-2 \mathrm{ml}$ & 2 & & & & & \\
\hline cloreto de cálcio $100 \mathrm{mg} / \mathrm{ml}-5 \mathrm{ml}$ & 4 & & & & & \\
\hline dexametasona $4 \mathrm{mg} / \mathrm{ml}-1 \mathrm{ml}$ & 12 & & & & & \\
\hline diazepam $5 \mathrm{mg} / \mathrm{ml}-2 \mathrm{ml}$ & & 2 & & & & \\
\hline dipirona $500 \mathrm{mg} / \mathrm{ml}-2 \mathrm{ml}$ & 12 & & & & & \\
\hline efedrina $25 \mathrm{mg} / \mathrm{ml}-1 \mathrm{ml}$ & 12 & & & & & \\
\hline epinefrina $1 \mathrm{mg} / \mathrm{ml}-1 \mathrm{ml}$ & 1 & & & & & \\
\hline etomidato $2 \mathrm{mg} / \mathrm{ml}-10 \mathrm{ml}$ & & 2 & & & & \\
\hline $\begin{array}{l}\text { fentanil + droperidol }(0,05 \mathrm{mg}+2,5 \mathrm{mg}) / \mathrm{ml}- \\
2 \mathrm{ml}\end{array}$ & & 4 & & & & \\
\hline fentanil $0,05 \mathrm{mg} / \mathrm{ml}-5 \mathrm{ml}$ & & 6 & 5 & 1,8 & 9 & 24,3 \\
\hline furosemida $10 \mathrm{mg} / \mathrm{ml}-2 \mathrm{ml}$ & 4 & & 3 & 0,13 & 0,39 & 1,05 \\
\hline glicose $50 \%-10 \mathrm{ml}$ & 2 & & & & & \\
\hline heparina IV 5000UI $-5 \mathrm{ml}$ & 1 & & & & & \\
\hline hidralazina $20 \mathrm{mg} / \mathrm{ml}-1 \mathrm{ml}$ & 4 & & & & & \\
\hline hidrocortisona 500mg & 4 & & & & & \\
\hline lidocaína sem epinefrina $2 \%-20 \mathrm{ml}$ & 2 & & & & & \\
\hline $\begin{array}{l}\text { lidocaína com epinefrina }(20 \mathrm{mg}+5 \mathrm{mcg}) / \mathrm{ml}- \\
20 \mathrm{ml}\end{array}$ & 2 & & & & & \\
\hline lidocaína geléia $2 \%$ - 30g & 2 & & 1 & 1,12 & 1,12 & 3,02 \\
\hline manitol $20 \%-250 \mathrm{ml}$ & & 2 & 2 & 1,51 & 3,02 & 8,15 \\
\hline metaraminol 10mg/ml - $1 \mathrm{ml}$ & 4 & & & & & \\
\hline metoclopramida $5 \mathrm{mg} / \mathrm{ml}-2 \mathrm{ml}$ & 4 & & 1 & 0,15 & 0,15 & 0,41 \\
\hline midazolam $5 \mathrm{mg} / \mathrm{ml}-3 \mathrm{ml}$ & & 2 & 1 & 2,35 & 2,35 & 6,35 \\
\hline morfina $2 \mathrm{mg} / \mathrm{ml}-1 \mathrm{ml}$ & & 3 & 2 & 0,41 & 0,82 & 2,21 \\
\hline neostigmina $0,05 \mathrm{mg} / \mathrm{ml}-1 \mathrm{ml}$ & 12 & & & & & \\
\hline petidina $50 \mathrm{mg} / \mathrm{ml}-2 \mathrm{ml}$ & & 2 & & & & \\
\hline propofol $10 \mathrm{mg} / \mathrm{ml}-20 \mathrm{ml}$ & & 4 & 2 & 8,51 & 17,02 & 46 \\
\hline ranitidina $10 \mathrm{mg} / \mathrm{ml}-5 \mathrm{ml}$ & 4 & & 2 & 0,18 & 0,36 & 0,97 \\
\hline suxametonio $100 \mathrm{mg}$ & 4 & & & & & \\
\hline tenoxicam $20 \mathrm{mg}$ & 2 & & & & & \\
\hline tramadol $50 \mathrm{mg} / \mathrm{ml}-1 \mathrm{ml}$ & & 1 & 1 & 1,52 & 1,52 & 4,1 \\
\hline Total & 130 & 28 & 20 & 17,68 & 35,75 & 96,56 \\
\hline
\end{tabular}


Tabela 32: Segundo dia de consumo na sala 21 fase pós implantação

SALA 21 - SEGUNDO DIA DE CONSUMO

\begin{tabular}{|c|c|c|c|c|c|c|}
\hline Medicamento & $\begin{array}{l}\text { Físico Inicial } \\
\text { (elenco kit) }\end{array}$ & Extra & $\begin{array}{l}\text { Quantidade } \\
\text { Utilizada }\end{array}$ & $\begin{array}{c}\text { Preço } \\
\text { Unitário }\end{array}$ & $\begin{array}{l}\text { Preço } \\
\text { Final }\end{array}$ & $\begin{array}{l}\text { Valor em } \\
\text { dólar }\end{array}$ \\
\hline agua destilada $-10 \mathrm{ml}$ & 18 & & 13 & 0,1 & 1,3 & 3,5 \\
\hline aminofilina $24 \mathrm{mg} / \mathrm{ml}-10 \mathrm{ml}$ & 3 & & 1 & 0,05 & 0,05 & 0,14 \\
\hline atropina $0,5 \mathrm{mg} / \mathrm{ml}-1 \mathrm{ml}$ & 18 & & 1 & 0,01 & 0,01 & 0,03 \\
\hline $\begin{array}{l}\text { bupivacaína com } \\
\text { epinefrina }(5 \mathrm{mg}+9,1 \mathrm{mcg}) / \mathrm{ml}\end{array}$ & 3 & & 1 & 3,98 & 3,98 & 10,75 \\
\hline bupivacaína sem epinefrina $0,5 \%-20 \mathrm{ml}$ & 3 & & & & & \\
\hline bupivacaína hiperbárica $0,5 \%-4 \mathrm{ml}$ & 3 & & 1 & 3,59 & 3,59 & 9,7 \\
\hline cefalotina $1 \mathrm{~g}$ & 6 & & 4 & 1,53 & 6,12 & 16,52 \\
\hline cetoprofeno $50 \mathrm{mg} / \mathrm{ml}-2 \mathrm{ml}$ & 3 & & 1 & 3,43 & 3,43 & 9,26 \\
\hline cloreto de cálcio $100 \mathrm{mg} / \mathrm{ml}-5 \mathrm{ml}$ & 6 & & & & & \\
\hline dexametasona $4 \mathrm{mg} / \mathrm{ml}-1 \mathrm{ml}$ & 18 & & & & & \\
\hline diazepam $5 \mathrm{mg} / \mathrm{ml}-2 \mathrm{ml}$ & & 3 & & & & \\
\hline dipirona $500 \mathrm{mg} / \mathrm{ml}-2 \mathrm{ml}$ & 18 & & 5 & 0,16 & 0,8 & 2,16 \\
\hline efedrina $25 \mathrm{mg} / \mathrm{ml}-1 \mathrm{ml}$ & 18 & & & & & \\
\hline epinefrina $1 \mathrm{mg} / \mathrm{ml}-1 \mathrm{ml}$ & 3 & & 1 & 0,15 & 0,15 & 0,41 \\
\hline etomidato $2 \mathrm{mg} / \mathrm{ml}-10 \mathrm{ml}$ & & 3 & & & & \\
\hline $\begin{array}{l}\text { fentanil + droperidol }(0,05 \mathrm{mg}+2,5 \mathrm{mg}) / \mathrm{ml}- \\
2 \mathrm{ml}\end{array}$ & & 6 & & & & \\
\hline fentanil $0,05 \mathrm{mg} / \mathrm{ml}-5 \mathrm{ml}$ & & 9 & 5 & 1,8 & 9 & 24,3 \\
\hline furosemida $10 \mathrm{mg} / \mathrm{ml}-2 \mathrm{ml}$ & 6 & & & & & \\
\hline glicose $50 \%-10 \mathrm{ml}$ & 3 & & 3 & 0,16 & 0,48 & 1,3 \\
\hline heparina IV 5000UI $-5 \mathrm{ml}$ & 3 & & & & & \\
\hline hidralazina $20 \mathrm{mg} / \mathrm{ml}-1 \mathrm{ml}$ & 6 & & & & & \\
\hline hidrocortisona $500 \mathrm{mg}$ & 6 & & & & & \\
\hline isoprenalina $0,2 \mathrm{mg} / \mathrm{ml}-1 \mathrm{ml}$ & & 1 & 1 & 0,32 & 0,32 & 0,86 \\
\hline lidocaína sem epinefrina $2 \%-20 \mathrm{ml}$ & 3 & & 1 & 0,68 & 0,68 & 1,84 \\
\hline $\begin{array}{l}\text { lidocaína com epinefrina }(20 \mathrm{mg}+5 \mathrm{mcg}) / \mathrm{ml}- \\
20 \mathrm{ml}\end{array}$ & 3 & & 1 & 1,31 & 1,31 & 3,54 \\
\hline lidocaína geléia $2 \%-30 \mathrm{~g}$ & 3 & & 3 & 1,12 & 3,36 & 9,07 \\
\hline metaraminol10mg/ml - 1ml & 6 & & & & & \\
\hline metoclopramida $5 \mathrm{mg} / \mathrm{ml}-2 \mathrm{ml}$ & 6 & & 1 & 0,15 & 0,15 & 0,41 \\
\hline midazolam $5 \mathrm{mg} / \mathrm{ml}-3 \mathrm{ml}$ & & 3 & 2 & 2,35 & 4,7 & 12,69 \\
\hline morfina $2 \mathrm{mg} / \mathrm{ml}-1 \mathrm{ml}$ & & 3 & 1 & 0,41 & 0,41 & 1,11 \\
\hline neostigmina $0,05 \mathrm{mg} / \mathrm{ml}-1 \mathrm{ml}$ & 18 & & & & & \\
\hline petidina $50 \mathrm{mg} / \mathrm{ml}-2 \mathrm{ml}$ & & 3 & & & & \\
\hline propofol 10mg/ml -20ml & & 6 & 1 & 8,51 & 8,51 & 22,98 \\
\hline ranitidina $10 \mathrm{mg} / \mathrm{ml}-5 \mathrm{ml}$ & 6 & & 2 & 0,18 & 0,36 & 0,97 \\
\hline suxametonio $100 \mathrm{mg}$ & 6 & & 1 & 1,53 & 1,53 & 4,13 \\
\hline tenoxicam $20 \mathrm{mg}$ & 3 & & & & & \\
\hline tramadol $50 \mathrm{mg} / \mathrm{ml}-1 \mathrm{ml}$ & & 1 & 1 & 1,52 & 1,52 & 4,1 \\
\hline Total & 198 & 38 & 51 & 33,04 & 51,76 & 139,77 \\
\hline
\end{tabular}


Tabela 33: Terceiro dia de consumo na sala 21 fase pós implantação

SALA 21 - TERCERO DIA DE CONSUMO

\begin{tabular}{|c|c|c|c|c|c|c|}
\hline Medicamento & $\begin{array}{l}\text { Físico Inicial } \\
\text { (elenco kit) }\end{array}$ & Extra & $\begin{array}{l}\text { Quantidade } \\
\text { Utilizada }\end{array}$ & $\begin{array}{c}\text { Preço } \\
\text { Unitário }\end{array}$ & $\begin{array}{l}\text { Preço } \\
\text { Final }\end{array}$ & $\begin{array}{l}\text { Valor em } \\
\text { dólar }\end{array}$ \\
\hline agua destilada $-10 \mathrm{ml}$ & 12 & & 7 & 0,1 & 0,7 & 1,89 \\
\hline Alfentanila $0,5 \mathrm{mg} / \mathrm{ml}-5 \mathrm{ml}$ & & 1 & 1 & 8,63 & 8,63 & 23,3 \\
\hline Aminofilina $24 \mathrm{mg} / \mathrm{ml}-10 \mathrm{ml}$ & 2 & & & & & \\
\hline Atropina $0,5 \mathrm{mg} / \mathrm{ml}-1 \mathrm{ml}$ & 12 & & 1 & 0,01 & 0,01 & 0,03 \\
\hline $\begin{array}{l}\text { bupivacaína com } \\
\text { epinefrina }(5 \mathrm{mg}+9,1 \mathrm{mcg}) / \mathrm{ml}-20 \mathrm{ml}\end{array}$ & 2 & & & & & \\
\hline bupivacaína sem epinefrina $0,5 \%-20 \mathrm{ml}$ & 2 & & & & & \\
\hline bupivacaína hiperbárica $0,5 \%-4 \mathrm{ml}$ & 2 & & & & & \\
\hline Cefalotina $1 \mathrm{~g}$ & 4 & & 4 & 1,53 & 6,12 & 16,52 \\
\hline Cetoprofeno $50 \mathrm{mg} / \mathrm{ml}-2 \mathrm{ml}$ & 2 & & 1 & 3,43 & 3,43 & 9,26 \\
\hline Cloreto de cálcio $100 \mathrm{mg} / \mathrm{ml}-5 \mathrm{ml}$ & 4 & & & & & \\
\hline Dexametasona $4 \mathrm{mg} / \mathrm{ml}-1 \mathrm{ml}$ & 12 & & & & & \\
\hline Diazepam $5 \mathrm{mg} / \mathrm{ml}-2 \mathrm{ml}$ & & 2 & & & & \\
\hline Dipirona $500 \mathrm{mg} / \mathrm{ml}-1 \mathrm{ml}$ & 12 & & 2 & 0,16 & 0,32 & 0,86 \\
\hline Efedrina $25 \mathrm{mg} / \mathrm{ml}-1 \mathrm{ml}$ & 12 & & & & & \\
\hline Epinefrina $1 \mathrm{mg} / \mathrm{ml}-1 \mathrm{ml}$ & 2 & & & & & \\
\hline Etomidato $2 \mathrm{mg} / \mathrm{ml}-10 \mathrm{ml}$ & & 2 & 1 & 3,18 & 3,18 & 8,59 \\
\hline $\begin{array}{l}\text { fentanil + droperidol }(0,05 \mathrm{mg}+2,5 \mathrm{mg}) / \mathrm{ml}- \\
2 \mathrm{ml}\end{array}$ & & 4 & & & & \\
\hline fentanil $0,05 \mathrm{mg} / \mathrm{ml}-5 \mathrm{ml}$ & & 6 & 5 & 1,8 & 9 & 24,3 \\
\hline Furosemida $10 \mathrm{mg} / \mathrm{ml}-2 \mathrm{ml}$ & 4 & & & & & \\
\hline glicose $50 \%-10 \mathrm{ml}$ & 2 & & & & & \\
\hline heparina IV 5000UI - 5ml & 2 & & & & & \\
\hline hidralazina $20 \mathrm{mg} / \mathrm{ml}-1 \mathrm{ml}$ & 4 & & & & & \\
\hline hidrocortisona $500 \mathrm{mg}$ & 4 & & & & & \\
\hline lidocaína sem epinefrina $2 \%-20 \mathrm{ml}$ & 2 & & 1 & 0,68 & 0,68 & 1,84 \\
\hline $\begin{array}{l}\text { lidocaína com epinefrina }(20 \mathrm{mg}+5 \mathrm{mcg}) / \mathrm{ml}- \\
20 \mathrm{ml}\end{array}$ & 2 & & 1 & 1,31 & 1,31 & 3,54 \\
\hline lidocaína geléia $2 \%-30 \mathrm{~g}$ & 2 & & & & & \\
\hline metaraminol $10 \mathrm{mg} / \mathrm{ml}-1 \mathrm{ml}$ & 4 & & & & & \\
\hline metoclopramida $5 \mathrm{mg} / \mathrm{ml}-2 \mathrm{ml}$ & 4 & & 2 & 0,15 & 0,3 & 0,81 \\
\hline midazolam $5 \mathrm{mg} / \mathrm{ml}-3 \mathrm{ml}$ & & 2 & & & & \\
\hline morfina $2 \mathrm{mg} / \mathrm{ml}-1 \mathrm{ml}$ & & 2 & & & & \\
\hline neostigmina $0,05 \mathrm{mg} / \mathrm{ml}-1 \mathrm{ml}$ & 12 & & 2 & 0,46 & 0,92 & 2,48 \\
\hline petidina $50 \mathrm{mg} / \mathrm{ml}-2 \mathrm{ml}$ & & 2 & & & & \\
\hline propofol $10 \mathrm{mg} / \mathrm{ml}-20 \mathrm{ml}$ & & 2 & 2 & 8,51 & 17,02 & 45,95 \\
\hline ranitidina $10 \mathrm{mg} / \mathrm{ml}-5 \mathrm{ml}$ & 4 & & 2 & 0,18 & 0,36 & 0,97 \\
\hline suxametonio $100 \mathrm{mg}$ & 4 & & & & & \\
\hline tenoxicam $20 \mathrm{mg}$ & 2 & & & & & \\
\hline Total & 132 & 25 & 32 & 30,13 & 51,98 & 140,34 \\
\hline
\end{tabular}


Tabela 34: Primeiro dia de consumo na sala 22 fase pós implantação

\begin{tabular}{|c|c|c|c|c|c|c|}
\hline \multicolumn{7}{|c|}{ SALA 22 - PRIMEIRO DIA DE CONSUMO } \\
\hline Medicamento & $\begin{array}{l}\text { Físico Inicial } \\
\text { (elenco kit) }\end{array}$ & Extra & $\begin{array}{l}\text { Quantidade } \\
\text { Utilizada }\end{array}$ & $\begin{array}{c}\text { Preço } \\
\text { Unitário }\end{array}$ & $\begin{array}{l}\text { Preço } \\
\text { Final }\end{array}$ & $\begin{array}{l}\text { Valor em } \\
\text { dólar }\end{array}$ \\
\hline agua destilada $-10 \mathrm{ml}$ & 18 & & & & & \\
\hline Aminofilina $24 \mathrm{mg} / \mathrm{ml}-10 \mathrm{ml}$ & 3 & & & & & \\
\hline Atropina $0,5 \mathrm{mg} / \mathrm{ml}-1 \mathrm{ml}$ & 18 & & & & & \\
\hline $\begin{array}{l}\text { bupivacaína com } \\
\text { epinefrina }(5 \mathrm{mg}+9,1 \mathrm{mcg}) / \mathrm{ml}-20 \mathrm{ml}\end{array}$ & 3 & & & & & \\
\hline bupivacaína sem epinefrina $0,5 \%-20 \mathrm{ml}$ & 3 & & & & & \\
\hline bupivacaína hiperbárica $0,5 \%-4 \mathrm{ml}$ & 3 & & & & & \\
\hline Cefalotina $1 \mathrm{~g}$ & 6 & & 1 & 1,53 & 1,53 & 4,13 \\
\hline Cetoprofeno $50 \mathrm{mg} / \mathrm{ml}-2 \mathrm{ml}$ & 3 & & & & & \\
\hline Cloreto de cálcio $100 \mathrm{mg} / \mathrm{ml}-5 \mathrm{ml}$ & 6 & & & & & \\
\hline Dexametasona $4 \mathrm{mg} / \mathrm{ml}-1 \mathrm{ml}$ & 18 & & & & & \\
\hline Diazepam $5 \mathrm{mg} / \mathrm{ml}-2 \mathrm{ml}$ & & 3 & & & & \\
\hline Dipirona $500 \mathrm{mg} / \mathrm{ml}-2 \mathrm{ml}$ & 18 & & 1 & 0,16 & 0,16 & 0,43 \\
\hline Efedrina $25 \mathrm{mg} / \mathrm{ml}-1 \mathrm{ml}$ & 18 & & & & & \\
\hline Epinefrina $1 \mathrm{mg} / \mathrm{ml}-1 \mathrm{ml}$ & 3 & & & & & \\
\hline Etomidato $2 \mathrm{mg} / \mathrm{ml}-10 \mathrm{ml}$ & & 3 & & & & \\
\hline $\begin{array}{l}\text { fentanil + droperidol }(0,05 \mathrm{mg}+2,5 \mathrm{mg}) / \mathrm{ml}- \\
2 \mathrm{ml}\end{array}$ & & 6 & & & & \\
\hline Fentanil $0,05 \mathrm{mg} / \mathrm{ml}-5 \mathrm{ml}$ & & 9 & 5 & 1,8 & 9 & 24,3 \\
\hline Furosemida $10 \mathrm{mg} / \mathrm{ml}-2 \mathrm{ml}$ & 6 & & & & & \\
\hline glicose $50 \%-10 \mathrm{ml}$ & 3 & & & & & \\
\hline heparina IV 5000UI $-5 \mathrm{ml}$ & 3 & & & & & \\
\hline hidralazina $20 \mathrm{mg} / \mathrm{ml}-1 \mathrm{ml}$ & 6 & & & & & \\
\hline hidrocortisona $500 \mathrm{mg}$ & 6 & & & & & \\
\hline lidocaína sem epinefrina $2 \%-20 \mathrm{ml}$ & 3 & & & & & \\
\hline $\begin{array}{l}\text { lidocaína com epinefrina }(20 \mathrm{mg}+5 \mathrm{mcg}) / \mathrm{ml}- \\
20 \mathrm{ml}\end{array}$ & 3 & & 1 & 1,31 & 1,31 & 3,54 \\
\hline lidocaína geléia $2 \%-30 \mathrm{~g}$ & 3 & & 3 & 1,12 & 3,36 & 9,07 \\
\hline metaraminol $10 \mathrm{mg} / \mathrm{ml}-1 \mathrm{ml}$ & 6 & & & & & \\
\hline metoclopramida $5 \mathrm{mg} / \mathrm{ml}-2 \mathrm{ml}$ & 6 & & 2 & 0,15 & 0,3 & 0,81 \\
\hline midazolam $5 \mathrm{mg} / \mathrm{ml}-3 \mathrm{ml}$ & & 3 & 2 & 2,35 & 4,7 & 12,7 \\
\hline morfina $2 \mathrm{mg} / \mathrm{ml}-1 \mathrm{ml}$ & & 3 & 2 & 0,41 & 0,82 & 2,21 \\
\hline neostigmina $0,05 \mathrm{mg} / \mathrm{ml}-1 \mathrm{ml}$ & 18 & & & & & \\
\hline petidina $50 \mathrm{mg} / \mathrm{ml}-2 \mathrm{ml}$ & & 3 & & & & \\
\hline propofol $10 \mathrm{mg} / \mathrm{ml}-20 \mathrm{ml}$ & & 6 & 4 & 8,51 & 34,04 & 91,91 \\
\hline ranitidina $10 \mathrm{mg} / \mathrm{ml}-5 \mathrm{ml}$ & 6 & & 4 & 0,18 & 0,72 & 1,94 \\
\hline suxametonio $100 \mathrm{mg}$ & 6 & & & & & \\
\hline tenoxicam $20 \mathrm{mg}$ & 3 & & & & & \\
\hline Total & 198 & 36 & 25 & 17,52 & 55,94 & 151,04 \\
\hline
\end{tabular}


Tabela 35: Segundo dia de consumo na sala 22 fase pós implantação

SALA 22 - SEGUNDO DIA DE CONSUMO

\begin{tabular}{|c|c|c|c|c|c|c|}
\hline Medicamento & $\begin{array}{l}\text { Físico Inicial } \\
\text { (elenco kit) }\end{array}$ & Extra & $\begin{array}{l}\text { Quantidade } \\
\text { Utilizada }\end{array}$ & $\begin{array}{c}\text { Preço } \\
\text { Unitário }\end{array}$ & $\begin{array}{l}\text { Preço } \\
\text { Final }\end{array}$ & $\begin{array}{l}\text { Valor em } \\
\text { dólar }\end{array}$ \\
\hline agua destilada $-10 \mathrm{ml}$ & 18 & & & & & \\
\hline Aminofilina $24 \mathrm{mg} / \mathrm{ml}-10 \mathrm{ml}$ & 3 & & & & & \\
\hline Atropina $0,5 \mathrm{mg} / \mathrm{ml}-1 \mathrm{ml}$ & 18 & & & & & \\
\hline $\begin{array}{l}\text { bupivacaína com } \\
\text { epinefrina }(5 \mathrm{mg}+9,1 \mathrm{mcg}) / \mathrm{ml}-20 \mathrm{ml}\end{array}$ & 3 & & & & & \\
\hline bupivacaína sem epinefrina $0,5 \%-20 \mathrm{ml}$ & 3 & & & & & \\
\hline bupivacaína hiperbárica $0,5 \%-4 \mathrm{ml}$ & 3 & & & & & \\
\hline Cefalotina $1 \mathrm{~g}$ & 6 & & 2 & 1,53 & 3,06 & 8,26 \\
\hline Cetoprofeno $50 \mathrm{mg} / \mathrm{ml}-2 \mathrm{ml}$ & 3 & & & & & \\
\hline Cloreto de cálcio $100 \mathrm{mg} / \mathrm{ml}-10 \mathrm{ml}$ & 6 & & & & & \\
\hline Dexametasona 4mg/ml -1ml & 18 & & & & & \\
\hline Diazepam $5 \mathrm{mg} / \mathrm{ml}-2 \mathrm{ml}$ & & 3 & & & & \\
\hline Dipirona $500 \mathrm{mg} / \mathrm{ml}-1 \mathrm{ml}$ & 18 & & 2 & 0,16 & 0,32 & 0,86 \\
\hline Efedrina $25 \mathrm{mg} / \mathrm{ml}-1 \mathrm{ml}$ & 18 & & & & & \\
\hline Epinefrina $1 \mathrm{mg} / \mathrm{ml}-1 \mathrm{ml}$ & 3 & & & & & \\
\hline Etomidato $2 \mathrm{mg} / \mathrm{ml}-10 \mathrm{ml}$ & & 3 & & & & \\
\hline $\begin{array}{l}\text { fentanil + droperidol }(0,05 \mathrm{mg}+2,5 \mathrm{mg}) / \mathrm{ml}- \\
2 \mathrm{ml}\end{array}$ & & 6 & & & & \\
\hline fentanil $0,05 \mathrm{mg} / \mathrm{ml}-5 \mathrm{ml}$ & & 9 & 7 & 1,8 & 12,6 & 34,02 \\
\hline Furosemida $10 \mathrm{mg} / \mathrm{ml}-2 \mathrm{ml}$ & 6 & & & & & \\
\hline glicose $50 \%-10 \mathrm{ml}$ & 3 & & & & & \\
\hline heparina IV 5000UI - 5ml & 3 & & & & & \\
\hline hidralazina $20 \mathrm{mg} / \mathrm{ml}-1 \mathrm{ml}$ & 6 & & & & & \\
\hline hidrocortisona $500 \mathrm{mg}$ & 6 & & & & & \\
\hline lidocaína sem epinefrina $2 \%$ - $20 \mathrm{ml}$ & 3 & & & & & \\
\hline $\begin{array}{l}\text { lidocaína com epinefrina }(20 \mathrm{mg}+5 \mathrm{mcg}) / \mathrm{ml}- \\
20 \mathrm{ml}\end{array}$ & 3 & & & & & \\
\hline lidocaína geléia $2 \%-30 \mathrm{~g}$ & 3 & & 2 & 1,12 & 2,24 & 6,05 \\
\hline metaraminol $10 \mathrm{mg} / \mathrm{ml}-1 \mathrm{ml}$ & 6 & & & & & \\
\hline metoclopramida $5 \mathrm{mg} / \mathrm{ml}-2 \mathrm{ml}$ & 6 & & 3 & 0,15 & 0,45 & 1,22 \\
\hline midazolam $5 \mathrm{mg} / \mathrm{ml}-3 \mathrm{ml}$ & & 3 & 2 & 2,35 & 4,7 & 12,69 \\
\hline morfina $2 \mathrm{mg} / \mathrm{ml}-1 \mathrm{ml}$ & & 3 & & & & \\
\hline neostigmina $0,05 \mathrm{mg} / \mathrm{ml}-1 \mathrm{ml}$ & 18 & & & & & \\
\hline petidina $50 \mathrm{mg} / \mathrm{ml}-2 \mathrm{ml}$ & & 3 & & & & \\
\hline propofol $10 \mathrm{mg} / \mathrm{ml}-20 \mathrm{ml}$ & & 6 & 3 & 8,51 & 25,23 & 68,12 \\
\hline ranitidina $10 \mathrm{mg} / \mathrm{ml}-5 \mathrm{ml}$ & 6 & & 5 & 0,18 & 0,9 & 2,43 \\
\hline suxametonio $100 \mathrm{mg}$ & 6 & & & & & \\
\hline tenoxicam $20 \mathrm{mg}$ & 3 & & & & & \\
\hline Total & 198 & 36 & 26 & 15,7 & 49,5 & 133,65 \\
\hline
\end{tabular}


Tabela 36: Terceiro dia de consumo na sala 22 fase pós implantação

\begin{tabular}{|c|c|c|c|c|c|c|}
\hline \multicolumn{7}{|c|}{ SALA 22 - TERCEIRO DIA DE CONSUMO } \\
\hline Medicamento & $\begin{array}{l}\text { Físico Inicial } \\
\text { (elenco kit) }\end{array}$ & Extra & $\begin{array}{l}\text { Quantidade } \\
\text { Utilizada }\end{array}$ & $\begin{array}{c}\text { Preço } \\
\text { Unitário }\end{array}$ & $\begin{array}{l}\text { Preço } \\
\text { Final }\end{array}$ & $\begin{array}{l}\text { Valor em } \\
\text { dólar }\end{array}$ \\
\hline agua destilada $-10 \mathrm{ml}$ & 18 & & & & & \\
\hline aminofilina $24 \mathrm{mg} / \mathrm{ml}-10 \mathrm{ml}$ & 3 & & & & & \\
\hline atropina $0,5 \mathrm{mg} / \mathrm{ml}-1 \mathrm{ml}$ & 18 & & 1 & 0,01 & 0,01 & 0,03 \\
\hline $\begin{array}{l}\text { bupivacaína com } \\
\text { epinefrina }(5 \mathrm{mg}+9,1 \mathrm{mcg}) / \mathrm{ml}-20 \mathrm{ml}\end{array}$ & 3 & & & & & \\
\hline bupivacaína sem epinefrina $0,5 \%-20 \mathrm{ml}$ & 3 & & & & & \\
\hline bupivacaína hiperbárica $0,5 \%-4 \mathrm{ml}$ & 3 & & 1 & 3,59 & 3,59 & 9,69 \\
\hline cefalotina $1 \mathrm{~g}$ & 6 & & 3 & 1,53 & 4,59 & 12,39 \\
\hline cetoprofeno $50 \mathrm{mg} / \mathrm{ml}-2 \mathrm{ml}$ & 3 & & & & & \\
\hline cloreto de cálcio $100 \mathrm{mg} / \mathrm{ml}-5 \mathrm{ml}$ & 6 & & & & & \\
\hline dexametasona $4 \mathrm{mg} / \mathrm{ml}-1 \mathrm{ml}$ & 18 & & & & & \\
\hline diazepam $5 \mathrm{mg} / \mathrm{ml}-2 \mathrm{ml}$ & & 3 & & & & \\
\hline dipirona $500 \mathrm{mg} / \mathrm{ml}-2 \mathrm{ml}$ & 18 & & 1 & 0,16 & 0,16 & 0,43 \\
\hline efedrina $25 \mathrm{mg} / \mathrm{ml}-1 \mathrm{ml}$ & 18 & & & & & \\
\hline epinefrina $1 \mathrm{mg} / \mathrm{ml}-1 \mathrm{ml}$ & 3 & & & & & \\
\hline etominato $2 \mathrm{mg} / \mathrm{ml}-10 \mathrm{ml}$ & & 3 & & & & \\
\hline $\begin{array}{l}\text { fentanil + droperidol }(0,05 \mathrm{mg}+2,5 \mathrm{mg}) / \mathrm{ml}- \\
2 \mathrm{ml}\end{array}$ & & 6 & & & & \\
\hline fentanil $0,05 \mathrm{mg} / \mathrm{ml}-5 \mathrm{ml}$ & & 9 & 5 & 1,8 & 9 & 24,3 \\
\hline furosemida $10 \mathrm{mg} / \mathrm{ml}-2 \mathrm{ml}$ & 6 & & & & & \\
\hline glicose $50 \%-10 \mathrm{ml}$ & 3 & & 1 & 0,16 & 0,16 & 0,43 \\
\hline heparina IV 5000UI - 5ml & 3 & & & & & \\
\hline hidralazina $20 \mathrm{mg} / \mathrm{ml}-1 \mathrm{ml}$ & 6 & & & & & \\
\hline hidrocortisona $500 \mathrm{mg}$ & 6 & & & & & \\
\hline lidocaína sem epinefrina $2 \%-20 \mathrm{ml}$ & 3 & & & & & \\
\hline $\begin{array}{l}\text { lidocaína com epinefrina }(20 \mathrm{mg}+5 \mathrm{mcg}) / \mathrm{ml}- \\
20 \mathrm{ml}\end{array}$ & 3 & & 1 & 1,31 & 1,31 & 3,54 \\
\hline lidocaína geléia $2 \%-30 \mathrm{~g}$ & 3 & & 1 & 1,12 & 1,12 & 3,02 \\
\hline metaraminol $10 \mathrm{mg} / \mathrm{ml}-1 \mathrm{ml}$ & 6 & & & & & \\
\hline metoclopramida $5 \mathrm{mg} / \mathrm{ml}-2 \mathrm{ml}$ & 6 & & 1 & 0,15 & 0,15 & 0,41 \\
\hline midazolam $5 \mathrm{mg} / \mathrm{ml}-3 \mathrm{ml}$ & & 3 & 2 & 2,35 & 4,7 & 12,69 \\
\hline morfina $2 \mathrm{mg} / \mathrm{ml}-1 \mathrm{ml}$ & & 3 & 1 & 0,41 & 0,41 & 1,11 \\
\hline neostigmina $0,05 \mathrm{mg} / \mathrm{ml}-1 \mathrm{ml}$ & 18 & & & & & \\
\hline petidina $50 \mathrm{mg} / \mathrm{ml}-2 \mathrm{ml}$ & & 3 & & & & \\
\hline propofol $10 \mathrm{mg} / \mathrm{ml}-20 \mathrm{ml}$ & & 6 & 2 & 8,51 & 17,02 & 45,95 \\
\hline ranitidina $10 \mathrm{mg} / \mathrm{ml}-5 \mathrm{ml}$ & 6 & & 2 & 0,18 & 0,36 & 0,97 \\
\hline suxametônio $100 \mathrm{mg}$ & 6 & & 1 & 1,53 & 1,53 & 4,13 \\
\hline tenoxicam $20 \mathrm{mg}$ & 3 & & & & & \\
\hline Total & 198 & 36 & 23 & 22,81 & 44,11 & 119,09 \\
\hline
\end{tabular}


Tabela 37: Primeiro dia de consumo na sala 23 fase pós implantação

\begin{tabular}{|c|c|c|c|c|c|c|}
\hline \multicolumn{7}{|c|}{ SALA 23 - PRIMEIRO DIA DE CONSUMO } \\
\hline Medicamento & $\begin{array}{l}\text { Físico Inicial } \\
\text { (elenco kit) }\end{array}$ & Extra & $\begin{array}{c}\text { Quantidade } \\
\text { Utilizada }\end{array}$ & \begin{tabular}{|c|} 
Preço \\
Unitário \\
\end{tabular} & $\begin{array}{l}\text { Preço } \\
\text { Final }\end{array}$ & $\begin{array}{l}\text { Valor em } \\
\text { dólar }\end{array}$ \\
\hline agua destilada $-10 \mathrm{ml}$ & 12 & & & & & \\
\hline amido hidroxietílico $6 \%-500 \mathrm{ml}$ & & 1 & 1 & 17,64 & 17,64 & 47,63 \\
\hline aminofilina $24 \mathrm{mg} / \mathrm{ml}-10 \mathrm{ml}$ & 2 & & & & & \\
\hline atropina $0,5 \mathrm{mg} / \mathrm{ml}-1 \mathrm{ml}$ & 12 & & & & & \\
\hline $\begin{array}{l}\text { bupivacaína com } \\
\text { epinefrina }(5 \mathrm{mg}+9,1 \mathrm{mcg}) / \mathrm{ml}-20 \mathrm{ml}\end{array}$ & 2 & & 2 & 3,98 & 7,96 & 21,49 \\
\hline bupivacaína sem epinefrina $0,5 \%-20 \mathrm{ml}$ & 2 & & & & & \\
\hline bupivacaína hiperbárica $0,5 \%-4 \mathrm{ml}$ & 2 & & & & & \\
\hline cefalotina $1 \mathrm{~g}$ & 4 & & & & & \\
\hline cefoxitina $1 \mathrm{~g}$ & & 1 & 1 & 8,27 & 8,27 & 22,33 \\
\hline cetoprofeno $50 \mathrm{mg} / \mathrm{ml}-2 \mathrm{ml}$ & 2 & & 2 & 0,49 & 0,98 & 2,65 \\
\hline cloreto de cálcio $100 \mathrm{mg} / \mathrm{ml}-5 \mathrm{ml}$ & 4 & & & & & \\
\hline dexametasona $4 \mathrm{mg} / \mathrm{ml}-1 \mathrm{ml}$ & 12 & & & & & \\
\hline diazepam $5 \mathrm{mg} / \mathrm{ml}-2 \mathrm{ml}$ & & 2 & & & & \\
\hline dipirona $500 \mathrm{mg} / \mathrm{ml}-2 \mathrm{ml}$ & 12 & & 4 & 0,16 & 0,64 & 1,73 \\
\hline efedrina $25 \mathrm{mg} / \mathrm{ml}-1 \mathrm{ml}$ & 12 & & & & & \\
\hline epinefrina $1 \mathrm{mg} / \mathrm{ml}-1 \mathrm{ml}$ & 2 & & & & & \\
\hline etomidato $2 \mathrm{mg} / \mathrm{ml}-10 \mathrm{ml}$ & & 2 & 1 & 3,18 & 3,18 & 8,59 \\
\hline $\begin{array}{l}\text { fentanil + droperidol }(0,05 \mathrm{mg}+2,5 \mathrm{mg}) / \mathrm{ml}- \\
2 \mathrm{ml}\end{array}$ & & 4 & & & & \\
\hline fentanil $0,05 \mathrm{mg} / \mathrm{ml}-5 \mathrm{ml}$ & & 6 & 5 & 1,8 & 9 & 24,3 \\
\hline furosemida $10 \mathrm{mg} / \mathrm{ml}-2 \mathrm{ml}$ & 4 & & 1 & 0,13 & 0,13 & 0,35 \\
\hline glicose $50 \%-10 \mathrm{ml}$ & 2 & & & & & \\
\hline heparina IV 5000UI $-5 \mathrm{ml}$ & 2 & & & & & \\
\hline hidralazina $20 \mathrm{mg} / \mathrm{ml}-1 \mathrm{ml}$ & 4 & & & & & \\
\hline hidrocortisona $500 \mathrm{mg}$ & 4 & & & & & \\
\hline isoprenalina $0,2 \mathrm{mg} / \mathrm{ml}-1 \mathrm{ml}$ & & 1 & 1 & 0,32 & 0,32 & 0,86 \\
\hline lidocaína sem epinefrina $2 \%-20 \mathrm{ml}$ & 2 & & 2 & 0,68 & 1,36 & 3,67 \\
\hline $\begin{array}{l}\text { lidocaína com epinefrina }(20 \mathrm{mg}+5 \mathrm{mcg}) / \mathrm{ml} \\
-20 \mathrm{ml}\end{array}$ & 2 & & & & & \\
\hline lidocaína geléia $2 \%-30 \mathrm{~g}$ & 2 & & & & & \\
\hline metaraminol $10 \mathrm{mg} / \mathrm{ml}-2 \mathrm{ml}$ & 4 & & & & & \\
\hline metoclopramida $5 \mathrm{mg} / \mathrm{ml}-2 \mathrm{ml}$ & 4 & & 1 & 0,15 & 0,15 & 0,41 \\
\hline metronidazol 5mg/ml -100ml & & 1 & 1 & 9,24 & 9,24 & 24,95 \\
\hline metoprolol 1mg/ml -5ml & & 1 & 1 & 9,24 & 9,24 & 24,95 \\
\hline midazolam $5 \mathrm{mg} / \mathrm{ml}-3 \mathrm{ml}$ & & 2 & 2 & 2,35 & 4,7 & 12,69 \\
\hline morfina $2 \mathrm{mg} / \mathrm{ml}-1 \mathrm{ml}$ & & 2 & & & & \\
\hline neostigmina $0,05 \mathrm{mg} / \mathrm{ml}-1 \mathrm{ml}$ & 12 & & & & & \\
\hline petidina $50 \mathrm{mg} / \mathrm{ml}-2 \mathrm{ml}$ & & 2 & & & & \\
\hline propofol $10 \mathrm{mg} / \mathrm{ml}-20 \mathrm{ml}$ & & 4 & 2 & 8,51 & 17,02 & 45,95 \\
\hline ranitidina $10 \mathrm{mg} / \mathrm{ml}-2 \mathrm{ml}$ & 4 & & 1 & 0,18 & 0,18 & 0,49 \\
\hline sufentanila $50 \mathrm{mcg} / \mathrm{ml}-1 \mathrm{ml}$ & & 3 & 3 & 4,08 & 12,24 & 33,05 \\
\hline suxametonio $100 \mathrm{mg}$ & 4 & & & & & \\
\hline tenoxicam $20 \mathrm{mg}$ & 2 & & & & & \\
\hline Total & 132 & 32 & 31 & 70,4 & 102,25 & 276,09 \\
\hline
\end{tabular}


Tabela 38: Segundo dia de consumo na sala 23 fase pós implantação

\begin{tabular}{|c|c|c|c|c|c|c|}
\hline \multicolumn{7}{|c|}{ SALA 23 - SEGUNDO DIA DE CONSUMO } \\
\hline Medicamento & $\begin{array}{l}\text { Físico Inicial } \\
\text { (elenco kit) }\end{array}$ & Extra & $\begin{array}{l}\text { Quantidade } \\
\text { Utilizada }\end{array}$ & $\begin{array}{c}\text { Preço } \\
\text { Unitário }\end{array}$ & $\begin{array}{l}\text { Preço } \\
\text { Final }\end{array}$ & $\begin{array}{l}\text { Valor em } \\
\text { dólar }\end{array}$ \\
\hline agua destilada $-10 \mathrm{ml}$ & 12 & & & & & \\
\hline alfentanila $0,5 \mathrm{mg} / \mathrm{ml}-5 \mathrm{ml}$ & & 5 & 5 & 8,63 & 43,15 & 116,51 \\
\hline aminofilina $24 \mathrm{mg} / \mathrm{ml}-10 \mathrm{ml}$ & 2 & & & & & \\
\hline atropina $0,5 \mathrm{mg} / \mathrm{ml}-1 \mathrm{ml}$ & 12 & & & & & \\
\hline $\begin{array}{l}\text { bupivacaína com } \\
\text { epinefrina }(5 \mathrm{mg}+9,1 \mathrm{mcg}) / \mathrm{ml}-20 \mathrm{ml}\end{array}$ & 2 & & & & & \\
\hline bupivacaína sem epinefrina $0,5 \%-20 \mathrm{ml}$ & 2 & & & & & \\
\hline bupivacaína hiperbárica $0,5 \%-4 \mathrm{ml}$ & 2 & & & & & \\
\hline cefalotina $1 \mathrm{~g}$ & 4 & & & & & \\
\hline cetoprofeno $50 \mathrm{mg} / \mathrm{ml}-2 \mathrm{ml}$ & 2 & & & & & \\
\hline cloreto de cálcio $100 \mathrm{mg} / \mathrm{ml}-5 \mathrm{ml}$ & 4 & & & & & \\
\hline dexametasona $4 \mathrm{mg} / \mathrm{ml}-1 \mathrm{ml}$ & 12 & & & & & \\
\hline diazepam $5 \mathrm{mg} / \mathrm{ml}-2 \mathrm{ml}$ & & 2 & & & & \\
\hline dipirona $500 \mathrm{mg} / \mathrm{ml}-2 \mathrm{ml}$ & 12 & & 2 & 0,16 & 0,32 & 0,86 \\
\hline efedrina $25 \mathrm{mg} / \mathrm{ml}-1 \mathrm{ml}$ & 12 & & & & & \\
\hline epinefrina $1 \mathrm{mg} / \mathrm{ml}-1 \mathrm{ml}$ & 2 & & & & & \\
\hline esponja gel hemostática -1unidade & & 1 & 1 & 70,36 & 70,36 & 189,97 \\
\hline etomidato $2 \mathrm{mg} / \mathrm{ml}-10 \mathrm{ml}$ & & 2 & 1 & 3,18 & 3,18 & 8,59 \\
\hline $\begin{array}{l}\text { fentanil + droperidol }(0,05 \mathrm{mg}+2,5 \mathrm{mg}) / \mathrm{ml}- \\
2 \mathrm{ml}\end{array}$ & & 4 & & & & \\
\hline fentanil $0,05 \mathrm{mg} / \mathrm{ml}-5 \mathrm{ml}$ & & 6 & 5 & 1,8 & 9 & 24,3 \\
\hline furosemida $10 \mathrm{mg} / \mathrm{ml}-2 \mathrm{ml}$ & 4 & & & & & \\
\hline glicose $50 \%-10 \mathrm{ml}$ & 2 & & & 1 & 1 & 2,7 \\
\hline heparina IV 500UI - 5ml & 2 & & & & & \\
\hline hidralazina $20 \mathrm{mg} / \mathrm{ml}-1 \mathrm{ml}$ & 4 & & & & & \\
\hline hidrocortisona $500 \mathrm{mg}$ & 4 & & & & & \\
\hline lidocaína sem epinefrina $2 \%-20 \mathrm{ml}$ & 2 & & & & & \\
\hline $\begin{array}{l}\text { lidocaína com epinefrina }(20 \mathrm{mg}+5 \mathrm{mcg}) / \mathrm{ml} \\
-20 \mathrm{ml}\end{array}$ & 2 & & & & & \\
\hline lidocaína geléia $2 \%$ - 30g & 2 & & & & & \\
\hline metaraminol $10 \mathrm{mg} / \mathrm{ml}-1 \mathrm{ml}$ & 4 & & & & & \\
\hline metoclopramida $5 \mathrm{mg} / \mathrm{ml}-2 \mathrm{ml}$ & 4 & & 2 & 0,15 & 0,3 & 0,81 \\
\hline midazolam $5 \mathrm{mg} / \mathrm{ml}-3 \mathrm{ml}$ & & 2 & 2 & 2,35 & 4,7 & 12,69 \\
\hline morfina $2 \mathrm{mg} / \mathrm{ml}-1 \mathrm{ml}$ & & 2 & & & & \\
\hline neostigmina $0,05 \mathrm{mg} / \mathrm{ml}-1 \mathrm{ml}$ & 12 & & & & & \\
\hline petidina $50 \mathrm{mg} / \mathrm{ml}-2 \mathrm{ml}$ & & 2 & & & & \\
\hline propofol $10 \mathrm{mg} / \mathrm{ml}-20 \mathrm{ml}$ & & 4 & 4 & 8,51 & 34,04 & 91,91 \\
\hline ranitidina $10 \mathrm{mg} / \mathrm{ml}-5 \mathrm{ml}$ & 4 & & 2 & 0,18 & 0,36 & 0,97 \\
\hline sufentanila $50 \mathrm{mcg} / \mathrm{ml}-1 \mathrm{ml}$ & & 4 & 4 & 4,08 & 16,32 & 44,06 \\
\hline suxametonio $100 \mathrm{mg}$ & 4 & & & & & \\
\hline tenoxicam $20 \mathrm{mg}$ & 2 & & & & & \\
\hline total & 132 & 34 & 28 & 100,4 & 182,73 & 493,37 \\
\hline
\end{tabular}


Tabela 39: Terceiro dia de consumo na sala 23 fase pós implantação

\begin{tabular}{|c|c|c|c|c|c|c|}
\hline \multicolumn{7}{|c|}{ SALA 23 - TERCEIRO DIA DE CONSUMO } \\
\hline Medicamento & $\begin{array}{l}\text { Físico Inicial } \\
\text { (elenco kit) }\end{array}$ & Extra & $\begin{array}{l}\text { Quantidade } \\
\text { Utilizada }\end{array}$ & \begin{tabular}{c|} 
Preço \\
Unitário
\end{tabular} & $\begin{array}{l}\text { Preço } \\
\text { Final }\end{array}$ & $\begin{array}{c}\text { Valor em } \\
\text { dólar }\end{array}$ \\
\hline agua destilada $-10 \mathrm{ml}$ & 6 & 1 & 7 & 0,1 & 0,7 & 1,89 \\
\hline aminofilina $24 \mathrm{mg} / \mathrm{ml}-10 \mathrm{ml}$ & 1 & & & & & \\
\hline atropina $0,5 \mathrm{mg} / \mathrm{ml}-1 \mathrm{ml}$ & 6 & & 2 & 0,01 & 0,02 & 0,05 \\
\hline $\begin{array}{l}\text { bupivacaína com } \\
\text { epinefrina }(5 \mathrm{mg}+9,1 \mathrm{mcg}) / \mathrm{ml}-20 \mathrm{ml}\end{array}$ & 1 & & 1 & 3,98 & 3,98 & 10,75 \\
\hline bupivacaína sem epinefrina $0,5 \%-20 \mathrm{ml}$ & 1 & & & & & \\
\hline bupivacaína hiperbárica $0,5 \%-4 \mathrm{ml}$ & 1 & & 1 & 3,59 & 3,59 & 9,69 \\
\hline cefalotina $1 \mathrm{~g}$ & 2 & & 1 & 1,53 & 1,53 & 4,13 \\
\hline cetoprofeno $50 \mathrm{mg} / \mathrm{ml}-2 \mathrm{ml}$ & 1 & & 2 & 0,49 & 0,98 & 2,65 \\
\hline cloreto de clácio $100 \mathrm{mg} / \mathrm{ml}-5 \mathrm{ml}$ & 2 & & & & & \\
\hline dexametasona $4 \mathrm{mg} / \mathrm{ml}-1 \mathrm{ml}$ & 6 & & & & & \\
\hline diazepam $5 \mathrm{mg} / \mathrm{ml}-2 \mathrm{ml}$ & & 1 & & & & \\
\hline dipirona $500 \mathrm{~g} / \mathrm{ml}-2 \mathrm{ml}$ & 6 & & 2 & 0,16 & 0,32 & 0,86 \\
\hline efedrina $25 \mathrm{mg} / \mathrm{mnl}-1 \mathrm{ml}$ & 6 & & & & & \\
\hline epinefrina $1 \mathrm{mg} / \mathrm{ml}-1 \mathrm{ml}$ & 1 & & & & & \\
\hline etomidato $2 \mathrm{mg} / \mathrm{ml}-10 \mathrm{ml}$ & & 1 & & & & \\
\hline $\begin{array}{l}\text { fentanil + droperidol }(0,05 \mathrm{mg}+2,5 \mathrm{mg}) / \mathrm{ml}- \\
2 \mathrm{ml}\end{array}$ & & 2 & & & & \\
\hline fentanil $0,05 \mathrm{mg} / \mathrm{ml}-5 \mathrm{ml}$ & & 5 & 5 & 1,8 & 9 & 24,3 \\
\hline furosemida $10 \mathrm{mg} / \mathrm{ml}-2 \mathrm{ml}$ & 2 & & & & & \\
\hline glicose $50 \%-10 \mathrm{ml}$ & 1 & & & & & \\
\hline heparina IV 5000UI - 5ml & 1 & & & & & \\
\hline hidralazina $20 \mathrm{mg} / \mathrm{ml}-1 \mathrm{ml}$ & 2 & & & & & \\
\hline hidrocortisona $500 \mathrm{mg}$ & 2 & & & & & \\
\hline lidocaína sem epinefrina $2 \%-20 \mathrm{ml}$ & 1 & & 2 & 0,68 & 1,36 & 3,67 \\
\hline $\begin{array}{l}\text { lidocaína com epinefrina }(20 \mathrm{mg}+5 \mathrm{mcg}) / \mathrm{ml} \\
-20 \mathrm{ml}\end{array}$ & 1 & & & & & \\
\hline lidocaína geléia $2 \%-30 \mathrm{~g}$ & 1 & & & & & \\
\hline metaraminol $10 \mathrm{mg} / \mathrm{ml}-1 \mathrm{ml}$ & 2 & & & & & \\
\hline metoclopramida $5 \mathrm{mg} / \mathrm{ml}-2 \mathrm{ml}$ & 2 & & 1 & 0,15 & 0,15 & 0,41 \\
\hline midazolam $5 \mathrm{mg} / \mathrm{ml}-3 \mathrm{ml}$ & & 1 & 1 & 2,35 & 2,35 & 6,35 \\
\hline morfina $2 \mathrm{mg} / \mathrm{ml}-1 \mathrm{ml}$ & & 1 & 1 & 0,41 & 0,41 & 1,11 \\
\hline neostigmina $0,05 \mathrm{mg} / \mathrm{ml}-1 \mathrm{ml}$ & 6 & & & & & \\
\hline petidina $50 \mathrm{mg} / \mathrm{ml}-2 \mathrm{ml}$ & & 3 & 1 & 0,85 & 0,85 & 2,3 \\
\hline prropofol $10 \mathrm{mg} / \mathrm{ml}-20 \mathrm{ml}$ & & 3 & 3 & 8,51 & 25,53 & 68,93 \\
\hline ranitidina $10 \mathrm{mg} / \mathrm{ml}-5 \mathrm{ml}$ & 2 & & 2 & 0,18 & 0,36 & 0,97 \\
\hline suxametonio $100 \mathrm{mg}$ & 2 & & & & & \\
\hline tenoxicam $20 \mathrm{mg}$ & 1 & & & & & \\
\hline Total & 66 & 20 & 32 & 24,79 & 51,13 & 138,06 \\
\hline
\end{tabular}


Tabela 40: Primeiro dia de consumo na sala 24 fase pós implantação

\begin{tabular}{|c|c|c|c|c|c|c|}
\hline \multicolumn{7}{|c|}{ SALA 24 - PRIMEIRO DIA DE CONSUMO } \\
\hline Medicamento & $\begin{array}{l}\text { Físico Inicial } \\
\text { (elenco kit) }\end{array}$ & Extra & $\begin{array}{l}\text { Quantidade } \\
\text { Utilizada }\end{array}$ & $\begin{array}{c}\text { Preço } \\
\text { Unitário }\end{array}$ & $\begin{array}{l}\text { Preço } \\
\text { Final }\end{array}$ & $\begin{array}{l}\text { Valor em } \\
\text { dólar }\end{array}$ \\
\hline agua destilada $-10 \mathrm{ml}$ & 12 & & 2 & 0,1 & 0,2 & 0,54 \\
\hline aminofilina $24 \mathrm{mg} / \mathrm{ml}-10 \mathrm{ml}$ & 2 & & & & & \\
\hline atropina $0,5 \mathrm{mg} / \mathrm{ml}-1 \mathrm{ml}$ & 12 & & & & & \\
\hline $\begin{array}{l}\text { bupivacaína com } \\
\text { epinefrina }(5 \mathrm{mg}+9,1 \mathrm{mcg}) / \mathrm{ml}-20 \mathrm{ml}\end{array}$ & 2 & & & & & \\
\hline bupivacaína sem epinefrina $0,5 \%-20 \mathrm{ml}$ & 2 & & & & & \\
\hline bupivacaína hiperbárica $0,5 \%-4 \mathrm{ml}$ & 2 & & & & & \\
\hline cefalotina $1 \mathrm{~g}$ & 4 & 8 & 12 & 1,53 & 18,36 & 49,57 \\
\hline cetoprofeno $50 \mathrm{mg} / \mathrm{ml}-2 \mathrm{ml}$ & 2 & & & & & \\
\hline cloreto de clácio $100 \mathrm{mg} / \mathrm{ml}-5 \mathrm{ml}$ & 4 & & & & & \\
\hline dexametasona $4 \mathrm{mg} / \mathrm{ml}-1 \mathrm{ml}$ & 12 & & & & & \\
\hline diazepam $10 \mathrm{mg}-2 \mathrm{ml}$ & & 2 & & & & \\
\hline dipirona $1 \mathrm{~g}-2 \mathrm{ml}$ & 12 & & & & & \\
\hline efedrina $25 \mathrm{mg} / \mathrm{ml}-1 \mathrm{ml}$ & 12 & & & & & \\
\hline epinefrina $1 \mathrm{mg} / \mathrm{ml}-1 \mathrm{ml}$ & 2 & & & & & \\
\hline etomidato $2 \mathrm{mg} / \mathrm{ml}-10 \mathrm{ml}$ & & 2 & & & & \\
\hline $\begin{array}{l}\text { fentanil + droperidol }(0,05 \mathrm{mg}+2,5 \mathrm{mg}) / \mathrm{ml}- \\
2 \mathrm{ml}\end{array}$ & & 4 & & & & \\
\hline fentanil $0,05 \mathrm{mg} / \mathrm{ml}-5 \mathrm{ml}$ & & 6 & 5 & 1,8 & 9 & 24,3 \\
\hline furosemida $10 \mathrm{mg} / \mathrm{ml}-2 \mathrm{ml}$ & 4 & & & & & \\
\hline glicose $50 \%-10 \mathrm{ml}$ & 2 & & & & & \\
\hline heparina IV 5000UI $-5 \mathrm{ml}$ & 2 & & & & & \\
\hline hidralazina $20 \mathrm{mg} / \mathrm{ml}-1 \mathrm{ml}$ & 4 & & & & & \\
\hline hidrocortisona $500 \mathrm{mg}$ & 4 & & & & & \\
\hline isoprenalina $0,2 \mathrm{mg} / \mathrm{ml}-1 \mathrm{ml}$ & & 2 & 2 & 0,32 & 0,64 & 1,73 \\
\hline lidocaína sem epinefrina $2 \%-20 \mathrm{ml}$ & 2 & & & & & \\
\hline $\begin{array}{l}\text { lidocaína com epinefrina }(20 \mathrm{mg}+5 \mathrm{mcg}) / \mathrm{ml} \\
-20 \mathrm{ml}\end{array}$ & 2 & & & & & \\
\hline lidocaína geléia $2 \%-30 \mathrm{~g}$ & 2 & & & & & \\
\hline metaraminol $10 \mathrm{mg} / \mathrm{ml}-1 \mathrm{ml}$ & 4 & & & & & \\
\hline metoclopramida $5 \mathrm{mg} / \mathrm{ml}-2 \mathrm{ml}$ & 4 & & & & & \\
\hline midazolam $5 \mathrm{mg} / \mathrm{ml}-3 \mathrm{ml}$ & & 2 & & & & \\
\hline morfina $2 \mathrm{mg} / \mathrm{ml}-1 \mathrm{ml}$ & & 2 & & & & \\
\hline neostigmina $0,05 \mathrm{mg} / \mathrm{ml}-1 \mathrm{ml}$ & 12 & & & & & \\
\hline petidina $50 \mathrm{mg} / \mathrm{ml}-2 \mathrm{ml}$ & & 2 & & & & \\
\hline propofol $10 \mathrm{mg} / \mathrm{ml}-20 \mathrm{ml}$ & & 6 & 6 & 8,51 & 51,06 & 137,86 \\
\hline ranitidina $10 \mathrm{mg} / \mathrm{ml}-5 \mathrm{ml}$ & 4 & & & & & \\
\hline rocurônio $10 \mathrm{mg} / \mathrm{ml}-5 \mathrm{ml}$ & & 1 & 1 & 22 & 22 & 59,4 \\
\hline sufentanila $50 \mathrm{mcg} / \mathrm{ml}-1 \mathrm{ml}$ & & 8 & 8 & 4,08 & 32,64 & 88,13 \\
\hline suxametonio $100 \mathrm{mg}$ & 4 & & & & & \\
\hline tenoxicam $20 \mathrm{mg}$ & 2 & & & & & \\
\hline verde brilhante $100 \mathrm{mg} / \mathrm{ml}-1 \mathrm{ml}$ & & 5 & 5 & 0,36 & 1,8 & 4,86 \\
\hline Total & 132 & 50 & 41 & 38,7 & 135,7 & 366,39 \\
\hline
\end{tabular}


Tabela 41: Segundo dia de consumo na sala 24 fase pós implantação

\begin{tabular}{|c|c|c|c|c|c|c|}
\hline \multicolumn{7}{|c|}{ SALA 24 - SEGUNDO DIA DE CONSUMO } \\
\hline Medicamento & $\begin{array}{l}\text { Físico Inicial } \\
\text { (elenco kit) }\end{array}$ & Extra & $\begin{array}{l}\text { Quantidade } \\
\text { Utilizada }\end{array}$ & $\begin{array}{c}\text { Preço } \\
\text { Unitário }\end{array}$ & $\begin{array}{l}\text { Preço } \\
\text { Final }\end{array}$ & $\begin{array}{l}\text { Valor em } \\
\text { dólar }\end{array}$ \\
\hline agua destilada $-10 \mathrm{ml}$ & 12 & & 9 & 0,1 & 0,9 & 2,43 \\
\hline aminofilina $24 \mathrm{mg} / \mathrm{ml}-10 \mathrm{ml}$ & 2 & & & & & \\
\hline atropina $0,5 \mathrm{mg} / \mathrm{ml}-1 \mathrm{ml}$ & 12 & & & & & \\
\hline $\begin{array}{l}\text { bupivacaína com } \\
\text { epinefrina }(5 \mathrm{mg}+9,1 \mathrm{mcg}) / \mathrm{ml}-20 \mathrm{ml}\end{array}$ & 2 & & & & & \\
\hline bupivacaína sem epinefrina $0,5 \%-20 \mathrm{ml}$ & 2 & & & & & \\
\hline bupivacaína hiperbárica $0,5 \%-4 \mathrm{ml}$ & 2 & & 1 & 3,59 & 3,59 & 9,69 \\
\hline cefalotina $1 \mathrm{~g}$ & 4 & & 4 & 1,53 & 6,12 & 16,52 \\
\hline cetoprofeno $50 \mathrm{mg} / \mathrm{ml}-2 \mathrm{ml}$ & 2 & & 1 & 3,43 & 3,43 & 9,26 \\
\hline cloreto de clácio $100 \mathrm{mg} / \mathrm{ml}-5 \mathrm{ml}$ & 4 & & & & & \\
\hline dexametasona $4 \mathrm{mg} / \mathrm{ml}-1 \mathrm{ml}$ & 12 & & 3 & 0,39 & 1,17 & 3,16 \\
\hline diazepam $5 \mathrm{mg} / \mathrm{ml}-2 \mathrm{ml}$ & & 2 & & & & \\
\hline dipirona $500 \mathrm{mg} / \mathrm{ml}-2 \mathrm{ml}$ & 12 & & 4 & 0,16 & 0,64 & 1,73 \\
\hline efedrina $25 \mathrm{mg} / \mathrm{ml}-1 \mathrm{ml}$ & 12 & & 1 & 0,43 & 0,43 & 1,16 \\
\hline epinefrina $1 \mathrm{mg} / \mathrm{ml}-1 \mathrm{ml}$ & 2 & & & & & \\
\hline etomidato $2 \mathrm{mg} / \mathrm{ml}-10 \mathrm{ml}$ & & 2 & & & & \\
\hline $\begin{array}{l}\text { fentanil + droperidol }(0,05 \mathrm{mg}+2,5 \mathrm{mg}) / \mathrm{ml}- \\
2 \mathrm{ml}\end{array}$ & & 4 & & & & \\
\hline fentanil $0,05 \mathrm{mg} / \mathrm{ml} \mathrm{-} 5 \mathrm{ml}$ & & 6 & 2 & 1,8 & 3,6 & 9,72 \\
\hline furosemida $10 \mathrm{mg} / \mathrm{ml}-2 \mathrm{ml}$ & 4 & & & & & \\
\hline glicose $50 \%-10 \mathrm{ml}$ & 2 & & & & & \\
\hline heparina IV 5000UI - 5ml & 2 & & & & & \\
\hline hidralazina $20 \mathrm{mg} / \mathrm{ml}-1 \mathrm{ml}$ & 4 & & & & & \\
\hline hidrocortisona $500 \mathrm{mg}$ & 4 & & 1 & 2,88 & 2,88 & 7,78 \\
\hline lidocaína sem epinefrina $2 \%-20 \mathrm{ml}$ & 2 & & & & & \\
\hline $\begin{array}{l}\text { lidocaína com epinefrina }(20 \mathrm{mg}+5 \mathrm{mcg}) / \mathrm{ml} \\
-20 \mathrm{ml}\end{array}$ & 2 & & & & & \\
\hline lidocaína geléia $2 \%-30 \mathrm{~g}$ & 2 & & & & & \\
\hline metaraminol $10 \mathrm{mg} / \mathrm{ml}-1 \mathrm{ml}$ & 4 & & & & & \\
\hline metoclopramida $5 \mathrm{mg} / \mathrm{ml}-2 \mathrm{ml}$ & 4 & & 2 & 0,15 & 0,3 & 0,81 \\
\hline midazolam $5 \mathrm{mg} / \mathrm{ml}-3 \mathrm{ml}$ & & 2 & 2 & 2,35 & 4,7 & 12,69 \\
\hline morfina $2 \mathrm{mg} / \mathrm{ml}-1 \mathrm{ml}$ & & 2 & & & & \\
\hline neostigmina $0,05 \mathrm{mg} / \mathrm{ml}-1 \mathrm{ml}$ & 12 & & & & & \\
\hline petidina $50 \mathrm{mg} / \mathrm{ml}-2 \mathrm{ml}$ & & 2 & & & & \\
\hline propofol $10 \mathrm{mg} / \mathrm{ml}-20 \mathrm{ml}$ & & 4 & 1 & 8,51 & 8,51 & 22,98 \\
\hline ranitidina $10 \mathrm{mg} / \mathrm{ml}-5 \mathrm{ml}$ & 4 & & 2 & 0,18 & 0,36 & 0,97 \\
\hline suxametonio $100 \mathrm{mg}$ & 4 & & 1 & 1,53 & 1,53 & 4,13 \\
\hline tenoxicam $20 \mathrm{mg}$ & 2 & & & & & \\
\hline Total & 132 & 24 & 34 & 27,03 & 38,16 & 103,03 \\
\hline
\end{tabular}


Tabela 42: Terceiro dia de consumo na sala 24 fase pós implantação

\begin{tabular}{|c|c|c|c|c|c|c|}
\hline \multicolumn{7}{|c|}{ SALA 24 - TERCEIRO DIA DE CONSUMO } \\
\hline Medicamento & $\begin{array}{l}\text { Físico Inicial } \\
\text { (elenco kit) }\end{array}$ & Extra & $\begin{array}{l}\text { Quantidade } \\
\text { Utilizada }\end{array}$ & $\begin{array}{c}\text { Preço } \\
\text { Unitário }\end{array}$ & $\begin{array}{l}\text { Preço } \\
\text { Final }\end{array}$ & $\begin{array}{c}\text { Valor em } \\
\text { dólar }\end{array}$ \\
\hline agua destilada $-10 \mathrm{ml}$ & 12 & & 12 & 0,1 & 1,2 & 3,24 \\
\hline aminofilina $24 \mathrm{mg} / \mathrm{ml}-10 \mathrm{ml}$ & 2 & & & & & \\
\hline atropina $0,5 \mathrm{mg} / \mathrm{ml}-1 \mathrm{ml}$ & 12 & & & & & \\
\hline $\begin{array}{l}\text { bupivacaína com } \\
\text { epinefrina }(5 \mathrm{mg}+9,1 \mathrm{mcg}) / \mathrm{ml}-20 \mathrm{ml}\end{array}$ & 2 & & & & & \\
\hline bupivacaína sem epinefrina $0,5 \%-20 \mathrm{ml}$ & 2 & & & & & \\
\hline bupivacaína hiperbárica $0,5 \%-4 \mathrm{ml}$ & 2 & & & & & \\
\hline cefalotina $1 \mathrm{~g}$ & 4 & & 4 & 1,53 & 6,12 & 16,52 \\
\hline cetoprofeno $50 \mathrm{mg} / \mathrm{ml}-2 \mathrm{ml}$ & 2 & & 1 & 0,49 & 0,49 & 1,32 \\
\hline cloreto de cálcio $100 \mathrm{mg} / \mathrm{ml}-5 \mathrm{ml}$ & 4 & & & & & \\
\hline dexametasona $4 \mathrm{mg} / \mathrm{ml}-1 \mathrm{ml}$ & 12 & & 6 & 0,39 & 2,34 & 6,32 \\
\hline diazepam $5 \mathrm{mg} / \mathrm{ml}-2 \mathrm{ml}$ & 2 & & & & & \\
\hline dipirona $500 \mathrm{mg} / \mathrm{ml}-1 \mathrm{ml}$ & 12 & & 4 & 0,16 & 0,64 & 1,73 \\
\hline efedrina $25 \mathrm{mg} / \mathrm{ml}-1 \mathrm{ml}$ & 12 & & & & & \\
\hline epinefrina $1 \mathrm{mg} / \mathrm{ml}-1 \mathrm{ml}$ & 2 & & & & & \\
\hline etomidato $2 \mathrm{mg} / \mathrm{ml}-10 \mathrm{ml}$ & & 2 & & & & \\
\hline $\begin{array}{l}\text { fentanil }+ \text { droperidol }(0,05 \mathrm{mg}+2,5 \mathrm{mg}) / \mathrm{ml} \\
-2 \mathrm{ml}\end{array}$ & & 4 & & & & \\
\hline fentanil $0,05 \mathrm{mg} / \mathrm{ml}-5 \mathrm{ml}$ & & 6 & 4 & 1,8 & 7,2 & 19,44 \\
\hline furosemida $10 \mathrm{mg} / \mathrm{ml}-2 \mathrm{ml}$ & 4 & & & & & \\
\hline glicose $50 \%-10 \mathrm{ml}$ & 2 & & & & & \\
\hline hidralazina $20 \mathrm{mg} / \mathrm{ml}-1 \mathrm{ml}$ & 4 & & & & & \\
\hline hidrocortisona $500 \mathrm{mg}$ & 4 & & 2 & 2,88 & 5,76 & 15,55 \\
\hline lidocaína sem epinefrina $2 \%-20 \mathrm{ml}$ & 2 & & & & & \\
\hline $\begin{array}{l}\text { lidocaína com epinefrina(20mg } \\
+5 \mathrm{mcg}) / \mathrm{ml}-20 \mathrm{ml}\end{array}$ & 2 & & & & & \\
\hline lidocaína geléia $2 \%$ - $30 \mathrm{ml}$ & 2 & & & & & \\
\hline metaraminol $10 \mathrm{mg} / \mathrm{ml}-1 \mathrm{ml}$ & 4 & & & & & \\
\hline metoclopramida $5 \mathrm{mg} / \mathrm{ml}-2 \mathrm{ml}$ & 4 & & 2 & 0,15 & 0,3 & 0,81 \\
\hline midazolam $5 \mathrm{mg} / \mathrm{ml}-3 \mathrm{ml}$ & & 2 & 2 & 2,35 & 4,7 & 12,69 \\
\hline morfina $2 \mathrm{mg} / \mathrm{ml}-1 \mathrm{ml}$ & & 2 & & & & \\
\hline neostigmina $0,05 \mathrm{mg} / \mathrm{ml}-1 \mathrm{ml}$ & 12 & & & & & \\
\hline petidina $50 \mathrm{mg} / \mathrm{ml}-2 \mathrm{ml}$ & & 2 & & & & \\
\hline propofol $10 \mathrm{mg} / \mathrm{ml}-20 \mathrm{ml}$ & & 4 & 2 & 8,51 & 17,02 & 45,95 \\
\hline ranitidina $10 \mathrm{mg} / \mathrm{ml}-5 \mathrm{ml}$ & 4 & & 2 & 0,18 & 0,36 & 0,97 \\
\hline suxametonio $100 \mathrm{mg}$ & 4 & & 2 & 1,53 & 3,06 & 8,26 \\
\hline tenoxicam $20 \mathrm{mg}$ & 2 & & 1 & 2,16 & 2,16 & 5,83 \\
\hline Total & 130 & 24 & 44 & 22,23 & 51,35 & 138,63 \\
\hline
\end{tabular}


Tabela 43: Primeiro dia de consumo na sala 25 fase pós implantação

\begin{tabular}{|c|c|c|c|c|c|c|}
\hline \multicolumn{7}{|c|}{ SALA 25 - PRIMEIRO DIA DE CONSUMO } \\
\hline Medicamento & $\begin{array}{l}\text { Físico Inicial } \\
\text { (elenco kit) }\end{array}$ & Extra & $\begin{array}{l}\text { Quantidade } \\
\text { Utilizada }\end{array}$ & $\begin{array}{l}\text { Preço } \\
\text { Unitário }\end{array}$ & $\begin{array}{l}\text { Preço } \\
\text { Final }\end{array}$ & $\begin{array}{l}\text { Valor em } \\
\text { dólar }\end{array}$ \\
\hline agua destilada $-10 \mathrm{ml}$ & 12 & & 6 & 0,1 & 0,6 & 1,62 \\
\hline aminofilina $24 \mathrm{mg} / \mathrm{ml}-10 \mathrm{ml}$ & 2 & & & & & \\
\hline atracurim $10 \mathrm{mg} / \mathrm{ml}-5 \mathrm{ml}$ & & 2 & 2 & 6,95 & 13,9 & 37,53 \\
\hline atropina $0,5 \mathrm{mg} / \mathrm{ml}-1 \mathrm{ml}$ & 12 & & & & & \\
\hline $\begin{array}{l}\text { bupivacaína com } \\
\text { epinefrina }(5 \mathrm{mg}+9,1 \mathrm{mcg}) / \mathrm{ml}-20 \mathrm{ml}\end{array}$ & 2 & & & & & \\
\hline bupivacaína sem epinefrina $0,5 \%-20 \mathrm{ml}$ & 2 & & & & & \\
\hline bupivacaína hiperbárica $0,5 \%-4 \mathrm{ml}$ & 2 & & 1 & 3,59 & 3,59 & 9,69 \\
\hline cefalotina $1 \mathrm{~g}$ & 4 & & 2 & 1,53 & 3,06 & 8,26 \\
\hline cetoprofeno $50 \mathrm{mg} / \mathrm{ml}-2 \mathrm{ml}$ & 2 & & & & & \\
\hline cloreto de clácio $1200 \mathrm{mg} / \mathrm{ml}-5 \mathrm{ml}$ & 4 & & & & & \\
\hline cloreto de potassio $19,1 \%-10 \mathrm{ml}$ & & 1 & 1 & 0,2 & 0,2 & 0,54 \\
\hline dexametasona $4 \mathrm{mg} / \mathrm{ml}-1 \mathrm{ml}$ & 12 & & & & & \\
\hline diazepam $5 \mathrm{mg} / \mathrm{ml}-2 \mathrm{ml}$ & & 2 & & & & \\
\hline $\begin{array}{l}\text { dimenidrato+piridoxina }(50 \mathrm{mg}+50 \mathrm{mg})- \\
1 \mathrm{ml}\end{array}$ & & 1 & 1 & 1 & 1 & 2,7 \\
\hline dipirona $500 \mathrm{mg} / \mathrm{ml}-2 \mathrm{ml}$ & 12 & & 6 & 0,16 & 0,96 & 2,59 \\
\hline efedrina $25 \mathrm{mg} / \mathrm{ml}-1 \mathrm{ml}$ & 12 & & & & & \\
\hline epinefrina $1 \mathrm{mg} / \mathrm{ml}-1 \mathrm{ml}$ & 2 & & & & & \\
\hline etomidato $2 \mathrm{mg} / \mathrm{ml}-10 \mathrm{ml}$ & & 2 & & & & \\
\hline $\begin{array}{l}\text { fentanil }+ \text { droperidol }(0,05 \mathrm{mg}+2,5 \mathrm{mg}) / \mathrm{ml} \\
-2 \mathrm{ml}\end{array}$ & & 4 & & & & \\
\hline fentanil $0,05 \mathrm{mg} / \mathrm{ml}-5 \mathrm{ml}$ & & 6 & 3 & 1,8 & 5,4 & 14,58 \\
\hline furosemida $10 \mathrm{mg} / \mathrm{ml}-2 \mathrm{ml}$ & 4 & & & & & \\
\hline glicose $50 \%-10 \mathrm{ml}$ & 2 & & & & & \\
\hline heparina IV 5000UI - 5ml & 2 & & & & & \\
\hline hidralazina $20 \mathrm{mg} / \mathrm{ml}-1 \mathrm{ml}$ & 4 & & & & & \\
\hline hidrocortisona $500 \mathrm{mg}$ & 4 & & & & & \\
\hline isoprenalina $0,2 \mathrm{mg} / \mathrm{ml}-1 \mathrm{ml}$ & & 1 & 1 & 0,32 & 0,32 & 0,86 \\
\hline lidocaína sem epinefrina $2 \%-20 \mathrm{ml}$ & 2 & & 1 & 0,68 & 0,68 & 1,84 \\
\hline $\begin{array}{l}\text { lidocaína com } \\
\text { epinefrina }(20 \mathrm{mg}+5 \mathrm{mcg}) / \mathrm{ml}-20 \mathrm{ml}\end{array}$ & 2 & & 2 & 1,31 & 2,62 & 7,07 \\
\hline lidocaína geléia $2 \%-30 \mathrm{~g}$ & 2 & & & & & \\
\hline metaraminol $10 \mathrm{mg} / \mathrm{ml}-1 \mathrm{ml}$ & 4 & & & & & \\
\hline metoclopramida $5 \mathrm{mg} / \mathrm{ml}-2 \mathrm{ml}$ & 4 & & 1 & 0,15 & 0,15 & 0,41 \\
\hline midazolam $5 \mathrm{mg} / \mathrm{ml}-3 \mathrm{ml}$ & & 2 & 2 & 2,35 & 4,7 & 12,69 \\
\hline morfina $2 \mathrm{mg} / \mathrm{ml}-1 \mathrm{ml}$ & & 2 & 1 & 0,41 & 0,41 & 1,11 \\
\hline neostigmina $0,05 \mathrm{mg} / \mathrm{ml}-1 \mathrm{ml}$ & 12 & & & & & \\
\hline petidina $50 \mathrm{mg} / \mathrm{ml}-2 \mathrm{ml}$ & & 2 & & & & \\
\hline propofol $10 \mathrm{mg} / \mathrm{ml}-20 \mathrm{ml}$ & & 4 & 2 & 8,51 & 17,02 & 45,95 \\
\hline ranitidina $10 \mathrm{mg} / \mathrm{ml}-5 \mathrm{ml}$ & 4 & & 1 & 0,18 & 0,18 & 0,49 \\
\hline sulfato de magensio $10 \%-10 \mathrm{ml}$ & & 1 & 1 & 0,45 & 0,45 & 1,22 \\
\hline suxametonio $100 \mathrm{mg}$ & 4 & & & & & \\
\hline tenoxicam $20 \mathrm{mg}$ & 2 & & 2 & 2,16 & 4,32 & 11,66 \\
\hline Total & 132 & 30 & 36 & 31,85 & 59,56 & 160,81 \\
\hline
\end{tabular}


Tabela 44: Segundo dia de consumo na sala 25 fase pós implantação

\begin{tabular}{|c|c|c|c|c|c|c|}
\hline \multicolumn{7}{|c|}{ SALA 25- SEGUNDO DIA DE CONSUMO } \\
\hline medicamento & $\begin{array}{l}\text { Físico Inicial } \\
\text { (elenco kit) }\end{array}$ & Extra & $\begin{array}{l}\text { Quantidade } \\
\text { Utilizada }\end{array}$ & $\begin{array}{l}\text { Preço } \\
\text { Unitário }\end{array}$ & $\begin{array}{l}\text { Preço } \\
\text { Final }\end{array}$ & $\begin{array}{l}\text { Valor em } \\
\text { dólar }\end{array}$ \\
\hline agua destilada $-10 \mathrm{ml}$ & 12 & & 10 & 0,1 & 1 & 2,7 \\
\hline alfentanil $0,5 \mathrm{mg} / \mathrm{ml}-5 \mathrm{ml}$ & & 7 & 7 & 9,86 & 69,04 & 186,41 \\
\hline aminofilina $24 \mathrm{mg} / \mathrm{ml}-10 \mathrm{ml}$ & 2 & & & & & \\
\hline atropina $0,5 \mathrm{mg} / \mathrm{ml}-1 \mathrm{ml}$ & 12 & & & & & \\
\hline $\begin{array}{l}\text { bupivacaína com } \\
\text { epinefrina }(5 \mathrm{mg}+9,1 \mathrm{mcg}) / \mathrm{ml}-20 \mathrm{ml}\end{array}$ & 2 & & & & & \\
\hline bupivacaína sem epinefrina $0,5 \%-20 \mathrm{ml}$ & 2 & & & & & \\
\hline bupivacaína hiperbárica $0,5 \%-4 \mathrm{ml}$ & 2 & & & & & \\
\hline cefalotina $1 \mathrm{~g}$ & 4 & & 2 & 1,53 & 3,06 & 8,26 \\
\hline cetoprofeno $50 \mathrm{mg} / \mathrm{ml}-2 \mathrm{ml}$ & 2 & & & & & \\
\hline cloreto de clácio $100 \mathrm{mg} / \mathrm{ml}-5 \mathrm{ml}$ & 4 & & & & & \\
\hline dexametasona $4 \mathrm{mg} / \mathrm{ml}-1 \mathrm{ml}$ & 12 & & & & & \\
\hline diazepam $5 \mathrm{mg} / \mathrm{ml}-2 \mathrm{ml}$ & & 2 & & & & \\
\hline dipirona $500 \mathrm{mg} / \mathrm{ml}-2 \mathrm{ml}$ & 12 & & & & & \\
\hline efedrina $25 \mathrm{mg} / \mathrm{ml}-1 \mathrm{ml}$ & 12 & & & & & \\
\hline epinefrina $1 \mathrm{mg} / \mathrm{ml}-1 \mathrm{ml}$ & 2 & & & & & \\
\hline etomidato $2 \mathrm{mg} / \mathrm{ml}-10 \mathrm{ml}$ & & 2 & & & & \\
\hline $\begin{array}{l}\text { fentanil + droperidol }(0,05 \mathrm{mg}+2,5 \mathrm{mg}) / \mathrm{ml} \\
-2 \mathrm{ml}\end{array}$ & & 4 & & & & \\
\hline fentanil $0,05 \mathrm{mg} / \mathrm{ml}-5 \mathrm{ml}$ & & 6 & 4 & 1,8 & 7,2 & 19,44 \\
\hline furosemida $10 \mathrm{mg} / \mathrm{ml}-2 \mathrm{ml}$ & 4 & & & & & \\
\hline glicose $50 \%-10 \mathrm{ml}$ & 2 & & & & & \\
\hline heparina IV 5000UI - 5ml & 2 & & & & & \\
\hline hidralazina $20 \mathrm{mg} / \mathrm{ml}-1 \mathrm{ml}$ & 4 & & & & & \\
\hline hidrocortisona $500 \mathrm{mg}$ & 4 & & & & & \\
\hline isoprenalina $0,2 \mathrm{mg} / \mathrm{ml}-1 \mathrm{ml}$ & & 1 & 1 & 0,32 & 0,32 & 0,86 \\
\hline lidocaína sem epinefrina $2 \%-20 \mathrm{ml}$ & 2 & & 1 & 0,68 & 0,68 & 1,84 \\
\hline $\begin{array}{l}\text { lidocaína com } \\
\text { epinefrina }(20 \mathrm{mg}+5 \mathrm{mcg}) / \mathrm{ml}-20 \mathrm{ml}\end{array}$ & 2 & & & & & \\
\hline lidocaína geléia $2 \%$ - $30 \mathrm{~g}$ & 2 & & & & & \\
\hline metaraminol $10 \mathrm{mg} / \mathrm{ml}-1 \mathrm{ml}$ & 4 & & & & & \\
\hline metoclopramida $5 \mathrm{mg} / \mathrm{ml}-2 \mathrm{ml}$ & 4 & & 1 & 0,15 & 0,15 & 0,41 \\
\hline midazolam $5 \mathrm{mg} / \mathrm{ml}-3 \mathrm{ml}$ & & 2 & 1 & 2,35 & 2,35 & 6,35 \\
\hline morfina $2 \mathrm{mg} / \mathrm{ml}-1 \mathrm{ml}$ & & 2 & & & & \\
\hline neostigmina $0,05 \mathrm{mg} / \mathrm{ml}-1 \mathrm{ml}$ & 12 & & 5 & 0,46 & 2,3 & 6,21 \\
\hline petidina $50 \mathrm{mg} / \mathrm{ml}-2 \mathrm{ml}$ & & 2 & & & & \\
\hline propofol $10 \mathrm{mg} / \mathrm{ml}-10 \mathrm{ml}$ & & 9 & 7 & 8,51 & 59,57 & 160,84 \\
\hline ranitidina $10 \mathrm{mg} / \mathrm{ml}-5 \mathrm{ml}$ & 4 & & 1 & 0,18 & 0,18 & 0,49 \\
\hline suxametonio $100 \mathrm{mg}$ & 4 & & & & & \\
\hline tenoxicam $20 \mathrm{mg}$ & 2 & & & & & \\
\hline Total & 132 & 37 & 40 & 25,94 & 145,85 & 393,81 \\
\hline
\end{tabular}


Tabela 45: Terceiro dia de consumo na sala 25 fase pós implantação

SALA 25- TERCEIRO DIA DE CONSUMO

\begin{tabular}{|c|c|c|c|c|c|c|}
\hline \\
\hline Medicamento & $\begin{array}{c}\text { Físico Inicial } \\
\text { (elenco kit) }\end{array}$ & Extra & $\begin{array}{c}\text { Quantidade } \\
\text { Utilizada }\end{array}$ & $\begin{array}{c}\text { Preço } \\
\text { Unitário }\end{array}$ & $\begin{array}{c}\text { Preço } \\
\text { Final } \\
\end{array}$ & $\begin{array}{c}\text { Valor em } \\
\text { dólar }\end{array}$ \\
\hline agua destilada $-10 \mathrm{ml}$ & 18 & & 4 & 0,1 & 0,4 & 1,08 \\
\hline aminofilina $24 \mathrm{mg} / \mathrm{ml}-10 \mathrm{ml}$ & 3 & & & & & \\
\hline atropina $0,5 \mathrm{mg} / \mathrm{ml}-1 \mathrm{ml}$ & 18 & & & & & \\
\hline $\begin{array}{l}\text { bupivacaína com } \\
\text { epinefrina }(5 \mathrm{mg}+9,1 \mathrm{mcg}) / \mathrm{ml}-20 \mathrm{ml}\end{array}$ & 3 & & & & & \\
\hline bupivacaína sem epinefrina $0,5 \%-20 \mathrm{ml}$ & 3 & & & & & \\
\hline bupivacaína hiperbárica $0,5 \%-4 \mathrm{ml}$ & 3 & & 1 & 3,59 & 3,59 & 9,69 \\
\hline cefalotina $1 \mathrm{~g}$ & 6 & & 2 & 1,53 & 3,06 & 8,26 \\
\hline cetoprofeno $50 \mathrm{mg} / \mathrm{ml}-2 \mathrm{ml}$ & 3 & & & & & \\
\hline cloreto de cálcio $100 \mathrm{mg} / \mathrm{ml}-5 \mathrm{ml}$ & 6 & & & & & \\
\hline dexametasona $4 \mathrm{mg} / \mathrm{ml}-1 \mathrm{ml}$ & 18 & & & & & \\
\hline diazepam $5 \mathrm{mg} / \mathrm{ml}-2 \mathrm{ml}$ & & 3 & & & & \\
\hline dipirona $500 \mathrm{mg} / \mathrm{ml}-2 \mathrm{ml}$ & 18 & & & & & \\
\hline efedrina $1 \mathrm{mg} / \mathrm{ml}-1 \mathrm{ml}$ & 18 & & & & & \\
\hline epinefrina $1 \mathrm{mg} / \mathrm{ml}-1 \mathrm{ml}$ & 3 & & & & & \\
\hline etomidato $2 \mathrm{mg} / \mathrm{ml}-10 \mathrm{ml}$ & & 3 & & & & \\
\hline $\begin{array}{l}\text { fentanil }+ \text { droperidol }(0,05 \mathrm{mg}+2,5 \mathrm{mg}) / \mathrm{ml} \\
-2 \mathrm{ml}\end{array}$ & & 6 & & & & \\
\hline fentanil $0,05 \mathrm{mg} / \mathrm{ml}-5 \mathrm{ml}$ & & 9 & 4 & 1,8 & 7,2 & 19,44 \\
\hline furosemida $10 \mathrm{mg} / \mathrm{ml}-2 \mathrm{ml}$ & 6 & & & & & \\
\hline glicose $50 \%-10 \mathrm{ml}$ & 3 & & & & & \\
\hline heparina IV 5.000UI - 5ml & 3 & & & & & \\
\hline hidralazina $20 \mathrm{mg} / \mathrm{ml}-1 \mathrm{ml}$ & 6 & & & & & \\
\hline hidrocortisona $500 \mathrm{mg}$ & 6 & & & & & \\
\hline isoprenalina $0,2 \mathrm{mg} / \mathrm{ml}-1 \mathrm{ml}$ & & 1 & 1 & 0,32 & 0,32 & 0,86 \\
\hline lidocaína sem epinefrina $2 \%-20 \mathrm{ml}$ & 3 & & 1 & 0,68 & 0,68 & 1,84 \\
\hline $\begin{array}{l}\text { lidocaína com } \\
\text { epinefrina }(20 \mathrm{mg}+5 \mathrm{mcg}) / \mathrm{ml}-20 \mathrm{ml}\end{array}$ & 3 & & & & & \\
\hline lidocaína geléia $2 \%-30 \mathrm{~g}$ & 3 & & & & & \\
\hline metaraminol $10 \mathrm{mg} / \mathrm{ml}-1 \mathrm{ml}$ & 6 & & & & & \\
\hline metoclopramida $5 \mathrm{mg} / \mathrm{ml}-2 \mathrm{ml}$ & 6 & & 1 & 0,15 & 0,15 & 0,41 \\
\hline midazolam $15 \mathrm{mg} / \mathrm{ml}-3 \mathrm{ml}$ & & 3 & 1 & 2,35 & 2,35 & 6,35 \\
\hline morfina $2 \mathrm{mg} / \mathrm{ml}-1 \mathrm{ml}$ & & 3 & & & & \\
\hline neostigmina $0,05 \mathrm{mg} / \mathrm{ml}-1 \mathrm{ml}$ & 18 & & & & & \\
\hline petidina $50 \mathrm{mg} / \mathrm{ml}-2 \mathrm{ml}$ & & 3 & 1 & 0,18 & 0,18 & 0,49 \\
\hline propofol $10 \mathrm{mg} / \mathrm{ml}-20 \mathrm{ml}$ & & 13 & 9 & 8,51 & 76,59 & 206,79 \\
\hline suxametonio $100 \mathrm{mg}$ & 6 & & & & & \\
\hline tenoxicam $20 \mathrm{mg}$ & 3 & & & & & \\
\hline Total & 192 & 44 & 25 & 19,21 & $\mathbf{9 4 , 5 2}$ & 255,21 \\
\hline
\end{tabular}


Tabela 46: Primeiro dia de consumo na sala 26 fase pós implantação

SALA 26- PRIMEIRO DIA DE CONSUMO

\begin{tabular}{|c|c|c|c|c|c|c|}
\hline Medicamento & $\begin{array}{c}\text { Físico Inicial } \\
\text { (elenco kit) }\end{array}$ & Extra & $\begin{array}{l}\text { Quantidade } \\
\text { Utilizada }\end{array}$ & \begin{tabular}{|c|} 
Preço \\
Unitário
\end{tabular} & $\begin{array}{l}\text { Preço } \\
\text { Final }\end{array}$ & $\begin{array}{l}\text { Valor em } \\
\text { dólar }\end{array}$ \\
\hline agua destilada $-10 \mathrm{ml}$ & 12 & & 4 & 0,1 & 0,4 & 1,08 \\
\hline aminofilina $24 \mathrm{mg} / \mathrm{ml}-10 \mathrm{ml}$ & 2 & & & & & \\
\hline atropina $0,5 \mathrm{mg} / \mathrm{ml}-1 \mathrm{ml}$ & 12 & & 1 & 0,01 & 0,01 & 0,03 \\
\hline $\begin{array}{l}\text { bupivacaína com } \\
\text { epinefrina }(5 \mathrm{mg}+9,1 \mathrm{mcg}) / \mathrm{ml}-20 \mathrm{ml}\end{array}$ & 2 & & 1 & 3,89 & 3,89 & 10,5 \\
\hline bupivacaína sem epinefrina $0,5 \%-20 \mathrm{ml}$ & 2 & & & & & \\
\hline bupivacaína hiperbárica $0,5 \%-4 \mathrm{ml}$ & 2 & & & & & \\
\hline cefalotina $1 \mathrm{~g}$ & 4 & & 3 & 1,53 & 4,59 & 12,39 \\
\hline cetoprofeno $50 \mathrm{mg} / \mathrm{ml}-2 \mathrm{ml}$ & 2 & & & & & \\
\hline cloreto de cálcio $100 \mathrm{mg} / \mathrm{ml}-5 \mathrm{ml}$ & 4 & & & & & \\
\hline dexametasona $4 \mathrm{mg} / \mathrm{ml}-1 \mathrm{ml}$ & 12 & & & & & \\
\hline diazepam $5 \mathrm{mg} / \mathrm{ml}-2 \mathrm{ml}$ & & 2 & & & & \\
\hline dipirona $500 \mathrm{mg} / \mathrm{ml}-2 \mathrm{ml}$ & 12 & & 4 & 0,16 & 0,64 & 1,73 \\
\hline efedrina $25 \mathrm{mg} / \mathrm{ml}-1 \mathrm{ml}$ & 12 & & 1 & 0,43 & 0,43 & 1,16 \\
\hline epinefrina $1 \mathrm{mg} / \mathrm{ml}-1 \mathrm{ml}$ & 2 & & & & & \\
\hline etomidato $2 \mathrm{mg} / \mathrm{ml}-10 \mathrm{ml}$ & & 2 & & & & \\
\hline $\begin{array}{l}\text { fentanil + droperidol }(0,05 \mathrm{mg}+2,5 \mathrm{mg}) / \mathrm{ml} \\
-2 \mathrm{ml}\end{array}$ & & 4 & & & & \\
\hline fentanil $0,05 \mathrm{mg} / \mathrm{ml}-5 \mathrm{ml}$ & & 6 & 2 & 1,8 & 3,6 & 9,72 \\
\hline furosemida $10 \mathrm{mg} / \mathrm{ml}-2 \mathrm{ml}$ & 4 & & & & & \\
\hline glicose $50 \%-10 \mathrm{ml}$ & 1 & & & & & \\
\hline heparina IV 5.000UI $-5 \mathrm{ml}$ & 2 & & 1 & 3,45 & 3,45 & 9,32 \\
\hline hidralazina $20 \mathrm{mg} / \mathrm{ml}-1 \mathrm{ml}$ & 4 & & & & & \\
\hline hidrocortisona $500 \mathrm{mg}$ & 4 & & & & & \\
\hline lidocaína sem epinefrina $2 \%-20 \mathrm{ml}$ & 2 & & & & & \\
\hline $\begin{array}{l}\text { lidocaína com } \\
\text { epinefrina }(20 \mathrm{mg}+5 \mathrm{mcg}) / \mathrm{ml}-20 \mathrm{ml}\end{array}$ & 2 & & & & & \\
\hline lidocaína geléia $2 \%$ - $30 \mathrm{ml}$ & 2 & & 1 & 1,12 & 1,12 & 3,02 \\
\hline metaraminol $10 \mathrm{mg} / \mathrm{ml}-1 \mathrm{ml}$ & 4 & & 1 & 1,95 & 1,95 & 5,27 \\
\hline metoclopramida $5 \mathrm{mg} / \mathrm{ml}-2 \mathrm{ml}$ & 4 & & 1 & 0,15 & 0,15 & 0,41 \\
\hline metoprolol $1 \mathrm{mg} / \mathrm{ml}-5 \mathrm{ml}$ & & 2 & 2 & 9,24 & 18,48 & 49,9 \\
\hline midazolam $5 \mathrm{mg} / \mathrm{ml}-3 \mathrm{ml}$ & & 2 & & & & \\
\hline morfina $2 \mathrm{mg} / \mathrm{ml}-1 \mathrm{ml}$ & & 2 & 1 & 0,41 & 0,41 & 1,11 \\
\hline neostigmina $0,05 \mathrm{mg} / \mathrm{ml}-1 \mathrm{ml}$ & 6 & & 2 & 0,46 & 0,92 & 2,48 \\
\hline petidina $50 \mathrm{mg} / \mathrm{ml} 2 \mathrm{ml}$ & & 2 & & & & \\
\hline propofol $10 \mathrm{mg} / \mathrm{ml}-20 \mathrm{ml}$ & & 4 & 2 & 8,51 & 17,02 & 45,95 \\
\hline ranitidina $10 \mathrm{mg} / \mathrm{ml}-5 \mathrm{ml}$ & 4 & & 2 & 0,18 & 0,36 & 0,97 \\
\hline sufentanila $50 \mathrm{mcg} / \mathrm{ml}-1 \mathrm{ml}$ & & 2 & 2 & 4,08 & 8,16 & 22,03 \\
\hline suxametônio $100 \mathrm{mg}$ & 4 & & & & & \\
\hline tenoxicam $20 \mathrm{mg}$ & 2 & & & & & \\
\hline Total & 132 & 28 & 31 & 37,47 & 65,58 & 177,07 \\
\hline
\end{tabular}


Tabela 47: Segundo dia de consumo na sala 26 fase pós implantação

\begin{tabular}{|c|c|c|c|c|c|c|}
\hline \multicolumn{7}{|c|}{ SALA 26- SEGUNDO DIA DE CONSUMO } \\
\hline Medicamento & $\begin{array}{l}\text { Físico Inicial } \\
\text { (elenco kit) }\end{array}$ & Extra & $\begin{array}{l}\text { Quantidade } \\
\text { Utilizada }\end{array}$ & \begin{tabular}{c|} 
Preço \\
Unitário
\end{tabular} & $\begin{array}{l}\text { Preço } \\
\text { Final }\end{array}$ & $\begin{array}{l}\text { Valor em } \\
\text { dólar }\end{array}$ \\
\hline agua destilada $-10 \mathrm{ml}$ & 12 & & 3 & 0,1 & 0,3 & 0,81 \\
\hline aminofilina $24 \mathrm{mg} / \mathrm{ml}-10 \mathrm{ml}$ & 2 & & & & & \\
\hline atropina $0,5 \mathrm{mg} / \mathrm{ml}-1 \mathrm{ml}$ & 12 & & & & & \\
\hline $\begin{array}{l}\text { bupivacaína com } \\
\text { epinefrina }(5 \mathrm{mg}+9,1 \mathrm{mcg}) / \mathrm{ml}-20 \mathrm{ml}\end{array}$ & 2 & & & & & \\
\hline bupivacaína sem epinefrina $0,5 \%-20 \mathrm{ml}$ & 2 & & & & & \\
\hline bupivacaína hiperbárica $0,5 \%$ - $4 \mathrm{ml}$ & 2 & & & & & \\
\hline cefalotina $1 \mathrm{~g}$ & 4 & & 2 & 1,53 & 3,06 & 8,26 \\
\hline cetoprofeno $50 \mathrm{mg} / \mathrm{ml}-2 \mathrm{ml}$ & 2 & & & & & \\
\hline cloreto de cálcio $100 \mathrm{mg} / \mathrm{ml}-5 \mathrm{ml}$ & 4 & & & & & \\
\hline dexametasona $4 \mathrm{mg} / \mathrm{ml}-1 \mathrm{ml}$ & 12 & & & & & \\
\hline diazepam $5 \mathrm{mg} / \mathrm{ml}-2 \mathrm{ml}$ & & 2 & & & & \\
\hline dipirona $500 \mathrm{mg} / \mathrm{ml}-2 \mathrm{ml}$ & 12 & & 4 & 0,16 & 0,64 & 1,73 \\
\hline efedrina $25 \mathrm{mg} / \mathrm{ml}-1 \mathrm{ml}$ & 12 & & & & & \\
\hline epinefrina $1 \mathrm{mg} / \mathrm{ml}-1 \mathrm{ml}$ & 2 & & & & & \\
\hline etomidato $2 \mathrm{mg} / \mathrm{ml}-10 \mathrm{ml}$ & & 2 & & & & \\
\hline $\begin{array}{l}\text { fentanil }+ \text { droperidol }(0,05 \mathrm{mg}+2,5 \mathrm{mg}) / \mathrm{ml} \\
-2 \mathrm{ml}\end{array}$ & & 4 & & & & \\
\hline fentanil $0,05 \mathrm{mg} / \mathrm{ml}-5 \mathrm{ml}$ & & 6 & 4 & 1,8 & 7,2 & 19,44 \\
\hline furosemida $10 \mathrm{mg} / \mathrm{ml}-2 \mathrm{ml}$ & 4 & & & & & \\
\hline glicose $50 \%-10 \mathrm{ml}$ & 2 & & & & & \\
\hline heparina IV 5.000UI - 5ml & 2 & & & & & \\
\hline hidralazina $20 \mathrm{mg} / \mathrm{ml}-1 \mathrm{ml}$ & 4 & & & & & \\
\hline hidrocortisona 500mg & 4 & & & & & \\
\hline lidocaína sem epinefrina $2 \%$ - $20 \mathrm{ml}$ & 2 & & & & & \\
\hline $\begin{array}{l}\text { lidocaína com } \\
\text { epinefrina }(20 \mathrm{mg}+5 \mathrm{mcg}) / \mathrm{ml}-20 \mathrm{ml}\end{array}$ & 2 & & & & & \\
\hline lidocaína geléia $2 \%$ - 30ml & 2 & & & & & \\
\hline metaraminol $10 \mathrm{mg} / \mathrm{ml}-1 \mathrm{ml}$ & 4 & & & & & \\
\hline metoclopramida $5 \mathrm{mg} / \mathrm{ml}-2 \mathrm{ml}$ & 4 & & 2 & 0,15 & 0,3 & 0,81 \\
\hline midazolam $5 \mathrm{mg} / \mathrm{ml}-3 \mathrm{ml}$ & & 2 & 1 & 2,35 & 2,35 & 6,35 \\
\hline morfina $2 \mathrm{mg} / \mathrm{ml}-1 \mathrm{ml}$ & & 2 & 1 & 0,41 & 0,41 & 1,11 \\
\hline neostigmina $0,05 \mathrm{mg} / \mathrm{ml}-1 \mathrm{ml}$ & 12 & & & & & \\
\hline petidina $50 \mathrm{mg} / \mathrm{ml} 2 \mathrm{ml}$ & & 2 & & & & \\
\hline propofol $10 \mathrm{mg} / \mathrm{ml}-20 \mathrm{ml}$ & & 4 & 1 & 8,51 & 8,51 & 22,98 \\
\hline ranitidina $10 \mathrm{mg} / \mathrm{ml}-2 \mathrm{ml}$ & 4 & & 1 & 0,18 & 0,18 & 0,49 \\
\hline suxametônio $100 \mathrm{mg}$ & 4 & & & & & \\
\hline tenoxicam $20 \mathrm{mg}$ & 2 & & & & & \\
\hline Total & 130 & 24 & 19 & 15,19 & 22,95 & 61,98 \\
\hline
\end{tabular}


Tabela 48: Terceiro dia de consumo na sala 26 fase pós implantação

\begin{tabular}{|c|c|c|c|c|c|c|}
\hline \multicolumn{7}{|c|}{ SALA 26- TERCEIRO DIA DE CONSUMO } \\
\hline Medicamento & $\begin{array}{l}\text { Físico Inicial } \\
\text { (elenco kit) }\end{array}$ & Extra & $\begin{array}{l}\text { Quantidade } \\
\text { Utilizada }\end{array}$ & $\begin{array}{l}\text { Preço } \\
\text { Unitário }\end{array}$ & $\begin{array}{l}\text { Preço } \\
\text { Final }\end{array}$ & $\begin{array}{l}\text { Valor em } \\
\text { dólar }\end{array}$ \\
\hline agua destilada $-10 \mathrm{ml}$ & 12 & & 2 & 0,1 & 0,2 & 0,54 \\
\hline aminofilina $24 \mathrm{mg} / \mathrm{ml}-10 \mathrm{ml}$ & 2 & & & & & \\
\hline atropina $0,5 \mathrm{mg} / \mathrm{ml}-1 \mathrm{ml}$ & 12 & & 1 & 0,01 & 0,01 & 0,03 \\
\hline $\begin{array}{l}\text { bupivacaína com } \\
\text { epinefrina }(5 \mathrm{mg}+9,1 \mathrm{mcg}) / \mathrm{ml}-20 \mathrm{ml}\end{array}$ & 2 & & & & & \\
\hline bupivacaína sem epinefrina $0,5 \%-20 \mathrm{ml}$ & 2 & & 1 & 4 & 4 & 10,8 \\
\hline bupivacaína hiperbárica $0,5 \%-4 \mathrm{ml}$ & 2 & & & & & \\
\hline cefalotina $1 \mathrm{~g}$ & 4 & & 4 & 1,53 & 6,12 & 16,52 \\
\hline \multicolumn{7}{|l|}{ efedrina $25 \mathrm{mg} / \mathrm{ml}-1 \mathrm{ml}$} \\
\hline cetoprofeno $50 \mathrm{mg} / \mathrm{ml}-2 \mathrm{ml}$ & 2 & & & & & \\
\hline cloreto de cálcio $100 \mathrm{mg} / \mathrm{ml}-5 \mathrm{ml}$ & 4 & & & & & \\
\hline dexametasona $4 \mathrm{mg} / \mathrm{ml}-1 \mathrm{ml}$ & 12 & & & & & \\
\hline diazepam $5 \mathrm{mg} / \mathrm{ml} \mathrm{-} 2 \mathrm{ml}$ & 2 & & & & & \\
\hline dipirona $500 \mathrm{mg} / \mathrm{ml}-2 \mathrm{ml}$ & 12 & & 4 & 0,16 & 0,64 & 1,73 \\
\hline efedrina $25 \mathrm{mg} / \mathrm{ml}-1 \mathrm{ml}$ & 12 & & & & & \\
\hline \multicolumn{7}{|l|}{ epinefrina $1 \mathrm{mg} / \mathrm{ml}-1 \mathrm{ml}$} \\
\hline etomidato $2 \mathrm{mg} / \mathrm{ml}-10 \mathrm{ml}$ & 2 & & & & & \\
\hline $\begin{array}{l}\text { fentanil + droperidol }(0,05 \mathrm{mg}+2,5 \mathrm{mg}) / \mathrm{ml} \\
-2 \mathrm{ml}\end{array}$ & 4 & & & & & \\
\hline fentanil $0,05 \mathrm{mg} / \mathrm{ml}-5 \mathrm{ml}$ & 6 & & 3 & 1,8 & 5,4 & 14,58 \\
\hline furosemida $10 \mathrm{mg} / \mathrm{ml} \mathrm{-} 2 \mathrm{ml}$ & 4 & & & & & \\
\hline glicose $50 \%-10 \mathrm{ml}$ & 2 & & 1 & 0,16 & 0,16 & 0,43 \\
\hline heparina IV 5.000UI - $5 \mathrm{ml}$ & 2 & & 1 & 3,45 & 3,45 & 9,32 \\
\hline hidralazina $20 \mathrm{mg} / \mathrm{ml}-1 \mathrm{ml}$ & 4 & & & & & \\
\hline hidrocortisona $500 \mathrm{mg}$ & 4 & & & & & \\
\hline lidocaína sem epinefrina $2 \%-20 \mathrm{ml}$ & 2 & & 2 & 0,68 & 1,36 & 3,67 \\
\hline $\begin{array}{l}\text { lidocaína com } \\
\text { epinefrina }(20 \mathrm{mg}+5 \mathrm{mcg}) / \mathrm{ml}-20 \mathrm{ml}\end{array}$ & 2 & & & & & \\
\hline lidocaína geléia $2 \%$ - 30ml & 2 & & & & & \\
\hline metaraminol $10 \mathrm{mg} / \mathrm{ml}-1 \mathrm{ml}$ & 2 & & 1 & 1,95 & 1,95 & 5,27 \\
\hline metoclopramida $5 \mathrm{mg} / \mathrm{ml}-2 \mathrm{ml}$ & 4 & & 2 & 0,15 & 0,3 & 0,81 \\
\hline midazolam $5 \mathrm{mg} / \mathrm{ml}-3 \mathrm{ml}$ & 2 & & 1 & 2,35 & 2,35 & 6,35 \\
\hline morfina $2 \mathrm{mg} / \mathrm{ml}-1 \mathrm{ml}$ & 2 & & & & & \\
\hline neostigmina $0,05 \mathrm{mg} / \mathrm{ml}-1 \mathrm{ml}$ & 12 & & & & & \\
\hline petidina $50 \mathrm{mg} / \mathrm{ml} 2 \mathrm{ml}$ & 2 & & & & & \\
\hline propofol $10 \mathrm{mg} / \mathrm{ml}-20 \mathrm{ml}$ & 4 & & 1 & 8,51 & 8,51 & 22,98 \\
\hline ranitidina $10 \mathrm{mg} / \mathrm{ml}-2 \mathrm{ml}$ & 4 & & 2 & 0,18 & 0,36 & 0,97 \\
\hline suxametônio $100 \mathrm{mg}$ & 4 & & & & & \\
\hline tenoxicam $20 \mathrm{mg}$ & 2 & & & & & \\
\hline Total & 142 & 24 & 26 & 25,03 & 34,81 & 94 \\
\hline
\end{tabular}


Tabela 49: Primeiro dia de consumo na sala 27 fase pós implantação

\begin{tabular}{|c|c|c|c|c|c|c|}
\hline \multicolumn{7}{|c|}{ SALA 27 - PRIMEIRO DIA DE CONSUMO } \\
\hline Medicamento & $\begin{array}{c}\text { Físico Inicial } \\
\text { (elenco kit) }\end{array}$ & Extra & \begin{tabular}{|c} 
Quantidade \\
Utilizada
\end{tabular} & $\begin{array}{c}\text { Preço } \\
\text { Unitária }\end{array}$ & $\begin{array}{l}\text { Preço } \\
\text { Final }\end{array}$ & $\begin{array}{l}\text { Valor em } \\
\text { dólar }\end{array}$ \\
\hline agua destilada $-10 \mathrm{ml}$ & 12 & & 3 & 0,1 & 0,3 & 0,81 \\
\hline aminofilina $24 \mathrm{mg} / \mathrm{ml}-10 \mathrm{ml}$ & 2 & & & & & \\
\hline atropina $0,5 \mathrm{mg} / \mathrm{ml}-1 \mathrm{ml}$ & 12 & & & & & \\
\hline $\begin{array}{l}\text { bupivacaína com } \\
\text { epinefrina }(5 \mathrm{mg}+9,1 \mathrm{mcg}) / \mathrm{ml}-20 \mathrm{ml}\end{array}$ & 2 & & & & & \\
\hline bupivacaína sem epinefrina $0,5 \%-20 \mathrm{ml}$ & 2 & & 1 & 4 & 4 & 10,8 \\
\hline bupivacaína hiperbárica $0,5 \%-4 \mathrm{ml}$ & 2 & & & & & \\
\hline cefalotina $1 \mathrm{~g}$ & 4 & & 1 & 1,53 & 1,53 & 4,13 \\
\hline Cefotaxima $1 \mathrm{~g}$ & & 1 & 1 & 2,57 & 2,57 & 6,94 \\
\hline cetoprofeno $50 \mathrm{mg} / \mathrm{ml}-2 \mathrm{ml}$ & 2 & & 1 & 3,43 & 3,43 & 9,26 \\
\hline cloreto de cálcio $100 \mathrm{mg} / \mathrm{ml}-5 \mathrm{ml}$ & 4 & & & & & \\
\hline dexametasona $4 \mathrm{mg} / \mathrm{ml}-1 \mathrm{ml}$ & 12 & & & & & \\
\hline diazepam $5 \mathrm{mg} / \mathrm{ml}-2 \mathrm{ml}$ & & 2 & & & & \\
\hline dipirona $500 \mathrm{mg} / \mathrm{ml}-2 \mathrm{ml}$ & 12 & & 2 & 0,16 & 0,32 & 0,86 \\
\hline efedrina $25 \mathrm{mg} / \mathrm{ml}-1 \mathrm{ml}$ & 12 & & & & & \\
\hline epinefrina $1 \mathrm{mg} / \mathrm{ml}-1 \mathrm{ml}$ & 2 & & 1 & 0,15 & 0,15 & 0,41 \\
\hline etomidato $2 \mathrm{mg} / \mathrm{ml}-10 \mathrm{ml}$ & & 2 & & & & \\
\hline $\begin{array}{l}\text { fentanil + droperidol }(0,05 \mathrm{mg}+2,5 \mathrm{mg}) / \mathrm{ml} \\
-2 \mathrm{ml}\end{array}$ & & 4 & & & & \\
\hline fentanil $0,05 \mathrm{mg} / \mathrm{ml}-5 \mathrm{ml}$ & & 6 & 3 & 1,8 & 5,4 & 14,58 \\
\hline furosemida $10 \mathrm{mg} / \mathrm{ml} \mathrm{-} 2 \mathrm{ml}$ & 4 & & & & & \\
\hline glicose $50 \%-10 \mathrm{ml}$ & 2 & & & & & \\
\hline heparina IV 5.000UI - 5ml & 2 & & & & & \\
\hline hidralazina $20 \mathrm{mg} / \mathrm{ml}-1 \mathrm{ml}$ & 4 & & & & & \\
\hline hidrocortisona $500 \mathrm{mg}$ & 4 & & & & & \\
\hline lidocaína sem epinefrina $2 \%-20 \mathrm{ml}$ & 2 & & & & & \\
\hline $\begin{array}{l}\text { lidocaína com epinefrina(20mg+ } \\
5 \mathrm{mcg}) / \mathrm{ml}-20 \mathrm{ml}\end{array}$ & 2 & & & & & \\
\hline lidocaína geléia $2 \%$ - $30 \mathrm{ml}$ & 2 & & 1 & 1,12 & 1,12 & 3,02 \\
\hline metaraminol $10 \mathrm{mg} / \mathrm{ml}-1 \mathrm{ml}$ & 4 & & & & & \\
\hline metoclopramida $5 \mathrm{mg} / \mathrm{ml}-2 \mathrm{ml}$ & 4 & & 2 & 0,15 & 0,3 & 0,81 \\
\hline midazolam $5 \mathrm{mg} / \mathrm{ml}-3 \mathrm{ml}$ & & 2 & 2 & 2,35 & 4,7 & 12,69 \\
\hline morfina $2 \mathrm{mg} / \mathrm{ml}-1 \mathrm{ml}$ & & 2 & & & & \\
\hline neostigmina $0,05 \mathrm{mg} / \mathrm{ml}-1 \mathrm{ml}$ & 12 & & & & & \\
\hline petidina $50 \mathrm{mg} / \mathrm{ml} 2 \mathrm{ml}$ & & 2 & & & & \\
\hline propofol $10 \mathrm{mg} / \mathrm{ml}-20 \mathrm{ml}$ & & 4 & 3 & 8,51 & 25,53 & 68,93 \\
\hline ranitidina $10 \mathrm{mg} / \mathrm{ml}-\mathrm{ml}$ & 4 & & 2 & 0,18 & 0,36 & 0,97 \\
\hline suxametônio $100 \mathrm{mg}$ & 4 & & & & & \\
\hline tenoxicam $20 \mathrm{mg}$ & 2 & & & & & \\
\hline verde brilhante $100 \mathrm{mg} / \mathrm{ml}-1 \mathrm{ml}$ & & 1 & 1 & 0,36 & 0,36 & 0,97 \\
\hline Total & 132 & 26 & 24 & 26,41 & $\mathbf{5 0 , 0 7}$ & 135,18 \\
\hline
\end{tabular}


Tabela 50: Segundo dia de consumo na sala 27 fase pós implantação

\begin{tabular}{|c|c|c|c|c|c|c|}
\hline \multicolumn{7}{|c|}{ SALA 27 - SEGUNDO DIA DE CONSUMO } \\
\hline Medicamento & $\begin{array}{l}\text { Físico Inicial } \\
\text { (elenco kit) }\end{array}$ & Extra & $\begin{array}{l}\text { Quantidade } \\
\text { Utilizada }\end{array}$ & \begin{tabular}{c|} 
Preço \\
Unitário
\end{tabular} & $\begin{array}{l}\text { Preço } \\
\text { Final }\end{array}$ & $\begin{array}{l}\text { Valor em } \\
\text { dólar }\end{array}$ \\
\hline agua destilada $-10 \mathrm{ml}$ & 24 & & 9 & 0,1 & 0,9 & 2,43 \\
\hline aminofilina $24 \mathrm{mg} / \mathrm{ml}-10 \mathrm{ml}$ & 4 & & & & & \\
\hline atropina $0,5 \mathrm{mg} / \mathrm{ml}-1 \mathrm{ml}$ & 24 & & & & & \\
\hline $\begin{array}{l}\text { bupivacaína com } \\
\text { epinefrina }(5 \mathrm{mg}+9,1 \mathrm{mcg}) / \mathrm{ml}-20 \mathrm{ml}\end{array}$ & 4 & & & & & \\
\hline bupivacaína sem epinefrina $0,5 \%-20 \mathrm{ml}$ & 4 & & & & & \\
\hline bupivacaína hiperbárica $0,5 \%-4 \mathrm{ml}$ & 4 & & & & & \\
\hline cefalotina $1 \mathrm{~g}$ & 8 & & 6 & 1,53 & 9,18 & 24,79 \\
\hline cetoprofeno $50 \mathrm{mg} / \mathrm{ml}-2 \mathrm{ml}$ & 4 & & & & & \\
\hline cloreto de cálcio $100 \mathrm{mg} / \mathrm{ml}-5 \mathrm{ml}$ & 8 & & & & & \\
\hline dexametasona $4 \mathrm{mg} / \mathrm{ml}-1 \mathrm{ml}$ & 24 & & & & & \\
\hline diazepam $5 \mathrm{mg} / \mathrm{ml}-2 \mathrm{ml}$ & 4 & & & & & \\
\hline dipirona $500 \mathrm{mg} / \mathrm{ml}-2 \mathrm{ml}$ & 24 & & 8 & 0,16 & 1,28 & 3,46 \\
\hline efedrina $25 \mathrm{mg} / \mathrm{ml}-1 \mathrm{ml}$ & 24 & & & & & \\
\hline epinefrina $1 \mathrm{mg} / \mathrm{ml}-1 \mathrm{ml}$ & 4 & & & & & \\
\hline etomidato $2 \mathrm{mg} / \mathrm{ml}-10 \mathrm{ml}$ & & 4 & 1 & 3,18 & 3,18 & 8,59 \\
\hline $\begin{array}{l}\text { fentanil + droperidol }(0,05 \mathrm{mg}+2,5 \mathrm{mg}) / \mathrm{ml} \\
-2 \mathrm{ml}\end{array}$ & & 8 & 1 & 3,51 & 3,51 & 9,48 \\
\hline fentanil $0,05 \mathrm{mg} / \mathrm{ml}-5 \mathrm{ml}$ & & 12 & 9 & 1,8 & 16,2 & 43,74 \\
\hline furosemida $10 \mathrm{mg} / \mathrm{ml}-2 \mathrm{ml}$ & 8 & & & & & \\
\hline glicose $50 \%-10 \mathrm{ml}$ & 4 & & & & & \\
\hline heparina IV 5.000UI - 5ml & 4 & & & & & \\
\hline hidralazina $20 \mathrm{mg} / \mathrm{ml}-1 \mathrm{ml}$ & 8 & & & & & \\
\hline hidrocortisona $500 \mathrm{mg}$ & 8 & & 3 & 2,88 & 8,64 & 23,33 \\
\hline isoprenalina $0,2 \mathrm{mg} / \mathrm{ml}-1 \mathrm{ml}$ & & 1 & 1 & 0,32 & 0,32 & 0,86 \\
\hline lidocaína sem epinefrina $2 \%$ - $20 \mathrm{ml}$ & 4 & & & & & \\
\hline $\begin{array}{l}\text { lidocaína com } \\
\text { epinefrina }(20 \mathrm{mg}+5 \mathrm{mcg}) / \mathrm{ml}-20 \mathrm{ml}\end{array}$ & 4 & & 1 & 1,31 & 1,31 & 3,54 \\
\hline lidocaína geléia $2 \%$ - 30ml & 4 & & 2 & 1,12 & 2,24 & 6,05 \\
\hline metaraminol $10 \mathrm{mg} / \mathrm{ml}-1 \mathrm{ml}$ & 8 & & & & & \\
\hline metoclopramida $5 \mathrm{mg} / \mathrm{ml}-2 \mathrm{ml}$ & 8 & & 3 & 0,15 & 0,45 & 1,22 \\
\hline midazolam $5 \mathrm{mg} / \mathrm{ml}-3 \mathrm{ml}$ & & 4 & 3 & 2,35 & 7,05 & 19,04 \\
\hline morfina $2 \mathrm{mg} / \mathrm{ml}-1 \mathrm{ml}$ & & 4 & 1 & 0,41 & 0,41 & 1,11 \\
\hline neostigmina $0,05 \mathrm{mg} / \mathrm{ml}-1 \mathrm{ml}$ & 24 & & & & & \\
\hline petidina $50 \mathrm{mg} / \mathrm{ml} 2 \mathrm{ml}$ & & 4 & 1 & 0,18 & 0,18 & 0,49 \\
\hline propofol $10 \mathrm{mg} / \mathrm{ml}-20 \mathrm{ml}$ & & 8 & 3 & 8,51 & 25,53 & 68,93 \\
\hline ranitidina $10 \mathrm{mg} / \mathrm{ml}-5 \mathrm{ml}$ & 8 & & 3 & 0,18 & 0,54 & 1,46 \\
\hline suxametônio $100 \mathrm{mg}$ & 8 & & & & & \\
\hline tenoxicam $20 \mathrm{mg}$ & 4 & & & & & \\
\hline Total & 274 & 49 & 55 & 27,69 & 80,92 & 218,52 \\
\hline
\end{tabular}


Tabela 51: Terceiro dia de consumo na sala 27 fase pós implantação

SALA 27- TERCEIRO DIA DE CONSUMO

\begin{tabular}{|c|c|c|c|c|c|c|}
\hline Medicamento & $\begin{array}{l}\text { Físico Inicial } \\
\text { (elenco kit) }\end{array}$ & Extra & $\begin{array}{l}\text { Quantidade } \\
\text { Utilizada }\end{array}$ & $\begin{array}{c}\text { Preço } \\
\text { Unitário }\end{array}$ & $\begin{array}{l}\text { Preço } \\
\text { Final }\end{array}$ & $\begin{array}{c}\text { Valor em } \\
\text { dólar }\end{array}$ \\
\hline agua destilada $-10 \mathrm{ml}$ & 12 & & 3 & 0,1 & 0,3 & 0,81 \\
\hline aminofilina $24 \mathrm{mg} / \mathrm{ml}-10 \mathrm{ml}$ & 2 & & & & & \\
\hline atropina $0,5 \mathrm{mg} / \mathrm{ml}-1 \mathrm{ml}$ & 12 & & 3 & 0,01 & 0,03 & 0,08 \\
\hline $\begin{array}{l}\text { bupivacaína com } \\
\text { epinefrina }(5 \mathrm{mg}+9,1 \mathrm{mcg}) / \mathrm{ml}-20 \mathrm{ml}\end{array}$ & 2 & & & & & \\
\hline bupivacaína sem epinefrina $0,5 \%-20 \mathrm{ml}$ & 2 & & & & & \\
\hline bupivacaína hiperbárica $0,5 \%-4 \mathrm{ml}$ & 2 & & 1 & 3,59 & 3,59 & 9,69 \\
\hline cefalotina $1 \mathrm{~g}$ & 4 & & 3 & 1,53 & 4,59 & 12,39 \\
\hline cetoprofeno $50 \mathrm{mg} / \mathrm{ml}-2 \mathrm{ml}$ & 2 & & & & & \\
\hline cloreto de cálcio $100 \mathrm{mg} / \mathrm{ml}-5 \mathrm{ml}$ & 4 & & & & & \\
\hline dexametasona $4 \mathrm{mg} / \mathrm{ml}-1 \mathrm{ml}$ & 12 & & & & & \\
\hline diazepam $5 \mathrm{mg} / \mathrm{ml}-2 \mathrm{ml}$ & 2 & & & & & \\
\hline dipirona $500 \mathrm{mg} / \mathrm{ml}-2 \mathrm{ml}$ & 12 & & 7 & 0,16 & 1,12 & 3,02 \\
\hline efedrina $25 \mathrm{mg} / \mathrm{ml}-1 \mathrm{ml}$ & 12 & & & & & \\
\hline epinefrina $1 \mathrm{mg} / \mathrm{ml}-1 \mathrm{ml}$ & 2 & & & & & \\
\hline etomidato $2 \mathrm{mg} / \mathrm{ml}-10 \mathrm{ml}$ & & 2 & & & & \\
\hline $\begin{array}{l}\text { fentanil }+ \text { droperidol }(0,05 \mathrm{mg}+2,5 \mathrm{mg}) / \mathrm{ml} \\
-2 \mathrm{ml}\end{array}$ & & 4 & & & & \\
\hline fentanil $0,05 \mathrm{mg} / \mathrm{ml}-5 \mathrm{ml}$ & & 6 & & & & \\
\hline furosemida $10 \mathrm{mg} / \mathrm{ml}-2 \mathrm{ml}$ & 4 & & 1 & 0,13 & 0,13 & 0,35 \\
\hline glicose $50 \%-10 \mathrm{ml}$ & 2 & & & & & \\
\hline heparina IV 5.000UI - 5ml & 2 & & & & & \\
\hline hidralazina $20 \mathrm{mg} / \mathrm{ml}-1 \mathrm{ml}$ & 4 & & & & & \\
\hline hidrocortisona $500 \mathrm{mg}$ & 4 & & & & & \\
\hline lidocaína sem epinefrina $2 \%-20 \mathrm{ml}$ & 2 & & 1 & 0,68 & 0,68 & 1,84 \\
\hline $\begin{array}{l}\text { lidocaína com } \\
\text { epinefrina }(20 \mathrm{mg}+5 \mathrm{mcg}) / \mathrm{ml}-20 \mathrm{ml}\end{array}$ & 2 & & 1 & 1,31 & 1,31 & 3,54 \\
\hline lidocaína geléia $2 \%$ - 30ml & 2 & & & & & \\
\hline metaraminol $10 \mathrm{mg} / \mathrm{ml}-1 \mathrm{ml}$ & 4 & & & & & \\
\hline metoclopramida $5 \mathrm{mg} / \mathrm{ml}-2 \mathrm{ml}$ & 4 & & 1 & 0,15 & 0,15 & 0,41 \\
\hline midazolam $15 \mathrm{mg}-3 \mathrm{ml}$ & & 2 & 1 & 2,35 & 2,35 & 6,35 \\
\hline morfina $2 \mathrm{mg} / \mathrm{ml}-1 \mathrm{ml}$ & & 2 & 1 & 0,41 & 0,41 & 1,11 \\
\hline neostigmina $0,05 \mathrm{mg} / \mathrm{ml}-1 \mathrm{ml}$ & 12 & & & & & \\
\hline petidina $50 \mathrm{mg} / \mathrm{ml} 2 \mathrm{ml}$ & & 2 & & & & \\
\hline propofol $10 \mathrm{mg} / \mathrm{ml}-20 \mathrm{ml}$ & & 4 & 1 & 8,51 & 8,51 & 22,98 \\
\hline ranitidina $10 \mathrm{mg} / \mathrm{ml}-5 \mathrm{ml}$ & 4 & & 2 & 0,18 & 0,36 & 0,97 \\
\hline suxametônio $100 \mathrm{mg}$ & 4 & & & & & \\
\hline tenoxicam $20 \mathrm{mg}$ & 2 & & & & & \\
\hline Total & 132 & 24 & 26 & 19,11 & 23,53 & 63,54 \\
\hline
\end{tabular}


Tabela 52: Primeiro dia de consumo na sala 28 fase pós implantação

\begin{tabular}{|c|c|c|c|c|c|c|}
\hline \multicolumn{7}{|c|}{ SALA 28 - PRIMEIRO DIA DE CONSUMO } \\
\hline Medicamento & $\begin{array}{l}\text { Físico Inicial } \\
\text { (elenco kit) }\end{array}$ & Extra & $\begin{array}{l}\text { Quantidade } \\
\text { Utilizada }\end{array}$ & $\begin{array}{c}\text { Preço } \\
\text { Unitário }\end{array}$ & $\begin{array}{l}\text { Preço } \\
\text { Final }\end{array}$ & $\begin{array}{l}\text { Valor em } \\
\text { dólar }\end{array}$ \\
\hline agua destilada $-10 \mathrm{ml}$ & 6 & & 1 & 0,1 & 0,1 & 0,27 \\
\hline aminofilina $24 \mathrm{mg} / \mathrm{ml}-10 \mathrm{ml}$ & 1 & & & & & \\
\hline atropina $0,5 \mathrm{mg} / \mathrm{ml}-1 \mathrm{ml}$ & 6 & & 1 & 0,01 & 0,01 & 0,03 \\
\hline $\begin{array}{l}\text { bupivacaína com } \\
\text { epinefrina }(5 \mathrm{mg}+9,1 \mathrm{mcg}) / \mathrm{ml}-20 \mathrm{ml}\end{array}$ & 1 & & & & & \\
\hline bupivacaína sem epinefrina $0,5 \%-20 \mathrm{ml}$ & 1 & & & & & \\
\hline bupivacaína hiperbárica $0,5 \%-4 \mathrm{ml}$ & 1 & & & & & \\
\hline cefalotina $1 \mathrm{~g}$ & 2 & & & & & \\
\hline cetoprofeno $50 \mathrm{mg} / \mathrm{ml}-2 \mathrm{ml}$ & 1 & & & & & \\
\hline cloreto de cálcio $100 \mathrm{mg} / \mathrm{ml}-5 \mathrm{ml}$ & 2 & & & & & \\
\hline dexametasona $4 \mathrm{mg} / \mathrm{ml}-1 \mathrm{ml}$ & 6 & & & & & \\
\hline diazepam $10 \mathrm{mg}-2 \mathrm{ml}$ & 1 & & & & & \\
\hline dipirona $500 \mathrm{mg} / \mathrm{ml}-2 \mathrm{ml}$ & 6 & & 1 & 0,16 & 0,16 & 0,43 \\
\hline efedrina $25 \mathrm{mg} / \mathrm{ml}-1 \mathrm{ml}$ & 6 & & & & & \\
\hline epinefrina $1 \mathrm{mg} / \mathrm{ml}-1 \mathrm{ml}$ & 1 & & & & & \\
\hline etomidato $2 \mathrm{mg} / \mathrm{ml}-10 \mathrm{ml}$ & & 1 & & & & \\
\hline $\begin{array}{l}\text { fentanil + droperidol }(0,05 \mathrm{mg}+2,5 \mathrm{mg}) / \mathrm{ml} \\
-2 \mathrm{ml}\end{array}$ & & 2 & & & & \\
\hline fentanil $0,05 \mathrm{mg} / \mathrm{ml} \mathrm{-} 5 \mathrm{ml}$ & & 3 & 1 & 1,8 & 1,8 & 4,86 \\
\hline furosemida $10 \mathrm{mg} / \mathrm{ml}-2 \mathrm{ml}$ & 2 & & & & & \\
\hline glicose $50 \%-10 \mathrm{ml}$ & 1 & & 1 & 0,16 & 0,16 & 0,43 \\
\hline heparina IV 5.000UI - 5ml & 1 & & & & & \\
\hline hidralazina $20 \mathrm{mg} / \mathrm{ml}-1 \mathrm{ml}$ & 2 & & & & & \\
\hline hidrocortisona $500 \mathrm{mg}$ & 2 & & & & & \\
\hline lidocaína sem epinefrina $2 \%-20 \mathrm{ml}$ & 1 & & & & & \\
\hline $\begin{array}{l}\text { lidocaína com } \\
\text { epinefrina }(20 \mathrm{mg}+5 \mathrm{mcg}) / \mathrm{ml}-20 \mathrm{ml}\end{array}$ & 1 & & & & & \\
\hline lidocaína geléia $2 \%$ - $30 \mathrm{ml}$ & 1 & & 1 & 1,12 & 1,12 & 3,02 \\
\hline metaraminol $10 \mathrm{mg} / \mathrm{ml}-1 \mathrm{ml}$ & 2 & & & & & \\
\hline metoclopramida $5 \mathrm{mg} / \mathrm{ml}-2 \mathrm{ml}$ & 2 & & 1 & 0,15 & 0,15 & 0,41 \\
\hline midazolam $5 \mathrm{mg} / \mathrm{ml}-3 \mathrm{ml}$ & & 1 & 1 & 2,35 & 2,35 & 6,35 \\
\hline morfina $2 \mathrm{mg} / \mathrm{ml}-1 \mathrm{ml}$ & & 1 & & & & \\
\hline neostigmina $0,05 \mathrm{mg} / \mathrm{ml}-1 \mathrm{ml}$ & 6 & & & & & \\
\hline petidina $50 \mathrm{mg} / \mathrm{ml} 2 \mathrm{ml}$ & & 1 & & & & \\
\hline propofol $10 \mathrm{mg} / \mathrm{ml}-20 \mathrm{ml}$ & & 2 & 2 & 8,51 & 17,02 & 45,95 \\
\hline ranitidina $10 \mathrm{mg} / \mathrm{ml}-5 \mathrm{ml}$ & 2 & & & & & \\
\hline suxametônio $100 \mathrm{mg}$ & 2 & & & & & \\
\hline tenoxicam $20 \mathrm{mg}$ & 1 & & & & & \\
\hline Total & 66 & 12 & 10 & 14,36 & 22,87 & 61,75 \\
\hline
\end{tabular}


Tabela 53: Segundo dia de consumo na sala 28 fase pós implantação

\begin{tabular}{|c|c|c|c|c|c|c|}
\hline \multicolumn{7}{|c|}{ SALA 28 - SEGUNDO DIA DE CONSUMO } \\
\hline Medicamento & $\begin{array}{l}\text { Físico Inicial } \\
\text { (elenco kit) }\end{array}$ & Extra & $\begin{array}{l}\text { Quantidade } \\
\text { Utilizada }\end{array}$ & $\begin{array}{l}\text { Preço } \\
\text { Unitário }\end{array}$ & $\begin{array}{l}\text { Preço } \\
\text { Final }\end{array}$ & $\begin{array}{l}\text { Valor em } \\
\text { dólar }\end{array}$ \\
\hline agua destilada $-10 \mathrm{ml}$ & 12 & & & & & \\
\hline aminofilina $24 \mathrm{mg} / \mathrm{ml}-10 \mathrm{ml}$ & 2 & & & & & \\
\hline atropina $0,5 \mathrm{mg} / \mathrm{ml}-1 \mathrm{ml}$ & 12 & & & & & \\
\hline $\begin{array}{l}\text { bupivacaína com } \\
\text { epinefrina }(5 \mathrm{mg}+9,1 \mathrm{mcg}) / \mathrm{ml}-20 \mathrm{ml}\end{array}$ & 2 & & 1 & 3,98 & 3,98 & 10,75 \\
\hline bupivacaína sem epinefrina $0,5 \%-20 \mathrm{ml}$ & 2 & & & & & \\
\hline bupivacaína hiperbárica $0,5 \%-4 \mathrm{ml}$ & 2 & & & & & \\
\hline cefalotina $1 \mathrm{~g}$ & 4 & & 2 & 1,53 & 3,06 & 8,26 \\
\hline cefoxitina $1 \mathrm{~g}$ & & 3 & 3 & 8,27 & 24,81 & 66,99 \\
\hline cetoprofeno $50 \mathrm{mg} / \mathrm{ml}-2 \mathrm{ml}$ & 2 & & 1 & 0,49 & 0,49 & 1,32 \\
\hline cloreto de cálcio $100 \mathrm{mg} / \mathrm{ml}-5 \mathrm{ml}$ & 4 & & & & & \\
\hline dexametasona $4 \mathrm{mg} / \mathrm{ml}-1 \mathrm{ml}$ & 12 & & & & & \\
\hline diazepam $5 \mathrm{mg} / \mathrm{ml}-2 \mathrm{ml}$ & & 2 & & & & \\
\hline dipirona $500 \mathrm{mg} / \mathrm{ml}-2 \mathrm{ml}$ & 12 & & 8 & 0,16 & 1,28 & 3,46 \\
\hline efedrina $25 \mathrm{mg} / \mathrm{ml}-1 \mathrm{ml}$ & 12 & & & & & \\
\hline epinefrina $1 \mathrm{mg} / \mathrm{ml}-1 \mathrm{ml}$ & 2 & 1 & 3 & 0,15 & 0,45 & 1,22 \\
\hline etomidato $2 \mathrm{mg} / \mathrm{ml}-10 \mathrm{ml}$ & & 2 & 1 & 3,18 & 3,18 & 8,59 \\
\hline $\begin{array}{l}\text { fentanil + droperidol }(0,05 \mathrm{mg}+2,5 \mathrm{mg}) / \mathrm{ml} \\
-2 \mathrm{ml}\end{array}$ & & 4 & 1 & 3,51 & 3,51 & 9,48 \\
\hline fentanil $0,05 \mathrm{mg} / \mathrm{ml}-5 \mathrm{ml}$ & & 6 & 5 & 1,8 & 9 & 24,3 \\
\hline furosemida $10 \mathrm{mg} / \mathrm{ml}-2 \mathrm{ml}$ & 4 & & & & & \\
\hline glicose $50 \%-10 \mathrm{ml}$ & 2 & & & & & \\
\hline heparina IV 5.000UI - 5ml & 2 & & & & & \\
\hline hidralazina $20 \mathrm{mg} / \mathrm{ml}-1 \mathrm{ml}$ & 4 & & & & & \\
\hline hidrocortisona $500 \mathrm{mg}$ & 4 & & & & & \\
\hline lidocaína sem epinefrina $2 \%-20 \mathrm{ml}$ & 2 & & 1 & 0,68 & 0,68 & 1,84 \\
\hline $\begin{array}{l}\text { lidocaína com } \\
\text { epinefrina }(20 \mathrm{mg}+5 \mathrm{mcg}) / \mathrm{ml}-20 \mathrm{ml}\end{array}$ & 2 & & & & & \\
\hline lidocaína geléia $2 \%$ - 30ml & 2 & & & & & \\
\hline metaraminol $10 \mathrm{mg} / \mathrm{ml}-1 \mathrm{ml}$ & 4 & & & & & \\
\hline metoclopramida $5 \mathrm{mg} / \mathrm{ml}-2 \mathrm{ml}$ & 4 & & 3 & 0,15 & 0,45 & 1,22 \\
\hline midazolam $5 \mathrm{mg} / \mathrm{ml}-3 \mathrm{ml}$ & & 2 & 2 & 2,35 & 4,7 & 12,69 \\
\hline morfina $2 \mathrm{mg} / \mathrm{ml}-1 \mathrm{ml}$ & & 2 & 1 & 0,41 & 0,41 & 1,11 \\
\hline neostigmina $0,05 \mathrm{mg} / \mathrm{ml}-1 \mathrm{ml}$ & 12 & & & & & \\
\hline petidina $50 \mathrm{mg} / \mathrm{ml} 2 \mathrm{ml}$ & & 2 & & & & \\
\hline propofol $10 \mathrm{mg} / \mathrm{ml}-20 \mathrm{ml}$ & & 4 & & & & \\
\hline ranitidina $10 \mathrm{mg} / \mathrm{ml}-5 \mathrm{ml}$ & 4 & & 2 & 0,18 & 0,36 & 0,97 \\
\hline suxametônio $100 \mathrm{mg}$ & 4 & & & & & \\
\hline tenoxicam $20 \mathrm{mg}$ & 2 & & & & & \\
\hline Total & 132 & 28 & 34 & 26,84 & 56,36 & 152,2 \\
\hline
\end{tabular}


Tabela 54: Terceiro dia de consumo na sala 28 fase pós implantação

\begin{tabular}{|c|c|c|c|c|c|c|}
\hline \multicolumn{7}{|c|}{ SALA 28 - TERCEIRO DIA DE CONSUMO } \\
\hline Medicamento & $\begin{array}{l}\text { Físico Inicial } \\
\text { (elenco kit) }\end{array}$ & Extra & $\begin{array}{l}\text { Quantidade } \\
\text { Utilizada }\end{array}$ & $\begin{array}{c}\text { Preço } \\
\text { Unitário }\end{array}$ & $\begin{array}{l}\text { Preço } \\
\text { Final }\end{array}$ & $\begin{array}{l}\text { Valor em } \\
\text { dólar }\end{array}$ \\
\hline agua destilada $-10 \mathrm{ml}$ & 18 & & 2 & 0,1 & 0,2 & 0,54 \\
\hline aminofilina $24 \mathrm{mg} / \mathrm{ml}-10 \mathrm{ml}$ & 3 & & & & & \\
\hline atropina $0,5 \mathrm{mg} / \mathrm{ml}-1 \mathrm{ml}$ & 18 & & & & & \\
\hline $\begin{array}{l}\text { bupivacaína com } \\
\text { epinefrina }(5 \mathrm{mg}+9,1 \mathrm{mcg}) / \mathrm{ml}-20 \mathrm{ml}\end{array}$ & 3 & & 1 & 3,98 & 3,98 & 10,75 \\
\hline bupivacaína sem epinefrina $0,5 \%-20 \mathrm{ml}$ & 3 & & & & & \\
\hline bupivacaína hiperbárica $0,5 \%-4 \mathrm{ml}$ & 3 & & 1 & 3,59 & 3,59 & 9,69 \\
\hline cefalotina $1 \mathrm{~g}$ & 6 & & 4 & 1,53 & 6,12 & 16,52 \\
\hline cefoxitina $1 \mathrm{~g}$ & & 2 & 2 & 8,27 & 16,54 & 44,66 \\
\hline cetamina $50 \mathrm{mg} / \mathrm{ml}-10 \mathrm{ml}$ & & 1 & 1 & 25,15 & 25,15 & 67,91 \\
\hline cetoprofeno $50 \mathrm{mg} / \mathrm{ml}-2 \mathrm{ml}$ & 3 & & & & & \\
\hline cloreto de cálcio $100 \mathrm{mg} / \mathrm{ml}-5 \mathrm{ml}$ & 6 & & & & & \\
\hline dexametasona $4 \mathrm{mg} / \mathrm{ml}-1 \mathrm{ml}$ & 18 & & & & & \\
\hline diazepam $5 \mathrm{mg} / \mathrm{ml}-2 \mathrm{ml}$ & & 3 & & & & \\
\hline dipirona $500 \mathrm{mg} / \mathrm{ml}-2 \mathrm{ml}$ & 18 & & & & & \\
\hline efedrina $25 \mathrm{mg} / \mathrm{ml}-1 \mathrm{ml}$ & 18 & & & & & \\
\hline \multicolumn{7}{|l|}{ epinefrina $1 \mathrm{mg} / \mathrm{ml}-1 \mathrm{ml}$} \\
\hline etomidato $2 \mathrm{mg} / \mathrm{ml}-10 \mathrm{ml}$ & & 3 & & & & \\
\hline $\begin{array}{l}\text { fentanil }+ \text { droperidol }(0,05 \mathrm{mg}+2,5 \mathrm{mg}) / \mathrm{ml} \\
-2 \mathrm{ml}\end{array}$ & & 6 & & & & \\
\hline fentanil $0,05 \mathrm{mg} / \mathrm{ml}-5 \mathrm{ml}$ & & 9 & 5 & 1,8 & 9 & 24,3 \\
\hline furosemida $10 \mathrm{mg} / \mathrm{ml}-2 \mathrm{ml}$ & 6 & & & & & \\
\hline glicose $50 \%-10 \mathrm{ml}$ & 3 & & & & & \\
\hline heparina IV 5.000UI - 5ml & 3 & & & & & \\
\hline hidralazina $20 \mathrm{mg} / \mathrm{ml}-1 \mathrm{ml}$ & 6 & & & & & \\
\hline hidrocortisona 500mg & 6 & & 4 & 2,88 & 11,52 & 31,1 \\
\hline lidocaína sem epinefrina $2 \%$ - $20 \mathrm{ml}$ & 3 & & 1 & 0,68 & 0,68 & 1,84 \\
\hline $\begin{array}{l}\text { lidocaína com } \\
\text { epinefrina }(20 \mathrm{mg}+5 \mathrm{mcg}) / \mathrm{ml}-20 \mathrm{ml}\end{array}$ & 3 & & & & & \\
\hline lidocaína geléia $2 \%$ - 30ml & 3 & & 1 & 1,12 & 1,12 & 3,02 \\
\hline metaraminol 10mg/ml-1ml & 6 & & & & & \\
\hline metoclopramida $5 \mathrm{mg} / \mathrm{ml}-2 \mathrm{ml}$ & 6 & & 1 & 0,15 & 0,15 & 0,41 \\
\hline midazolam $15 \mathrm{mg}-3 \mathrm{ml}$ & & 3 & 2 & 2,35 & 4,7 & 12,69 \\
\hline morfina $2 \mathrm{mg} / \mathrm{ml}-1 \mathrm{ml}$ & & 3 & 1 & 0,41 & 0,41 & 1,11 \\
\hline neostigmina $0,05 \mathrm{mg} / \mathrm{ml}-1 \mathrm{ml}$ & 18 & & & & & \\
\hline petidina $50 \mathrm{mg} / \mathrm{ml} 2 \mathrm{ml}$ & & 3 & & & & \\
\hline propofol $10 \mathrm{mg} / \mathrm{ml}-20 \mathrm{ml}$ & & 6 & 1 & 8,51 & 8,51 & 22,98 \\
\hline ranitidina $10 \mathrm{mg} / \mathrm{ml}-5 \mathrm{ml}$ & 6 & & 3 & 0,18 & 0,54 & 1,46 \\
\hline salbutamol $0,5 \mathrm{mg} / \mathrm{ml}-1 \mathrm{ml}$ & & 1 & 1 & 0,99 & 0,99 & 2,67 \\
\hline suxametônio $100 \mathrm{mg}$ & 6 & & & & & \\
\hline tenoxicam 20mg & 3 & & & & & \\
\hline Total & 198 & 40 & 31 & 61,69 & 93,2 & 251,65 \\
\hline
\end{tabular}


Tabela 55: Primeiro dia de consumo na sala 29 fase pós implantação

\begin{tabular}{|c|c|c|c|c|c|c|}
\hline \multicolumn{7}{|c|}{ SALA 29 - PRIMEIRO DIA DE CONSUMO } \\
\hline Medicamento & $\begin{array}{c}\text { Físico Inicial } \\
\text { (elenco kit) }\end{array}$ & Extra & $\begin{array}{l}\text { Quantidade } \\
\text { Utilizada }\end{array}$ & $\begin{array}{c}\text { Preço } \\
\text { Unitário }\end{array}$ & $\begin{array}{l}\text { Preço } \\
\text { Final }\end{array}$ & $\begin{array}{l}\text { Valor em } \\
\text { dólar }\end{array}$ \\
\hline agua destilada $-10 \mathrm{ml}$ & 18 & & & & & \\
\hline aminofilina $24 \mathrm{mg} / \mathrm{ml}-10 \mathrm{ml}$ & 3 & & & & & \\
\hline ampicilina $1 \mathrm{~g}$ & & 1 & 1 & 0,9 & 0,9 & 2,43 \\
\hline atropina $0,5 \mathrm{mg} / \mathrm{ml}-1 \mathrm{ml}$ & 18 & & & & & \\
\hline $\begin{array}{l}\text { bupivacaína com } \\
\text { epinefrina }(5 \mathrm{mg}+9,1 \mathrm{mcg}) / \mathrm{ml}-20 \mathrm{ml}\end{array}$ & 3 & & & & & \\
\hline bupivacaína sem epinefrina $0,5 \%-20 \mathrm{ml}$ & 3 & & & & & \\
\hline bupivacaína hiperbárica $0,5 \%-4 \mathrm{ml}$ & 3 & & & & & \\
\hline cefalotina $1 \mathrm{~g}$ & 6 & & 4 & 1,53 & 6,12 & 16,52 \\
\hline ceftriaxona $1 \mathrm{~g}$ & & 1 & 1 & 2,76 & 2,76 & 7,45 \\
\hline cetoprofeno $50 \mathrm{mg} / \mathrm{ml}-2 \mathrm{ml}$ & 3 & & 2 & 0,49 & 0,98 & 2,65 \\
\hline cloreto de cálcio $100 \mathrm{mg} / \mathrm{ml}-5 \mathrm{ml}$ & 6 & & & & & \\
\hline dexametasona $4 \mathrm{mg} / \mathrm{ml}-1 \mathrm{ml}$ & 18 & & & & & \\
\hline diazepam $5 \mathrm{mg} / \mathrm{ml}-2 \mathrm{ml}$ & & 3 & & & & \\
\hline dipirona $500 \mathrm{mg} / \mathrm{ml}-2 \mathrm{ml}$ & 18 & & 6 & 0,16 & 0,96 & 2,59 \\
\hline efedrina $25 \mathrm{mg} / \mathrm{ml}-1 \mathrm{ml}$ & 18 & & & & & \\
\hline epinefrina $1 \mathrm{mg} / \mathrm{ml}-1 \mathrm{ml}$ & 3 & & & & & \\
\hline etomidato $2 \mathrm{mg} / \mathrm{ml}-10 \mathrm{ml}$ & & 3 & 2 & 3,18 & 6,36 & 17,17 \\
\hline $\begin{array}{l}\text { fentanil + droperidol } 0,05 \mathrm{mg}+2,5 \mathrm{mg}) / \mathrm{ml} \\
-2 \mathrm{ml}\end{array}$ & & 6 & 1 & 3,51 & 3,51 & 9,48 \\
\hline fentanil $0,05 \mathrm{mg} / \mathrm{ml}-5 \mathrm{ml}$ & & 9 & 9 & 1,8 & 16,2 & 43,74 \\
\hline furosemida $10 \mathrm{mg} / \mathrm{ml}-2 \mathrm{ml}$ & 6 & & & & & \\
\hline glicose $50 \%-10 \mathrm{ml}$ & 3 & & & & & \\
\hline heparina IV 5.000UI - 5ml & 3 & & & & & \\
\hline hidralazina $20 \mathrm{mg} / \mathrm{ml}-1 \mathrm{ml}$ & 6 & & & & & \\
\hline hidrocortisona $500 \mathrm{mg}$ & 6 & & & & & \\
\hline lidocaína sem epinefrina $2 \%-20 \mathrm{ml}$ & 3 & & & & & \\
\hline $\begin{array}{l}\text { lidocaína com epinefrina(20mg+ } \\
5 \mathrm{mcg}) / \mathrm{ml}-20 \mathrm{ml}\end{array}$ & 3 & & & & & \\
\hline lidocaína geléia $2 \%$ - $30 \mathrm{ml}$ & 3 & & & & & \\
\hline metaraminol $10 \mathrm{mg} / \mathrm{ml}-1 \mathrm{ml}$ & 6 & & & & & \\
\hline metoclopramida $5 \mathrm{mg} / \mathrm{ml}-2 \mathrm{ml}$ & 6 & & 2 & 0,15 & 0,3 & 0,81 \\
\hline metronidazol $5 \mathrm{mg} / \mathrm{ml}-100 \mathrm{ml}$ & & 1 & 1 & 0,65 & 0,65 & 1,76 \\
\hline midazolam $5 \mathrm{mg} / \mathrm{ml}-3 \mathrm{ml}$ & & 3 & 3 & 2,35 & 7,05 & 19,04 \\
\hline morfina $2 \mathrm{mg} / \mathrm{ml}-1 \mathrm{ml}$ & & 3 & & & & \\
\hline neostigmina $0,05 \mathrm{mg} / \mathrm{ml}-1 \mathrm{ml}$ & 18 & & & & & \\
\hline petidina $50 \mathrm{mg} / \mathrm{ml} 2 \mathrm{ml}$ & & 3 & & & & \\
\hline propofol $10 \mathrm{mg} / \mathrm{ml}-20 \mathrm{ml}$ & & 6 & 3 & 8,51 & 25,53 & 68,93 \\
\hline ranitidina $10 \mathrm{mg} / \mathrm{ml}-5 \mathrm{ml}$ & 6 & & 6 & 0,18 & 1,08 & 2,92 \\
\hline sufentanila $50 \mathrm{mcg} / \mathrm{ml}-1 \mathrm{ml}$ & & 2 & 2 & 4,08 & 8,16 & 22,03 \\
\hline suxametônio $100 \mathrm{mg}$ & 6 & & & & & \\
\hline tenoxicam $20 \mathrm{mg}$ & 3 & & & & & \\
\hline tramadol $50 \mathrm{mg} / \mathrm{ml}-1 \mathrm{ml}$ & & 1 & 1 & 1,52 & 1,52 & 4,1 \\
\hline Total & 198 & 43 & 44 & 31,77 & 82,08 & 221,62 \\
\hline
\end{tabular}


Tabela 56: Segundo dia de consumo na sala 29 fase pós implantação

\begin{tabular}{|c|c|c|c|c|c|c|}
\hline \multicolumn{7}{|c|}{ SALA 29- SEGUNDO DIA DE CONSUMO } \\
\hline Medicamento & $\begin{array}{l}\text { Físico Inicial } \\
\text { (elenco kit) }\end{array}$ & Extra & $\begin{array}{l}\text { Quantidade } \\
\text { Utilizada }\end{array}$ & $\begin{array}{l}\text { Preço } \\
\text { Unitário }\end{array}$ & $\begin{array}{l}\text { Preço } \\
\text { Final }\end{array}$ & $\begin{array}{l}\text { Valor em } \\
\text { dólar }\end{array}$ \\
\hline alfentanil $0,5 \mathrm{mg} / \mathrm{ml}-5 \mathrm{ml}$ & & 3 & 3 & 8,63 & 25,89 & 69,9 \\
\hline água destilada $-10 \mathrm{ml}$ & 12 & & 10 & 0,1 & 1 & 2,7 \\
\hline aminofilina $24 \mathrm{mg} / \mathrm{ml}-10 \mathrm{ml}$ & 2 & & & & & \\
\hline atropina $0,5 \mathrm{mg} / \mathrm{ml}-1 \mathrm{ml}$ & 12 & & & & & \\
\hline $\begin{array}{l}\text { bupivacaína com } \\
\text { epinefrina }(5 \mathrm{mg}+9,1 \mathrm{mcg}) / \mathrm{ml}-20 \mathrm{ml}\end{array}$ & 2 & & & & & \\
\hline bupivacaína sem epinefrina $0,5 \%-20 \mathrm{ml}$ & 2 & & & & & \\
\hline bupivacaína hiperbárica $0,5 \%-4 \mathrm{ml}$ & 2 & & & & & \\
\hline cefalotina $1 \mathrm{~g}$ & 4 & 3 & 7 & 1,53 & 10,71 & 28,92 \\
\hline cetoprofeno $50 \mathrm{mg} / \mathrm{ml}-2 \mathrm{ml}$ & 2 & & 1 & 0,49 & 0,49 & 1,32 \\
\hline cloreto de cálcio $100 \mathrm{mg} / \mathrm{ml}-5 \mathrm{ml}$ & 4 & & & & & \\
\hline dexametasona $4 \mathrm{mg} / \mathrm{ml}-1 \mathrm{ml}$ & 12 & & & & & \\
\hline diazepam $5 \mathrm{mg} / \mathrm{ml}-2 \mathrm{ml}$ & & 2 & 1 & 0,17 & 0,17 & 0,46 \\
\hline dipirona $500 \mathrm{mg} / \mathrm{ml}-2 \mathrm{ml}$ & 12 & & & & & \\
\hline dopamina $5 \mathrm{mg} / \mathrm{ml}-10 \mathrm{ml}$ & & 1 & 1 & 0,34 & 0,34 & 0,92 \\
\hline efedrina $25 \mathrm{mg} / \mathrm{ml}-1 \mathrm{ml}$ & 12 & & & & & \\
\hline epinefrina $1 \mathrm{mg} / \mathrm{ml}-1 \mathrm{ml}$ & 2 & & & & & \\
\hline etomidato $2 \mathrm{mg} / \mathrm{ml}-10 \mathrm{ml}$ & & 2 & & & & \\
\hline $\begin{array}{l}\text { fentanil }+ \text { droperidol } \\
(0,05 \mathrm{mg}+2,5 \mathrm{mg}) / \mathrm{ml}-2 \mathrm{ml}\end{array}$ & & 4 & 2 & 3,51 & 7,02 & 18,95 \\
\hline fentanil $0,05 \mathrm{mg} / \mathrm{ml}-5 \mathrm{ml}$ & & 6 & 4 & 1,8 & 7,2 & 19,44 \\
\hline furosemida $10 \mathrm{mg} / \mathrm{ml}-2 \mathrm{ml}$ & 4 & & & & & \\
\hline glicose $50 \%-10 \mathrm{ml}$ & 2 & & 1 & 0,16 & 0,16 & 1,62 \\
\hline heparina IV 5.000UI $-5 \mathrm{ml}$ & 2 & & & & & \\
\hline hidralazina $20 \mathrm{mg} / \mathrm{ml}-1 \mathrm{ml}$ & 4 & & & & & \\
\hline hidrocortisona $500 \mathrm{mg}$ & 4 & & & & & \\
\hline lidocaína sem epinefrina $2 \%-20 \mathrm{ml}$ & 2 & & & & & \\
\hline $\begin{array}{l}\text { lidocaína com epinefrina(20mg+ } \\
5 \mathrm{mcg}) / \mathrm{ml}-20 \mathrm{ml}\end{array}$ & 2 & & & & & \\
\hline lidocaína geléia $2 \%$ - 30ml & 2 & & & & & \\
\hline metaraminol $10 \mathrm{mg} / \mathrm{ml}-1 \mathrm{ml}$ & 4 & & & & & \\
\hline metoclopramida $5 \mathrm{mg} / \mathrm{ml}-2 \mathrm{ml}$ & 4 & 2 & 6 & 0,15 & 0,9 & 2,43 \\
\hline midazolam $5 \mathrm{mg} / \mathrm{ml}-3 \mathrm{ml}$ & & 2 & 1 & 2,35 & 2,35 & 6,35 \\
\hline morfina $2 \mathrm{mg} / \mathrm{ml}-1 \mathrm{ml}$ & & 2 & & & & \\
\hline neostigmina $0,05 \mathrm{mg} / \mathrm{ml}-1 \mathrm{ml}$ & 12 & & & & & \\
\hline petidina $50 \mathrm{mg} / \mathrm{ml} 2 \mathrm{ml}$ & 2 & & & & & \\
\hline propofol $10 \mathrm{mg} / \mathrm{ml}-20 \mathrm{ml}$ & 4 & & 2 & 8,51 & 17,02 & 45,95 \\
\hline ranitidina $10 \mathrm{mg} / \mathrm{ml}-5 \mathrm{ml}$ & 4 & 4 & 8 & 0,18 & 1,44 & 3,89 \\
\hline suxametônio $100 \mathrm{mg}$ & 4 & & & & & \\
\hline tenoxicam $20 \mathrm{mg}$ & 2 & & & & & \\
\hline Total & 132 & 37 & 47 & 27,92 & 74,69 & 202,85 \\
\hline
\end{tabular}


Tabela 57: Terceiro dia de consumo na sala 29 fase pós implantação

\begin{tabular}{|c|c|c|c|c|c|c|}
\hline \multicolumn{7}{|c|}{ SALA 29 - TERCEIRO DIA DE CONSUMO } \\
\hline Medicamento & $\begin{array}{c}\text { Físico Inicial } \\
\text { (elenco kit) }\end{array}$ & Extra & \begin{tabular}{|c} 
Quantidade \\
Utilizada
\end{tabular} & \begin{tabular}{|c|} 
Preço \\
Unitário
\end{tabular} & $\begin{array}{l}\text { Preço } \\
\text { Final }\end{array}$ & $\begin{array}{l}\text { Valor em } \\
\text { dólar }\end{array}$ \\
\hline alfentanil $0,5 \mathrm{mg} / \mathrm{ml}-5 \mathrm{ml}$ & & 7 & 7 & 0,63 & 60,41 & 163,11 \\
\hline agua destilada $-10 \mathrm{ml}$ & 18 & & 4 & 0,1 & 0,4 & 1,08 \\
\hline aminofilina $24 \mathrm{mg} / \mathrm{ml}-10 \mathrm{ml}$ & 3 & & & & & \\
\hline atropina $0,5 \mathrm{mg}-1 \mathrm{ml}$ & 18 & & & & & \\
\hline $\begin{array}{l}\text { bupivacaína com } \\
\text { epinefrina }(5 \mathrm{mg}+9,1 \mathrm{mcg}) / \mathrm{ml}-20 \mathrm{ml}\end{array}$ & 3 & & & & & \\
\hline bupivacaína sem epinefrina $0,5 \%-20 \mathrm{ml}$ & 3 & & & & & \\
\hline bupivacaína hiperbárica $0,5 \%-4 \mathrm{ml}$ & 3 & & & & & \\
\hline cefalotina $1 \mathrm{~g}$ & 6 & & 6 & 1,53 & 9,18 & 24,79 \\
\hline cetoprofeno $50 \mathrm{mg} / \mathrm{ml}-2 \mathrm{ml}$ & 3 & & & & & \\
\hline cloreto de cálcio $100 \mathrm{mg} / \mathrm{ml}-5 \mathrm{ml}$ & 6 & & & & & \\
\hline dexametasona $4 \mathrm{mg} / \mathrm{ml}-1 \mathrm{ml}$ & 18 & & & & & \\
\hline diazepam $5 \mathrm{mg} / \mathrm{ml}-2 \mathrm{ml}$ & & 3 & 1 & 0,17 & 0,17 & 0,46 \\
\hline dipirona $500 \mathrm{mg} / \mathrm{ml}-2 \mathrm{ml}$ & 18 & & 4 & 0,16 & 0,64 & 1,73 \\
\hline efedrina $25 \mathrm{mg} / \mathrm{ml}-1 \mathrm{ml}$ & 18 & & & & & \\
\hline epinefrina $1 \mathrm{mg} / \mathrm{ml}-1 \mathrm{ml}$ & 3 & & & & & \\
\hline etomidato $2 \mathrm{mg} / \mathrm{ml}-10 \mathrm{ml}$ & & 3 & & & & \\
\hline $\begin{array}{l}\text { fentanil }+ \text { droperidol }(0,05 \mathrm{mg}+2,5 \mathrm{mg}) / \mathrm{ml} \\
-2 \mathrm{ml}\end{array}$ & & 6 & & & & \\
\hline fentanil $0,05 \mathrm{mg} / \mathrm{ml}-5 \mathrm{ml}$ & & 9 & 3 & 1,8 & 5,4 & 14,58 \\
\hline furosemida $10 \mathrm{mg} / \mathrm{ml}-2 \mathrm{ml}$ & 6 & & & & & \\
\hline glicose $50 \%-10 \mathrm{ml}$ & 3 & & & & & \\
\hline heparina IV 5.000UI - 5ml & 3 & & & & & \\
\hline hidralazina $20 \mathrm{mg} / \mathrm{ml}-1 \mathrm{ml}$ & 6 & & & & & \\
\hline hidrocortisona $500 \mathrm{mg}$ & 6 & & & & & \\
\hline isoprenalina $0,2 \mathrm{mg} / \mathrm{ml}-1 \mathrm{ml}$ & & 1 & 1 & 0,32 & 0,32 & 0,86 \\
\hline lidocaína sem epinefrina $2 \%-20 \mathrm{ml}$ & 3 & & & & & \\
\hline $\begin{array}{l}\text { lidocaína com epinefrina }(20 \mathrm{mg}+ \\
5 \mathrm{mcg}) / \mathrm{ml}-20 \mathrm{ml}\end{array}$ & 3 & & & & & \\
\hline lidocaína geléia $2 \%$ - $30 \mathrm{ml}$ & 3 & & & & & \\
\hline metaraminol $10 \mathrm{mg} / \mathrm{ml}-1 \mathrm{ml}$ & 6 & & & & & \\
\hline metoclopramida $5 \mathrm{mg} / \mathrm{ml}-2 \mathrm{ml}$ & 6 & & 3 & 0,15 & 0,45 & 1,22 \\
\hline midazolam $5 \mathrm{mg} / \mathrm{ml}-3 \mathrm{ml}$ & & 3 & 2 & 2,35 & 4,7 & 12,69 \\
\hline morfina $2 \mathrm{mg} / \mathrm{ml}-1 \mathrm{ml}$ & & 3 & 1 & 0,41 & 0,41 & 1,11 \\
\hline neostigmina $0,05 \mathrm{mg} / \mathrm{ml}-1 \mathrm{ml}$ & 18 & & & & & \\
\hline petidina $50 \mathrm{mg} / \mathrm{ml} 2 \mathrm{ml}$ & & 3 & 1 & 0,18 & 0,18 & 0,49 \\
\hline propofol $10 \mathrm{mg} / \mathrm{ml}-20 \mathrm{ml}$ & & 6 & 3 & 8,51 & 25,53 & 68,93 \\
\hline ranitidina $10 \mathrm{mg} / \mathrm{ml}-5 \mathrm{ml}$ & 6 & & 5 & 0,18 & 0,9 & 2,43 \\
\hline sufentanila $50 \mathrm{mcg} / \mathrm{ml}-1 \mathrm{ml}$ & & 3 & 3 & 4,08 & 12,24 & 33,05 \\
\hline suxametônio $100 \mathrm{mg}$ & 6 & & & & & \\
\hline tenoxicam $20 \mathrm{mg}$ & 3 & & & & & \\
\hline Total & 198 & 47 & 44 & 20,57 & 120,93 & 326,53 \\
\hline
\end{tabular}


Tabela 58: Primeiro dia de consumo na sala 30 fase pós implantação

SALA 30- PRIMEIRO DIA DE CONSUMO

\begin{tabular}{|c|c|c|c|c|c|c|}
\hline \\
\hline Medicamento & $\begin{array}{c}\text { Físico Inicial } \\
\text { (elenco kit) }\end{array}$ & Extra & \begin{tabular}{|c} 
Quantidade \\
Utilizada \\
\end{tabular} & $\begin{array}{c}\text { Preço } \\
\text { Unitário } \\
\end{array}$ & $\begin{array}{l}\text { Preço } \\
\text { Final }\end{array}$ & $\begin{array}{c}\text { Valor em } \\
\text { dólar }\end{array}$ \\
\hline agua destilada $-10 \mathrm{ml}$ & 12 & & 1 & 0,1 & 0,1 & 0,27 \\
\hline aminofilina $24 \mathrm{mg} / \mathrm{ml}-10 \mathrm{ml}$ & 2 & & & & & \\
\hline atropina $0,5 \mathrm{mg} / \mathrm{ml}-1 \mathrm{ml}$ & 12 & & 4 & 0,01 & 0,04 & 0,11 \\
\hline $\begin{array}{l}\text { bupivacaína com } \\
\text { epinefrina }(5 \mathrm{mg}+9,1 \mathrm{mcg}) / \mathrm{ml}-20 \mathrm{ml}\end{array}$ & 2 & & & & & \\
\hline bupivacaína sem epinefrina $0,5 \%-20 \mathrm{ml}$ & 2 & & 2 & 4 & 8 & 21,6 \\
\hline bupivacaína hiperbárica $0,5 \%-4 \mathrm{ml}$ & 2 & & & & & \\
\hline cefalotina $1 \mathrm{~g}$ & 4 & & 2 & 1,53 & 3,06 & 8,26 \\
\hline cetoprofeno $50 \mathrm{mg} / \mathrm{ml}-2 \mathrm{ml}$ & 2 & & 2 & 0,49 & 0,98 & 2,65 \\
\hline cloreto de cálcio $100 \mathrm{mg} / \mathrm{ml}-5 \mathrm{ml}$ & 4 & & & & & \\
\hline dexametasona $4 \mathrm{mg} / \mathrm{ml}-1 \mathrm{ml}$ & 12 & & 3 & 0,39 & 1,17 & 3,16 \\
\hline diazepam $5 \mathrm{mg} / \mathrm{ml} \mathrm{-} 2 \mathrm{ml}$ & & 2 & & & & \\
\hline dipirona $500 \mathrm{mg} / \mathrm{ml}-2 \mathrm{ml}$ & 12 & & 5 & 0,16 & 0,8 & 2,16 \\
\hline efedrina $25 \mathrm{mg} / \mathrm{ml}-1 \mathrm{ml}$ & 12 & & & & & \\
\hline epinefrina $1 \mathrm{mg} / \mathrm{ml}-1 \mathrm{ml}$ & 2 & & & & & \\
\hline etomidato $2 \mathrm{mg} / \mathrm{ml}-10 \mathrm{ml}$ & & 2 & & & & \\
\hline $\begin{array}{l}\text { fentanil }+ \text { droperidol }(0,05 \mathrm{mg}+2,5 \mathrm{mg}) / \mathrm{ml} \\
-2 \mathrm{ml}\end{array}$ & & 4 & 1 & 3,51 & 3,51 & 9,48 \\
\hline fentanil $0,05 \mathrm{mg} / \mathrm{ml}-5 \mathrm{ml}$ & & 6 & 4 & 1,8 & 7,2 & 19,44 \\
\hline furosemida $10 \mathrm{mg} / \mathrm{ml}-2 \mathrm{ml}$ & 4 & & & & & \\
\hline glicose $50 \%-10 \mathrm{ml}$ & 2 & & 1 & 0,16 & 0,16 & 0,43 \\
\hline heparina IV 5.000UI - 5ml & 2 & & 1 & 3,45 & 3,45 & 9,32 \\
\hline hidralazina $20 \mathrm{mg} / \mathrm{ml} \mathrm{-} 1 \mathrm{ml}$ & 4 & & & & & \\
\hline hidrocortisona $500 \mathrm{mg}$ & 4 & & & & & \\
\hline lidocaína sem epinefrina $2 \%-20 \mathrm{ml}$ & 2 & & 2 & 0,68 & 1,36 & 3,67 \\
\hline $\begin{array}{l}\text { lidocaína com epinefrina(20mg+ } \\
5 \mathrm{mcg}) / \mathrm{ml}-20 \mathrm{ml}\end{array}$ & 2 & & & & & \\
\hline lidocaína geléia $2 \%$ - $30 \mathrm{ml}$ & 2 & & & & & \\
\hline metaraminol $10 \mathrm{mg} / \mathrm{ml}-1 \mathrm{ml}$ & 4 & & & & & \\
\hline metoclopramida $5 \mathrm{mg} / \mathrm{ml}-2 \mathrm{ml}$ & 4 & & 2 & 0,15 & 0,3 & 0,81 \\
\hline midazolam $15 \mathrm{mg}-3 \mathrm{ml}$ & & 2 & 1 & 2,35 & 2,35 & 6,35 \\
\hline morfina $2 \mathrm{mg} / \mathrm{ml}-1 \mathrm{ml}$ & & 2 & 1 & 0,41 & 0,41 & 1,11 \\
\hline neostigmina $0,05 \mathrm{mg} / \mathrm{ml}-1 \mathrm{ml}$ & 12 & & & & & \\
\hline petidina $50 \mathrm{mg} / \mathrm{ml} 2 \mathrm{ml}$ & & 2 & & & & \\
\hline propofol $10 \mathrm{mg} / \mathrm{ml}-20 \mathrm{ml}$ & & 4 & 2 & 8,51 & 17,02 & 45,95 \\
\hline ranitidina $10 \mathrm{mg} / \mathrm{ml}-5 \mathrm{ml}$ & 4 & & 2 & 0,18 & 0,36 & 0,97 \\
\hline suxametônio $100 \mathrm{mg}$ & 4 & & 1 & 1,53 & 1,53 & 4,13 \\
\hline tenoxicam $20 \mathrm{mg}$ & 2 & & & & & \\
\hline Total & 132 & 24 & 37 & 29,41 & 51,8 & 139,87 \\
\hline
\end{tabular}


Tabela 59: Segundo dia de consumo na sala 30 fase pós implantação

\begin{tabular}{|c|c|c|c|c|c|c|}
\hline \multicolumn{7}{|c|}{ SALA 30- SEGUNDO DIA DE CONSUMO } \\
\hline Medicamento & $\begin{array}{l}\text { Físico Inicial } \\
\text { (elenco kit) }\end{array}$ & Extra & $\begin{array}{l}\text { Quantidade } \\
\text { Utilizada }\end{array}$ & $\begin{array}{l}\text { Preço } \\
\text { Unitário }\end{array}$ & $\begin{array}{l}\text { Preço } \\
\text { Final }\end{array}$ & $\begin{array}{l}\text { Valor em } \\
\text { dólar }\end{array}$ \\
\hline agua destilada $-10 \mathrm{ml}$ & 12 & & & & & \\
\hline aminofilina $24 \mathrm{mg} / \mathrm{ml}-10 \mathrm{ml}$ & 2 & & & & & \\
\hline atropina $0,5 \mathrm{mg} / \mathrm{ml}-1 \mathrm{ml}$ & 12 & & & & & \\
\hline $\begin{array}{l}\text { bupivacaína com } \\
\text { epinefrina }(5 \mathrm{mg}+9,1 \mathrm{mcg}) / \mathrm{ml}-20 \mathrm{ml}\end{array}$ & 2 & & & & & \\
\hline bupivacaína sem epinefrina $0,5 \%-20 \mathrm{ml}$ & 2 & & 1 & 4 & 4 & 10,8 \\
\hline bupivacaína hiperbárica $0,5 \%-4 \mathrm{ml}$ & 2 & & & & & \\
\hline cefalotina $1 \mathrm{~g}$ & 4 & & 4 & 1,53 & 6,12 & 16,52 \\
\hline cetoprofeno $50 \mathrm{mg} / \mathrm{ml}-2 \mathrm{ml}$ & 2 & & 2 & 0,49 & 0,98 & 2,65 \\
\hline cloreto de cálcio $100 \mathrm{mg} / \mathrm{ml}-5 \mathrm{ml}$ & 4 & & & & & \\
\hline dexametasona $4 \mathrm{mg} / \mathrm{ml}-1 \mathrm{ml}$ & 12 & & 2 & 0,39 & 0,78 & 2,11 \\
\hline diazepam $5 \mathrm{mg} / \mathrm{ml}-2 \mathrm{ml}$ & & 2 & & & & \\
\hline dipirona $1 \mathrm{~g}-2 \mathrm{ml}$ & 12 & & 3 & 0,16 & 0,48 & 1,3 \\
\hline efedrina $25 \mathrm{mg} / \mathrm{ml}-1 \mathrm{ml}$ & 12 & & & & & \\
\hline epinefrina $1 \mathrm{mg} / \mathrm{ml}-1 \mathrm{ml}$ & 2 & & & & & \\
\hline etomidato $2 \mathrm{mg} / \mathrm{ml}-10 \mathrm{ml}$ & & 2 & & & & \\
\hline $\begin{array}{l}\text { fentanil }+ \text { droperidol }(0,05 \mathrm{mg}+ \\
2,5 \mathrm{mg}) / \mathrm{ml}-2 \mathrm{ml}\end{array}$ & & 4 & & & & \\
\hline fentanil $0,05 \mathrm{mg} / \mathrm{ml}-5 \mathrm{ml}$ & & 6 & 2 & 1,8 & 3,6 & 9,72 \\
\hline furosemida $10 \mathrm{mg} / \mathrm{ml}-2 \mathrm{ml}$ & 4 & & & & & \\
\hline glicose $50 \%-10 \mathrm{ml}$ & 2 & & & & & \\
\hline heparina IV 5.000UI $-5 \mathrm{ml}$ & 2 & & & & & \\
\hline hidralazina $20 \mathrm{mg} / \mathrm{ml}-1 \mathrm{ml}$ & 4 & & & & & \\
\hline hidrocortisona $500 \mathrm{mg}$ & 4 & & & & & \\
\hline lidocaína sem epinefrina $2 \%-20 \mathrm{ml}$ & 2 & & 1 & 0,68 & 0,68 & 1,84 \\
\hline $\begin{array}{l}\text { lidocaína com epinefrina(20mg+ } \\
5 \mathrm{mcg}) / \mathrm{ml}-20 \mathrm{ml}\end{array}$ & 2 & & & & & \\
\hline lidocaína geléia $2 \%$ - 30ml & 2 & & & & & \\
\hline metaraminol $10 \mathrm{mg} / \mathrm{ml}-1 \mathrm{ml}$ & 4 & & & & & \\
\hline metoclopramida $5 \mathrm{mg} / \mathrm{ml}-2 \mathrm{ml}$ & 4 & & 2 & 0,15 & 0,3 & 0,81 \\
\hline midazolam $5 \mathrm{mg} / \mathrm{ml}-3 \mathrm{ml}$ & & 2 & 2 & 2,35 & 4,7 & 12,69 \\
\hline morfina $2 \mathrm{mg} / \mathrm{ml}-1 \mathrm{ml}$ & & 2 & & & & \\
\hline neostigmina $0,05 \mathrm{mg} / \mathrm{ml}-1 \mathrm{ml}$ & 12 & & & & & \\
\hline petidina $50 \mathrm{mg} / \mathrm{ml} 2 \mathrm{ml}$ & & 2 & 1 & 0,18 & 0,18 & 0,49 \\
\hline propofol $10 \mathrm{mg} / \mathrm{ml}-20 \mathrm{ml}$ & & 4 & 2 & 8,51 & 17,02 & 45,95 \\
\hline ranitidina $10 \mathrm{mg} / \mathrm{ml}-5 \mathrm{ml}$ & 4 & & 2 & 0,18 & 0,36 & 0,97 \\
\hline suxametônio $100 \mathrm{mg}$ & 4 & & & & & \\
\hline tenoxicam $20 \mathrm{mg}$ & 2 & & & & & \\
\hline Total & 132 & 24 & 24 & 20,42 & 39,2 & 105,85 \\
\hline
\end{tabular}


Tabela 60: Terceiro dia de consumo na sala 30 fase pós implantação

SALA 30- TERCEIRO DIA DE CONSUMO

\begin{tabular}{|c|c|c|c|c|c|c|}
\hline Medicamento & $\begin{array}{l}\text { Físico Inicial } \\
\text { (elenco kit) }\end{array}$ & Extra & $\begin{array}{l}\text { Quantidade } \\
\text { Utilizada }\end{array}$ & $\begin{array}{c}\text { Preço } \\
\text { Unitário }\end{array}$ & $\begin{array}{l}\text { Preço } \\
\text { Final }\end{array}$ & $\begin{array}{c}\text { Valor em } \\
\text { dólar }\end{array}$ \\
\hline alfentanil $0,5 \mathrm{mg} / \mathrm{ml}-5 \mathrm{ml}$ & & 5 & 5 & 8,63 & 43,15 & 116,51 \\
\hline agua destilada $-10 \mathrm{ml}$ & 12 & & & & & \\
\hline aminofilina $24 \mathrm{mg} / \mathrm{ml} \mathrm{-} 10 \mathrm{ml}$ & 2 & & & & & \\
\hline atropina $0,5 \mathrm{mg}-1 \mathrm{ml}$ & 12 & & & & & \\
\hline $\begin{array}{l}\text { bupivacaína com } \\
\text { epinefrina }(5 \mathrm{mg}+9,1 \mathrm{mcg}) / \mathrm{ml}-20 \mathrm{ml}\end{array}$ & 2 & & & & & \\
\hline bupivacaína sem epinefrina $0,5 \%-20 \mathrm{ml}$ & 2 & & 1 & 4 & 4 & 10,8 \\
\hline bupivacaína hiperbárica $0,5 \%-4 \mathrm{ml}$ & 2 & & & & & \\
\hline cefalotina $1 \mathrm{~g}$ & 4 & & 4 & 1,53 & 6,12 & 16,52 \\
\hline cetoprofeno $50 \mathrm{mg} / \mathrm{ml}-2 \mathrm{ml}$ & 2 & & 1 & 0,49 & 0,49 & 1,32 \\
\hline cloreto de cálcio $100 \mathrm{mg} / \mathrm{ml}-5 \mathrm{ml}$ & 4 & & & & & \\
\hline dexametasona $4 \mathrm{mg} / \mathrm{ml}-1 \mathrm{ml}$ & 12 & & 2 & 0,39 & 0,78 & 2,11 \\
\hline diazepam $5 \mathrm{mg} / \mathrm{ml}-2 \mathrm{ml}$ & & 2 & & & & \\
\hline dipirona $500 \mathrm{mg} / \mathrm{ml}-2 \mathrm{ml}$ & 12 & & 4 & 0,16 & 0,64 & 1,73 \\
\hline efedrina $25 \mathrm{mg} / \mathrm{ml}-1 \mathrm{ml}$ & 12 & & & & & \\
\hline epinefrina $1 \mathrm{mg} / \mathrm{ml}-1 \mathrm{ml}$ & 2 & & & & & \\
\hline etomidato $2 \mathrm{mg} / \mathrm{ml}-10 \mathrm{ml}$ & & 2 & & & & \\
\hline $\begin{array}{l}\text { fentanil + droperidol }(0,05 \mathrm{mg}+ \\
2,5 \mathrm{mg}) / \mathrm{ml}-2 \mathrm{ml}\end{array}$ & & 4 & 1 & 3,51 & 3,51 & 9,5 \\
\hline fentanil $0,05 \mathrm{mg} / \mathrm{ml}-5 \mathrm{ml}$ & & 6 & 1 & 1,8 & 1,8 & 4,86 \\
\hline furosemida $10 \mathrm{mg} / \mathrm{ml}-2 \mathrm{ml}$ & 4 & & & & & \\
\hline glicose $50 \%-10 \mathrm{ml}$ & 2 & & & & & \\
\hline heparina IV 5.000UI - 5ml & 2 & & & & & \\
\hline hidralazina $20 \mathrm{mg} / \mathrm{ml}-1 \mathrm{ml}$ & 4 & & & & & \\
\hline hidrocortisona $500 \mathrm{mg}$ & 4 & & & & & \\
\hline isoprenalina $0,2 \mathrm{mg} / \mathrm{ml}-1 \mathrm{ml}$ & & 1 & 1 & 0,32 & 0,32 & 0,86 \\
\hline lidocaína sem epinefrina $2 \%-20 \mathrm{ml}$ & 2 & & & & & \\
\hline $\begin{array}{l}\text { lidocaína com } \\
\text { epinefrina }(20 \mathrm{mg}+5 \mathrm{mcg}) / \mathrm{ml}-20 \mathrm{ml}\end{array}$ & 2 & & & & & \\
\hline lidocaína geléia $2 \%$ - $30 \mathrm{ml}$ & 2 & & & & & \\
\hline metaraminol $10 \mathrm{mg} / \mathrm{ml}-1 \mathrm{ml}$ & 4 & & & & & \\
\hline metoclopramida $5 \mathrm{mg} / \mathrm{ml}-2 \mathrm{ml}$ & 4 & & 2 & 0,15 & 0,3 & 0,81 \\
\hline midazolam $15 \mathrm{mg}-3 \mathrm{ml}$ & & 2 & 2 & 2,35 & 4,7 & 12,69 \\
\hline morfina $2 \mathrm{mg} / \mathrm{ml}-1 \mathrm{ml}$ & & 2 & & & & \\
\hline nalbufina $10 \mathrm{mg} 1 \mathrm{ml}$ & & 1 & 1 & 5,79 & 5,79 & 15,63 \\
\hline petidina $50 \mathrm{mg} / \mathrm{ml} 2 \mathrm{ml}$ & & 2 & & & & \\
\hline propofol $10 \mathrm{mg} / \mathrm{ml}-20 \mathrm{ml}$ & & 4 & 1 & 8,51 & 8,51 & 22,98 \\
\hline neostigmina $0,05 \mathrm{mg} / \mathrm{ml}-1 \mathrm{ml}$ & 12 & & & & & \\
\hline ranitidina $50 \mathrm{mg}-2 \mathrm{ml}$ & 4 & & 2 & 0,18 & 0,36 & 0,97 \\
\hline suxametônio $100 \mathrm{mg}$ & 4 & & & & & \\
\hline tenoxicam $20 \mathrm{mg}$ & 2 & & & & & \\
\hline Total & 132 & 31 & 28 & $\mathbf{3 7 , 8 1}$ & $\mathbf{8 0 , 4 7}$ & 217,29 \\
\hline
\end{tabular}


Os resultados principais são apresentados em forma de gráfico, onde houve comparação dos valores pré e pós kits segundo distintos critérios, sempre evidenciando indiscutíveis benefícios.

Tabela 61: Comparação da quantidade de estoque inicial de medicamentos de cada sala cirúrgica antes e após a implantação do kit:

\begin{tabular}{cccccccccccc}
\hline & SO21 & SO22 & SO23 & SO24 & SO25 & SO26 & SO27 & SO28 & SO29 & SO30 & Total \\
\hline Pré-kit & 1016 & 744 & 997 & 846 & 871 & 837 & 1048 & 1145 & 1010 & 1075 & 9589 \\
\hline Pós-kit & 537 & 699 & 388 & 460 & 535 & 466 & 623 & 468 & 624 & 468 & 5268 \\
\hline
\end{tabular}

Gráfico 3: Alterações no estoque físico inicial das salas

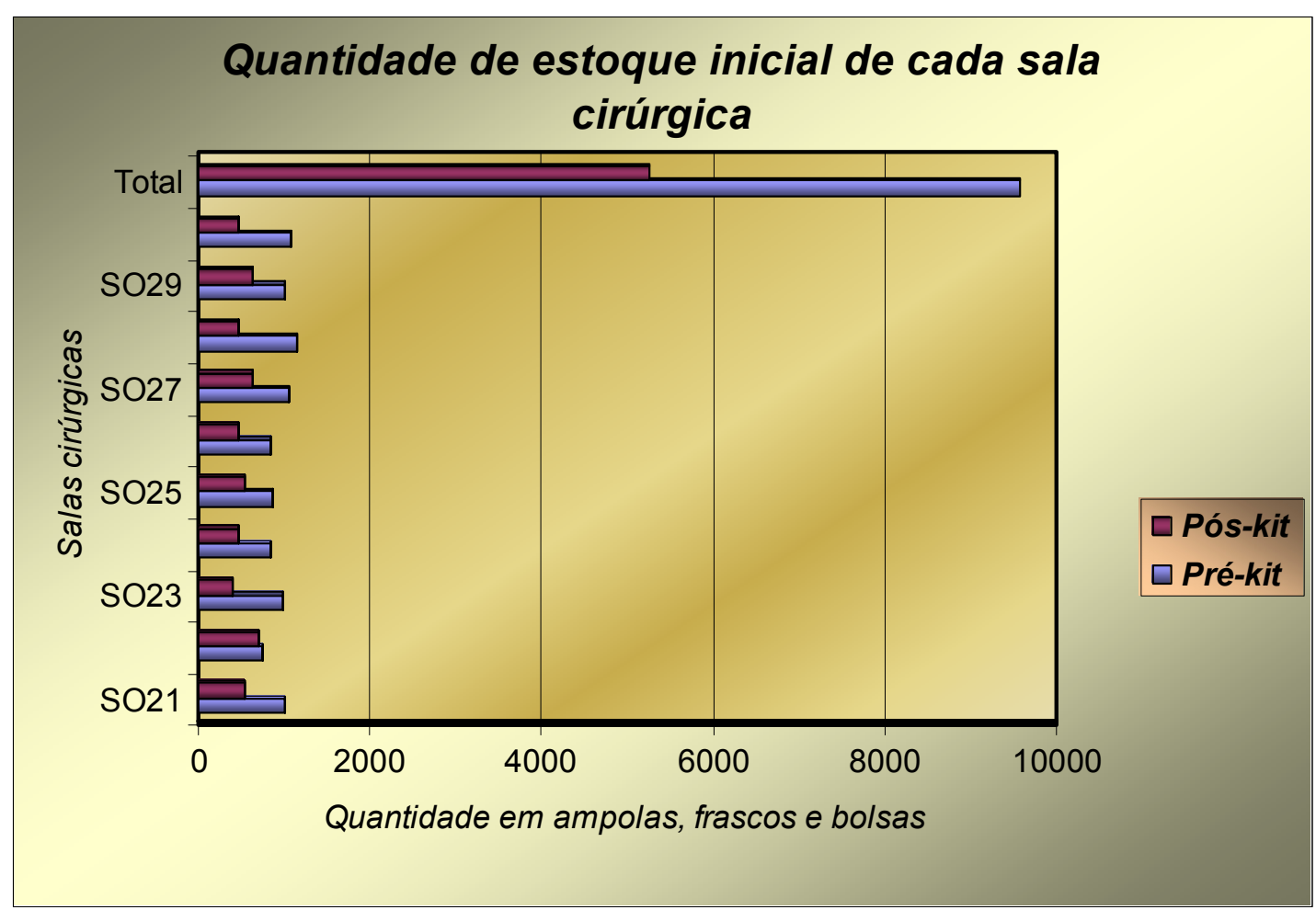

Houve uma redução de aproximadamente $47 \%$ na quantidade de estoque inicial na etapa pós implantação do kit. 
Tabela 62: Comparação da quantidade extra de medicamentos necessários em cada sala cirúrgica antes e após a implantação do kit:

\begin{tabular}{cccccccccccc}
\hline & SO21 & SO22 & SO23 & SO24 & SO25 & SO26 & SO27 & SO28 & SO29 & SO30 & Total \\
\hline Pré-kit & 139 & 339 & 169 & 155 & 82 & 110 & 242 & 129 & 192 & 148 & 1705 \\
\hline Pós-kit & 12 & 0 & 31 & 26 & 28 & 4 & 3 & 8 & 30 & 7 & 149 \\
\hline
\end{tabular}

Gráfico 4: Medicamentos extra solicitados

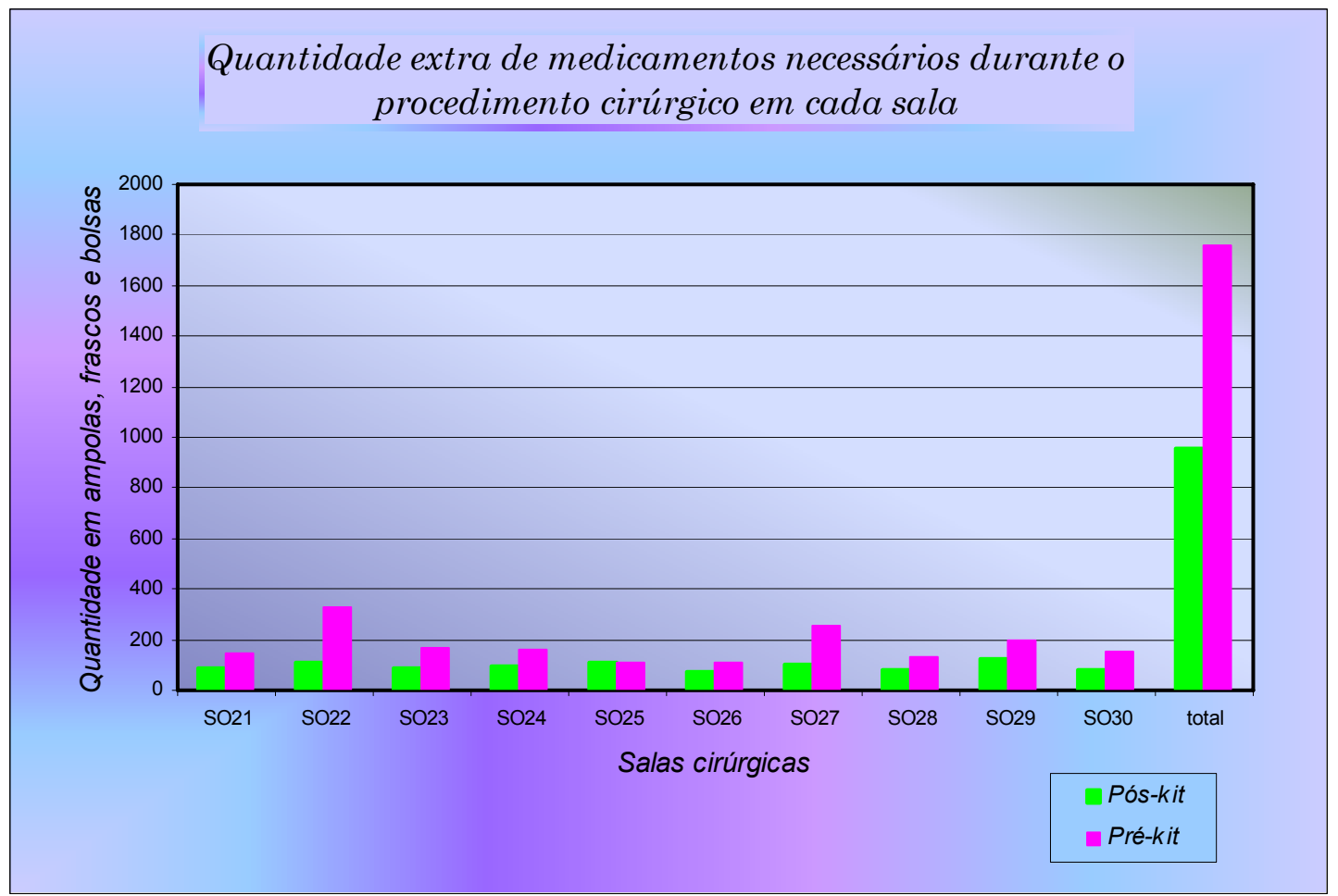

Houve uma redução de aproximadamente $54 \%$ de solicitações extra na etapa pós implantação do kit. Confirmando que o elenco do kit era adequado e comprovando a aceitação médica, por não causar nenhum transtorno durante o procedimento por falta de medicamentos. 
Tabela 63 - Comparação da quantidade utilizada de medicamentos de cada sala cirúrgica antes e após a implantação do kit:

\begin{tabular}{cccccccccccc}
\hline & SO21 & SO22 & SO23 & SO24 & SO25 & SO26 & SO27 & SO28 & SO29 & SO30 & Total \\
\hline Pré-kit & 293 & 407 & 219 & 155 & 171 & 189 & 390 & 180 & 228 & 246 & 2478 \\
\hline Pós-kit & 105 & 74 & 98 & 121 & 102 & 74 & 105 & 73 & 135 & 84 & 971 \\
\hline
\end{tabular}

Gráfico 5: Consumo de medicamentos por sala

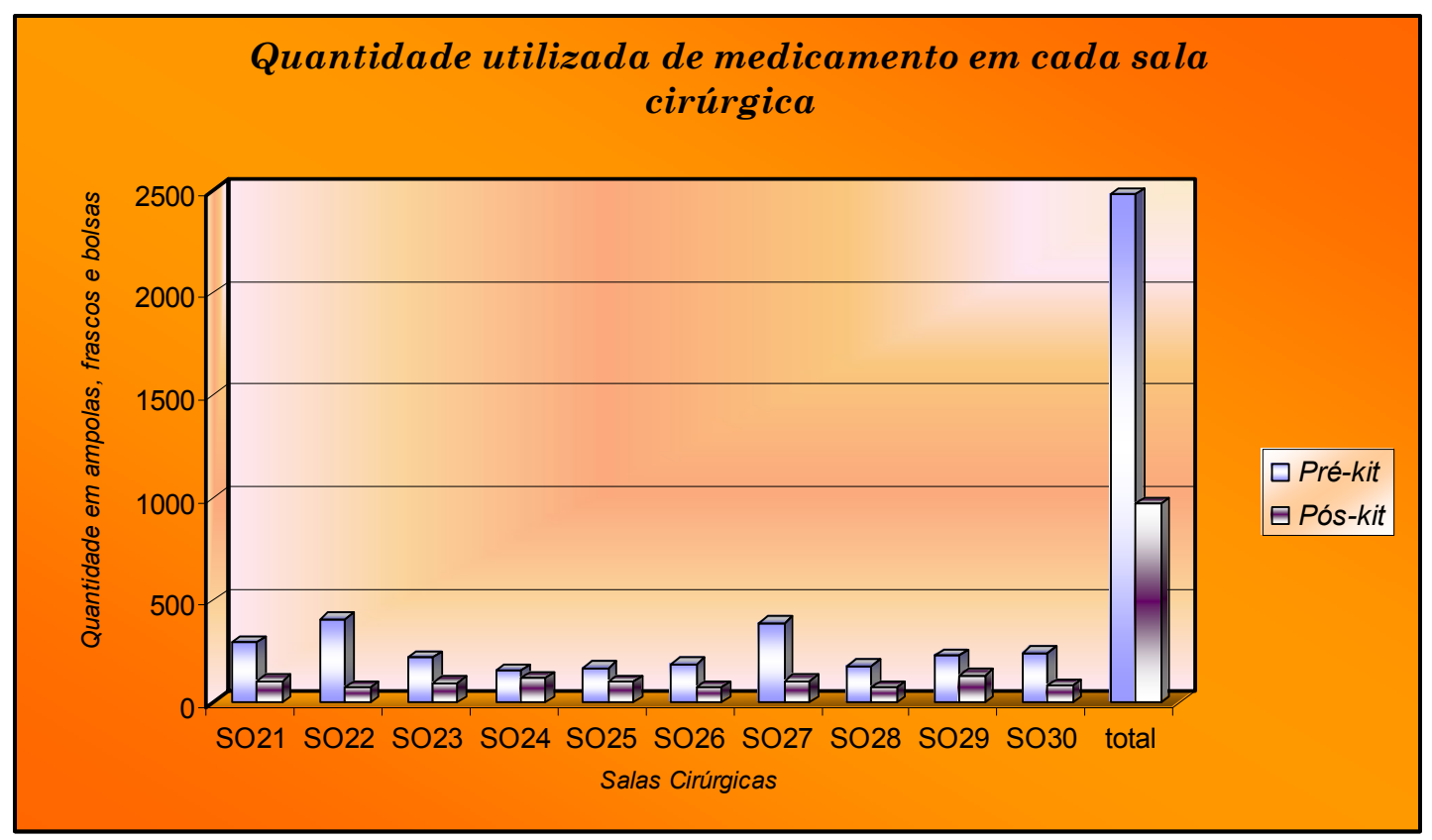

Houve uma redução de aproximadamente $30,4 \%$ na quantidade utilizada, ou seja consumida na etapa pós implantação do kit. Confirmando que anteriormente existia desperdícios e perdas.

Embora a contribuição de medicamentos vencidos não tenha sido especificamente documentada, ela constituiu um porcentual apreciável desta economia de $30,4 \%$. 
Tabela 64: Comparação de recursos financeiros (custo/medicamentos) gastos antes e após a implantação do kit:

\begin{tabular}{llllllllllll}
\hline & SO21 & SO22 & SO23 & SO24 & SO25 & SO26 & SO27 & SO28 & SO29 & SO30 & Total \\
\hline Pré-kit & 304,1 & 605,37 & 244,48 & 201,01 & 413,52 & 533,77 & 456,32 & 216,01 & 402,95 & 307,35 & 3684,88 \\
\hline Pós-kit & 142,51 & 149,85 & 458,15 & 225,51 & 308,44 & 121,98 & 153,71 & 175,01 & 286,52 & 179,57 & 2201,25 \\
\hline
\end{tabular}

* valores calculados em 2002, onde a taxa de conversão era de US dólar 2,70.

Gráfico 6: Consumo das salas convertido em reais

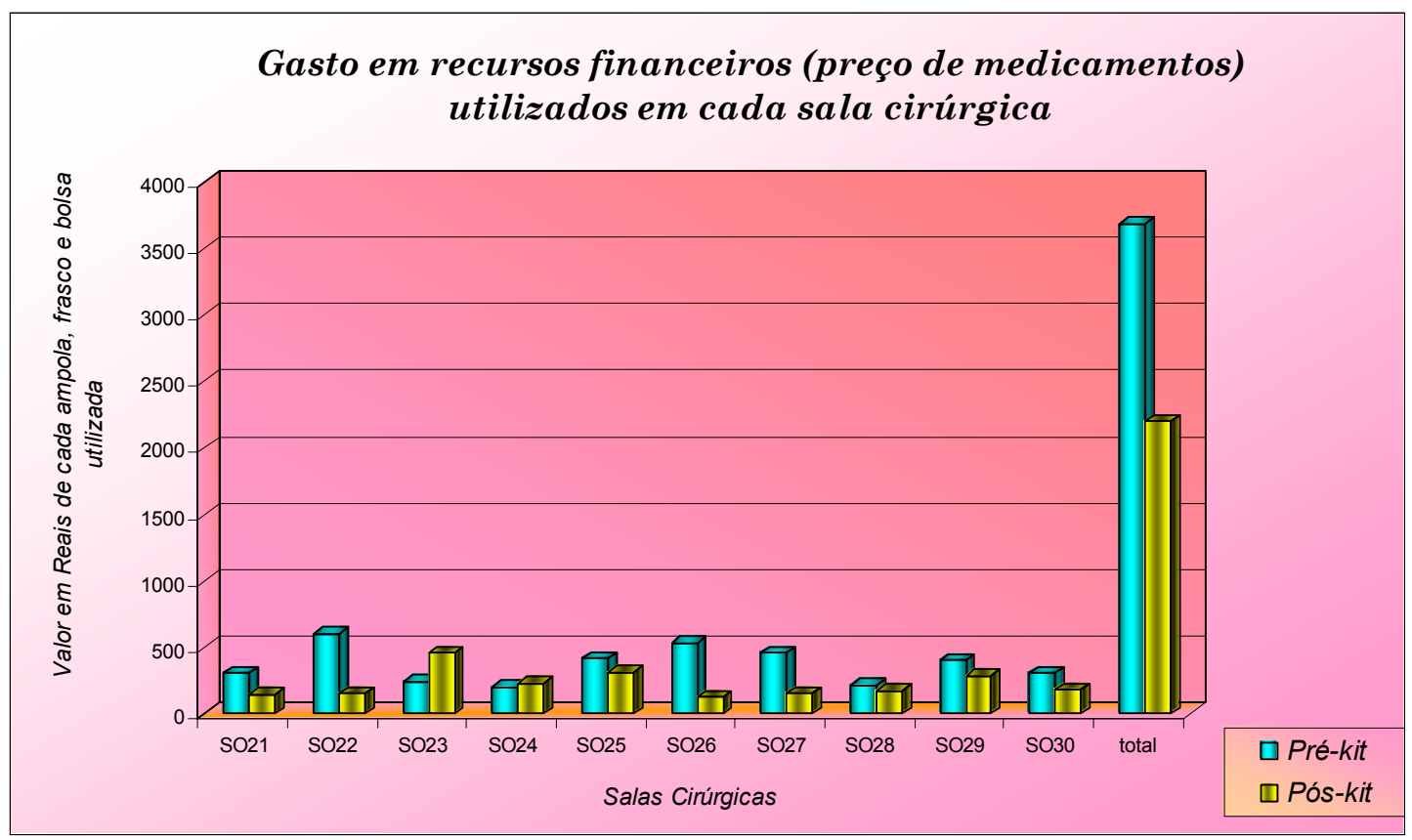

No gasto (custo de medicamentos), notamos que nas salas 23 e 24 da etapa pós kit há uma elevação com relação a pré kit, isto ocorre devido, termos nestas duas pacientes com um quadro clínico mais complexo, exigindo medicamentos, que normalmente não fazem parte da rotina, assim aumentando os gastos. Mesmo com esta diversidade houve ainda uma redução de aproximadamente $60 \%$ dos gastos com medicamentos. 
A tabela abaixo mostra os índices deo teste de médias (teste " $t$ " de Student) realizado visando comparar a influência do kit implementado em cirurgias. O resultado do teste mostrou em relação as variáveis estudadas: estoque inicial de medicamentos, quantidades extra de medicamentos, quantidade utilizada de medicamentos e recursos financeiros gastos; que a implementação do kit não influenciou significativamente os resultados em relação as variáveis observadas.

Tabela 65: Teste "t" comparando os dados coletados em cada sala cirúrgica antes e após a implantação do kit

\begin{tabular}{ll}
\hline Variáveis Estudadas & Sign. \\
\hline $\begin{array}{l}\text { Estoque inicial de medicamentos antes e após a } \\
\text { implantação do kit }\end{array}$ & $\mathrm{P}<0,01$ \\
\hline $\begin{array}{l}\text { Quantidade extra de medicamentos antes e após a } \\
\text { implantação do kit }\end{array}$ & $\mathrm{P}<0,03$ \\
\hline $\begin{array}{l}\text { Quantidade utilizada de medicamentos antes e após a } \\
\text { implantação do kit }\end{array}$ & $\mathrm{P}<0,05$ \\
\hline $\begin{array}{l}\text { Recursos financeiros gastos (preço dos medicamentos) } \\
\text { antes e após a implantação do kit }\end{array}$ & $\mathrm{P}<0,05$ \\
\hline
\end{tabular}

\section{Impacto Econômico Institucional}

Para uma contextualização mais satisfatória do estudo farmacoeconômico realizado, uma das opções cogitadas foi a comparação com o orçamento geral do Hospital das Clínicas.

Tal não foi realizado porque os kits significam apenas uma pequena parcela do orçamento da farmácia do centro cirúrgico, que por sua vez se soma a diversos outros setores individualizados da Divisão de Farmácia.

Esta por sua vez representa também uma das fontes de receitas e despesas de um único instituto, em um universo de dez institutos.

Portanto, analisamos com relação ao dólar (valor no momento do estudo), para dar uma noção da amplitude da economia feita. 


\subsection{Experiência Internacional}

Uma apreciação extensa e detalhada sobre as vantagens do sistema de kits é apresentada por Aouizerate et al, em $2002^{11}$. O protocolo lida com antibióticos prescritos no centro cirúrgico pelos anestesistas na indução anestésica e durante o ato operatório, como profiláticos, e utilizando parâmetros de infecção hospitalar como indicadores de resultado.

Ressaltamos que, não há considerações farmacoeconômicas encontradas na literatura para esse tipo de investigação, portanto, os procedimentos para criação, padronização, implantação e aferição de resultados foram análogos aos aqui utilizados, enfrentando obstáculos comparáveis e obtendo o sucesso final.

Os kits eram compostos de antibióticos previstos para cada indicação, nas quantidades suficientes para administração segundo o protocolo vigente. As unidades terapêuticas eram embaladas em saco plástico ou cartonado, dependendo do volume.

Uma ficha impressa com a listagem dos produtos era fornecida e inserida no programa informatizado de gestão farmacêutica Pharma ${ }^{\circledR}$ (Computer Engineering). Esse sistema gerava uma etiqueta detalhada com código de barras que era afixada na embalagem, contendo composição qualitativa e quantitativa, data de fabricação e vencimento.

O gerenciador eletrônico lia as etiquetas e debitava automaticamente o consumo, dando baixa correspondente no estoque.

Para disseminar as informações sobre a implantação dos kits, foram utilizados cartazes e malas diretas para os profissionais envolvidos. Nesse protocolo de prescrição, dispensação e administração participaram enfermeiras e médicos cirurgiões de 15 departamentos, sendo incluídos 30 diferentes kits. Desde 1998 até 2001, 5586 cirurgias receberam o kit, e em 5\% dos casos preferiram o de segunda escolha : 1848 (33\%) cirurgiais de vísceras, 764 (13,8\%) urologicas, 802 (14\%) ortopédicas, $13(0,2 \%)$ vasculares e torácicas, $1236(22 \%)$ otorinolaringo, gástricas e 
oftálmicas e 923 (17\%) ginecológicas e obstétricas, 93\% das prescrições retornaram à farmacia espontaneamente.

O custo, ao longo destes quatro anos, foi quantificado em francos franceses de: $157871 \mathrm{~F}$ para os 15 departamentos incluídos, $26123 \mathrm{~F}$ cirurgiais de vísceras, $13520 \mathrm{~F}$ urologicas, $73741 \mathrm{~F}$ ortopédicas, $569 \mathrm{~F}$ vasculares e torácicas, $39720 \mathrm{~F}$ otorinolaringo, gástricas e oftálmicas e $4198 \mathrm{~F}$ ginecológicas e obstétricas.

O Comitê de Infecção Hospitalar observou uma redução na freqüência de infecções pós-operatórias desde que os kits começaram a ser utilizados, incluindo na contagem da classificação de Altemeier ( termos de infecções pós-operatórias): 1,6\% a $0,5 \%$ da classe I, $6,5 \%$ a $4,3 \%$ da classe II e $11 \%$ a $8,5 \%$ da classe III. As diferenças estatísticas foram significantes apenas entre as classes I $(p<0,01)$ e II ( $\mathrm{p}<0,001)$, e não alterou na classe III $(\mathrm{p}=0,3)$. O grupo foi composto de médicos cirurgiões e enfermeiras que também fizeram a avaliação final do estudo: houve sensível diminuição nos níveis de infecções pós-operatórias, resultado da menor manipulação durante sua administração. Os kits prescritos estavam sistematicamente adequados com as indicações cirúrgicas, sendo que apenas os departamentos de ortopedia e cirurgias viscerais é que necessitaram de uma maior variação de kits com relação ao protocolo de tempo de duração de tratamento, mas todos estes problemas foram resolvidos. Uma constante atualização e acompanhamento da organização, associado a auditorias, devem autorizar a manutenção e o aperfeiçoamento desses resultados, possibilitanto reduzir o tempo de duração do tratamento.

\subsection{Aplicação dos kits em pesquisas}

Holbrook et al, $2002^{20}$, realizaram um estudo randomizado para avaliar se a vacina de Influenza era segura para asmático, utilizando o sistema de distribuição de drogas por kits, embalavam, mascaravam o placebo com suas respectivas seringas, identificando com etiquetas numéricas.

Desse estudo, participaram 2032 pacientes, no período de 15 de setembro a 30 de novembro de 2000, e cada um dos participantes recebia um kit individualizado com duas seringas (vacina ou placebo). De acordo com a ordem de randomização, todos pacientes fizeram a primeira injeção e apenas 2009 (98,9\%), a segunda. 
O fato de embalar os kits individualizados de seringa não foi apenas a chave para a baixa da taxa de erro, como também auxiliou o rastreamento de possíveis problemas no estudo, como por exemplo, foi detectado que cinco pacientes receberam kits em ordem trocada.

Outra vantagem é que a simples randomização permitiu que qualquer kit pudesse ser utilizado em diversas clínicas, dando flexibilidade ao estudo e facilitando a baixa dos kits.

Portanto, a utilização de kits individuais de seringa, todos com a identificação para o paciente, kit e droga designada e dispensada, vinda de uma central, propiciou o sucesso da pesquisa.

\subsection{Dificuldades na utilização e interpretação da farmacoeconomia}

Spath et al, $2003^{26}$, realizam entrevistas qualitativas com farmacêuticos em hospitais e clínicas na França para verificar as regras e determinar elenco de medicamentos padronizados em formulário nacional. Identificaram as barreiras que dificultam o uso dessas informações e estudaram qual o grau de influência dos estabelecimentos de saúde.

A amostra deste estudo foi constituída por 100 leitos de curta permanência, escolhidos em diversos serviços de saúde, que foram: treze hospitais públicos e semipúblicos (financiados por um orçamento global) e seis clínicas privadas com bases de pagamentos por serviços. O estudo foi realizado de outubro de 1999 a janeiro de 2000, sendo codificados por dois pesquisadores.

As dificuldades encontradas foram:

$\checkmark$ Falta de tempo e de recursos para coleta e análise de dados apresentados por todos os farmacêuticos de todos estabelecimentos;

$\checkmark$ Treinamento insuficiente em economia de saúde, em cinco clínicas e oito hospitais;

$\checkmark$ O orçamento fechado apresentado por nove hospitais e três clínicas propicia pouco incentivo em considerar os custos globais como recursos economizados; 
$\checkmark$ Resistência dos médicos em alterar sua prescrição devido aos custos, constatada em duas clínicas e sete hospitais ;

$\checkmark$ Falta de credibilidade nos dados fornecidos pela indústria farmacêutica, pois os tomadores de decisão acreditam que lhe eram apresentadas apenas as vantagens, opinião de três clínicas e onze hospitais ;

$\checkmark$ Limitada transferência de dados econômicos aos farmacêuticos, com a alegação de que outros dados de outros contextos não são aplicáveis à sua tomada de decisão. Esse procedimento foi verificado em cinco clínicas e nove hospitais.

Todas as razãoes frequentemente citadas foram de que as práticas clínicas e operatórias diferem de país para país e entre hospitais; o mesmo ocorre com os preços dos medicamentos.

Interessante notar que os obstáculos mencionados foram relacionados ao contexto de tomada de decisão, enquanto apenas dois foram devido à natureza dos dados econômicos propriamente ditos.

\subsection{Tentativa de adequação da dispensação em nosso meio (salientar que não se trata de kit)}

Erros de medicação e sistema de dispensação de medicamento em uma farmácia hospitalar estão diretamente ligados. Falhas na dispensação significam o rompimento de um dos elos na segurança do uso de medicamentos. Ainda que não causem danos aos pacientes, sua existência denuncia fragilidade no processo e indica um risco maior de ocorrência de acidentes mais graves, como mostram Anacleto et al, $2005^{31}$.

Os conceitos atuais dos incidentes relacionados a medicamentos podem ser caracterizados em grupos e incluem as reações adversas, os eventos adversos e os erros de medicação. Dentre estes se incluem os erros de dispensação, cujas causas mais comuns se associam ao caráter inseguro e ineficiente dos próprios sistemas de dispensação. 
Sistema coletivo é considerado tradicional, antigo e mais obsoleto. Apresenta como vantagens: a droga está disponível com mais rapidez na unidade; há pouca exigência da área farmacêutica, o que diminui os gastos de farmácia no tocante a RH (mão de obra) e material. As desvantagens são: alta taxa de erro de medicação, e o mais comum é a medicação ser dada duas vezes ou administração de droga não prescrita; o ineficiente controle de estoque e aumento de gastos devido à perda de medicamentos. De acordo com a primeira fonte de informações de farmácia no Brasil em 2002, 51.2\% das farmácias dos hospitais utilizam dispensação de sistema coletivo.

Sistema de dose individualizada - os farmacêuticos participam mais ativamente com a enfermeira e as taxas de erros não diminuem tanto. No Brasil, 43,8\% dos hospitais utilizam sistema de dispensação individualizada para pacientes internados. O sistema pode ser descrito como indireto, e há a transcrição manual diariamente da prescrição médica, aumentando o risco de erro e roubo; falha e omissão de itens que não constavam da prescrição original podem ser acrescentados. Vantagens: possibilidade de revisar a prescrição médica, de aumentar o controle sobre o uso do medicamento, de diminuir a necessidade de inventário no hospital, proporciona redução de roubo e perdas.

Desvantagens: alta taxa de erro de dispensação e entrega, perda do tempo das enfermeiras calculando e preparando os medicamentos, sendo que há a necessadade de um aumento do quadro de pessoal e do material na farmácia.

Sistema misto combina o coletivo com o individualizado. Unidades dos hospitais utilizam parcialmente ou totalmente sistema individualizado; já algumas unidades específicas usam o sistema coletivo como : radiologia, endoscopia, emergência, paciente externo. O sistema misto é utilizado por $13,2 \%$ dos hospitais no Brasil.

A principal desvantagem é a tendência a se inclinar mais ao sistema coletivo do que o sistema de dose individualizada, favorecendo a dispensação por unidade e não por paciente, devido a ser mais simples separar por unidade do que ficar separando e empacotando itens por pacientes.

E por fim, o sistema de dose por unidade que apresenta como vantagens: identificação bem no momento de entrega, baixas taxas de erro de medicação, menor tempo gasto pela enfermeira manuseando a medicação, aumento do tempo da enfermagem atendendo o paciente, menos inventário com diminuição de perda, 
otimização do retorno das drogas não usadas, melhor controle de infecção hospitalar, aumento na adaptação à automação, aumento de precisão de ministração ao paciente, aumento da segurança do farmacêutico de que a medicação será ministrada, participação efetiva do farmacêutico na definição da drogaterapia, melhora no controle do padrão e do tempo de entrega da droga, menos espaço usado para manter as drogas nas unidades do hospital. Suas desvantagens são: resistência das enfermeiras ao sistema, necessidade de mais funcionários e infraestrutura da farmácia, necessidade de aquisição de equipamentos específicos e um alto investimento inicial. A implantação desse sistema no Brasil é um desafio; somente $0,4 \%$ dos hospitais utilizam-no.

Um estudo de 1965 compara a incidência de erros de medicação em hospitais usando diferentes sistemas de dispensação. $O$ resultado apresentado foi uma redução significante da taxa de erros com o sistema de dose de unidade. Os erros detectados comparam prescrição e entrega de medicação, reduzidos de $31,2 \%$ para 13,4\% ( uma redução de 57\%). Esse sistema aumenta a participação do farmacêutico no controle de medicação e distribuição por 39,3\% e o tempo em que a enfermeira se envolve com manipulação de medicação foi reduzido para 13.7\%. A taxa de erro de dispensação relatada no sistema de dose por unidade foi de $3.8 \%$.

Um outro estudo feito na América do norte, em 1969, comparando o sistema tradicional com o sistema de dose de unidade de dispensação, encontrou $50 \%$ de redução no envolvimento da enfermeira com drogas e controle, e uma drástica redução na taxa de erro de medicação de $26 \%$ para $2 \%$

Em estudos norte-americanos, canadenses e britânicos, nos anos 70 e 80, feitos em hospitais que não adotaram a dose de unidade, foi encontrada uma taxa de erro de medicação de 1 por paciente /dia. Outro estudo, de 1983, foi verificado que em hospitais, usando esse sistema, foram reduzidas as taxas de erro por volta de 2 a 3 erros por paciente/ semana. Ainda outro estudo, conduzido por 23 dias em 1994, comparando taxas de erro de dispensação no ambiente de trabalho com vários níveis de interrupções, distração, barulho e sobrecarga de trabalho, encontrou taxas de erro de 3, 23\% e 1,23\% em ambientes com maior e menor níveis dessas variáveis respectivamente.

Em 1999, estudo em um hospital brasileiro baseado em relatórios de situação associada a erro de entrega de drogas foi notado que $26,8 \%$ dos procedimentos 
apresentaram falhas no sistema de dispensação e preparação de droga. Falhas incluindo atraso de entrega, medicamento com embalagem e etiquetas parecidas, muitas drogas ao mesmo tempo com atraso de ministração e drogas enviadas com apresentação errada.

Todos esses estudos mostram que, embora o erro de dispensação ainda em muitos casos possa ser classificado como banal, assume níveis epidemiológicos importantes.

\subsection{Redução de custos}

A visão do profissional da saúde para custo é relativamente estreita, em economia este conceito é substancialmente mais amplo e abrange dezenas de definições e categorias.

Tendo se em vista que o foco deste protocolo foi a implantação do kit de medicamentos, optou-se por não desdobrar extensamente o quesito de custos com todas suas implicações.

Dentro desta ótica, houve vantagens significantes para o sistema de kits, quando cotejado com a metodologia anteriormente empregada no centro cirúrgico.

\subsection{Considerações Finais}

O envolvimento multiprofissional é fundamental para garantir o uso seguro e racional de medicamentos, evitando o uso indiscriminado e o desperdício, e para isso, em se tratando de Centro Cirúrgico, podemos concluir que é o sistema de distribuição de medicamentos por kits que se apresenta como o mais vantajoso, não só pela viabilidade econômica, mas pelo atendimento aos principais requisitos que visam aos benefícios para o paciente.

Os achados altamente auspiciosos deste protocolo encorajam novos esforços, com o intutito fé estender seus benefícios para novos domínios, neste sentido, partiram desse estudo novas propostas a serem desenvolvidas futuramente: 
Elaboração de kit de medicamentos e psicofármacos/entorpecentes para o Centro Obstétrico;

$\checkmark$ Implantação de kits para o setor de Convênios;

$\checkmark$ Desenvolvimento de kits de pequenas cirurgias para o Ambulatório;

$\checkmark$ Aprimoramento do controle e distribuição de anestésicos inalatórios;

$\checkmark$ Desenvolvimento e implantação de um sistema de controle por código de barras na Farmácia do Centro Cirúrgico;

$\checkmark$ Início do estudo da redução do tempo gasto com atividades relacionadas aos medicamentos pela equipe de enfermagem antes e após a adequação deste sistema de distribuição.

\subsection{Dose unitária X Sistema kit}

$\mathrm{Na}$ tese de Ribeiro, $1991^{14}$ várias das conclusões guardam grande semelhança com as nossas e apontam as vantagens do sistema unitario comparativamente ao método tradicional. Por exemplo, redução significante do tempo que a equipe de enfermagem gasta em atividades relacionadas com medicamentos, possibilitando o emprego desse tempo na melhoria da qualidade da assistência dispensada aos pacientes; garante à equipe médica que a terapêutica medicamentosa está sendo cumprida segunda sua orientação; facilita a integração do farmacêutico à equipe multiprofissional, e demonstra que o custo para implantar um novo sistema em instituições de saúde não deve ser evocado como um obstáculo antes de se avaliar os seus benefícios. As vantagens proporcionadas tanto pelo sistema de dose unitária quanto o sistema por kit maior segurança ao paciente, melhor utilização dos profissionais envolvidos, maior controle dos medicamentos - não podem ser descartadas. Devemos lembrar, que a melhoria da qualidade da assistência prestada ao paciente acelera a reabilitação e diminui a permanência no hospital, o que reduz o custo do tratamento de maneira expressiva para ambas as partes.

Na presente investigação foi possível dar um passo a mais na medida em que benefícios adicionais foram logrados medianrte a introdução do sistema kit. 
7. CONCLUSÕES 
Este trabalho permitiu as seguintes conclusões:

$\checkmark$ Foi viável e prática a implantação dos kits, sem transtornos ou incidentes registrados;

$\checkmark$ O estoque de complementação (extra) foi significativamente menos solicitado após a padronização;

$\checkmark$ Houve substancial redução de gastos, da ordem de $60 \%$, traduzindo menores perdas e desperdícios. 
1. Neto JFM. Farmácia hospitalar: um enfoque sistêmico. Brasília: Thesaurus; 1990.

2. Bittar OV. Hospital: qualidade \& produtividade. São Paulo: Sarvier; 1996.

3. Borba VR. Administração hospitalar princípios básicos. $3^{0}$ ed. São Paulo: Cedas; 1991.

4. Martins D. Introdução à contabilidade hospitalar. São Paulo: Athas; 1999.

5. Martins D. Custos e orçamentos hospitalares. São Paulo: Athas; 2000.

6. Cimino JS. Iniciação á farmácia hospitalar. São Paulo: Obelisco; 1973.

7. Gomes MJ, Reis, AM. Ciências farmacêuticas: uma abordagem em farmácia hospitalar. São Paulo: Atheneu; 2001.

8. Zanini AC, Farhat FG, Ribeiro E, Follador W. Farmacoeconomia: Conceitos e Aspectos Operacionais. Rev. Bras. Ciênc. Farm. 2001;37(3):225-37.

9. Gomes MJ, Reis AM. Farmácia hospitalar: histórico, objetivo e funções. São Paulo: Atheneu; 2001.

10. Cosentino M, Leoni O, Banfi F, Lecchini S, Frigo G. An approach for the estimation of drug prescribing using the defined daily dose methodology and drug dispensation data. Eur J Clin Pharmacol. 2000;56:513-7.

11. Aouizerate P, Guizard M. Creation of surgical antibioprophylaxis kits: Evaluation of the impact on prescribing habits. Therapie. 2002;57:214-28. 
12. Meneu R. Alternativas a la distribución de medicamentos y su retribución. Gaceta Sanitaria. 2002;16(2):171-81.

13. Bogotá. Organización Panamericana de la Salud. Oficina Sanitária Panamericana. Bases para el desarrollo y aprovechamiento sanitario de la farmacia hospitalaria. 2a. Ed. Bogotá; 1987.

14. Ribeiro E. Dose Unitária - Sistema de distribuição de medicamentos em hospitais. São Paulo: Fundação Getúlio Vargas;1991.

15. Garrison TJ. Medication distribution systems, smith, mickey c, thomas. Handbo-ok of institutionad pharmacy pratice. London:Willians \& Willians; 1979.

16. Cavallini ME, Bisson MP. Farmácia hospitalar: um estoque em sistema de saúde. São Paulo: Manole; 2002.

17. Lima CR, Silva MG, Reis NL. Sistemas de distribuição de medicamentos em farmácia hospitalar. São Paulo: Atheneu; 2000.

18. Brasil. Ministério da Saúde. Coordenação de Controle de infecção Hosp. Guia Básico para Farmácia Hospitalar. Brasília; 1994.

19. Kleisner I., Komarkova I., Konopkova M.. A new technique of ${ }^{99 m}$ Tcciprofloxacin kit preparation. Nucklearmedizin.2002;41(5):224-9.

20. Holbrook JT, Wise RA, Gerald LB. Drug distribution for a large crossower trial of the safety of inactivated influenza vaccine in asthmatics. Control Clin Trials. 2002;23(1):87-92..

21. Castillo JS. Farmacoeconomía y evoluacion económia de medicamentos. Introduccion Castillo. In: Castillo J, Llach XB, Forns JR, editores. Madrid: Editores Medicos; 1995.

22. Lyles A. Stardards and certification to recognize pharmacoeconomics as a profession. Clin Therap. 2003;25(3):1004-6. 
23. Basile AC, Zanini AC. DCPL: denominações comuns em língua portuguesa: estudo para a Organização Mundial da Saúde [CD-ROM]. São Roque; 2000.

24. Bevilácqua, LP. Farmacoeconomia. São Paulo: Atheneu; 2001.

25. Robertson J, Lang D, Hill S. Use of pharmacoeconomics in prescribing research. Part 1: costs - moving beyond the acquisition price for drugs. Journal of Clinical Pharmacy and Therapeutics.2003;28:73-9.

26. Späth HM, Charavel M, Morelle M, Carrere MO. A qualitative approach to the use of economic data in the selection of medicines for hospital formularies: a Frech survey.Pharm World Sci. 2003;25(6):269-75.

27. www.widebiz.com.br/gente/silvio/telegestor.html, consultado no dia 30/11/05.

28. Santos Mattos, EM. Processo de Implantação de kits individualizados de medicamentos em Centro Cirúrgico. In: I Congresso Internacional de Dose Unitária. São Paulo: Livreto de temas livres. 2001.

29. Santos Mattos, EM. Validação dos Kits Individualizados de Medicamentos. In: I Congresso Internacional de Dose Unitária. São Paulo: Livrete de temas livres.2001.

30. Cipriano SL, Cunha GW, Barbosa AO, Sforsin AC, Maluvayshi $\mathrm{CH}$, Chaves CE, Nova Gomes GV, Nunes de Oliveira LA, Carneiro MB, Cassales Chen MA, Mário Marin ML, Castanheira MF, Freitas Neto ST, Petilo Bricola AS, Juliani SR, Walczak SZ, Santos VG, Ezequiel VC, Pinto VB. Guia Farmacoterapêutico HC/Hospital das Clínicas da Faculdade de Medicina de Universidade de São Paulo. São Paulo: Divisão de Farmácia; 2002.

31. Anacleto TA, Perini E, Rosa MB, César CC. Erros de medicação e sistemas de dispensação de medicamentos em farmácia hospitalar. Clinics - Formerly Revista do Hospital das Clínicas da FMUSP. 2005;60:325-332. 